Supplementary Information for

\title{
Mucoid Coating Provides a Growth Advantage to Pseudomonas aeruginosa at Oil-Water Interfaces
}

Sricharani Rao Balmuri', Vienvilay Phandanouvong-Lozano' ${ }^{1}$, Stephen D. House ${ }^{1,2}$, Judith C. Yang ${ }^{1,2,3}$, Tagbo H.R. Niepa ${ }^{1,4,5,6,7,8 *}$

1. Department of Chemical and Petroleum Engineering, 2. Environmental TEM Catalysis Consortium (ECC), ${ }^{3 .}$ Department of Physics and Astronomy, ${ }^{4}$. Department of Bioengineering, 5. Department of Civil and Environmental Engineering, ${ }^{6}$. Department of Mechanical Engineering and Materials Science, ${ }^{7}$ Center for Medicine and the Microbiome, ${ }^{8}$ The McGowan Institute for Regenerative Medicine, University of Pittsburgh, Pittsburgh, PA (USA)

*Corresponding author: tniepa@pitt.edu

Keywords: Pseudomonas aeruginosa; biofilms; transcriptomics; interfacial stress; interfacial materials; exopolysaccharides; alginate.

Here, we include supplementary information of primer sets used in RT-PCR studies to determine the mRNA expression. We also include supplementary STEM figures contrast the morphological change in the non-mucoid and the mucoid $P$. aeruginosa cells following interfacial confinements. The volcano plots showing differential gene expression of alginate, pel and ps/ genes in PANT and PASL are discussed. The number of genes which showed a fold change of greater than 2 folds and which are upregulated and downregulated are represented based on functions. Controls for the confocal imaging are discussed. The total lists of genes which showed a fold change of greater than 2-fold and a false discovery rate (FDR) $<0.01$ for PANT and PASL are shown. 


\section{1- Primer design}

\begin{tabular}{|c|c|c|c|c|c|}
\hline \multicolumn{6}{|c|}{ Table S1: List of primers used in RT-PCR experiments } \\
\hline Gene & Primer & Primer sequence & Gene & Primer & Primer sequence \\
\hline \multirow[t]{2}{*}{$r p / U$} & Forward & CGCAGTGATTGTTACCGGTG & \multirow[t]{2}{*}{ pelA } & Forward & CCTTCAGCCATCCGTTCTTCT \\
\hline & Reverse & AGGCCTGAATGCCGGTGATC & & Reverse & TCGCGTACGAAGTCGACCTT \\
\hline \multirow[t]{2}{*}{$\operatorname{alg} U$} & Forward & AAGACGATTCGCTGGGACGCT & \multirow[t]{2}{*}{ pelc } & Forward & GACCACGTAGGCCAGCTTC \\
\hline & Reverse & AACGCAGCCGGCATCCTCG & & Reverse & GCCGCTGCTCAATTATTCCC \\
\hline \multirow[t]{2}{*}{ algD } & Forward & GCGACCTGGACCTGGGCT & \multirow[t]{2}{*}{ pelD } & Forward & ACTCGAAGGCATACAGGCAG \\
\hline & Reverse & TCCTCGATCAGCGGGATC & & Reverse & GCCGTTCTTCGTCTTCAACG \\
\hline \multirow[t]{2}{*}{ algR } & Forward & TAGGGCAACTGGACGGCTAT & \multirow[t]{2}{*}{ pelE } & Forward & CGTCGCTGAACATCATGTCG \\
\hline & Reverse & CGGATATCCAGCAGGACGA & & Reverse & TCTTCAGCCTGGCCTTCTTC \\
\hline \multirow[t]{2}{*}{$\operatorname{alg} Q$} & Forward & TATCTCGGCTTCTCCATCGT & \multirow[t]{2}{*}{ psIA } & Forward & TTCAAGATCAAGCGCATCGTGGTG \\
\hline & Reverse & GGGGGATCCTTCGAGATCGACCTGCTG & & Reverse & GGGGGATCCTTCGAGATCGACCTGCTG \\
\hline \multirow[t]{2}{*}{ alg44 } & Forward & CCCAACCAGCAGATCACCAT & \multirow[t]{2}{*}{ psIl } & Forward & TCGACCTGTACATCAGCACC \\
\hline & Reverse & AGAGCTTCTCGATGTTGCCC & & Reverse & CTGACCCGATAGACCAGTGC \\
\hline \multirow[t]{2}{*}{$\operatorname{algL}$} & Forward & TCGACGACGAGGAAACCTTC & \multirow[t]{2}{*}{ psIF } & Forward & GCCATCGACTGGAACCTGAA \\
\hline & Reverse & CTTCTTCGCCTCGAGCATCT & & Reverse & CCGAGCAGACCGAGTTTCTT \\
\hline \multirow[t]{2}{*}{$\operatorname{algK}$} & Forward & CTACTACGACGGCAAGTGGG & \multirow[t]{2}{*}{$p s / M$} & Forward & GAGGAGGACATCGAGCAACC \\
\hline & Reverse & TTCTGCGGATAGACCTTGCC & & Reverse & CTCGAAGAAGGCCACCATGT \\
\hline \multirow[t]{2}{*}{ mucA } & Forward & GCGGATGAACTCGAGTTG & & & \\
\hline & Reverse & CACTGACGGCGGATTGTT & & & \\
\hline
\end{tabular}

\section{2- STEM analysis of the Interfacial films}

Scanning transmission electron microscopy (STEM) was utilized to analyze the phenotypic changes in cells after exposure to interfaces. Eight $\mu \mathrm{L}$ droplets of cells in hexadecane were aged for a period of $24 \mathrm{~h}$ and collected on ultrathin carbon-coated copper TEM grids previously treated with Cell-Tak. The samples were fixed in $2.5 \%$ glutaraldehyde overnight followed by staining with uranyl acetate. High-angle annular dark-field (HAADF) STEM imaging was performed using a ThermoFisher Themis G2 200 S/TEM at an operating voltage of $200 \mathrm{kV}$ and probe current of 51 pA. The results shown in Fig. S1A demonstrate that most of the $P$. aeruginosa PANT cells experienced membrane damage at fluid interface and released cell content. On the other end, the PASL cells were covered by exopolysaccharide matrix, which acted as a shield against the interfacial stress. Consequently, a smaller number of the PASL cells experienced membrane damage (Fig. S1B). 

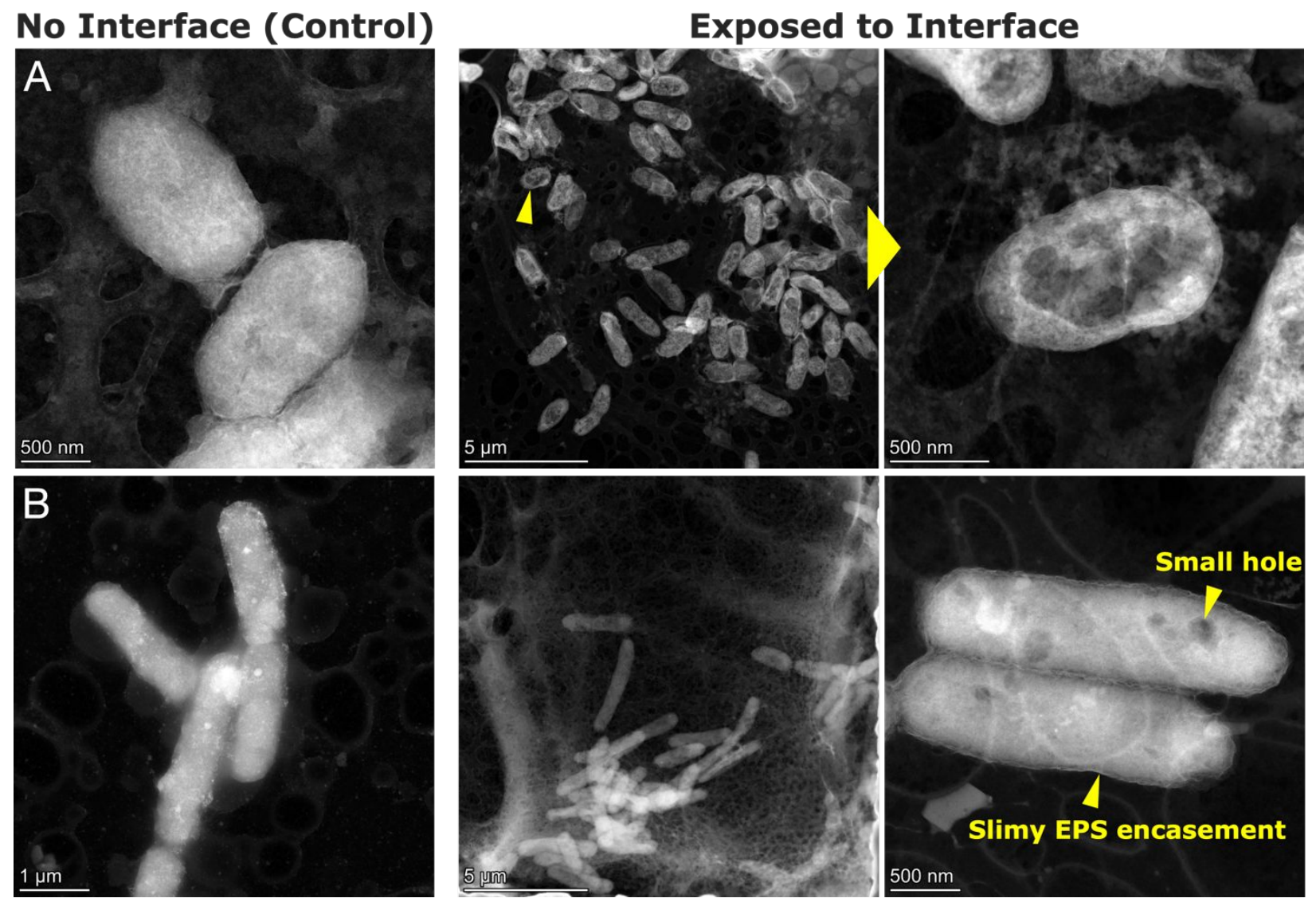

Figure S1: HAADF-STEM images of (A) control PANT cells and (B) the PASL cells are compared to their counterparts exposed to oil-water interface. The interfacial confinement severely damaged the membrane properties of the PANT cells. In contrast, PASL secreted an EPS matrix that contributed to lessening the detrimental effects of the interfaces.

\section{3- Fluorescence microscopy of the Controls}

To establish the staining procedures followed by confocal imaging, live-dead staining was performed on PANT and PASL cells derived from the exponential phase and cells subjected to thermal shock (dead cells). To confirm the absence of autofluorescence, cells were imaged without exposure to any stain. Syto-9 and propidium iodide (Live-dead staining kit) were used to stain the live and dead cells respectively.

\section{a) Exponential cells (control)}

Exponential phase cells of PANT were obtained by culturing the bacteria for a duration of $12 \mathrm{~h}$. PASL cells were grown for a duration of $15 \mathrm{~h}$ to obtain the cells from exponential phase. The four image panels represent the live cells (in green), dead cells (in magenta), merged panel with live and dead cells and BF (brightfield). The bar plots to the right represent the quantitative analysis of fluorescence intensity of live and dead cells using imageJ. 
As expected, the exponential phase cells of PANT (Fig. S2A) and PASL (Fig. S2B) showed relatively higher proportion of live cells compared to the dead cells.
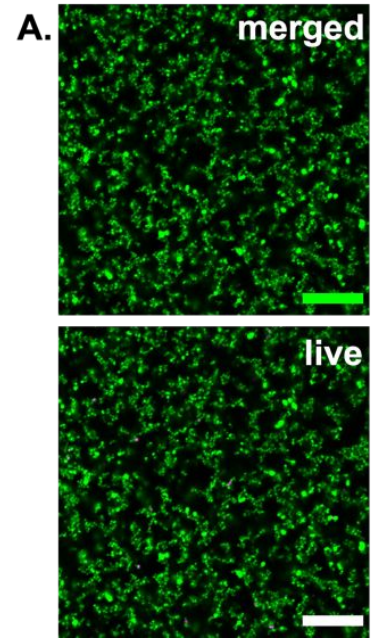

B.
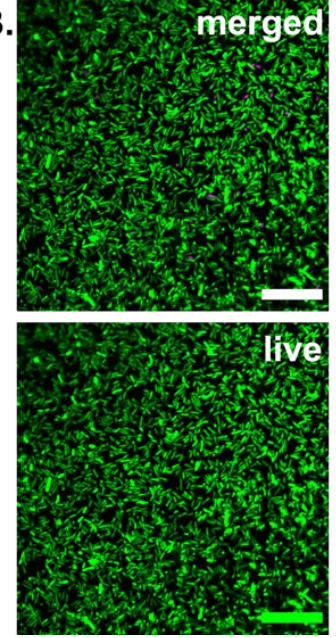
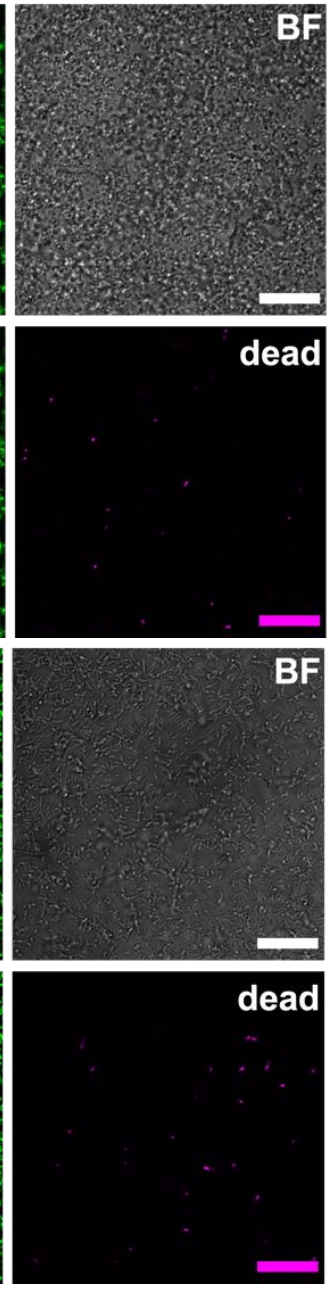
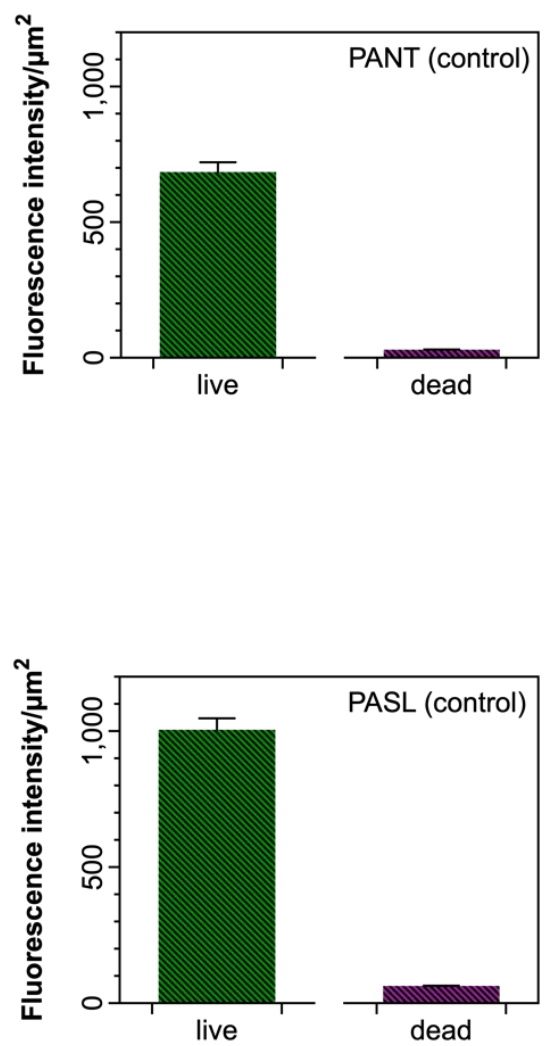

Figure S2: Live-dead staining of exponential cells of (A) PANT (B) PASL grown for a period of $12 \mathrm{~h}$ and $15 \mathrm{~h}$, respectively. Scale bar $=20 \mu \mathrm{m}$.

\section{b) Positive control}

Control for the dead cells were obtained by subjecting PANT and PASL cells to thermal shock at $80^{\circ} \mathrm{C}$ for a duration of $40 \mathrm{~min}$. Subsequently, the cells were stained to analyze the quantity of live and dead cells in the samples. As mentioned above, the four image panels represent the live cells (in green), dead cells (in magenta), merged panel with live and dead cells and BF (brightfield). The bar plots to the right represent the quantitative analysis of fluorescence intensity of live and dead cells using imageJ. Our results showed that, thermal shock killed majority of cells which are stained with propidium iodide in magenta for both PANT (Fig. S3A) and PASL cells (Fig. S3B). This condition was performed to establish a positive control for the dead cells. 


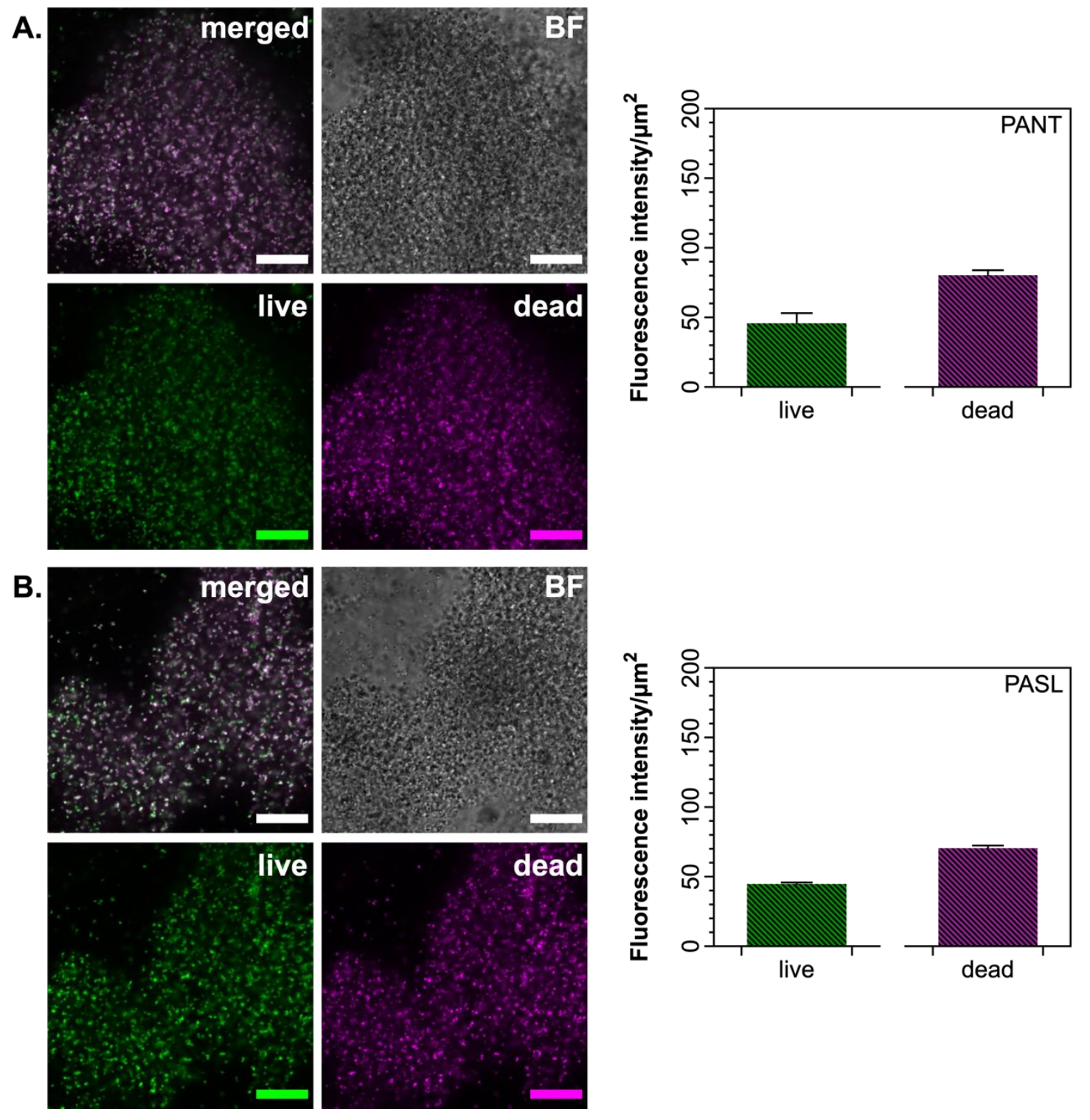

Figure S3: Live-dead staining of cells subjected to thermal shock (A) PANT (B) PASL. PANT cells were grown for a period of $12 \mathrm{~h}$ and PASL cells were grown for a period of $15 \mathrm{~h}$ to reach exponential phase. Here, thermal shock was used to kill the cells for positive control. Scale bar $=20 \mu \mathrm{m}$.

\section{c) No stain control:}

To determine the autofluorescence from the samples at the imaging conditions, no stain control was analyzed. The data are represented below in Fig. S4. The top panel represents BF (brightfield), live and dead PANT cells. The bottom panel represents BF (brightfield), live and dead PASL cells. No auto fluorescence was observed at the imaging conditions in both the panels. 


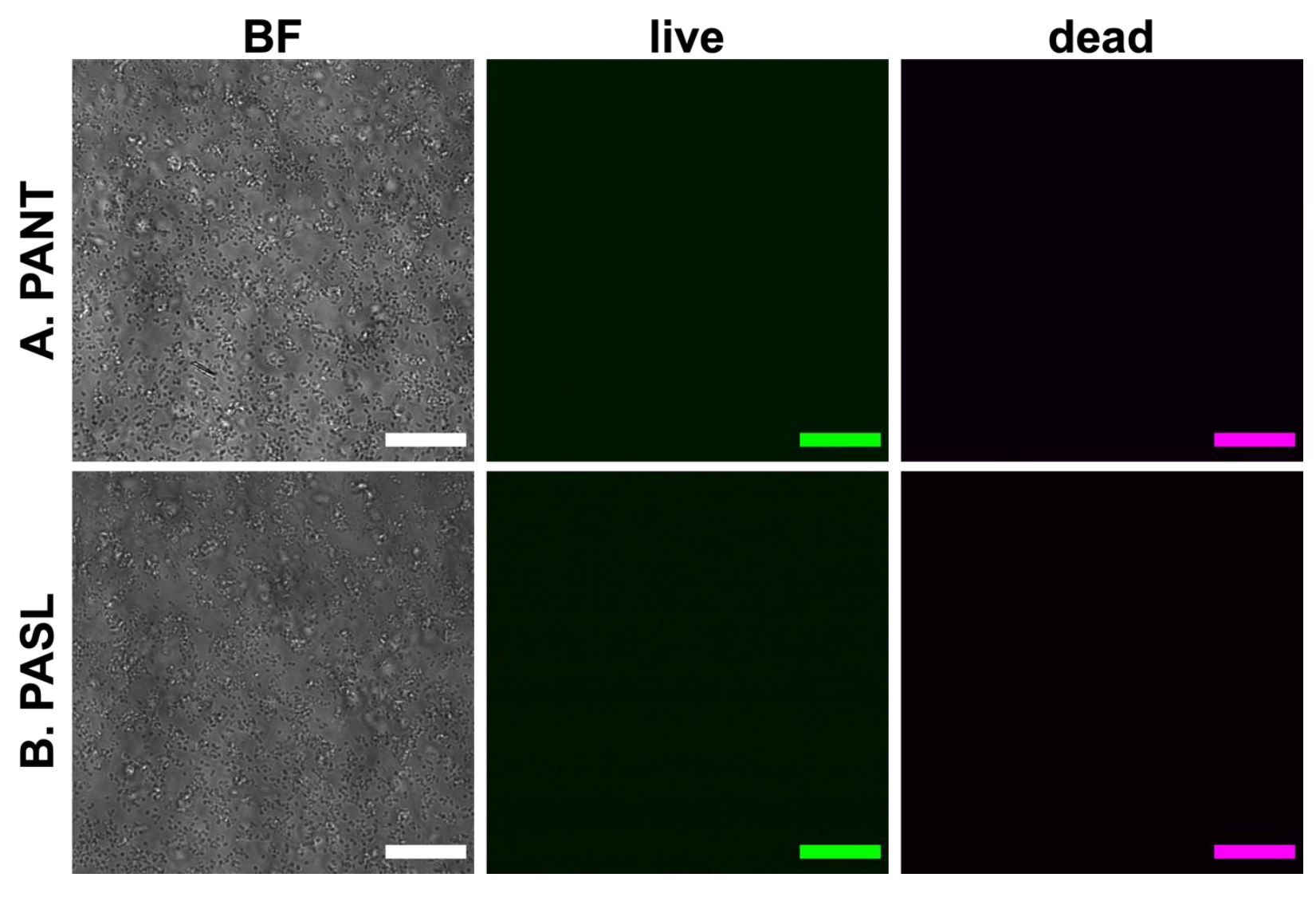

Figure S4: Representative confocal images of non-florescent $P$. aeruginosa (A) PANT (B) PASL. No fluorescent recorded through imaging of cells. Scale bar $=20 \mu \mathrm{m}$.

\section{4- Transcriptomic analysis}

Transcriptional profiling of PANT and PASL cells exposed to interfacial environment for a period of $24 \mathrm{~h}$ was performed to determine differential gene expression on exposure to interfaces vs their planktonic counterparts. Our initial results from microscopic techniques (Fig. 1-3) revealed that cell viability at interfaces strongly depended on their EPS composition. Alginate, pel and ps/ are the three main extracellular polymeric substances (EPS) constituting the films of Pseudomonas aeruginosa. Therefore, gene expression of alginate, pel and ps/ genes was analyzed using RNAseq. analysis as described in section 2.5. The genes that are significantly upregulated are shown in blue and the genes that are significantly downregulated are shown in red. The genes that did not show any significant differences are shown in gray. Transcriptomic analysis showed that PANT upregulated 6 genes (algl, algL, algX, algK, algJ, alg44) and downregulated 4 genes $(a l g U, a l g R, a l g P, a l g Q)$ involved in alginate biosynthetic pathway (Fig. S5A). The genes 
upregulated are found to be involved in the later stages of alginate biosynthetic pathway[1]. PASL also showed upregulation of 3 genes ( $a l g U$, algZ and algR) and downregulation of 3 genes (algJ, alg44, algE) (Fig. S5D). Interestingly the differential expression of alginate genes by PANT and PASL on interfacial exposure indicates that these two strains do not regulate the alginate biosynthetic pathway similarly on interfacial exposure. Pel genes pelA, pelB, pelC and pelE were also upregulated by PANT cells under interfacial confinement (Fig. S5B). On the contrary, PASL cells downregulated pelB, pelC and pelE genes along with peID and upregulated pelG on interfacial exposure (Fig. S5E). ps/H, ps/F, psIM, ps/N, ps/K and $p s / l$ of the $p s /$ biosynthetic pathway were upregulated in PANT cells whereas $p s / H, p s / F, p s / M, p s / K, p s / l$ and $p s / J$ were downregulated in PASL cells on interfacial exposure (Fig. S5C\&F). ps/A, the precursor component necessary for $p s / /$ synthesis was found to be upregulated in PASL cells on interfacial exposure. Similar results were obtained for pel and psl genes when tested using qRT-PCR. However, RNA-seq. indicated that PASL cells downregulated pel and ps/ genes on interfacial exposure which is complementary to our results from qRT-PCR where PASL genes upregulated the expression of pel and psl genes.
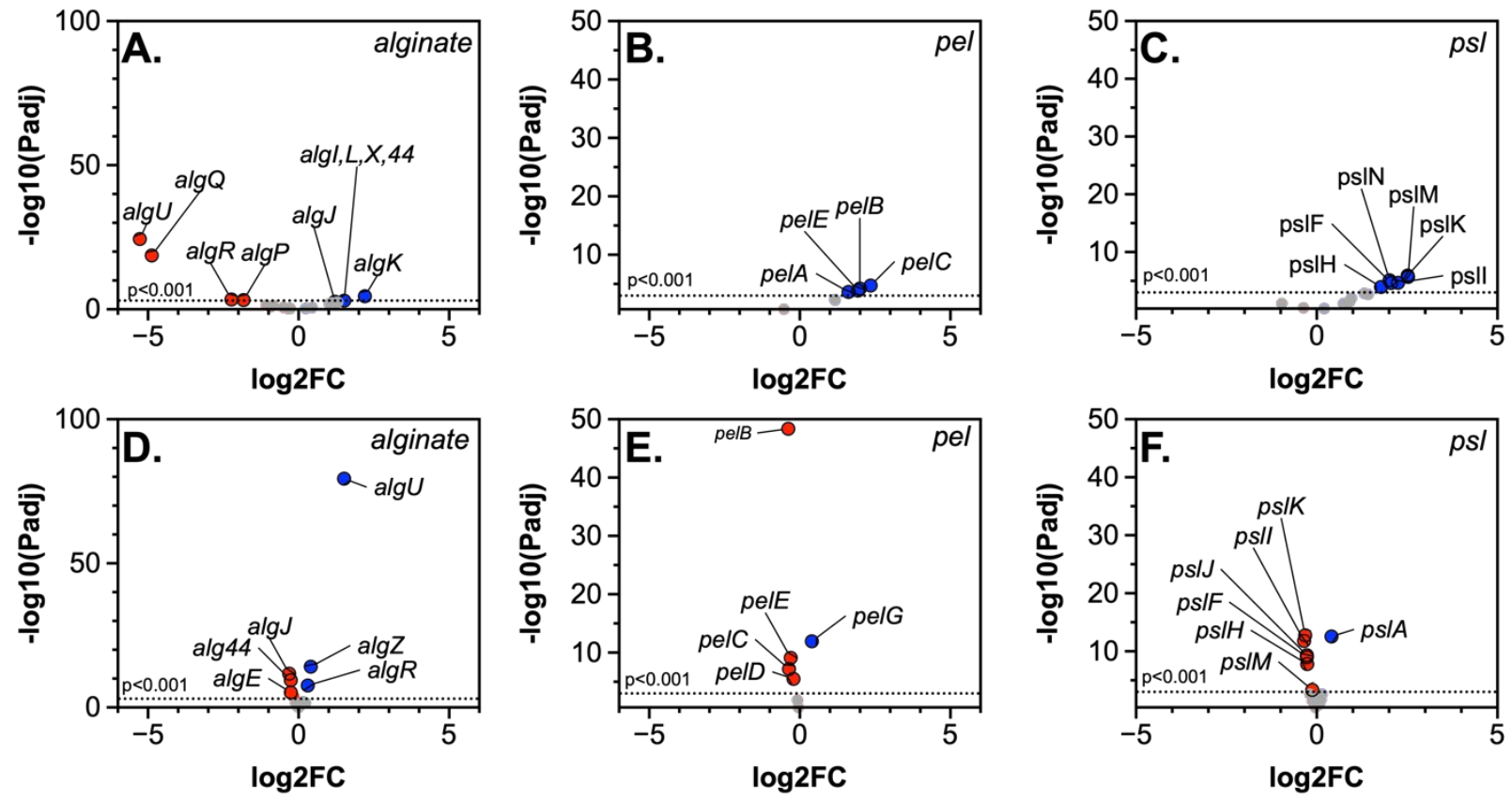

Figure S5: Volcano plot showing statistical significance (Padj) vs. fold change for genes differentially expressed due to interfacial exposure. (A) alginate gene expression in PANT (B) pel gene expression in PANT (C) psl gene expression in PANT (D) alginate gene expression in PASL (E) pel gene expression in PASL $(F)$ ps/ gene expression in PASL. 


\section{A. PANT}

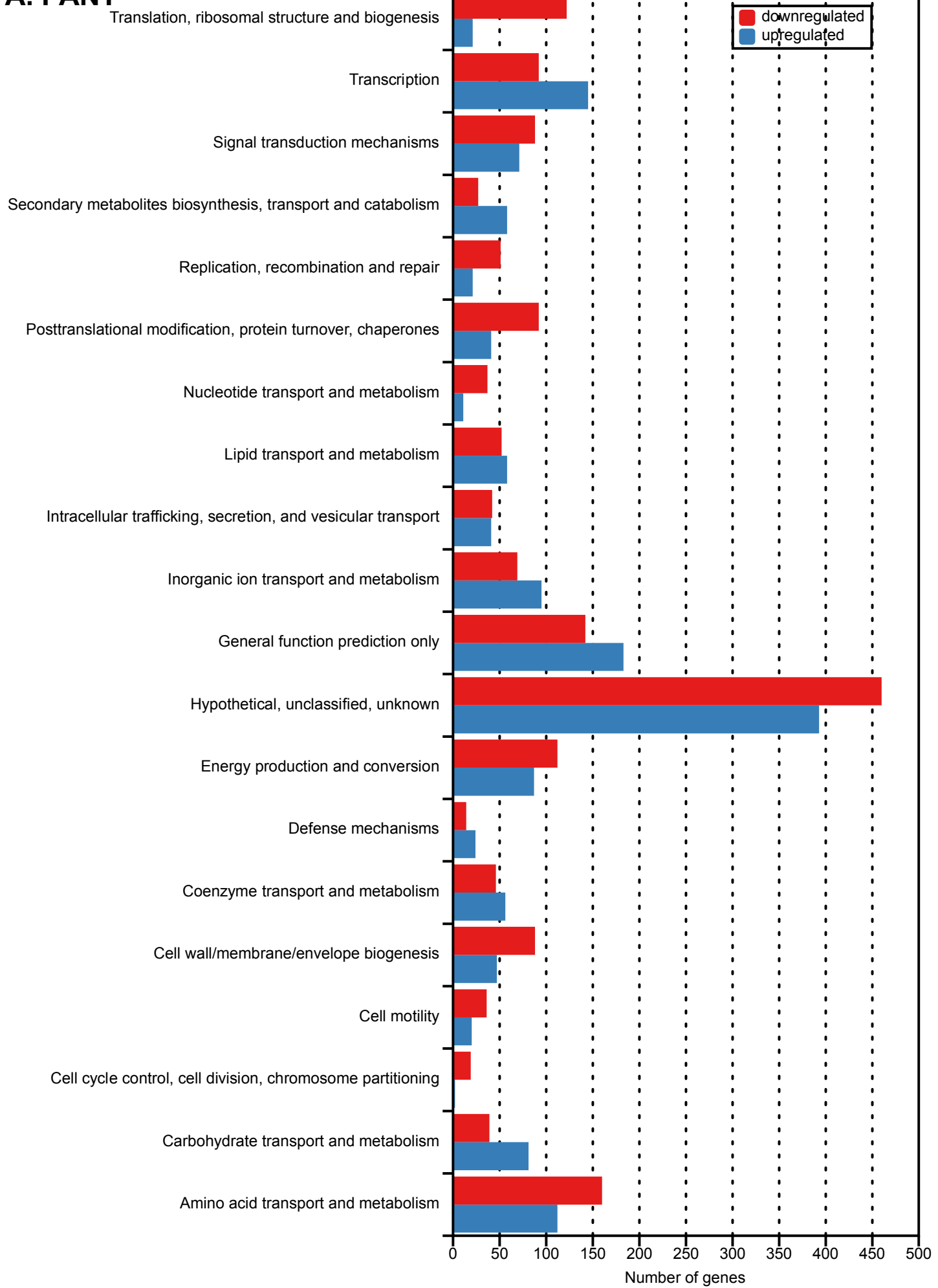


B. PASL

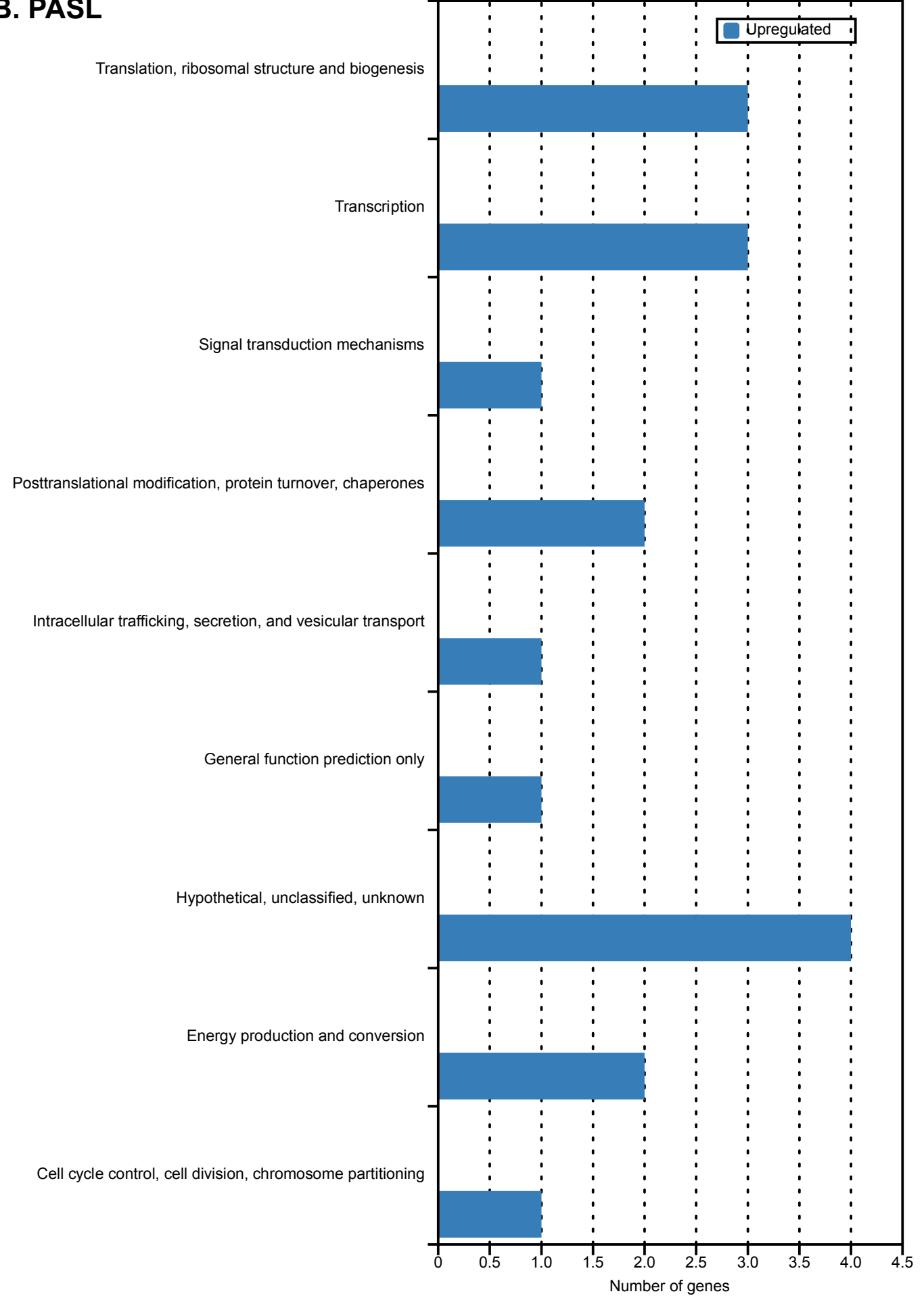

Figure S6: Transcriptional profile of (A) PANT (B) PASL after confinement at hexadecane-water interface for $24 \mathrm{~h}$. The number of genes upregulated and downregulated are represented based on their functions. 
Table S2. List of genes upregulated in PANT by at least 2-fold with a false discovery rate (FDR) $<0.01$ during exposure to hexadecane-water interface for $24 \mathrm{~h}$ versus the control.

\begin{tabular}{|c|c|c|c|}
\hline Gene & Description & $\begin{array}{l}\text { Fold } \\
\text { Change }\end{array}$ & $\begin{array}{l}\text { Padj- } \\
\text { value }\end{array}$ \\
\hline \multicolumn{4}{|c|}{ Amino acid transport and metabolism } \\
\hline PA1977 & hypothetical protein & 8.37 & 1.69E-63 \\
\hline PA1497 & transporter & 8.25 & 1.57E-73 \\
\hline$p q q H$ & peptidase & 7.10 & 4.03E-50 \\
\hline PA1620 & hypothetical protein & 6.83 & 8.59E-48 \\
\hline PA2124 & dehydrogenase & 6.44 & $1.45 \mathrm{E}-30$ \\
\hline PA1341 & amino acid $A B C$ transporter permease & 6.28 & 3.77E-12 \\
\hline PA2202 & amino acid permease & 6.14 & 1.33E-37 \\
\hline phzC1 & phenazine biosynthesis protein $\mathrm{PhzC}$ & 6.03 & $3.71 \mathrm{E}-58$ \\
\hline PA1214 & hypothetical protein & 5.99 & 2.09E-54 \\
\hline PA2084 & asparagine synthetase & 5.86 & $5.62 \mathrm{E}-40$ \\
\hline PA2916 & hypothetical protein & 5.74 & $5.11 \mathrm{E}-38$ \\
\hline PA1108 & major facilitator superfamily transporter & 5.70 & 1.73E-47 \\
\hline PA1267 & hypothetical protein & 5.63 & $2.16 \mathrm{E}-38$ \\
\hline phzC2 & phenazine biosynthesis protein $\mathrm{PhzC}$ & 5.55 & 5.87E-50 \\
\hline PA1143 & hypothetical protein & 5.43 & 9.07E-42 \\
\hline PA1486 & hypothetical protein & 5.32 & 1.74E-35 \\
\hline PA1268 & 4-hydroxyproline 2-epimerase & 5.18 & 1.33E-42 \\
\hline PA1346 & hypothetical protein & 4.94 & $7.15 \mathrm{E}-35$ \\
\hline PA1566 & hypothetical protein & 4.74 & $2.31 \mathrm{E}-42$ \\
\hline PA1966 & hypothetical protein & 4.65 & 6.07E-26 \\
\hline PA2062 & pyridoxal-phosphate dependent protein & 4.59 & 4.06E-27 \\
\hline PA1282 & major facilitator superfamily transporter & 4.57 & $2.55 \mathrm{E}-42$ \\
\hline PA3175 & formimidoylglutamase & 4.56 & $3.38 \mathrm{E}-26$ \\
\hline PA2203 & amino acid permease & 4.48 & 1.27E-28 \\
\hline PA2024 & ring-cleaving dioxygenase & 4.44 & $3.45 \mathrm{E}-19$ \\
\hline PA3424 & hypothetical protein & 4.44 & 9.41E-37 \\
\hline PA0813 & hypothetical protein & 4.26 & 2.01E-31 \\
\hline PA3750 & hypothetical protein & 4.21 & 2.38E-31 \\
\hline hcnC & hydrogen cyanide synthase subunit HcnC & 4.19 & $5.22 \mathrm{E}-25$ \\
\hline PA2531 & aminotransferase & 4.17 & 2.03E-25 \\
\hline$c o b C$ & threonine-phosphate decarboxylase & 4.04 & 1.29E-24 \\
\hline PA3956 & hypothetical protein & 3.99 & $5.75 \mathrm{E}-22$ \\
\hline $\operatorname{dau} A$ & $\begin{array}{l}\text { FAD-dependent catabolic D-arginine } \\
\text { dehydrogenase DauA }\end{array}$ & 3.83 & $3.35 E-30$ \\
\hline PA5084 & oxidoreductase & 3.65 & 3.35E-24 \\
\hline
\end{tabular}




\begin{tabular}{|c|c|c|c|}
\hline PA4165 & transcriptional regulator & 3.63 & $6.71 \mathrm{E}-26$ \\
\hline$p d x B$ & erythronate-4-phosphate dehydrogenase & 3.58 & $6.46 \mathrm{E}-25$ \\
\hline$m d / C$ & benzoylformate decarboxylase & 3.58 & $1.93 \mathrm{E}-23$ \\
\hline PA1147 & amino acid permease & 3.58 & $1.34 \mathrm{E}-2 \varepsilon$ \\
\hline PA1255 & trans-3-hydroxy-L-proline dehydratase & 3.56 & $1.82 \mathrm{E}-17$ \\
\hline PA4908 & ornithine cyclodeaminase & 3.53 & $7.38 \mathrm{E}-26$ \\
\hline phnB & anthranilate synthase component II & 3.51 & $4.20 \mathrm{E}-21$ \\
\hline cpg2 & glutamate carboxypeptidase & 3.43 & $5.68 \mathrm{E}-23$ \\
\hline PA0244 & shikimate 5-dehydrogenase & 3.39 & $7.22 \mathrm{E}-18$ \\
\hline glts & glutamate/sodium ion symporter GltS & 3.36 & $3.62 \mathrm{E}-21$ \\
\hline PA5341 & hypothetical protein & 3.32 & $8.24 \mathrm{E}-24$ \\
\hline PA2035 & thiamine pyrophosphate protein & 3.29 & $1.89 \mathrm{E}-22$ \\
\hline PA0268 & transcriptional regulator & 3.26 & $5.08 \mathrm{E}-27$ \\
\hline PA1732 & hypothetical protein & 3.24 & $1.01 \mathrm{E}-10$ \\
\hline PA1258 & $A B C$ transporter permease & 3.20 & $3.65 \mathrm{E}-13$ \\
\hline PA1129 & glutathione transferase FosA & 3.20 & 2.93E-14 \\
\hline phzE1 & phenazine biosynthesis protein PhzE & 3.16 & $3.94 \mathrm{E}-24$ \\
\hline PA4510 & hypothetical protein & 3.15 & $1.29 \mathrm{E}-10$ \\
\hline PA4509 & hypothetical protein & 3.10 & $4.84 \mathrm{E}-10$ \\
\hline PA2943 & phospho-2-dehydro-3-deoxyheptonate aldolase & 3.08 & $2.17 \mathrm{E}-18$ \\
\hline PA4860 & $A B C$ transporter permease & 3.08 & $1.55 \mathrm{E}-18$ \\
\hline PA3665 & hypothetical protein & 3.00 & $9.73 \mathrm{E}-1 \mathrm{C}$ \\
\hline PA2252 & AGCS sodium/alanine/glycine symporter & 2.99 & $1.08 \mathrm{E}-08$ \\
\hline PA0851 & hypothetical protein & 2.93 & $1.38 \mathrm{E}-19$ \\
\hline PA4926 & hypothetical protein & 2.93 & $7.41 \mathrm{E}-16$ \\
\hline PA1254 & dihydrodipicolinate synthetase & 2.93 & $2.48 \mathrm{E}-10$ \\
\hline PA5390 & acetylornithine deacetylase & 2.92 & $1.49 \mathrm{E}-16$ \\
\hline PA4507 & hypothetical protein & 2.88 & $2.89 \mathrm{E}-14$ \\
\hline$d s d A$ & D-serine dehydratase & 2.87 & $3.04 \mathrm{E}-15$ \\
\hline PA0326 & ABC transporter ATP-binding protein & 2.87 & $1.99 \mathrm{E}-19$ \\
\hline PA5093 & histidine/phenylalanine ammonia-lyase & 2.86 & $1.12 \mathrm{E}-2 \mathrm{C}$ \\
\hline braZ & $\begin{array}{l}\text { branched-chain amino acid transport system } 3 \\
\text { carrier protein }\end{array}$ & 2.86 & $5.43 \mathrm{E}-17$ \\
\hline PA0164 & gamma-glutamyltranspeptidase & 2.85 & $1.09 \mathrm{E}-17$ \\
\hline PA2873 & protein-glutamine gamma-glutamyltransferase & 2.84 & $5.93 \mathrm{E}-21$ \\
\hline PA4192 & ABC transporter ATP-binding protein & 2.80 & $5.25 \mathrm{E}-13$ \\
\hline PA0361 & gamma-glutamyltranspeptidase & 2.79 & $1.10 \mathrm{E}-18$ \\
\hline$p v d H$ & $\begin{array}{l}\text { diaminobutyrate--2-oxoglutarate } \\
\text { aminotransferase }\end{array}$ & 2.78 & $2.01 \mathrm{E}-11$ \\
\hline PA2683 & serine/threonine dehydratase & 2.75 & $1.55 \mathrm{E}-17$ \\
\hline PA5508 & glutamine synthetase & 2.71 & $1.41 \mathrm{E}-15$ \\
\hline gcvT2 & glycine cleavage system protein $\mathrm{T} 2$ & 2.71 & $4.34 \mathrm{E}-15$ \\
\hline
\end{tabular}




\begin{tabular}{|c|c|c|c|}
\hline PA4677 & hypothetical protein & 2.71 & 8.06E-17 \\
\hline PA3749 & major facilitator superfamily transporter & 2.70 & $5.23 \mathrm{E}-18$ \\
\hline PA2110 & hypothetical protein & 2.68 & 1.52E-07 \\
\hline PA1918 & hypothetical protein & 2.63 & $3.89 \mathrm{E}-09$ \\
\hline PA1567 & hypothetical protein & 2.62 & 1.62E-12 \\
\hline$I d h$ & leucine dehydrogenase & 2.60 & $1.01 \mathrm{E}-12$ \\
\hline hisQ & histidine $A B C$ transporter permease HisQ & 2.57 & $1.70 \mathrm{E}-07$ \\
\hline PA4985 & hypothetical protein & 2.52 & $5.48 \mathrm{E}-13$ \\
\hline PA0534 & hypothetical protein & 2.52 & $9.16 \mathrm{E}-14$ \\
\hline chpE & chemotactic transduction protein ChpE & 2.52 & $1.68 \mathrm{E}-12$ \\
\hline PA5155 & amino acid $A B C$ transporter permease & 2.48 & $1.76 \mathrm{E}-11$ \\
\hline potA & $\begin{array}{l}\text { polyamine transporter ATP-binding protein } \\
\text { PotA }\end{array}$ & 2.47 & 3.67E-11 \\
\hline dauB & $\begin{array}{l}\mathrm{NAD}(\mathrm{P}) \mathrm{H} \text {-dependent anabolic L-arginine } \\
\text { dehydrogenase DauB }\end{array}$ & 2.46 & $1.00 \mathrm{E}-13$ \\
\hline PA4025 & ethanolamine ammonia-lyase small subunit & 2.42 & $4.32 \mathrm{E}-12$ \\
\hline PA1028 & oxidoreductase & 2.40 & $2.30 \mathrm{E}-13$ \\
\hline aruH & arginine:pyruvate transaminase $\mathrm{AruH}$ & 2.39 & $2.52 \mathrm{E}-11$ \\
\hline PA2835 & major facilitator superfamily transporter & 2.38 & 3.83E-11 \\
\hline PA0242 & hypothetical protein & 2.38 & $9.51 \mathrm{E}-14$ \\
\hline SOXA & sarcosine oxidase subunit alpha & 2.38 & $4.20 \mathrm{E}-16$ \\
\hline PA2111 & hypothetical protein & 2.37 & $1.07 \mathrm{E}-07$ \\
\hline ureA & urease subunit gamma & 2.37 & $3.65 \mathrm{E}-08$ \\
\hline ilvA2 & threonine dehydratase & 2.33 & $2.73 E-13$ \\
\hline PA2058 & $\mathrm{ABC}$ transporter & 2.31 & $1.60 \mathrm{E}-11$ \\
\hline PA0777 & hypothetical protein & 2.27 & 4.71E-08 \\
\hline PA1257 & amino acid $A B C$ transporter permease & 2.24 & $1.99 \mathrm{E}-08$ \\
\hline PA3125 & hypothetical protein & 2.22 & 2.03E-09 \\
\hline PA0902 & hypothetical protein & 2.22 & 5.44E-08 \\
\hline dapE & succinyl-diaminopimelate desuccinylase & 2.18 & 4.98E-08 \\
\hline PA1819 & amino acid permease & 2.16 & $6.49 \mathrm{E}-11$ \\
\hline gpuA & guanidinopropionase & 2.12 & 5.18E-09 \\
\hline PA2079 & amino acid permease & 2.11 & $3.26 \mathrm{E}-07$ \\
\hline PA3254 & $A B C$ transporter ATP-binding protein & 2.10 & $1.06 \mathrm{E}-08$ \\
\hline PA2929 & hypothetical protein & 2.10 & 5.98E-07 \\
\hline PA4804 & amino acid permease & 2.08 & $5.15 \mathrm{E}-10$ \\
\hline$s d a B$ & L-serine dehydratase & 2.06 & $7.98 \mathrm{E}-09$ \\
\hline PA2958 & hypothetical protein & 2.06 & 4.88E-09 \\
\hline PA3187 & ABC transporter ATP-binding protein & 2.05 & 3.04E-07 \\
\hline PA2842 & hypothetical protein & 2.04 & $5.05 \mathrm{E}-08$ \\
\hline PA3667 & cysteine desulfurase & 2.03 & $3.19 \mathrm{E}-08$ \\
\hline \multicolumn{4}{|c|}{ Carbohydrate transport and metabolism } \\
\hline
\end{tabular}




\begin{tabular}{|c|c|c|c|}
\hline PA2092 & major facilitator superfamily transporter & 8.65 & $2.41 \mathrm{E}-46$ \\
\hline PA2163 & 4-alpha-glucanotransferase & 8.10 & 1.11E-47 \\
\hline PA1908 & major facilitator superfamily transporter & 7.79 & $1.58 \mathrm{E}-56$ \\
\hline PA2472 & major facilitator superfamily transporter & 7.20 & $1.41 \mathrm{E}-55$ \\
\hline PA1352 & hypothetical protein & 7.11 & $8.19 \mathrm{E}-63$ \\
\hline PA1265 & hypothetical protein & 6.67 & 3.74E-41 \\
\hline PA1412 & hypothetical protein & 6.64 & 1.74E-56 \\
\hline PA2091 & hypothetical protein & 6.39 & $1.70 \mathrm{E}-45$ \\
\hline PA2261 & 2-ketogluconate kinase & 5.74 & $2.64 \mathrm{E}-45$ \\
\hline PA2162 & malto-oligosyltrehalose synthase & 5.67 & 1.39E-33 \\
\hline PA2933 & major facilitator superfamily transporter & 5.61 & $1.52 \mathrm{E}-47$ \\
\hline PA2172 & hypothetical protein & 5.05 & $2.79 \mathrm{E}-40$ \\
\hline PA4903 & major facilitator superfamily transporter & 4.82 & 7.06E-34 \\
\hline PA3358 & hypothetical protein & 4.71 & $2.79 \mathrm{E}-38$ \\
\hline PA1131 & major facilitator superfamily transporter & 4.70 & $3.14 \mathrm{E}-41$ \\
\hline $\operatorname{tre} A$ & trehalase & 4.60 & 1.57E-23 \\
\hline PA3303 & major facilitator superfamily transporter & 4.55 & $3.04 \mathrm{E}-40$ \\
\hline PA1993 & hypothetical protein & 4.48 & $1.93 \mathrm{E}-29$ \\
\hline PA1144 & major facilitator superfamily transporter & 4.47 & $7.82 \mathrm{E}-36$ \\
\hline PA3773 & hypothetical protein & 4.37 & $6.03 E-39$ \\
\hline PA1740 & hypothetical protein & 4.29 & $2.22 \mathrm{E}-30$ \\
\hline PA2269 & hypothetical protein & 4.27 & $2.79 \mathrm{E}-26$ \\
\hline PA1052 & hypothetical protein & 4.10 & $3.12 \mathrm{E}-26$ \\
\hline PA4900 & major facilitator superfamily transporter & 4.09 & $2.98 \mathrm{E}-21$ \\
\hline PA0811 & major facilitator superfamily transporter & 4.05 & $1.05 \mathrm{E}-34$ \\
\hline $\operatorname{arn} D$ & $\begin{array}{l}\text { 4-deoxy-4-formamido-L-arabinose- } \\
\text { phosphoundecaprenol deformylase ArnD }\end{array}$ & 4.05 & $1.34 \mathrm{E}-23$ \\
\hline PA4128 & 2,4-dihydroxyhept-2-ene-1,7-dioic acid aldolase & 3.95 & $6.06 \mathrm{E}-32$ \\
\hline PA2260 & hypothetical protein & 3.94 & $5.70 \mathrm{E}-17$ \\
\hline PA0883 & acyl-CoA lyase subunit beta & 3.92 & $2.44 \mathrm{E}-18$ \\
\hline$g \lg B$ & 1,4-alpha-glucan branching protein GlgB & 3.91 & 1.89E-24 \\
\hline PA1313 & major facilitator superfamily transporter & 3.85 & $4.81 \mathrm{E}-29$ \\
\hline PA4136 & major facilitator superfamily transporter & 3.83 & 2.91E-32 \\
\hline PA2152 & trehalose synthase & 3.77 & 4.46E-29 \\
\hline PA4355 & major facilitator superfamily transporter & 3.71 & $1.28 \mathrm{E}-28$ \\
\hline PA0238 & hypothetical protein & 3.66 & $2.56 \mathrm{E}-18$ \\
\hline PA1286 & major facilitator superfamily transporter & 3.65 & 3.87E-28 \\
\hline PA3760 & $\begin{array}{l}\mathrm{N} \text {-acetyl-D-glucosamine phosphotransferase } \\
\text { system transporter }\end{array}$ & 3.62 & $9.38 \mathrm{E}-27$ \\
\hline rbsA & ribose transporter RbsA & 3.62 & 7.67E-17 \\
\hline PA2164 & glycosyl hydrolase & 3.57 & $1.14 \mathrm{E}-15$ \\
\hline muck & cis,cis-muconate transporter MucK & 3.56 & $7.75 \mathrm{E}-26$ \\
\hline
\end{tabular}




\begin{tabular}{|c|c|c|c|}
\hline PA2589 & hypothetical protein & 3.54 & $1.15 \mathrm{E}-23$ \\
\hline fruk & 1-phosphofructokinase & 3.53 & $1.42 \mathrm{E}-27$ \\
\hline PA1280 & hypothetical protein & 3.49 & $5.73 \mathrm{E}-23$ \\
\hline PA1109 & transcriptional regulator & 3.48 & $8.14 \mathrm{E}-25$ \\
\hline$p g l$ & 6-phosphogluconolactonase & 3.40 & $8.62 \mathrm{E}-24$ \\
\hline PA2210 & major facilitator superfamily transporter & 3.37 & $1.59 \mathrm{E}-10$ \\
\hline PA2077 & hypothetical protein & 3.30 & $2.14 \mathrm{E}-19$ \\
\hline PA0334 & major facilitator superfamily transporter & 3.22 & $4.72 \mathrm{E}-25$ \\
\hline PA4779 & hypothetical protein & 3.19 & $1.08 \mathrm{E}-1 \mathrm{c}$ \\
\hline PA2006 & major facilitator superfamily transporter & 3.17 & $4.54 \mathrm{E}-21$ \\
\hline frul & $\begin{array}{l}\text { PTS system fructose-specific transporter } \\
\text { subunit Frul }\end{array}$ & 3.17 & $9.30 \mathrm{E}-24$ \\
\hline fruA & $\begin{array}{l}\text { PTS system fructose-specific transporter } \\
\text { subunit IIBC }\end{array}$ & 3.17 & $2.37 \mathrm{E}-25$ \\
\hline PA3024 & carbohydrate kinase & 3.13 & $1.25 \mathrm{E}-21$ \\
\hline PA1236 & major facilitator superfamily transporter & 3.04 & $1.67 \mathrm{E}-21$ \\
\hline$g / k$ & glucokinase & 2.97 & $2.18 \mathrm{E}-2 \mathrm{C}$ \\
\hline PA3682 & hypothetical protein & 2.96 & $1.08 \mathrm{E}-19$ \\
\hline PA2214 & major facilitator superfamily transporter & 2.95 & $1.30 \mathrm{E}-15$ \\
\hline PA4096 & major facilitator superfamily transporter & 2.94 & $2.99 \mathrm{E}-14$ \\
\hline PA3467 & major facilitator superfamily transporter & 2.87 & $8.46 \mathrm{E}-10$ \\
\hline PA3222 & hypothetical protein & 2.81 & $1.94 \mathrm{E}-14$ \\
\hline PA2165 & glycogen synthase & 2.78 & $3.15 \mathrm{E}-15$ \\
\hline rbsk & ribokinase & 2.77 & $1.76 \mathrm{E}-14$ \\
\hline PA4120 & transcriptional regulator & 2.74 & $7.54 \mathrm{E}-15$ \\
\hline PA5282 & major facilitator superfamily transporter & 2.73 & $2.40 \mathrm{E}-18$ \\
\hline PA5219 & hypothetical protein & 2.73 & $1.15 \mathrm{E}-15$ \\
\hline PA3780 & hypothetical protein & 2.73 & $4.10 \mathrm{E}-12$ \\
\hline ps/B & biofilm formation protein PsIB & 2.60 & $6.90 \mathrm{E}-14$ \\
\hline PA1499 & hypothetical protein & 2.55 & 3.93E-11 \\
\hline PA0550 & hypothetical protein & 2.40 & 4.07E-12 \\
\hline PA3131 & aldolase & 2.39 & $4.00 \mathrm{E}-10$ \\
\hline PA2414 & L-sorbosone dehydrogenase & 2.38 & $1.78 \mathrm{E}-0 \mathrm{~S}$ \\
\hline$b g I X$ & beta-glucosidase & 2.30 & $3.82 \mathrm{E}-13$ \\
\hline PA3181 & 2-dehydro-3-deoxy-phosphogluconate aldolase & 2.12 & $6.72 \mathrm{E}-08$ \\
\hline PA3573 & major facilitator superfamily transporter & 2.10 & $2.36 \mathrm{E}-08$ \\
\hline PA4113 & sugar efflux transporter & 2.09 & $8.41 \mathrm{E}-10$ \\
\hline pslL & hypothetical protein & 2.05 & $1.08 \mathrm{E}-06$ \\
\hline PA3758 & $\mathrm{N}$-acetylglucosamine-6-phosphate deacetylase & 2.04 & $3.10 \mathrm{E}-0 \mathrm{~g}$ \\
\hline PA3189 & sugar $A B C$ transporter permease & 2.04 & $9.15 \mathrm{E}-08$ \\
\hline PA3781 & transporter & 2.03 & $2.03 \mathrm{E}-0 \mathrm{c}$ \\
\hline PA2262 & 2-ketogluconate transporter & 2.02 & $5.57 \mathrm{E}-08$ \\
\hline
\end{tabular}




\begin{tabular}{|c|c|c|c|}
\hline PA1046 & hypothetical protein & 2.01 & $5.68 \mathrm{E}-09$ \\
\hline PA2151 & $\begin{array}{l}\text { alpha-1,4-glucan:maltose-1-phosphate } \\
\text { maltosyltransferase }\end{array}$ & 2.00 & $2.18 \mathrm{E}-07$ \\
\hline \multicolumn{4}{|c|}{ Cell cycle control, cell division, chromosome partitioning } \\
\hline PA3638 & tRNA(Ile)-lysidine synthase & 2.83 & $2.30 \mathrm{E}-20$ \\
\hline PA4478 & hypothetical protein & 2.24 & $2.26 \mathrm{E}-09$ \\
\hline \multicolumn{4}{|c|}{ Cell motility } \\
\hline PA0687 & type II secretion system protein & 5.19 & $7.24 \mathrm{E}-45$ \\
\hline$p s c Q$ & type III secretion system protein & 4.96 & $1.36 \mathrm{E}-34$ \\
\hline PA2920 & chemotaxis transducer & 4.46 & $1.46 \mathrm{E}-34$ \\
\hline cupC2 & chaperone CupC2 & 4.31 & $1.85 \mathrm{E}-03$ \\
\hline PA1697 & type III secretion system ATPase & 4.18 & $1.67 \mathrm{E}-28$ \\
\hline PA0173 & $\begin{array}{l}\text { chemotaxis response regulator protein- } \\
\text { glutamate methylesterase }\end{array}$ & 4.04 & $3.73 \mathrm{E}-25$ \\
\hline PA4844 & chemotaxis transducer & 3.95 & 8.99E-35 \\
\hline сирA2 & chaperone CupA2 & 3.77 & $6.83 \mathrm{E}-18$ \\
\hline PA1251 & chemotaxis transducer & 3.69 & $2.74 \mathrm{E}-22$ \\
\hline cupB4 & chaperone CupB4 & 3.68 & $1.40 \mathrm{E}-17$ \\
\hline PA0686 & type II secretion system protein HxcR & 3.67 & $5.27 \mathrm{E}-28$ \\
\hline PA4651 & pili assembly chaperone & 3.30 & 5.37E-21 \\
\hline PA0685 & type II secretion system protein & 3.19 & $1.41 \mathrm{E}-21$ \\
\hline PA5072 & chemotaxis transducer & 3.06 & $1.73 \mathrm{E}-22$ \\
\hline PA0078 & hypothetical protein & 3.00 & $8.25 \mathrm{E}-18$ \\
\hline flio & flagellar protein FliO & 2.42 & 3.87E-11 \\
\hline $\operatorname{pscC}$ & type III secretion outer membrane protein PscC & 2.39 & 4.77E-12 \\
\hline$x c p S$ & type II secretion system protein $\mathrm{F}$ & 2.36 & $4.31 \mathrm{E}-13$ \\
\hline PA4652 & hypothetical protein & 2.36 & $3.71 \mathrm{E}-15$ \\
\hline PA0178 & two-component sensor & 2.14 & $2.08 \mathrm{E}-10$ \\
\hline PA2677 & type II secretion protein & 2.03 & $2.45 \mathrm{E}-07$ \\
\hline \multicolumn{4}{|c|}{ Cell wall/membrane/envelope biogenesis } \\
\hline psll & biofilm formation protein Psll & 6.15 & $8.85 \mathrm{E}-47$ \\
\hline PA1435 & $\begin{array}{l}\text { resistance-nodulation-cell division (RND) efflux } \\
\text { membrane fusion protein }\end{array}$ & 5.19 & $1.59 \mathrm{E}-41$ \\
\hline pslF & biofilm formation protein PsIF & 5.16 & $3.06 \mathrm{E}-37$ \\
\hline PA3404 & hypothetical protein & 4.66 & $2.19 \mathrm{E}-36$ \\
\hline opmQ & hypothetical protein & 4.52 & 8.27E-32 \\
\hline PA3431 & hypothetical protein & 4.39 & 4.03E-30 \\
\hline$p s / H$ & biofilm formation protein PsIH & 4.18 & $2.69 \mathrm{E}-33$ \\
\hline PA0842 & glycosyl transferase family protein & 4.15 & $4.80 \mathrm{E}-33$ \\
\hline tonB2 & transporter TonB & 4.04 & $1.10 \mathrm{E}-14$ \\
\hline PA0695 & hypothetical protein & 4.03 & $1.04 \mathrm{E}-20$ \\
\hline PA0333 & hypothetical protein & 4.00 & $2.03 E-37$ \\
\hline
\end{tabular}




\begin{tabular}{|c|c|c|c|}
\hline hasE & metalloprotease secretion protein & 3.97 & $3.29 \mathrm{E}-34$ \\
\hline$C z c B$ & $\begin{array}{l}\text { resistance-nodulation-cell division (RND) } \\
\text { divalent metal cation efflux membrane fusion } \\
\text { protein CzcB }\end{array}$ & 3.89 & 1.33E-22 \\
\hline PA3677 & $\begin{array}{l}\text { resistance-nodulation-cell division (RND) efflux } \\
\text { membrane fusion protein }\end{array}$ & 3.79 & $9.51 \mathrm{E}-27$ \\
\hline PA2548 & hypothetical protein & 3.65 & $5.17 \mathrm{E}-22$ \\
\hline $\operatorname{mexC}$ & $\begin{array}{l}\text { resistance-nodulation-cell division (RND) } \\
\text { multidrug efflux membrane fusion protein MexC }\end{array}$ & 3.53 & $7.39 \mathrm{E}-26$ \\
\hline $\operatorname{arnT}$ & $\begin{array}{l}\text { 4-amino-4-deoxy-L-arabinose lipid A } \\
\text { transferase }\end{array}$ & 3.48 & 1.79E-26 \\
\hline IasA & protease LasA & 3.45 & $5.06 \mathrm{E}-26$ \\
\hline PA4188 & hypothetical protein & 3.35 & $2.43 \mathrm{E}-19$ \\
\hline PA4818 & hypothetical protein & 3.26 & $8.52 \mathrm{E}-23$ \\
\hline waaA & 3-deoxy-D-manno-octulosonic acid transferase & 3.17 & $5.52 \mathrm{E}-25$ \\
\hline PA1408 & hypothetical protein & 3.12 & $2.99 \mathrm{E}-25$ \\
\hline PA2684 & hypothetical protein & 3.09 & $7.23 \mathrm{E}-20$ \\
\hline PA1874 & hypothetical protein & 3.05 & $3.00 \mathrm{E}-22$ \\
\hline PA3402 & hypothetical protein & 3.05 & $5.87 \mathrm{E}-18$ \\
\hline PA3759 & aminotransferase & 3.00 & $2.05 \mathrm{E}-19$ \\
\hline PA0157 & $\begin{array}{l}\text { resistance-nodulation-cell division (RND) efflux } \\
\text { membrane fusion protein }\end{array}$ & 2.75 & $4.01 \mathrm{E}-19$ \\
\hline PA3526 & hypothetical protein & 2.67 & $3.26 \mathrm{E}-17$ \\
\hline$n d v B$ & glycosyl transferase & 2.65 & $5.19 \mathrm{E}-18$ \\
\hline catB & muconate cycloisomerase I & 2.63 & 2.82E-10 \\
\hline PA1385 & glycosyl transferase family protein & 2.60 & 1.17E-03 \\
\hline PA2865 & glycosylase & 2.57 & 1.66E-12 \\
\hline PA4591 & hypothetical protein & 2.56 & $3.28 \mathrm{E}-15$ \\
\hline algl & alginate o-acetylase Algl & 2.55 & $2.15 \mathrm{E}-15$ \\
\hline PA1171 & transglycosylase & 2.54 & $7.22 \mathrm{E}-09$ \\
\hline$p b p C$ & penicillin-binding protein $3 \mathrm{~A}$ & 2.51 & $2.51 \mathrm{E}-10$ \\
\hline mexH & $\begin{array}{l}\text { resistance-nodulation-cell division (RND) efflux } \\
\text { membrane fusion protein }\end{array}$ & 2.46 & 1.22E-11 \\
\hline PA4041 & hypothetical protein & 2.42 & $9.62 \mathrm{E}-11$ \\
\hline PA4924 & hypothetical protein & 2.38 & $4.15 \mathrm{E}-11$ \\
\hline alg44 & alginate biosynthesis protein Alg44 & 2.38 & 1.67E-09 \\
\hline PA4819 & glycosyl transferase family protein & 2.34 & $5.58 \mathrm{E}-11$ \\
\hline aprE & alkaline protease secretion protein AprE & 2.33 & $1.25 \mathrm{E}-12$ \\
\hline PA3523 & $\begin{array}{l}\text { resistance-nodulation-cell division (RND) efflux } \\
\text { membrane fusion protein }\end{array}$ & 2.29 & $2.88 \mathrm{E}-11$ \\
\hline IpxK & tetraacyldisaccharide 4'-kinase & 2.28 & 4.49E-11 \\
\hline pelF & $\begin{array}{l}\text { pellicle/biofilm biosynthesis glycosyltransferase } \\
\text { PelF }\end{array}$ & 2.20 & $6.94 \mathrm{E}-10$ \\
\hline$p v d R$ & pyoverdine biosynthesis protein PvdR & 2.20 & $1.98 \mathrm{E}-08$ \\
\hline
\end{tabular}




\begin{tabular}{|c|c|c|c|}
\hline$p s / D$ & biofilm formation protein PsID & 2.16 & 1.18E-07 \\
\hline $\operatorname{mex} E$ & $\begin{array}{l}\text { resistance-nodulation-cell division (RND) } \\
\text { multidrug efflux membrane fusion protein MexE }\end{array}$ & 2.13 & $9.94 \mathrm{E}-10$ \\
\hline \multicolumn{4}{|c|}{ Chromatin structure and dynamics } \\
\hline aphA & acetylpolyamine aminohydrolase & 2.35 & 2.26E-11 \\
\hline \multicolumn{4}{|c|}{ Coenzyme transport and metabolism } \\
\hline PA1355 & hypothetical protein & 7.75 & $1.20 \mathrm{E}-47$ \\
\hline PA1923 & cobaltochelatase subunit CobN & 7.11 & $5.05 E-57$ \\
\hline PA2263 & 2-hydroxyacid dehydrogenase & 6.13 & $5.03 E-33$ \\
\hline PA2909 & cobalt-precorrin-6x reductase & 5.83 & 1.33E-35 \\
\hline PA2912 & ABC transporter ATP-binding protein & 5.43 & 1.30E-44 \\
\hline PA1417 & hypothetical protein & 5.38 & 1.14E-46 \\
\hline$c o b V$ & adenosylcobinamide-GDP ribazoletransferase & 5.13 & $8.18 E-40$ \\
\hline PA2941 & hypothetical protein & 5.12 & 1.94E-37 \\
\hline$c o b D$ & cobalamin biosynthesis protein CobD & 4.65 & 3.14E-39 \\
\hline cobJ & precorrin-3 methylase CobJ & 4.62 & $6.28 \mathrm{E}-43$ \\
\hline PA2942 & magnesium chelatase & 4.61 & 8.31E-40 \\
\hline phzG2 & pyridoxamine 5'-phosphate oxidase & 4.50 & $9.85 \mathrm{E}-28$ \\
\hline moeA1 & molybdenum cofactor biosynthesis protein $\mathrm{A}$ & 4.42 & 1.17E-33 \\
\hline $\mathrm{cobH}$ & precorrin-8X methylmutase & 4.42 & $1.60 \mathrm{E}-19$ \\
\hline PA0209 & $\begin{array}{l}\text { 2-(5"-triphosphoribosyl)-3'- } \\
\text { dephosphocoenzyme-A synthase }\end{array}$ & 4.39 & 1.20E-26 \\
\hline cobL & $\begin{array}{l}\text { precorrin-6y-dependent methyltransferase } \\
\text { CobL }\end{array}$ & 4.19 & $3.96 \mathrm{E}-30$ \\
\hline phzG1 & pyridoxamine 5'-phosphate oxidase & 4.11 & 2.34E-18 \\
\hline PA1957 & hypothetical protein & 4.01 & 8.03E-21 \\
\hline$c o b U$ & $\begin{array}{l}\text { nicotinate-nucleotide--dimethylbenzimidazole } \\
\text { phosphoribosyltransferase }\end{array}$ & 3.98 & 9.93E-30 \\
\hline mobA & molybdenum cofactor guanylyltransferase & 3.91 & $1.41 \mathrm{E}-24$ \\
\hline arul & hypothetical protein & 3.61 & 1.15E-26 \\
\hline PA2650 & hypothetical protein & 3.55 & $1.08 \mathrm{E}-21$ \\
\hline PA2108 & thiamine pyrophosphate protein & 3.49 & 3.01E-18 \\
\hline panE & 2-dehydropantoate 2-reductase & 3.48 & 1.11E-25 \\
\hline PA0510 & uroporphyrin-III C-methyltransferase & 3.47 & 9.24E-19 \\
\hline PA1958 & transporter & 3.39 & $4.60 \mathrm{E}-14$ \\
\hline thiE & thiamine-phosphate pyrophosphorylase & 3.38 & 9.43E-14 \\
\hline moaA1 & molybdenum cofactor biosynthesis protein $\mathrm{A}$ & 3.33 & 8.78E-20 \\
\hline$r r m A$ & rRNA methyltransferase & 3.30 & 8.88E-16 \\
\hline PA4286 & hypothetical protein & 3.24 & 8.92E-22 \\
\hline cobB & hydrogenobyrinate a,c-diamide synthase & 3.24 & 1.64E-21 \\
\hline cbiD & cobalt-precorrin-5B C(1)-methyltransferase & 3.23 & 4.44E-21 \\
\hline ispA & geranyltranstransferase & 3.20 & $2.72 \mathrm{E}-20$ \\
\hline PA0254 & hypothetical protein & 3.19 & 8.60E-21 \\
\hline
\end{tabular}




\begin{tabular}{|c|c|c|c|}
\hline PA4790 & hypothetical protein & 3.15 & $1.59 \mathrm{E}-20$ \\
\hline PA2679 & hypothetical protein & 3.06 & 1.43E-18 \\
\hline phzE2 & phenazine biosynthesis protein PhzE & 3.01 & $1.18 \mathrm{E}-18$ \\
\hline PA3119 & hypothetical protein & 2.95 & $8.41 \mathrm{E}-17$ \\
\hline $\operatorname{cobP}$ & $\begin{array}{l}\text { bifunctional adenosylcobinamide } \\
\text { kinase/adenosylcobinamide-phosphate } \\
\text { guanylyltransferase }\end{array}$ & 2.91 & $3.99 \mathrm{E}-17$ \\
\hline $\operatorname{cobN}$ & cobaltochelatase subunit CobN & 2.90 & $3.81 \mathrm{E}-22$ \\
\hline PA2212 & $\begin{array}{l}\text { 4-hydroxythreonine-4-phosphate } \\
\text { dehydrogenase }\end{array}$ & 2.85 & $3.11 \mathrm{E}-14$ \\
\hline$p m t A$ & phospholipid methyltransferase & 2.80 & $5.93 \mathrm{E}-15$ \\
\hline ribD & riboflavin-specific deaminase/reductase & 2.75 & $1.49 \mathrm{E}-16$ \\
\hline $\operatorname{cobQ}$ & cobyric acid synthase & 2.66 & 1.93E-16 \\
\hline PA4088 & aminotransferase & 2.64 & $9.44 \mathrm{E}-16$ \\
\hline thiL & thiamine monophosphate kinase & 2.57 & $3.22 \mathrm{E}-15$ \\
\hline antC & anthranilate dioxygenase reductase & 2.55 & $6.54 \mathrm{E}-07$ \\
\hline$p q q C$ & pyrroloquinoline-quinone synthase & 2.54 & 1.44E-07 \\
\hline PA4917 & hypothetical protein & 2.53 & $4.06 \mathrm{E}-08$ \\
\hline folk & $\begin{array}{l}\text { 2-amino-4-hydroxy-6- } \\
\text { hydroxymethyldihydropteridine } \\
\text { pyrophosphokinase }\end{array}$ & 2.42 & $5.15 \mathrm{E}-09$ \\
\hline folA & dihydrofolate reductase & 2.31 & $2.32 \mathrm{E}-11$ \\
\hline PA5357 & hypothetical protein & 2.26 & 7.89E-11 \\
\hline PA0386 & coproporphyrinogen III oxidase & 2.18 & $6.74 \mathrm{E}-12$ \\
\hline PA5228 & 5-formyltetrahydrofolate cyclo-ligase & 2.17 & $1.02 \mathrm{E}-10$ \\
\hline PA1598 & $\begin{array}{l}\text { 3-methyl-2-oxobutanoate } \\
\text { hydroxymethyltransferase }\end{array}$ & 2.10 & $8.32 \mathrm{E}-07$ \\
\hline thiD & phosphomethylpyrimidine kinase & 2.07 & $4.79 \mathrm{E}-08$ \\
\hline bioD & ATP-dependent dethiobiotin synthetase BioD & 2.05 & $2.51 \mathrm{E}-09$ \\
\hline GeneName & Description & FoldChange & Padj \\
\hline \multicolumn{4}{|c|}{ Defense mechanisms } \\
\hline PA1237 & multidrug resistance efflux pump & 6.78 & 6.63E-38 \\
\hline nosF & copper ABC transporter ATP-binding protein & 5.38 & $2.29 \mathrm{E}-40$ \\
\hline PA1231 & hypothetical protein & 5.13 & $6.39 \mathrm{E}-41$ \\
\hline PA3360 & secretion protein & 5.12 & $5.13 \mathrm{E}-43$ \\
\hline PA4821 & transporter & 4.62 & $4.65 \mathrm{E}-34$ \\
\hline PA2836 & secretion protein & 4.55 & $9.27 \mathrm{E}-36$ \\
\hline PA0073 & ABC transporter ATP-binding protein & 4.39 & $1.56 \mathrm{E}-34$ \\
\hline PA0072 & hypothetical protein & 4.28 & $1.01 \mathrm{E}-33$ \\
\hline PA1361 & multidrug resistance protein PmpM & 3.89 & $5.53 \mathrm{E}-29$ \\
\hline PA1876 & ABC transporter ATP-binding protein/permease & 3.88 & $5.61 \mathrm{E}-34$ \\
\hline PA4594 & ABC transporter ATP-binding protein & 3.48 & $5.30 \mathrm{E}-17$ \\
\hline PA4593 & $A B C$ transporter permease & 3.40 & $5.15 \mathrm{E}-26$ \\
\hline
\end{tabular}




\begin{tabular}{|c|c|c|c|}
\hline$p v d T$ & pyoverdine biosynthesis protein PvdT & 3.37 & $6.35 \mathrm{E}-26$ \\
\hline PA4064 & ABC transporter ATP-binding protein & 3.25 & $1.08 \mathrm{E}-18$ \\
\hline PA5294 & multidrug efflux protein NorA & 3.25 & $2.75 \mathrm{E}-26$ \\
\hline PA2228 & hypothetical protein & 2.73 & 1.19E-03 \\
\hline PA4222 & ABC transporter ATP-binding protein & 2.70 & 7.89E-14 \\
\hline PA1113 & ABC transporter ATP-binding protein/permease & 2.55 & $2.39 \mathrm{E}-15$ \\
\hline PA0468 & hypothetical protein & 2.35 & $3.32 \mathrm{E}-13$ \\
\hline PA1047 & esterase & 2.20 & 1.07E-09 \\
\hline PA0860 & ABC transporter ATP-binding protein/permease & 2.20 & $3.58 \mathrm{E}-11$ \\
\hline PA2527 & $\begin{array}{l}\text { resistance-nodulation-cell division (RND) efflux } \\
\text { transporter }\end{array}$ & 2.15 & $5.72 \mathrm{E}-10$ \\
\hline PA4347 & hypothetical protein & 2.12 & $3.31 \mathrm{E}-09$ \\
\hline PA3136 & secretion protein & 2.09 & $6.40 \mathrm{E}-07$ \\
\hline PA2987 & $\begin{array}{l}\text { lipoprotein-releasing system ABC transporter } \\
\text { ATP-binding protein }\end{array}$ & 2.08 & 2.60E-08 \\
\hline \multicolumn{4}{|c|}{ Energy production and conversion } \\
\hline$p v c D$ & paerucumarin biosynthesis protein $\mathrm{PvcD}$ & 8.08 & $4.91 \mathrm{E}-51$ \\
\hline napF & ferredoxin protein NapF & 7.37 & $9.66 \mathrm{E}-50$ \\
\hline PA2090 & hypothetical protein & 7.05 & 8.81E-34 \\
\hline psiM & FAD-binding dehydrogenase & 6.60 & 4.04E-63 \\
\hline PA3208 & hypothetical protein & 4.91 & $1.04 \mathrm{E}-35$ \\
\hline nosL & acessory protein NosL & 4.90 & $1.85 \mathrm{E}-30$ \\
\hline$g / c E$ & glycolate oxidase FAD binding subunit & 4.76 & 2.03E-37 \\
\hline PA3025 & $\begin{array}{l}\text { FAD-dependent glycerol-3-phosphate } \\
\text { dehydrogenase }\end{array}$ & 4.76 & $6.56 \mathrm{E}-44$ \\
\hline PA2125 & aldehyde dehydrogenase & 4.73 & $2.42 \mathrm{E}-24$ \\
\hline napB & cytochrome C protein NapB & 4.72 & $1.89 \mathrm{E}-18$ \\
\hline PA1253 & semialdehyde dehydrogenase & 4.67 & $1.81 \mathrm{E}-37$ \\
\hline$P A 2716$ & FMN oxidoreductase & 4.61 & $1.12 \mathrm{E}-30$ \\
\hline PA1880 & oxidoreductase & 4.55 & $2.48 \mathrm{E}-37$ \\
\hline PA1416 & hypothetical protein & 4.55 & 7.39E-36 \\
\hline PA3328 & FAD-dependent monooxygenase & 4.48 & $2.78 \mathrm{E}-24$ \\
\hline morB & morphinone reductase & 4.48 & 1.22E-29 \\
\hline PA1600 & cytochrome C & 4.40 & $1.38 \mathrm{E}-35$ \\
\hline PA1186 & hypothetical protein & 4.39 & $5.50 \mathrm{E}-35$ \\
\hline$P A 2217$ & aldehyde dehydrogenase & 4.33 & 4.44E-27 \\
\hline pelE & pellicle/biofilm biosynthesis protein PelE & 4.29 & 5.33E-22 \\
\hline PA2936 & hypothetical protein & 4.28 & $2.33 \mathrm{E}-26$ \\
\hline PA0521 & cytochrome C oxidase subunit & 4.14 & $2.42 \mathrm{E}-26$ \\
\hline PA3415 & $\begin{array}{l}\text { branched-chain alpha-keto acid dehydrogenase } \\
\text { subunit E2 }\end{array}$ & 4.10 & $1.92 E-29$ \\
\hline PA3444 & alkanesulfonate monooxygenase & 4.10 & $2.90 \mathrm{E}-23$ \\
\hline PA3491 & electron transport complex subunit C & 4.08 & $7.35 \mathrm{E}-38$ \\
\hline
\end{tabular}




\begin{tabular}{|c|c|c|c|}
\hline PA1146 & iron-containing alcohol dehydrogenase & 4.07 & $6.74 \mathrm{E}-35$ \\
\hline PA1274 & 5,6-dimethylbenzimidazole synthase & 4.05 & $2.42 \mathrm{E}-29$ \\
\hline PA2477 & thiol:disulfide interchange protein & 4.04 & $2.77 \mathrm{E}-17$ \\
\hline glcF & glycolate oxidase iron-sulfur subunit & 3.99 & $4.29 \mathrm{E}-29$ \\
\hline PA2691 & hypothetical protein & 3.91 & $1.26 \mathrm{E}-30$ \\
\hline$x y l z$ & $\begin{array}{l}\text { toluate 1,2-dioxygenase electron transfer } \\
\text { subunit }\end{array}$ & 3.89 & $2.54 \mathrm{E}-22$ \\
\hline PA4889 & oxidoreductase & 3.87 & 7.70E-32 \\
\hline PA5400 & electron transfer flavoprotein subunit alpha & 3.78 & 1.76E-31 \\
\hline PA1739 & oxidoreductase & 3.77 & 1.76E-17 \\
\hline PA1188 & hypothetical protein & 3.68 & $6.53 \mathrm{E}-29$ \\
\hline PA3417 & $\begin{array}{l}\text { pyruvate dehydrogenase E1 component } \\
\text { subunit alpha }\end{array}$ & 3.64 & $1.36 \mathrm{E}-23$ \\
\hline PA4189 & aldehyde dehydrogenase & 3.64 & 1.29E-19 \\
\hline $\operatorname{van} B$ & vanillate O-demethylase & 3.54 & $7.25 \mathrm{E}-25$ \\
\hline PA1334 & oxidoreductase & 3.54 & $1.50 \mathrm{E}-26$ \\
\hline nirC & cytochrome c55X & 3.53 & $4.09 \mathrm{E}-08$ \\
\hline PA0219 & aldehyde dehydrogenase & 3.52 & $2.32 \mathrm{E}-27$ \\
\hline PA2715 & ferredoxin & 3.49 & $1.24 \mathrm{E}-14$ \\
\hline PA4331 & hypothetical protein & 3.48 & $1.35 \mathrm{E}-26$ \\
\hline$m d c C$ & malonate decarboxylase acyl carrier protein & 3.44 & $2.84 \mathrm{E}-17$ \\
\hline PA2598 & hypothetical protein & 3.39 & $8.47 \mathrm{E}-21$ \\
\hline PA3534 & oxidoreductase & 3.26 & $2.43 E-23$ \\
\hline pauA & pimeloyl-CoA synthetase & 3.26 & $9.64 \mathrm{E}-24$ \\
\hline PA2078 & hypothetical protein & 3.26 & $6.79 \mathrm{E}-19$ \\
\hline PA4978 & hypothetical protein & 3.25 & $4.28 \mathrm{E}-24$ \\
\hline PA3416 & $\begin{array}{l}\text { pyruvate dehydrogenase E1 component } \\
\text { subunit beta }\end{array}$ & 3.22 & 2.69E-20 \\
\hline PA0101 & hypothetical protein & 3.21 & $5.40 \mathrm{E}-26$ \\
\hline PA3592 & hypothetical protein & 3.20 & $1.08 \mathrm{E}-21$ \\
\hline PA3772 & hypothetical protein & 3.16 & $1.08 \mathrm{E}-18$ \\
\hline PA0882 & hypothetical protein & 3.15 & 1.49E-22 \\
\hline PA0863 & oxidoreductase & 3.14 & $2.05 \mathrm{E}-18$ \\
\hline PA5186 & iron-containing alcohol dehydrogenase & 3.12 & $7.57 \mathrm{E}-23$ \\
\hline PA1487 & carbohydrate kinase & 3.10 & $1.32 \mathrm{E}-21$ \\
\hline PA5401 & hypothetical protein & 3.06 & $2.83 \mathrm{E}-16$ \\
\hline napE & nitrate reductase protein $\mathrm{NapE}$ & 3.01 & $6.67 \mathrm{E}-05$ \\
\hline $\mathrm{fadH} 2$ & 2,4-dienoyl-CoA reductase & 2.97 & $1.29 \mathrm{E}-20$ \\
\hline PA4859 & $\mathrm{ABC}$ transporter permease & 2.69 & $9.03 \mathrm{E}-19$ \\
\hline PA4792 & hypothetical protein & 2.64 & $5.55 \mathrm{E}-13$ \\
\hline PA3493 & electron transport complex subunit $\mathrm{G}$ & 2.58 & 1.46E-13 \\
\hline PA2600 & hypothetical protein & 2.49 & 3.31E-12 \\
\hline
\end{tabular}




\begin{tabular}{|c|c|c|c|}
\hline PA4150 & dehydrogenase E1 component & 2.48 & 4.97E-1C \\
\hline pntAA & $\mathrm{NAD}(\mathrm{P})$ transhydrogenase subunit alpha & 2.46 & $2.51 \mathrm{E}-13$ \\
\hline PA1601 & aldehyde dehydrogenase & 2.46 & $1.57 \mathrm{E}-15$ \\
\hline PA3492 & electron transport complex subunit $D$ & 2.45 & $9.90 \mathrm{E}-12$ \\
\hline PA3256 & oxidoreductase & 2.41 & $5.58 \mathrm{E}-13$ \\
\hline pqsL & monooxygenase & 2.40 & $1.45 \mathrm{E}-13$ \\
\hline$\| d A$ & L-lactate dehydrogenase & 2.40 & $3.19 \mathrm{E}-11$ \\
\hline PA1252 & $\begin{array}{l}\text { bifunctional Delta(1)-pyrroline-2- } \\
\text { carboxylate/Delta(1)-piperideine-2-carboxylate } \\
\text { reductase }\end{array}$ & 2.37 & 1.19E-1C \\
\hline PA1734 & hypothetical protein & 2.36 & 4.04E-08 \\
\hline Ipd3 & dihydrolipoamide dehydrogenase & 2.32 & $2.09 \mathrm{E}-12$ \\
\hline PA4155 & hypothetical protein & 2.30 & $5.21 \mathrm{E}-11$ \\
\hline PA4073 & aldehyde dehydrogenase & 2.30 & $7.06 \mathrm{E}-1 \mathrm{C}$ \\
\hline hpcC & $\begin{array}{l}\text { 5-carboxy-2-hydroxymuconate semialdehyde } \\
\text { dehydrogenase }\end{array}$ & 2.28 & $9.00 \mathrm{E}-1 \mathrm{C}$ \\
\hline PA1027 & aldehyde dehydrogenase & 2.28 & $2.41 \mathrm{E}-12$ \\
\hline PA2714 & molybdopterin oxidoreductase & 2.25 & $2.39 \mathrm{E}-12$ \\
\hline$d g c B$ & dimethylglycine catabolism protein $\mathrm{DgcB}$ & 2.20 & $2.77 \mathrm{E}-11$ \\
\hline PA3490 & electron transport complex subunit $B$ & 2.20 & $9.55 \mathrm{E}-0 \varepsilon$ \\
\hline PA2266 & cytochrome $\mathrm{C}$ & 2.19 & 1.03E-11 \\
\hline PA4899 & aldehyde dehydrogenase & 2.17 & $4.90 \mathrm{E}-1 \mathrm{C}$ \\
\hline PA2421 & hypothetical protein & 2.16 & $4.33 \mathrm{E}-06$ \\
\hline PA2378 & aldehyde dehydrogenase & 2.13 & $3.77 \mathrm{E}-0 \mathrm{~S}$ \\
\hline PA2482 & cytochrome C & 2.07 & $8.83 \mathrm{E}-0 \mathrm{~S}$ \\
\hline PA4152 & $\begin{array}{l}\text { branched-chain alpha-keto acid dehydrogenase } \\
\text { subunit E2 }\end{array}$ & 2.05 & $1.89 \mathrm{E}-0 \varepsilon$ \\
\hline narJ & respiratory nitrate reductase subunit delta & 2.04 & $3.72 \mathrm{E}-05$ \\
\hline \multicolumn{4}{|c|}{ Hypothetical, unclassified, unknown } \\
\hline PA1981 & hypothetical protein & 8.20 & $1.31 \mathrm{E}-53$ \\
\hline PA1960 & hypothetical protein & 7.21 & 4.25E-51 \\
\hline$P A 2370$ & hypothetical protein & 7.21 & $9.09 \mathrm{E}-55$ \\
\hline PA2048 & hypothetical protein & 6.93 & $7.79 \mathrm{E}-24$ \\
\hline PA2368 & hypothetical protein & 6.91 & $2.71 \mathrm{E}-3 \varepsilon$ \\
\hline PA1547 & hypothetical protein & 6.57 & $1.66 \mathrm{E}-45$ \\
\hline PA2369 & hypothetical protein & 6.16 & $1.47 \mathrm{E}-45$ \\
\hline PA2157 & hypothetical protein & 5.91 & $9.51 \mathrm{E}-35$ \\
\hline PA1849 & hypothetical protein & 5.86 & $9.17 \mathrm{E}-17$ \\
\hline PA1259 & hypothetical protein & 5.85 & $2.59 \mathrm{E}-53$ \\
\hline PA1270 & hypothetical protein & 5.64 & $7.37 \mathrm{E}-55$ \\
\hline PA1232 & hypothetical protein & 5.64 & $8.50 \mathrm{E}-42$ \\
\hline PA2362 & hypothetical protein & 5.56 & $4.66 \mathrm{E}-33$ \\
\hline
\end{tabular}




\begin{tabular}{|c|c|c|c|}
\hline PA2363 & hypothetical protein & 5.48 & $1.94 \mathrm{E}-50$ \\
\hline PA2412 & hypothetical protein & 5.48 & $8.16 \mathrm{E}-20$ \\
\hline PA3320 & hypothetical protein & 5.36 & 1.33E-31 \\
\hline PA3436 & hypothetical protein & 5.30 & $1.94 \mathrm{E}-28$ \\
\hline PA2198 & hypothetical protein & 5.12 & 1.13E-18 \\
\hline PA1495 & hypothetical protein & 5.12 & $8.91 \mathrm{E}-27$ \\
\hline PA3456 & $\begin{array}{l}\text { tRNA 5-methylaminomethyl-2-thiouridine } \\
\text { biosynthesis bifunctional protein MnmC }\end{array}$ & 5.11 & $1.72 \mathrm{E}-45$ \\
\hline PA3765 & hypothetical protein & 4.98 & $3.52 \mathrm{E}-33$ \\
\hline PA2154 & hypothetical protein & 4.92 & $2.15 \mathrm{E}-34$ \\
\hline PA2360 & hypothetical protein & 4.52 & 7.16E-24 \\
\hline$x q h A$ & secretion protein XqhA & 4.48 & $6.10 \mathrm{E}-40$ \\
\hline PA2181 & glutamate--cysteine ligase & 4.45 & $1.38 \mathrm{E}-35$ \\
\hline PA3089 & hypothetical protein & 4.39 & 4.05E-34 \\
\hline PA4149 & hypothetical protein & 4.25 & $1.71 \mathrm{E}-34$ \\
\hline PA1139 & hypothetical protein & 4.19 & $2.88 \mathrm{E}-25$ \\
\hline PA4129 & hypothetical protein & 4.14 & $6.92 \mathrm{E}-26$ \\
\hline PA2872 & hypothetical protein & 4.12 & $1.96 \mathrm{E}-32$ \\
\hline PA2148 & hypothetical protein & 4.03 & $1.04 \mathrm{E}-16$ \\
\hline PA3952 & hypothetical protein & 3.98 & $2.64 \mathrm{E}-14$ \\
\hline PA1349 & hypothetical protein & 3.92 & $3.62 \mathrm{E}-19$ \\
\hline PA2216 & hypothetical protein & 3.85 & $6.36 \mathrm{E}-21$ \\
\hline PA1469 & hypothetical protein & 3.81 & $2.01 \mathrm{E}-23$ \\
\hline PA1619 & transcriptional regulator & 3.80 & $4.49 \mathrm{E}-25$ \\
\hline PA2946 & hypothetical protein & 3.79 & $6.90 \mathrm{E}-30$ \\
\hline PA0801 & hypothetical protein & 3.79 & $3.19 \mathrm{E}-29$ \\
\hline PA2045 & membrane protein insertion efficiency factor & 3.77 & $6.00 \mathrm{E}-18$ \\
\hline PA0671 & hypothetical protein & 3.75 & $2.12 \mathrm{E}-22$ \\
\hline PA4181 & hypothetical protein & 3.72 & $9.24 \mathrm{E}-19$ \\
\hline popB & translocator protein PopB & 3.70 & $1.21 \mathrm{E}-23$ \\
\hline PA2844 & hypothetical protein & 3.67 & $3.61 \mathrm{E}-28$ \\
\hline PA3904 & hypothetical protein & 3.61 & $1.29 \mathrm{E}-17$ \\
\hline PA3388 & $\begin{array}{l}\text { S-adenosylmethionine-dependent } \\
\text { methyltransferase RcsF }\end{array}$ & 3.61 & $2.21 \mathrm{E}-17$ \\
\hline PA0110 & hypothetical protein & 3.60 & $5.30 \mathrm{E}-27$ \\
\hline PA2063 & hypothetical protein & 3.57 & 4.91E-22 \\
\hline PA1235 & transcriptional regulator & 3.55 & $3.00 \mathrm{E}-25$ \\
\hline PA3681 & hypothetical protein & 3.55 & 2.57E-23 \\
\hline PA0339 & hypothetical protein & 3.46 & $2.73 \mathrm{E}-25$ \\
\hline$P A 2361$ & hypothetical protein & 3.43 & $2.34 \mathrm{E}-25$ \\
\hline PA2839 & hypothetical protein & 3.42 & $2.64 \mathrm{E}-17$ \\
\hline PA3275 & hypothetical protein & 3.40 & $9.96 \mathrm{E}-14$ \\
\hline
\end{tabular}




\begin{tabular}{|c|c|c|c|}
\hline PA4219 & | hypothetical protein & 3.39 & 3.73E-24 \\
\hline PA4364 & hypothetical protein & 3.38 & $7.35 \mathrm{E}-17$ \\
\hline PA4362 & hypothetical protein & 3.35 & $2.38 \mathrm{E}-19$ \\
\hline PA2367 & hypothetical protein & 3.32 & 4.67E-16 \\
\hline PA4828 & hypothetical protein & 3.29 & $1.11 \mathrm{E}-13$ \\
\hline PA3282 & hypothetical protein & 3.28 & 4.37E-20 \\
\hline PA5391 & hypothetical protein & 3.27 & 7.37E-23 \\
\hline PA1424 & hypothetical protein & 3.23 & $9.01 \mathrm{E}-17$ \\
\hline PA4634 & hypothetical protein & 3.23 & 3.06E-18 \\
\hline PA3091 & hypothetical protein & 3.23 & $4.40 \mathrm{E}-25$ \\
\hline PA3305 & hypothetical protein & 3.22 & $3.86 \mathrm{E}-26$ \\
\hline PA1114 & hypothetical protein & 3.21 & $3.50 \mathrm{E}-16$ \\
\hline pelA & hypothetical protein & 3.20 & $2.00 \mathrm{E}-23$ \\
\hline exbB2 & transporter ExbB & 3.20 & $1.34 \mathrm{E}-25$ \\
\hline PA0806 & hypothetical protein & 3.19 & $2.29 \mathrm{E}-15$ \\
\hline PA1134 & hypothetical protein & 3.19 & $3.91 \mathrm{E}-15$ \\
\hline PA0076 & hypothetical protein & 3.18 & $5.62 \mathrm{E}-21$ \\
\hline PA4949 & hypothetical protein & 3.11 & $2.14 \mathrm{E}-22$ \\
\hline PA0332 & hypothetical protein & 3.10 & $9.28 \mathrm{E}-20$ \\
\hline PA0088 & hypothetical protein & 3.09 & 1.64E-25 \\
\hline PA0920 & hypothetical protein & 3.07 & $3.89 \mathrm{E}-23$ \\
\hline PA3796 & hypothetical protein & 3.03 & $1.97 \mathrm{E}-17$ \\
\hline PA3789 & hypothetical protein & 3.02 & $4.62 \mathrm{E}-23$ \\
\hline PA3419 & hypothetical protein & 2.99 & $1.89 \mathrm{E}-17$ \\
\hline PA4488 & hypothetical protein & 2.97 & $2.04 \mathrm{E}-20$ \\
\hline PA4369 & hypothetical protein & 2.97 & 1.05E-16 \\
\hline PA1149 & hypothetical protein & 2.95 & $5.03 \mathrm{E}-13$ \\
\hline PA0435 & hypothetical protein & 2.93 & $2.50 \mathrm{E}-20$ \\
\hline PA0093 & hypothetical protein & 2.92 & $1.13 \mathrm{E}-19$ \\
\hline PA4066 & hypothetical protein & 2.92 & $1.25 \mathrm{E}-12$ \\
\hline PA0082 & hypothetical protein & 2.89 & $1.63 \mathrm{E}-14$ \\
\hline PA0168 & hypothetical protein & 2.85 & $3.38 \mathrm{E}-17$ \\
\hline PA2374 & hypothetical protein & 2.84 & $1.36 \mathrm{E}-12$ \\
\hline PA0878 & hypothetical protein & 2.84 & $2.43 \mathrm{E}-18$ \\
\hline PA2207 & hypothetical protein & 2.83 & $2.70 \mathrm{E}-12$ \\
\hline PA2542 & hypothetical protein & 2.82 & $1.25 \mathrm{E}-21$ \\
\hline PA2183 & hypothetical protein & 2.78 & $3.12 \mathrm{E}-05$ \\
\hline PA4543 & hypothetical protein & 2.77 & $6.99 \mathrm{E}-18$ \\
\hline PA3985 & hypothetical protein & 2.77 & $9.88 \mathrm{E}-17$ \\
\hline PA3354 & hypothetical protein & 2.73 & $6.66 \mathrm{E}-13$ \\
\hline PA3535 & serine protease & 2.71 & $8.65 \mathrm{E}-20$ \\
\hline
\end{tabular}




\begin{tabular}{|c|c|c|c|}
\hline PA2075 & | hypothetical protein & 2.70 & $2.30 \mathrm{E}-12$ \\
\hline PA0097 & hypothetical protein & 2.70 & $2.28 \mathrm{E}-14$ \\
\hline PA5543 & hypothetical protein & 2.63 & $5.58 \mathrm{E}-13$ \\
\hline PA2880 & hypothetical protein & 2.63 & 3.47E-10 \\
\hline PA3606 & hypothetical protein & 2.63 & $1.55 \mathrm{E}-14$ \\
\hline PA5114 & hypothetical protein & 2.62 & $3.31 \mathrm{E}-18$ \\
\hline PA3294 & hypothetical protein & 2.58 & $4.58 \mathrm{E}-14$ \\
\hline PA2066 & hypothetical protein & 2.58 & $1.24 \mathrm{E}-11$ \\
\hline PA3453 & hypothetical protein & 2.58 & $2.27 \mathrm{E}-12$ \\
\hline PA1975 & hypothetical protein & 2.56 & 1.12E-11 \\
\hline PA4927 & hypothetical protein & 2.54 & $6.85 \mathrm{E}-18$ \\
\hline PA1357 & hypothetical protein & 2.52 & $2.60 \mathrm{E}-09$ \\
\hline PA4835 & hypothetical protein & 2.51 & $7.37 \mathrm{E}-10$ \\
\hline PA0312 & hypothetical protein & 2.49 & $4.71 \mathrm{E}-13$ \\
\hline PA2845 & hypothetical protein & 2.48 & 3.03E-07 \\
\hline PA2229 & hypothetical protein & 2.48 & $2.75 \mathrm{E}-10$ \\
\hline PA4319 & hypothetical protein & 2.48 & $1.84 \mathrm{E}-09$ \\
\hline PA2366 & uricase & 2.46 & $1.55 \mathrm{E}-13$ \\
\hline PA4095 & hypothetical protein & 2.46 & $2.27 \mathrm{E}-10$ \\
\hline PA0089 & hypothetical protein & 2.45 & $4.54 \mathrm{E}-14$ \\
\hline PA5407 & hypothetical protein & 2.44 & $1.35 \mathrm{E}-08$ \\
\hline PA2465 & hypothetical protein & 2.43 & $1.73 \mathrm{E}-09$ \\
\hline PA0812 & hypothetical protein & 2.43 & $2.49 \mathrm{E}-10$ \\
\hline PA2496 & hypothetical protein & 2.42 & $2.36 \mathrm{E}-08$ \\
\hline PA3893 & hypothetical protein & 2.41 & $5.05 \mathrm{E}-14$ \\
\hline PA2917 & transcriptional regulator & 2.34 & $9.18 \mathrm{E}-12$ \\
\hline PA4491 & hypothetical protein & 2.34 & $3.16 \mathrm{E}-14$ \\
\hline PA0875 & hypothetical protein & 2.33 & $2.88 \mathrm{E}-14$ \\
\hline PA4635 & hypothetical protein & 2.28 & $2.28 \mathrm{E}-10$ \\
\hline PA1494 & hypothetical protein & 2.25 & $4.52 \mathrm{E}-12$ \\
\hline PA1434 & hypothetical protein & 2.25 & $2.40 \mathrm{E}-09$ \\
\hline PA3110 & hypothetical protein & 2.24 & $1.32 \mathrm{E}-07$ \\
\hline PA3626 & tRNA pseudouridine synthase $D$ & 2.24 & $1.48 \mathrm{E}-09$ \\
\hline PA2134 & hypothetical protein & 2.22 & 4.38E-07 \\
\hline PA5395 & hypothetical protein & 2.19 & 7.09E-09 \\
\hline PA3403 & hypothetical protein & 2.16 & $1.24 \mathrm{E}-06$ \\
\hline PA1909 & hypothetical protein & 2.13 & $1.88 \mathrm{E}-05$ \\
\hline PA4177 & hypothetical protein & 2.12 & $5.79 \mathrm{E}-08$ \\
\hline PA1513 & hypothetical protein & 2.11 & $7.94 \mathrm{E}-10$ \\
\hline $\operatorname{cdhC}$ & carnitine dehydrogenase & 2.09 & $5.15 \mathrm{E}-08$ \\
\hline PA0255 & hypothetical protein & 2.09 & $2.70 \mathrm{E}-07$ \\
\hline
\end{tabular}




\begin{tabular}{|c|c|c|c|}
\hline PA1599 & transcriptional regulator & 2.04 & 8.06E-08 \\
\hline PA5151 & hypothetical protein & 2.03 & 1.12E-07 \\
\hline PA0079 & hypothetical protein & 2.03 & 6.09E-09 \\
\hline PA4035 & hypothetical protein & 2.03 & $7.98 \mathrm{E}-09$ \\
\hline icmF1 & type $\mathrm{VI}$ secretion protein IcmF & 2.02 & $1.75 \mathrm{E}-10$ \\
\hline PA0841 & hypothetical protein & 2.01 & 2.02E-07 \\
\hline PA2161 & hypothetical protein & 8.45 & 1.76E-24 \\
\hline PA1701 & hypothetical protein & 7.94 & $1.26 \mathrm{E}-42$ \\
\hline PA2107 & hypothetical protein & 7.25 & 4.17E-22 \\
\hline PA1891 & hypothetical protein & 6.98 & $6.89 \mathrm{E}-30$ \\
\hline PA1348 & hypothetical protein & 6.94 & $7.18 \mathrm{E}-49$ \\
\hline PA1952 & hypothetical protein & 6.83 & $2.73 \mathrm{E}-41$ \\
\hline PA2087 & hypothetical protein & 6.77 & $3.40 \mathrm{E}-31$ \\
\hline PA4298 & hypothetical protein & 6.73 & $5.14 \mathrm{E}-32$ \\
\hline PA2724 & hypothetical protein & 6.06 & $1.48 \mathrm{E}-41$ \\
\hline PA1702 & hypothetical protein & 5.94 & 8.87E-23 \\
\hline pelC & $\begin{array}{l}\text { pellicle/biofilm biosynthesis outer membrane } \\
\text { protein PelC }\end{array}$ & 5.91 & $2.26 \mathrm{E}-33$ \\
\hline PA2782 & hypothetical protein & 5.91 & $1.04 \mathrm{E}-44$ \\
\hline PA1848 & major facilitator superfamily transporter & 5.84 & $5.35 \mathrm{E}-47$ \\
\hline PA2655 & hypothetical protein & 5.66 & $9.61 \mathrm{E}-32$ \\
\hline PA2947 & hypothetical protein & 5.49 & $2.68 \mathrm{E}-34$ \\
\hline$p s c H$ & type III export protein $\mathrm{PscH}$ & 5.46 & $1.76 \mathrm{E}-29$ \\
\hline PA3307 & hypothetical protein & 5.41 & $5.39 \mathrm{E}-27$ \\
\hline PA2538 & hypothetical protein & 5.38 & 1.11E-32 \\
\hline PA4360a & hypothetical protein & 5.33 & $1.60 \mathrm{E}-26$ \\
\hline PA2441 & hypothetical protein & 5.22 & $1.39 \mathrm{E}-26$ \\
\hline arnE & $\begin{array}{l}\text { 4-amino-4-deoxy-L-arabinose- } \\
\text { phosphoundecaprenol flippase subunit ArnE }\end{array}$ & 5.20 & $7.01 \mathrm{E}-28$ \\
\hline PA2173 & hypothetical protein & 5.14 & $2.49 \mathrm{E}-19$ \\
\hline $\begin{array}{l}\text { GenelD:87809 } \\
0\end{array}$ & unknown & 5.13 & 3.57E-38 \\
\hline PA0683 & type II secretion system protein & 5.08 & $5.48 \mathrm{E}-37$ \\
\hline PA3884 & hypothetical protein & 5.07 & $1.18 \mathrm{E}-29$ \\
\hline PA2095 & hypothetical protein & 5.06 & $1.34 \mathrm{E}-30$ \\
\hline PA3089a & 1-aminocyclopropane-1-carboxylate deaminase & 5.04 & $2.04 \mathrm{E}-41$ \\
\hline PA3411 & hypothetical protein & 5.03 & $2.66 \mathrm{E}-25$ \\
\hline PA3072 & hypothetical protein & 5.02 & $1.57 \mathrm{E}-32$ \\
\hline pcrR & transcriptional regulator PcrR & 4.99 & $2.22 \mathrm{E}-25$ \\
\hline PA0855 & hypothetical protein & 4.99 & $2.05 \mathrm{E}-40$ \\
\hline PA4062 & hypothetical protein & 4.91 & $2.01 \mathrm{E}-28$ \\
\hline pcrG & type III secretion regulator & 4.89 & $2.04 \mathrm{E}-21$ \\
\hline
\end{tabular}




\begin{tabular}{|c|c|c|c|}
\hline$p s c B$ & type III export apparatus protein & 4.89 & $1.24 \mathrm{E}-29$ \\
\hline PA1711 & hypothetical protein & 4.86 & 1.37E-09 \\
\hline$p s c G$ & type III export protein PscG & 4.85 & 8.37E-22 \\
\hline popN & type III secretion outer membrane protein PopN & 4.80 & 3.16E-21 \\
\hline PA1896 & hypothetical protein & 4.78 & $1.06 \mathrm{E}-25$ \\
\hline PA3963a & hypothetical protein & 4.77 & 1.93E-29 \\
\hline aprl & alkaline proteinase inhibitor Aprl & 4.76 & $2.66 \mathrm{E}-24$ \\
\hline$p s c P$ & translocation protein in type III secretion & 4.75 & $2.43 \mathrm{E}-22$ \\
\hline arnF & $\begin{array}{l}\text { 4-amino-4-deoxy-L-arabinose- } \\
\text { phosphoundecaprenol flippase subunit ArnF }\end{array}$ & 4.58 & $6.00 \mathrm{E}-28$ \\
\hline PA3414 & hypothetical protein & 4.57 & 1.15E-34 \\
\hline PA1578 & hypothetical protein & 4.54 & $1.63 \mathrm{E}-29$ \\
\hline PA2375 & hypothetical protein & 4.50 & $1.89 \mathrm{E}-24$ \\
\hline $\begin{array}{l}\text { GeneID:88292 } \\
2\end{array}$ & unknown & 4.50 & $2.96 \mathrm{E}-37$ \\
\hline PA2581.1 & tRNA-Cys & 4.49 & $1.98 \mathrm{E}-06$ \\
\hline PA1595 & hypothetical protein & 4.49 & 1.79E-34 \\
\hline $\begin{array}{l}\text { GenelD:87892 } \\
0\end{array}$ & unknown & 4.47 & $3.94 \mathrm{E}-25$ \\
\hline PA4027a & hypothetical protein & 4.47 & $2.45 \mathrm{E}-36$ \\
\hline pscl & type III export protein Pscl & 4.44 & 4.93E-10 \\
\hline PA2068 & major facilitator superfamily transporter & 4.43 & $1.26 \mathrm{E}-30$ \\
\hline PA2928 & hypothetical protein & 4.43 & $2.02 \mathrm{E}-33$ \\
\hline PA1700 & hypothetical protein & 4.42 & 1.07E-19 \\
\hline PA1855 & hypothetical protein & 4.42 & 1.19E-14 \\
\hline PA0345 & hypothetical protein & 4.39 & $3.32 \mathrm{E}-33$ \\
\hline PA2434 & hypothetical protein & 4.37 & $1.43 \mathrm{E}-25$ \\
\hline PA2747a & hypothetical protein & 4.34 & $1.52 \mathrm{E}-19$ \\
\hline PA1743 & hypothetical protein & 4.34 & $2.11 \mathrm{E}-11$ \\
\hline PA2895 & hypothetical protein & 4.32 & $6.63 \mathrm{E}-28$ \\
\hline PA0213 & phosphoribosyl-dephospho-CoA transferase & 4.32 & $2.45 \mathrm{E}-23$ \\
\hline PA1483a & hypothetical protein & 4.27 & 4.30E-21 \\
\hline PA1289 & hypothetical protein & 4.27 & $3.30 \mathrm{E}-28$ \\
\hline $\mathrm{pscO}$ & translocation protein in type III secretion & 4.23 & 1.30E-22 \\
\hline PA2702 & hypothetical protein & 4.18 & $5.61 \mathrm{E}-22$ \\
\hline PA4824 & hypothetical protein & 4.18 & 3.99E-31 \\
\hline PA4816 & hypothetical protein & 4.17 & $9.89 \mathrm{E}-32$ \\
\hline PA4346 & hypothetical protein & 4.17 & $3.43 \mathrm{E}-23$ \\
\hline PA2503 & hypothetical protein & 4.15 & $3.35 \mathrm{E}-26$ \\
\hline PA3684 & hypothetical protein & 4.09 & $1.29 \mathrm{E}-14$ \\
\hline PA1956 & hypothetical protein & 4.06 & 1.07E-21 \\
\hline PA0753 & hypothetical protein & 4.04 & $4.83 \mathrm{E}-20$ \\
\hline
\end{tabular}




\begin{tabular}{|c|c|c|c|}
\hline PA4220 & | hypothetical protein & 3.99 & $5.36 \mathrm{E}-20$ \\
\hline PA4679 & hypothetical protein & 3.98 & $2.73 \mathrm{E}-24$ \\
\hline PA2898 & hypothetical protein & 3.96 & $1.53 \mathrm{E}-14$ \\
\hline PA0630 & hypothetical protein & 3.96 & 1.65E-21 \\
\hline PA1955 & hypothetical protein & 3.95 & $1.52 \mathrm{E}-18$ \\
\hline PA3292 & hypothetical protein & 3.95 & $2.08 \mathrm{E}-10$ \\
\hline PA5183 & hypothetical protein & 3.94 & 1.59E-25 \\
\hline PA1967 & hypothetical protein & 3.91 & $4.62 \mathrm{E}-17$ \\
\hline$p s c D$ & type III export protein PscD & 3.89 & 3.97E-24 \\
\hline PA2167 & hypothetical protein & 3.87 & $1.06 \mathrm{E}-13$ \\
\hline PA2720 & hypothetical protein & 3.86 & $3.15 \mathrm{E}-24$ \\
\hline PA1228 & hypothetical protein & 3.85 & $4.42 \mathrm{E}-19$ \\
\hline PA1356 & hypothetical protein & 3.83 & $8.69 \mathrm{E}-25$ \\
\hline PA2406 & hypothetical protein & 3.82 & $6.03 \mathrm{E}-20$ \\
\hline PA0028 & hypothetical protein & 3.79 & $8.67 \mathrm{E}-27$ \\
\hline PA1545 & hypothetical protein & 3.72 & $2.46 \mathrm{E}-19$ \\
\hline PA0700 & hypothetical protein & 3.69 & $3.16 \mathrm{E}-18$ \\
\hline PA0800 & hypothetical protein & 3.63 & $1.05 \mathrm{E}-19$ \\
\hline PA3939 & hypothetical protein & 3.61 & $7.98 \mathrm{E}-21$ \\
\hline PA2729 & hypothetical protein & 3.61 & $4.48 \mathrm{E}-23$ \\
\hline PA2136 & hypothetical protein & 3.61 & $1.82 \mathrm{E}-12$ \\
\hline $\begin{array}{l}\text { GeneID:88257 } \\
6\end{array}$ & unknown & 3.58 & $7.85 \mathrm{E}-34$ \\
\hline$o p d B$ & OpdB proline porin & 3.56 & $1.21 \mathrm{E}-21$ \\
\hline PA2937 & hypothetical protein & 3.55 & $2.28 \mathrm{E}-14$ \\
\hline PA3730 & hypothetical protein & 3.53 & $1.84 \mathrm{E}-22$ \\
\hline PA0720 & helix destabilizing protein of bacteriophage Pf1 & 3.52 & $7.14 \mathrm{E}-16$ \\
\hline PA1213 & hypothetical protein & 3.48 & $2.01 \mathrm{E}-24$ \\
\hline PA3273 & hypothetical protein & 3.48 & $4.94 \mathrm{E}-16$ \\
\hline PA0721 & hypothetical protein & 3.48 & $7.42 \mathrm{E}-04$ \\
\hline PA5120 & hypothetical protein & 3.47 & $1.61 \mathrm{E}-20$ \\
\hline PA0668.5 & 5S ribosomal RNA & 3.46 & $5.88 \mathrm{E}-03$ \\
\hline PA2030 & hypothetical protein & 3.46 & $1.25 \mathrm{E}-10$ \\
\hline PA2852.1 & tRNA-Ser & 3.44 & 1.70E-03 \\
\hline PA5115 & hypothetical protein & 3.42 & 2.82E-21 \\
\hline PA1870 & hypothetical protein & 3.39 & $1.70 \mathrm{E}-10$ \\
\hline PA1745 & hypothetical protein & 3.38 & $3.58 \mathrm{E}-18$ \\
\hline PA4871 & hypothetical protein & 3.34 & $2.03 \mathrm{E}-25$ \\
\hline PA0729.1 & tRNA-Gly & 3.33 & $1.50 \mathrm{E}-06$ \\
\hline PA1245 & hypothetical protein & 3.33 & $2.11 \mathrm{E}-18$ \\
\hline PA2420 & porin & 3.32 & $1.41 \mathrm{E}-17$ \\
\hline toxA & exotoxin $A$ & 3.32 & $1.42 \mathrm{E}-26$ \\
\hline
\end{tabular}




\begin{tabular}{|c|c|c|c|}
\hline PA2660 & | hypothetical protein & 3.30 & $3.59 \mathrm{E}-15$ \\
\hline PA1676 & hypothetical protein & 3.25 & 8.37E-12 \\
\hline PA2783 & hypothetical protein & 3.24 & $1.41 \mathrm{E}-21$ \\
\hline PA3207 & hypothetical protein & 3.23 & $3.48 \mathrm{E}-18$ \\
\hline PA4791 & hypothetical protein & 3.19 & $2.24 \mathrm{E}-23$ \\
\hline PA2450 & hypothetical protein & 3.19 & $1.79 \mathrm{E}-15$ \\
\hline PA3290 & hypothetical protein & 3.17 & $6.48 \mathrm{E}-21$ \\
\hline PA0111 & hypothetical protein & 3.16 & $3.90 \mathrm{E}-19$ \\
\hline PA2440 & hypothetical protein & 3.16 & $6.62 \mathrm{E}-15$ \\
\hline PA2789 & hypothetical protein & 3.14 & $6.46 \mathrm{E}-17$ \\
\hline PA2436 & hypothetical protein & 3.12 & $5.93 \mathrm{E}-15$ \\
\hline PA0349 & hypothetical protein & 3.11 & $2.06 \mathrm{E}-20$ \\
\hline PA0614 & hypothetical protein & 3.11 & $1.01 \mathrm{E}-16$ \\
\hline PA2122 & hypothetical protein & 3.09 & $1.21 \mathrm{E}-17$ \\
\hline PA3788 & hypothetical protein & 3.06 & $2.51 \mathrm{E}-16$ \\
\hline PA3298 & hypothetical protein & 3.04 & $2.06 \mathrm{E}-08$ \\
\hline PA0311 & hypothetical protein & 3.04 & $5.16 \mathrm{E}-18$ \\
\hline$p q q A$ & coenzyme $P Q Q$ synthesis protein $A$ & 3.03 & 8.10E-06 \\
\hline PA1019a & thioesterase & 3.03 & 3.36E-14 \\
\hline PA3680 & $\begin{array}{l}\text { ribosomal RNA small subunit methyltransferase } \\
\mathrm{J}\end{array}$ & 3.02 & $3.19 \mathrm{E}-15$ \\
\hline PA1133 & hypothetical protein & 3.02 & $1.55 \mathrm{E}-13$ \\
\hline PA2049 & hypothetical protein & 3.00 & $6.13 \mathrm{E}-14$ \\
\hline PA3178 & hypothetical protein & 2.97 & $1.55 \mathrm{E}-12$ \\
\hline PA3784 & hypothetical protein & 2.97 & $1.70 \mathrm{E}-15$ \\
\hline PA1160 & hypothetical protein & 2.96 & $3.16 \mathrm{E}-15$ \\
\hline PA0701a & AraC family transcriptional regulator & 2.96 & $3.02 \mathrm{E}-18$ \\
\hline PA2829 & hypothetical protein & 2.95 & $1.14 \mathrm{E}-13$ \\
\hline algJ & alginate o-acetylase AlgJ & 2.94 & $1.65 \mathrm{E}-17$ \\
\hline PA3317 & hypothetical protein & 2.94 & $5.08 \mathrm{E}-14$ \\
\hline PA2004 & hypothetical protein & 2.93 & $9.74 \mathrm{E}-15$ \\
\hline PA3065 & hypothetical protein & 2.91 & $1.42 \mathrm{E}-17$ \\
\hline PA3081 & hypothetical protein & 2.91 & 1.06E-14 \\
\hline PA1615 & lipase & 2.90 & $1.68 \mathrm{E}-09$ \\
\hline PA3464 & hypothetical protein & 2.90 & $2.09 \mathrm{E}-19$ \\
\hline PA0522 & hypothetical protein & 2.89 & $1.24 \mathrm{E}-08$ \\
\hline PA3075 & hypothetical protein & 2.89 & $2.10 \mathrm{E}-18$ \\
\hline PA3293 & hypothetical protein & 2.88 & $2.50 \mathrm{E}-16$ \\
\hline PA2380 & hypothetical protein & 2.85 & $5.08 \mathrm{E}-08$ \\
\hline PA0802 & hypothetical protein & 2.84 & $3.46 \mathrm{E}-12$ \\
\hline PA3907 & hypothetical protein & 2.82 & $4.32 \mathrm{E}-15$ \\
\hline PA2251 & hypothetical protein & 2.81 & $9.18 \mathrm{E}-10$ \\
\hline
\end{tabular}




\begin{tabular}{|l|l|r|r|}
\hline PA0418 & hypothetical protein & 2.80 & $2.97 \mathrm{E}-21$ \\
\hline PA0433 & hypothetical protein & 2.79 & $2.04 \mathrm{E}-11$ \\
\hline PA1394 & hypothetical protein & 2.79 & $4.52 \mathrm{E}-06$ \\
\hline pscK & type III export protein PscK & 2.79 & $3.50 \mathrm{E}-10$ \\
\hline PA2180 & hypothetical protein & 2.78 & $5.80 \mathrm{E}-13$ \\
\hline vreA & hypothetical protein & 2.77 & $2.19 \mathrm{E}-14$ \\
\hline PA0189 & porin & 2.77 & $1.09 \mathrm{E}-17$ \\
\hline PA4801 & hypothetical protein & 2.77 & $9.71 \mathrm{E}-14$ \\
\hline PA2919 & hypothetical protein & 2.76 & $4.84 \mathrm{E}-09$ \\
\hline psIJ & biofilm formation protein PsIJ & 2.74 & $7.62 \mathrm{E}-17$ \\
\hline GeneID:87932 & transcriptional regulator & & \\
4 & heneID:88042 & 2.74 & $7.64 \mathrm{E}-16$ \\
\hline unknown & & \\
\hline GeneID:87813 & unknown & 2.70 & $5.27 \mathrm{E}-06$ \\
\hline 9 & hypothetical protein & & \\
\hline PA2027 & hypothetical protein & 2.69 & $8.45 \mathrm{E}-17$ \\
\hline PA4823 & 2.68 & $2.11 \mathrm{E}-09$ \\
\hline PA1825 & hypothetical protein & 2.65 & $1.79 \mathrm{E}-07$ \\
\hline PA5381 & hypothetical protein & 2.65 & $1.40 \mathrm{E}-13$ \\
\hline PA4877 & hypothetical protein & 2.65 & $5.81 \mathrm{E}-11$ \\
\hline piV & endopeptidase IV & 2.64 & $9.91 \mathrm{E}-08$ \\
\hline PA3274 & hypothetical protein & 2.64 & $9.47 \mathrm{E}-13$ \\
\hline PA3786 & hypothetical protein & 2.63 & $5.08 \mathrm{E}-09$ \\
\hline PA0309 & hypothetical protein & 2.61 & $1.93 \mathrm{E}-13$ \\
\hline PA3421 & hypothetical protein & 2.61 & $7.12 \mathrm{E}-14$ \\
\hline PA5502 & hypothetical protein & 2.60 & $2.67 \mathrm{E}-13$ \\
\hline PA5182 & hypothetical protein & 2.59 & $7.23 \mathrm{E}-16$ \\
\hline PA4775 & hypothetical protein & 2.59 & $2.03 \mathrm{E}-13$ \\
\hline PA3969a & hypothetical protein & 2.58 & $1.61 \mathrm{E}-16$ \\
\hline PA0049 & hypothetical protein & 2.57 & $8.45 \mathrm{E}-09$ \\
\hline PA0788a & hypothetical protein & 2.56 & $3.45 \mathrm{E}-15$ \\
\hline PA4758.1 & P32 & 2.55 & $9.73 \mathrm{E}-07$ \\
\hline PA4586 & hypothetical protein & 2.55 & $1.67 \mathrm{E}-03$ \\
\hline PA2894 & hypothetical protein & 2.53 & $1.09 \mathrm{E}-09$ \\
\hline PA0631 & hypothetical protein & 2.51 & $9.38 \mathrm{E}-09$ \\
\hline PA3485 & hypothetical protein & 2.49 & $1.58 \mathrm{E}-07$ \\
\hline PA3016 & hypothetical protein & 2.48 & $5.62 \mathrm{E}-11$ \\
\hline PA5412 & hypothetical protein & 2.47 & $2.35 \mathrm{E}-09$ \\
\hline PA2274 & hypothetical protein & 2.47 & $2.18 \mathrm{E}-16$ \\
\hline PA0697 & hypothetical protein & 2.46 & $2.38 \mathrm{E}-07$ \\
\hline atuA & hypothetical protein & $1.62 \mathrm{E}-11$ \\
\hline & & \\
\hline
\end{tabular}




\begin{tabular}{|c|c|c|c|}
\hline PA4325 & | hypothetical protein & 2.42 & $1.09 \mathrm{E}-10$ \\
\hline PA1844 & hypothetical protein & 2.41 & $2.32 \mathrm{E}-06$ \\
\hline PA0383 & hypothetical protein & 2.41 & $2.81 \mathrm{E}-15$ \\
\hline PA4179 & porin & 2.41 & $7.03 \mathrm{E}-14$ \\
\hline PA1036 & hypothetical protein & 2.37 & $5.25 \mathrm{E}-11$ \\
\hline$P A 4826$ & hypothetical protein & 2.37 & 1.19E-06 \\
\hline PA1117 & hypothetical protein & 2.36 & 8.99E-08 \\
\hline PA1474 & hypothetical protein & 2.35 & $3.80 \mathrm{E}-13$ \\
\hline PA3905 & hypothetical protein & 2.34 & $2.22 \mathrm{E}-08$ \\
\hline PA0568 & hypothetical protein & 2.33 & $2.70 \mathrm{E}-08$ \\
\hline PA1233 & hypothetical protein & 2.33 & $9.10 \mathrm{E}-07$ \\
\hline PA0096 & hypothetical protein & 2.33 & $5.10 \mathrm{E}-06$ \\
\hline opdT & tyrosine porin OpdT & 2.32 & $2.83 \mathrm{E}-11$ \\
\hline PA1043 & hypothetical protein & 2.31 & $1.29 \mathrm{E}-08$ \\
\hline exsD & hypothetical protein & 2.31 & $6.04 \mathrm{E}-09$ \\
\hline PA1951 & hypothetical protein & 2.30 & 3.77E-11 \\
\hline PA1465 & hypothetical protein & 2.30 & $1.02 \mathrm{E}-08$ \\
\hline PA0466 & hypothetical protein & 2.29 & $1.72 \mathrm{E}-07$ \\
\hline PA2031 & hypothetical protein & 2.29 & 2.59E-04 \\
\hline PA5113 & hypothetical protein & 2.29 & $3.79 \mathrm{E}-11$ \\
\hline $\operatorname{alg} X$ & alginate biosynthesis protein AlgX & 2.28 & $1.61 \mathrm{E}-09$ \\
\hline PA2140 & metallothionein & 2.27 & $3.25 \mathrm{E}-03$ \\
\hline PA1052a & hypothetical protein & 2.25 & $2.87 \mathrm{E}-07$ \\
\hline PA4851 & hypothetical protein & 2.25 & $2.32 \mathrm{E}-09$ \\
\hline PA1652 & hypothetical protein & 2.24 & 1.62E-09 \\
\hline popD & translocator outer membrane protein PopD & 2.24 & $1.67 \mathrm{E}-10$ \\
\hline PA1645 & hypothetical protein & 2.24 & 1.60E-07 \\
\hline PA1123 & hypothetical protein & 2.24 & $7.67 \mathrm{E}-07$ \\
\hline PA2173a & hypothetical protein & 2.23 & $2.30 \mathrm{E}-04$ \\
\hline PA1889 & hypothetical protein & 2.23 & $5.97 \mathrm{E}-09$ \\
\hline PA3359 & hypothetical protein & 2.21 & $2.61 \mathrm{E}-09$ \\
\hline PA1496 & potassium channel & 2.20 & 1.05E-07 \\
\hline PA3850 & hypothetical protein & 2.20 & $2.02 \mathrm{E}-10$ \\
\hline PA4071 & hypothetical protein & 2.19 & 2.04E-07 \\
\hline PA0377 & hypothetical protein & 2.19 & 1.69E-09 \\
\hline PA1929 & hypothetical protein & 2.18 & $9.65 \mathrm{E}-07$ \\
\hline PA3069 & hypothetical protein & 2.18 & 1.06E-08 \\
\hline PA5318 & hypothetical protein & 2.18 & $3.53 \mathrm{E}-09$ \\
\hline PA5156 & hypothetical protein & 2.16 & $1.49 \mathrm{E}-11$ \\
\hline PA3386 & hypothetical protein & 2.16 & $1.72 \mathrm{E}-07$ \\
\hline PA0599 & hypothetical protein & 2.15 & $2.68 \mathrm{E}-08$ \\
\hline
\end{tabular}




\begin{tabular}{|c|c|c|c|}
\hline PA0696 & hypothetical protein & 2.15 & $2.68 \mathrm{E}-11$ \\
\hline PA3960 & hypothetical protein & 2.13 & $5.08 \mathrm{E}-06$ \\
\hline PA1624 & hypothetical protein & 2.12 & $1.58 \mathrm{E}-0 \mathrm{~s}$ \\
\hline PA3318 & hypothetical protein & 2.11 & $1.54 \mathrm{E}-06$ \\
\hline PA3906 & hypothetical protein & 2.11 & $1.15 \mathrm{E}-04$ \\
\hline PA3720 & hypothetical protein & 2.10 & $2.56 \mathrm{E}-06$ \\
\hline PA1872 & hypothetical protein & 2.09 & $3.87 \mathrm{E}-06$ \\
\hline PA2117 & hypothetical protein & 2.09 & $4.66 \mathrm{E}-05$ \\
\hline PA4724.1 & hypothetical protein & 2.09 & $6.35 \mathrm{E}-04$ \\
\hline PA0850 & hypothetical protein & 2.08 & $5.81 \mathrm{E}-07$ \\
\hline PA1578a & hypothetical protein & 2.06 & $1.52 \mathrm{E}-04$ \\
\hline PA1111 & hypothetical protein & 2.06 & $2.18 \mathrm{E}-06$ \\
\hline PA1471 & hypothetical protein & 2.05 & $2.62 \mathrm{E}-04$ \\
\hline $\operatorname{algL}$ & alginate lyase & 2.05 & $2.73 \mathrm{E}-0 \mathrm{c}$ \\
\hline PA4684 & hypothetical protein & 2.04 & $8.40 \mathrm{E}-10$ \\
\hline PA1865 & Fanconi-associated nuclease & 2.02 & $1.29 \mathrm{E}-07$ \\
\hline armR & MexR antirepressor ArmR & 2.01 & $6.51 \mathrm{E}-04$ \\
\hline PA1892 & hypothetical protein & 2.00 & $6.51 \mathrm{E}-06$ \\
\hline PA1332 & hypothetical protein & 2.00 & $3.85 \mathrm{E}-07$ \\
\hline \multicolumn{4}{|c|}{ General function prediction only } \\
\hline PA1266 & oxidoreductase & 7.10 & $7.11 \mathrm{E}-58$ \\
\hline PA1921 & hypothetical protein & 6.91 & $9.71 \mathrm{E}-26$ \\
\hline PA2689 & hypothetical protein & 6.84 & $1.42 \mathrm{E}-45$ \\
\hline$p s / K$ & biofilm formation protein PsIL & 6.64 & $2.28 \mathrm{E}-5 \mathrm{C}$ \\
\hline PA2498 & hypothetical protein & 6.32 & $2.70 \mathrm{E}-37$ \\
\hline PA2874 & hypothetical protein & 6.09 & $6.48 \mathrm{E}-5 \mathrm{C}$ \\
\hline PA2067 & hydrolase & 5.77 & $4.18 \mathrm{E}-32$ \\
\hline PA2061 & ABC transporter ATP-binding protein & 5.75 & $8.18 \mathrm{E}-46$ \\
\hline PA2156 & hypothetical protein & 5.73 & $1.23 \mathrm{E}-33$ \\
\hline PA1211 & hypothetical protein & 5.60 & $2.19 \mathrm{E}-36$ \\
\hline PA1329 & hypothetical protein & 5.52 & $7.14 \mathrm{E}-37$ \\
\hline$h c n A$ & hydrogen cyanide synthase subunit $\mathrm{Hcn} A$ & 5.47 & $2.93 \mathrm{E}-24$ \\
\hline PA2680 & quinone oxidoreductase & 5.10 & $3.41 \mathrm{E}-39$ \\
\hline hasD & transporter HasD & 5.08 & $1.42 \mathrm{E}-41$ \\
\hline PA0489 & phosphoribosyl transferase & 5.07 & $4.40 \mathrm{E}-39$ \\
\hline algK & alginate biosynthesis protein AlgK & 5.04 & $8.40 \mathrm{E}-43$ \\
\hline PA1488 & hypothetical protein & 5.02 & $2.29 \mathrm{E}-41$ \\
\hline PA1558 & hypothetical protein & 5.01 & $9.00 \mathrm{E}-37$ \\
\hline PA2803 & hypothetical protein & 4.97 & $1.01 \mathrm{E}-34$ \\
\hline PA3432 & hypothetical protein & 4.86 & $5.17 \mathrm{E}-28$ \\
\hline PA1425 & ABC transporter ATP-binding protein & 4.85 & $8.68 \mathrm{E}-39$ \\
\hline
\end{tabular}




\begin{tabular}{|c|c|c|c|}
\hline PA1907 & hypothetical protein & 4.82 & $4.85 \mathrm{E}-33$ \\
\hline PA2099 & short-chain dehydrogenase & 4.76 & $3.05 \mathrm{E}-20$ \\
\hline PA3209 & hypothetical protein & 4.71 & $4.51 \mathrm{E}-31$ \\
\hline PA1885 & hypothetical protein & 4.68 & $3.64 \mathrm{E}-31$ \\
\hline PA5144 & hypothetical protein & 4.68 & 1.10E-32 \\
\hline atuG & short-chain dehydrogenase & 4.67 & $5.89 \mathrm{E}-32$ \\
\hline PA2719 & hypothetical protein & 4.66 & $8.01 \mathrm{E}-35$ \\
\hline PA4097 & alcohol dehydrogenase & 4.64 & $7.88 \mathrm{E}-40$ \\
\hline PA2984 & hypothetical protein & 4.57 & $1.36 \mathrm{E}-42$ \\
\hline PA3457 & hypothetical protein & 4.56 & $2.86 \mathrm{E}-36$ \\
\hline PA2211 & hypothetical protein & 4.47 & $9.86 \mathrm{E}-27$ \\
\hline PA2088 & hypothetical protein & 4.41 & $4.42 \mathrm{E}-29$ \\
\hline PA1227 & hypothetical protein & 4.38 & 4.46E-35 \\
\hline PA3330 & short-chain dehydrogenase & 4.35 & 1.37E-28 \\
\hline PA2086 & epoxide hydrolase & 4.34 & $2.19 \mathrm{E}-19$ \\
\hline PA0787 & hypothetical protein & 4.29 & $1.09 \mathrm{E}-35$ \\
\hline PA2455 & hypothetical protein & 4.29 & $5.27 \mathrm{E}-19$ \\
\hline PA2922 & hydrolase & 4.27 & $1.64 \mathrm{E}-32$ \\
\hline PA1225 & $\mathrm{NAD}(\mathrm{P}) \mathrm{H}$ dehydrogenase & 4.25 & $5.08 \mathrm{E}-23$ \\
\hline pelB & pellicle/biofilm biosynthesis protein PelB & 4.25 & $5.90 \mathrm{E}-40$ \\
\hline$r h / C$ & rhamnosyltransferase & 4.24 & $1.71 \mathrm{E}-32$ \\
\hline PA0741 & hypothetical protein & 4.24 & $7.78 \mathrm{E}-26$ \\
\hline PA2847 & hypothetical protein & 4.18 & $1.28 \mathrm{E}-29$ \\
\hline PA2059 & $A B C$ transporter permease & 4.14 & 1.87E-22 \\
\hline$x y / L$ & $\begin{array}{l}\text { 1,6-dihydroxycyclohexa-2,4-diene-1- } \\
\text { carboxylate dehydrogenase }\end{array}$ & 4.13 & $2.79 \mathrm{E}-15$ \\
\hline$a p r D$ & $\begin{array}{l}\text { alkaline protease secretion ATP-binding protein } \\
\text { AprD }\end{array}$ & 4.08 & $5.44 \mathrm{E}-32$ \\
\hline PA2176 & hypothetical protein & 4.02 & $1.48 \mathrm{E}-16$ \\
\hline PA4202 & hypothetical protein & 4.02 & $1.35 \mathrm{E}-16$ \\
\hline nos $Y$ & membrane protein NosY & 4.00 & $1.68 \mathrm{E}-30$ \\
\hline PA2074 & hypothetical protein & 3.93 & 1.65E-05 \\
\hline PA2158 & alcohol dehydrogenase & 3.93 & 1.43E-21 \\
\hline PA3272 & ATP-dependent DNA helicase & 3.86 & $9.45 \mathrm{E}-39$ \\
\hline PA2141 & hypothetical protein & 3.85 & $5.09 \mathrm{E}-13$ \\
\hline PA1680 & hypothetical protein & 3.84 & 4.07E-22 \\
\hline PA2448 & hypothetical protein & 3.81 & 1.09E-24 \\
\hline phzF2 & $\begin{array}{l}\text { trans-2,3-dihydro-3-hydroxyanthranilate } \\
\text { isomerase }\end{array}$ & 3.80 & $5.93 \mathrm{E}-22$ \\
\hline PA4783 & hypothetical protein & 3.78 & 7.11E-31 \\
\hline phzF1 & $\begin{array}{l}\text { trans-2,3-dihydro-3-hydroxyanthranilate } \\
\text { isomerase }\end{array}$ & 3.75 & $6.52 \mathrm{E}-28$ \\
\hline PA1451 & hypothetical protein & 3.75 & $2.60 \mathrm{E}-25$ \\
\hline
\end{tabular}




\begin{tabular}{|c|c|c|c|}
\hline PA5132 & hypothetical protein & 3.72 & $7.02 \mathrm{E}-29$ \\
\hline PA3287 & hypothetical protein & 3.71 & $1.30 \mathrm{E}-23$ \\
\hline PA2778 & hypothetical protein & 3.69 & $6.42 \mathrm{E}-17$ \\
\hline PA3036 & hypothetical protein & 3.68 & $5.51 \mathrm{E}-24$ \\
\hline PA0086 & hypothetical protein & 3.67 & $1.41 \mathrm{E}-29$ \\
\hline PA1330 & short-chain dehydrogenase & 3.65 & $2.09 \mathrm{E}-23$ \\
\hline PA1503 & hypothetical protein & 3.64 & $4.27 \mathrm{E}-18$ \\
\hline PA4365 & transporter & 3.61 & $3.52 \mathrm{E}-17$ \\
\hline$p s / C$ & biofilm formation protein PsIC & 3.60 & $1.58 \mathrm{E}-17$ \\
\hline PA2529 & hypothetical protein & 3.56 & $2.00 \mathrm{E}-23$ \\
\hline PA2168 & hypothetical protein & 3.56 & $3.51 \mathrm{E}-14$ \\
\hline PA2060 & $A B C$ transporter permease & 3.53 & $4.76 \mathrm{E}-19$ \\
\hline PA1612 & hypothetical protein & 3.50 & $2.25 \mathrm{E}-21$ \\
\hline PA1360 & hypothetical protein & 3.50 & $9.53 \mathrm{E}-24$ \\
\hline PA4802 & hypothetical protein & 3.46 & $8.14 \mathrm{E}-23$ \\
\hline PA2271 & acetyltransferase & 3.44 & $1.25 \mathrm{E}-18$ \\
\hline PA2745 & hydrolase & 3.43 & $9.44 \mathrm{E}-18$ \\
\hline PA2712 & hypothetical protein & 3.40 & $6.63 \mathrm{E}-24$ \\
\hline PA4312 & hypothetical protein & 3.39 & 8.76E-18 \\
\hline PA2197 & hypothetical protein & 3.39 & $1.60 \mathrm{E}-21$ \\
\hline$h c n B$ & hydrogen cyanide synthase subunit $\mathrm{HcnB}$ & 3.38 & 4.61E-22 \\
\hline PA0136 & ABC transporter ATP-binding protein & 3.38 & $6.41 \mathrm{E}-20$ \\
\hline PA0790 & hypothetical protein & 3.34 & $8.48 \mathrm{E}-24$ \\
\hline PA2201 & hypothetical protein & 3.33 & $4.32 \mathrm{E}-16$ \\
\hline PA2502 & hypothetical protein & 3.30 & $3.11 \mathrm{E}-25$ \\
\hline$p v d Q$ & acyl-homoserine lactone acylase PvdQ & 3.25 & 1.15E-23 \\
\hline PA5466 & hypothetical protein & 3.25 & $2.09 \mathrm{E}-22$ \\
\hline PA0881 & hypothetical protein & 3.24 & $1.35 \mathrm{E}-21$ \\
\hline PA2192 & hypothetical protein & 3.23 & 3.80E-13 \\
\hline PA3259 & hypothetical protein & 3.20 & $2.43 \mathrm{E}-18$ \\
\hline PA5352 & hypothetical protein & 3.20 & 8.06E-17 \\
\hline PA2875 & hypothetical protein & 3.19 & $1.34 \mathrm{E}-21$ \\
\hline PA2454 & hypothetical protein & 3.18 & $3.92 \mathrm{E}-14$ \\
\hline PA0440 & oxidoreductase & 3.14 & $2.76 \mathrm{E}-19$ \\
\hline PA3132 & hydrolase & 3.13 & $9.84 \mathrm{E}-19$ \\
\hline PA4098 & short-chain dehydrogenase & 3.13 & $6.24 \mathrm{E}-16$ \\
\hline PA3074 & hypothetical protein & 3.12 & $6.99 E-21$ \\
\hline PA0480 & 3-oxoadipate enol-lactonase & 3.12 & $4.40 \mathrm{E}-17$ \\
\hline PA3618 & hypothetical protein & 3.10 & $5.88 \mathrm{E}-19$ \\
\hline PA0278 & hypothetical protein & 3.10 & 1.36E-18 \\
\hline PA4344 & hydrolase & 3.08 & $1.44 \mathrm{E}-23$ \\
\hline
\end{tabular}




\begin{tabular}{|c|c|c|c|}
\hline PАЗ3423 & transcriptional regulator & 3.05 & 8.37E-19 \\
\hline PA0344 & hypothetical protein & 3.02 & $4.69 \mathrm{E}-19$ \\
\hline PA3586 & hydrolase & 2.99 & $1.12 \mathrm{E}-15$ \\
\hline PA2635 & hypothetical protein & 2.98 & $5.48 \mathrm{E}-14$ \\
\hline PA4986 & oxidoreductase & 2.98 & $1.10 \mathrm{E}-21$ \\
\hline PA3941 & hypothetical protein & 2.98 & 1.82E-17 \\
\hline PA0629 & hypothetical protein & 2.94 & $1.42 \mathrm{E}-17$ \\
\hline PA1316 & major facilitator superfamily transporter & 2.93 & $1.81 \mathrm{E}-17$ \\
\hline PA1839 & RNA methyltransferase & 2.92 & $7.48 \mathrm{E}-15$ \\
\hline PA1917 & hypothetical protein & 2.92 & $2.75 \mathrm{E}-08$ \\
\hline PA5145 & hypothetical protein & 2.88 & $6.45 \mathrm{E}-18$ \\
\hline PA0810 & haloacid dehalogenase & 2.88 & $3.80 \mathrm{E}-17$ \\
\hline PA5430 & hypothetical protein & 2.84 & $2.18 \mathrm{E}-14$ \\
\hline PA3693 & hypothetical protein & 2.83 & $1.54 \mathrm{E}-14$ \\
\hline PA3073 & hypothetical protein & 2.83 & $9.95 \mathrm{E}-17$ \\
\hline nirQ & denitrification regulatory protein $\mathrm{Nir} Q$ & 2.82 & $7.26 \mathrm{E}-12$ \\
\hline $\operatorname{cdhB}$ & carnitine dehydrogenase & 2.79 & $7.90 \mathrm{E}-11$ \\
\hline PA1824 & hypothetical protein & 2.78 & $3.12 \mathrm{E}-12$ \\
\hline $\operatorname{Idh} A$ & D-lactate dehydrogenase & 2.77 & 7.00E-14 \\
\hline PA2530 & hypothetical protein & 2.74 & $1.74 \mathrm{E}-14$ \\
\hline PA0063 & hypothetical protein & 2.73 & $3.59 \mathrm{E}-10$ \\
\hline PA1893 & hypothetical protein & 2.72 & $2.53 \mathrm{E}-18$ \\
\hline PA3071 & hypothetical protein & 2.70 & $4.68 \mathrm{E}-16$ \\
\hline PA1470 & short-chain dehydrogenase & 2.69 & $2.19 \mathrm{E}-11$ \\
\hline PA1972 & hypothetical protein & 2.69 & $1.19 \mathrm{E}-15$ \\
\hline PA3241 & hypothetical protein & 2.68 & $1.23 \mathrm{E}-17$ \\
\hline PA3957 & short-chain dehydrogenase & 2.68 & $6.26 \mathrm{E}-13$ \\
\hline PA0751 & hypothetical protein & 2.64 & $2.46 \mathrm{E}-15$ \\
\hline PA0891 & hypothetical protein & 2.63 & $8.57 \mathrm{E}-15$ \\
\hline$p q q B$ & coenzyme $\mathrm{PQQ}$ synthesis protein $\mathrm{B}$ & 2.63 & $1.52 \mathrm{E}-13$ \\
\hline PA3324 & short-chain dehydrogenase & 2.59 & $2.74 \mathrm{E}-14$ \\
\hline PA4162 & short-chain dehydrogenase & 2.59 & $5.79 \mathrm{E}-13$ \\
\hline ppkA & serine/threonine protein kinase PpkA & 2.58 & $6.21 \mathrm{E}-15$ \\
\hline PA3368 & acetyltransferase & 2.58 & $1.35 \mathrm{E}-11$ \\
\hline PA0137 & $A B C$ transporter permease & 2.55 & $2.81 \mathrm{E}-12$ \\
\hline PA1024 & nitronate monooxygenase & 2.55 & $1.63 \mathrm{E}-13$ \\
\hline eddB & extracelullar DNA degradation protein EddB & 2.54 & $3.97 \mathrm{E}-14$ \\
\hline PA0562 & hydrolase & 2.53 & $5.49 \mathrm{E}-15$ \\
\hline PA2275 & alcohol dehydrogenase & 2.52 & $5.09 \mathrm{E}-13$ \\
\hline PA1407 & hypothetical protein & 2.52 & $1.27 \mathrm{E}-12$ \\
\hline hprA & glycerate dehydrogenase & 2.46 & $7.31 \mathrm{E}-13$ \\
\hline
\end{tabular}




\begin{tabular}{|c|c|c|c|}
\hline PA3668 & hypothetical protein & 2.45 & 4.56E-12 \\
\hline$P A 4803$ & hypothetical protein & 2.45 & $3.26 \mathrm{E}-08$ \\
\hline nirJ & heme $\mathrm{d} 1$ biosynthesis protein NirJ & 2.45 & $2.08 \mathrm{E}-10$ \\
\hline PA3829 & hypothetical protein & 2.44 & $1.27 \mathrm{E}-13$ \\
\hline PA3332 & hypothetical protein & 2.44 & $1.83 \mathrm{E}-08$ \\
\hline PA0237 & oxidoreductase & 2.43 & $9.22 \mathrm{E}-12$ \\
\hline PA3856 & hypothetical protein & 2.43 & $3.15 \mathrm{E}-10$ \\
\hline PA5031 & short-chain dehydrogenase & 2.43 & 2.03E-11 \\
\hline phzB2 & phenazine biosynthesis protein $\mathrm{PhzB}$ & 2.39 & $2.24 \mathrm{E}-05$ \\
\hline PA4962 & hypothetical protein & 2.38 & $2.09 \mathrm{E}-11$ \\
\hline PA4832 & short-chain dehydrogenase & 2.38 & $2.29 \mathrm{E}-0 \mathrm{~S}$ \\
\hline PA3958 & hypothetical protein & 2.38 & $2.12 \mathrm{E}-11$ \\
\hline PA1411 & hypothetical protein & 2.36 & $2.01 \mathrm{E}-11$ \\
\hline$p m b A$ & PmbA protein & 2.35 & $5.95 \mathrm{E}-12$ \\
\hline PA4612 & hypothetical protein & 2.34 & $2.96 \mathrm{E}-11$ \\
\hline PA1402 & hypothetical protein & 2.33 & $1.99 \mathrm{E}-10$ \\
\hline PA1418 & sodium:solute symport protein & 2.32 & $2.13 \mathrm{E}-12$ \\
\hline PA2804 & hypothetical protein & 2.31 & $1.56 \mathrm{E}-08$ \\
\hline PA0138 & $A B C$ transporter permease & 2.30 & $4.74 \mathrm{E}-10$ \\
\hline PA1450 & hypothetical protein & 2.29 & $8.69 \mathrm{E}-12$ \\
\hline PA3949 & hypothetical protein & 2.27 & $3.19 \mathrm{E}-12$ \\
\hline PA3214 & hypothetical protein & 2.27 & $6.96 \mathrm{E}-10$ \\
\hline$p q q E$ & coenzyme $\mathrm{PQQ}$ synthesis protein $\mathrm{E}$ & 2.26 & $1.45 \mathrm{E}-0 \mathrm{c}$ \\
\hline pcaD & 3-oxoadipate enol-lactonase & 2.23 & $2.36 \mathrm{E}-09$ \\
\hline PA2418 & quercetin 2,3-dioxygenase & 2.22 & $1.64 \mathrm{E}-08$ \\
\hline PA4350 & hypothetical protein & 2.19 & $1.58 \mathrm{E}-06$ \\
\hline PA4475 & hypothetical protein & 2.19 & $9.53 \mathrm{E}-12$ \\
\hline PA1943 & hypothetical protein & 2.18 & $4.76 \mathrm{E}-0 \mathrm{~s}$ \\
\hline PA3429 & epoxide hydrolase & 2.17 & $2.48 \mathrm{E}-10$ \\
\hline PA2188 & alcohol dehydrogenase & 2.17 & $2.47 \mathrm{E}-06$ \\
\hline PA1649 & short-chain dehydrogenase & 2.16 & $1.13 \mathrm{E}-06$ \\
\hline PA0201 & hypothetical protein & 2.13 & $5.59 \mathrm{E}-08$ \\
\hline PA3109 & hypothetical protein & 2.13 & $3.59 \mathrm{E}-06$ \\
\hline PA0246 & major facilitator superfamily transporter & 2.13 & $2.15 \mathrm{E}-11$ \\
\hline PA4323 & hypothetical protein & 2.12 & $1.70 \mathrm{E}-10$ \\
\hline PA3425 & hypothetical protein & 2.08 & $1.04 \mathrm{E}-05$ \\
\hline gpuP & 3-guanidinopropionate transporter & 2.08 & $2.25 \mathrm{E}-0 \subseteq$ \\
\hline PA3037 & hypothetical protein & 2.06 & 7.33E-06 \\
\hline PA4200 & hypothetical protein & 2.05 & $5.17 \mathrm{E}-08$ \\
\hline PA3093 & hypothetical protein & 2.02 & $8.36 \mathrm{E}-08$ \\
\hline PA4322 & hypothetical protein & 2.00 & $7.14 \mathrm{E}-0 \mathrm{~S}$ \\
\hline
\end{tabular}




\begin{tabular}{|c|c|c|c|}
\hline PA1137 & oxidoreductase & 2.00 & 2.13E-07 \\
\hline \multicolumn{4}{|c|}{ Inorganic ion transport and metabolism } \\
\hline PA2055 & major facilitator superfamily transporter & 6.70 & $1.52 \mathrm{E}-47$ \\
\hline foxR & anti-sigma factor FoxR & 6.49 & $3.82 \mathrm{E}-51$ \\
\hline PA3409 & transmembrane sensor & 6.18 & 9.52E-37 \\
\hline PA2435 & cation-transporting P-type ATPase & 5.78 & $3.43 E-51$ \\
\hline PA1262 & major facilitator superfamily transporter & 5.67 & $9.12 \mathrm{E}-54$ \\
\hline PA2135 & transporter & 5.41 & $6.28 \mathrm{E}-41$ \\
\hline PA2914 & $\mathrm{ABC}$ transporter permease & 5.35 & $1.75 \mathrm{E}-44$ \\
\hline fepD & ferric enterobactin transporter FepD & 5.33 & $1.70 \mathrm{E}-30$ \\
\hline PA3380 & hypothetical protein & 5.28 & $2.84 \mathrm{E}-24$ \\
\hline PA3442 & $\begin{array}{l}\text { aliphatic sulfonates ABC transporter ATP- } \\
\text { binding subunit }\end{array}$ & 5.27 & $6.39 \mathrm{E}-34$ \\
\hline PA1626 & major facilitator superfamily transporter & 5.21 & $1.42 \mathrm{E}-45$ \\
\hline PA2701 & major facilitator superfamily transporter & 5.15 & $6.12 \mathrm{E}-49$ \\
\hline PA3900 & transmembrane sensor & 5.14 & $1.28 \mathrm{E}-40$ \\
\hline PA3448 & $A B C$ transporter permease & 5.00 & $2.79 \mathrm{E}-37$ \\
\hline PA2051 & transmembrane sensor & 4.98 & $1.58 \mathrm{E}-25$ \\
\hline PA2906 & oxidoreductase & 4.95 & $6.23 \mathrm{E}-38$ \\
\hline fepG & ferric enterobactin transporter FepG & 4.84 & $8.20 \mathrm{E}-41$ \\
\hline arsB & arsenite-antimonite efflux pump ArsB & 4.81 & $5.11 \mathrm{E}-41$ \\
\hline PA3314 & $\begin{array}{l}\text { phosphonates ABC transporter ATP-binding } \\
\text { protein }\end{array}$ & 4.50 & $4.22 \mathrm{E}-36$ \\
\hline PA2913 & hypothetical protein & 4.45 & $1.13 \mathrm{E}-33$ \\
\hline PA3315 & phosphonates $A B C$ transporter permease & 4.26 & 4.47E-27 \\
\hline PA4289 & transporter & 4.18 & $3.26 \mathrm{E}-34$ \\
\hline PA0273 & major facilitator superfamily transporter & 4.11 & $2.32 \mathrm{E}-28$ \\
\hline PA0185 & $A B C$ transporter permease & 4.07 & $6.82 \mathrm{E}-28$ \\
\hline PA2033 & hypothetical protein & 4.06 & $1.41 \mathrm{E}-22$ \\
\hline nasA & nitrate transporter & 4.02 & $2.11 \mathrm{E}-30$ \\
\hline PA3316 & $A B C$ transporter permease & 4.02 & $2.82 \mathrm{E}-31$ \\
\hline fepC & ferric enterobactin transporter FepC & 3.95 & $1.05 \mathrm{E}-31$ \\
\hline PA0525 & denitrification protein NorD & 3.95 & $8.99 \mathrm{E}-34$ \\
\hline PA3376 & phosphonate C-P lyase system protein PhnK & 3.92 & $3.83 \mathrm{E}-28$ \\
\hline PA3379 & carbon-phosphorus lyase complex subunit & 3.84 & $3.60 \mathrm{E}-23$ \\
\hline$x y I X$ & toluate 1,2-dioxygenase subunit alpha & 3.78 & 1.97E-21 \\
\hline vreR & sigma factor regulator VreR & 3.78 & $2.52 \mathrm{E}-25$ \\
\hline phnC & $\begin{array}{l}\text { phosphonate ABC transporter ATP-binding } \\
\text { protein }\end{array}$ & 3.71 & $6.80 \mathrm{E}-24$ \\
\hline PA1301 & transmembrane sensor & 3.65 & 3.23E-24 \\
\hline cynt & carbonic anhydrase & 3.62 & $2.93 \mathrm{E}-20$ \\
\hline$p c o B$ & copper resistance protein $\mathrm{B}$ & 3.61 & $1.05 \mathrm{E}-16$ \\
\hline
\end{tabular}




\begin{tabular}{|c|c|c|c|}
\hline PA1549 & cation-transporting P-type ATPase & 3.60 & 4.14E-32 \\
\hline femA & ferric-mycobactin receptor FemA & 3.58 & 1.09E-22 \\
\hline PA0471 & transmembrane sensor & 3.54 & 1.05E-27 \\
\hline$n o s D$ & copper-binding periplasmic protein & 3.48 & $4.12 \mathrm{E}-24$ \\
\hline PA0703 & major facilitator superfamily transporter & 3.40 & $6.99 \mathrm{E}-21$ \\
\hline PA1922 & TonB-dependent receptor & 3.37 & $6.51 \mathrm{E}-23$ \\
\hline PA2500 & major facilitator superfamily transporter & 3.36 & $8.33 \mathrm{E}-20$ \\
\hline PA4513 & oxidoreductase & 3.32 & $5.05 \mathrm{E}-28$ \\
\hline PA0809 & divalent metal cation transporter $\mathrm{MntH}$ & 3.31 & 4.09E-26 \\
\hline PA3375 & ABC transporter ATP-binding protein & 3.28 & $1.69 \mathrm{E}-21$ \\
\hline PA4706 & hemin importer ATP-binding subunit & 3.24 & 1.73E-23 \\
\hline PA3936 & taurine $\mathrm{ABC}$ transporter permease & 3.22 & $3.26 \mathrm{E}-22$ \\
\hline PA3937 & taurine $A B C$ transporter ATP-binding protein & 3.11 & $1.38 \mathrm{E}-20$ \\
\hline PA5216 & iron $\mathrm{ABC}$ transporter substrate-binding protein & 3.03 & $1.14 \mathrm{E}-23$ \\
\hline PA4707 & $A B C$ transporter permease & 2.99 & $9.50 \mathrm{E}-21$ \\
\hline PA3373 & hypothetical protein & 2.97 & $3.10 \mathrm{E}-17$ \\
\hline PA4709 & hemin degrading factor & 2.92 & $1.73 \mathrm{E}-19$ \\
\hline cyns & cyanate hydratase & 2.92 & $2.04 \mathrm{E}-11$ \\
\hline fepB & $\begin{array}{l}\text { iron-enterobactin transporter periplasmic } \\
\text { binding protein }\end{array}$ & 2.92 & $5.17 \mathrm{E}-15$ \\
\hline PA2603 & thiosulfate sulfurtransferase & 2.91 & 4.24E-18 \\
\hline napD & nitrate reductase biosynthesis protein NapD & 2.91 & 8.69E-09 \\
\hline PA2097 & flavin-binding monooxygenase & 2.88 & $3.77 \mathrm{E}-13$ \\
\hline PA3374 & hypothetical protein & 2.84 & $7.75 \mathrm{E}-19$ \\
\hline PA1209 & hypothetical protein & 2.83 & 3.73E-14 \\
\hline PA2057 & hypothetical protein & 2.80 & 8.49E-15 \\
\hline PA1548 & hypothetical protein & 2.75 & 4.09E-05 \\
\hline PA2089 & hypothetical protein & 2.66 & $4.84 \mathrm{E}-12$ \\
\hline PA2662 & hypothetical protein & 2.64 & $1.24 \mathrm{E}-12$ \\
\hline PA2777 & hypothetical protein & 2.64 & $9.44 \mathrm{E}-14$ \\
\hline phut & heme-transporter PhuT & 2.63 & $8.49 \mathrm{E}-15$ \\
\hline $\operatorname{van} A$ & vanillate O-demethylase oxygenase & 2.59 & $3.74 \mathrm{E}-09$ \\
\hline PA0029 & sulfate transporter & 2.57 & $5.44 \mathrm{E}-17$ \\
\hline PA3443 & $A B C$ transporter permease & 2.54 & $1.85 \mathrm{E}-11$ \\
\hline PA2384 & hypothetical protein & 2.52 & $4.71 \mathrm{E}-05$ \\
\hline PA2408 & $A B C$ transporter ATP-binding protein & 2.50 & $2.42 \mathrm{E}-12$ \\
\hline PA3447 & $\mathrm{ABC}$ transporter ATP-binding protein & 2.48 & $2.47 \mathrm{E}-12$ \\
\hline PA3378 & hypothetical protein & 2.47 & 8.92E-13 \\
\hline PA3920 & metal transporting P-type ATPase & 2.43 & $8.91 \mathrm{E}-09$ \\
\hline PA4822 & hypothetical protein & 2.42 & $1.63 \mathrm{E}-11$ \\
\hline PA2407 & adhesion protein & 2.40 & $1.13 \mathrm{E}-09$ \\
\hline PA2596 & hypothetical protein & 2.40 & $1.23 \mathrm{E}-12$ \\
\hline
\end{tabular}




\begin{tabular}{|c|c|c|c|}
\hline PA3449 & hypothetical protein & 2.39 & 7.35E-12 \\
\hline PA2070 & hypothetical protein & 2.36 & 9.29E-09 \\
\hline PA1364 & transmembrane sensor & 2.36 & $2.14 \mathrm{E}-11$ \\
\hline $\bmod C$ & $\begin{array}{l}\text { molybdenum ABC transporter ATP-binding } \\
\text { protein ModC }\end{array}$ & 2.30 & 3.38E-11 \\
\hline$C Z C A$ & $\begin{array}{l}\text { resistance-nodulation-cell division (RND) } \\
\text { divalent metal cation efflux transporter CzcA }\end{array}$ & 2.29 & $1.98 \mathrm{E}-11$ \\
\hline PA1056 & monovalent cation $/ \mathrm{H}+$ antiporter subunit $\mathrm{D}$ & 2.28 & $1.42 \mathrm{E}-11$ \\
\hline PA4045 & hypothetical protein & 2.27 & $8.41 \mathrm{E}-11$ \\
\hline eddA & extracelullar DNA degradation protein EddA & 2.26 & $4.60 \mathrm{E}-10$ \\
\hline$p f e A$ & ferric enterobactin receptor & 2.26 & $1.50 \mathrm{E}-11$ \\
\hline fOxA & ferrioxamine receptor FoxA & 2.24 & 1.09E-10 \\
\hline PA5311 & major facilitator superfamily transporter & 2.16 & $8.01 \mathrm{E}-11$ \\
\hline PA5101 & hypothetical protein & 2.13 & 1.94E-09 \\
\hline PA3465 & hypothetical protein & 2.10 & $8.23 \mathrm{E}-10$ \\
\hline hasR & heme uptake outer membrane receptor HasR & 2.09 & $2.05 \mathrm{E}-10$ \\
\hline PA2765 & hypothetical protein & 2.02 & $2.21 \mathrm{E}-07$ \\
\hline PA2594 & hypothetical protein & 2.02 & $3.75 \mathrm{E}-05$ \\
\hline PA0151 & TonB-dependent receptor & 2.01 & 7.07E-08 \\
\hline PA0103 & sulfate transporter & 2.00 & 4.39E-10 \\
\hline \multicolumn{4}{|c|}{ Intracellular trafficking, secretion, and vesicular transport } \\
\hline xphA & type $\mathrm{VI}$ pilus biosynthesis protein & 8.15 & $3.64 \mathrm{E}-39$ \\
\hline PA1238 & multidrug efflux pump outer membrane protein & 6.53 & 1.20E-52 \\
\hline PA2837 & hypothetical protein & 5.94 & $7.52 \mathrm{E}-55$ \\
\hline cupA5 & chaperone CupA5 & 5.40 & $6.90 \mathrm{E}-18$ \\
\hline$c z c C$ & outer membrane protein $\mathrm{CzcC}$ & 5.22 & $6.34 \mathrm{E}-46$ \\
\hline$x c p Z$ & type II secretion system protein $\mathrm{M}$ & 4.83 & $2.05 E-33$ \\
\hline opmD & hypothetical protein & 4.81 & $2.40 \mathrm{E}-40$ \\
\hline $\operatorname{tad} D$ & type II secretion system protein TadD & 4.78 & $3.55 \mathrm{E}-35$ \\
\hline$x c p Y$ & type II secretion system protein $L$ & 4.77 & $5.42 \mathrm{E}-43$ \\
\hline PA0677 & HxcW pseudopilin & 4.77 & $5.49 \mathrm{E}-31$ \\
\hline PA3340 & hypothetical protein & 4.76 & $1.92 \mathrm{E}-38$ \\
\hline PA0678 & HxcU pseudopilin & 4.62 & $3.10 \mathrm{E}-30$ \\
\hline PA3521 & hypothetical protein & 4.57 & $5.80 \mathrm{E}-30$ \\
\hline PA0682 & HxcX atypical pseudopilin & 4.04 & $4.80 \mathrm{E}-33$ \\
\hline PA0021 & hypothetical protein & 3.93 & $2.75 \mathrm{E}-25$ \\
\hline oprN & multidrug efflux outer membrane protein OprN & 3.90 & $1.91 \mathrm{E}-26$ \\
\hline PA4144 & hypothetical protein & 3.76 & $1.13 \mathrm{E}-25$ \\
\hline PA0684 & type II secretion system protein & 3.69 & 1.03E-21 \\
\hline cupA4 & fimbrial subunit CupA4 & 3.59 & $3.53 E-19$ \\
\hline PA3894 & hypothetical protein & 3.54 & $3.22 \mathrm{E}-26$ \\
\hline rcpC & hypothetical protein & 3.50 & $2.11 \mathrm{E}-24$ \\
\hline
\end{tabular}




\begin{tabular}{|c|c|c|c|}
\hline cupA3 & usher CupA3 & 3.45 & $5.63 \mathrm{E}-25$ \\
\hline PA0041 & hemagglutinin & 3.40 & $6.52 \mathrm{E}-28$ \\
\hline PA1924 & hypothetical protein & 3.37 & $2.84 \mathrm{E}-08$ \\
\hline PA5158 & hypothetical protein & 3.19 & $2.78 \mathrm{E}-21$ \\
\hline cupA1 & fimbrial subunit CupA1 & 3.09 & $1.54 \mathrm{E}-09$ \\
\hline$x c p W$ & type II secretion system protein $\mathrm{J}$ & 3.04 & 1.17E-17 \\
\hline $\operatorname{tad} Z$ & hypothetical protein & 2.99 & $1.71 \mathrm{E}-20$ \\
\hline pscL & type III secretion system protein & 2.98 & $4.52 \mathrm{E}-12$ \\
\hline PA4718 & hypothetical protein & 2.94 & $1.84 \mathrm{E}-16$ \\
\hline PA0040 & hypothetical protein & 2.79 & 3.69E-20 \\
\hline PA2463 & hypothetical protein & 2.71 & $3.78 \mathrm{E}-17$ \\
\hline pcrD & type III secretory apparatus protein PcrD & 2.61 & $1.60 \mathrm{E}-15$ \\
\hline oprJ & multidrug efflux outer membrane protein OprJ & 2.52 & $8.10 \mathrm{E}-16$ \\
\hline PA0690 & hypothetical protein & 2.43 & 3.79E-18 \\
\hline$x c p R$ & type II secretion system protein $E$ & 2.42 & $6.51 \mathrm{E}-14$ \\
\hline$x c p X$ & type II secretion system protein $\mathrm{K}$ & 2.42 & $5.30 \mathrm{E}-10$ \\
\hline exbB1 & transporter ExbB & 2.37 & $3.80 \mathrm{E}-09$ \\
\hline $\operatorname{tad} B$ & type II secretion system protein TadB & 2.33 & $2.69 \mathrm{E}-10$ \\
\hline aprF & alkaline protease secretion protein AprF & 2.32 & 9.97E-11 \\
\hline$x c p V$ & type II secretion system protein I & 2.31 & $1.87 \mathrm{E}-08$ \\
\hline PA2462 & hypothetical protein & 2.06 & $1.54 \mathrm{E}-12$ \\
\hline \multicolumn{4}{|c|}{ Lipid transport and metabolism } \\
\hline PA2098 & esterase & 9.93 & $5.83 \mathrm{E}-70$ \\
\hline atuE & isohexenylglutaconyl-CoA hydratase & 6.76 & $5.07 \mathrm{E}-48$ \\
\hline PA2539 & hypothetical protein & 5.53 & $9.08 \mathrm{E}-44$ \\
\hline PA2597 & hypothetical protein & 5.33 & $6.05 \mathrm{E}-39$ \\
\hline PA1021 & enoyl-CoA hydratase & 5.28 & $6.51 \mathrm{E}-44$ \\
\hline PA1020 & acyl-CoA dehydrogenase & 4.83 & $2.46 \mathrm{E}-39$ \\
\hline PA1628 & 3-hydroxyacyl-CoA dehydrogenase & 4.80 & $1.25 \mathrm{E}-40$ \\
\hline PA2155 & cardiolipin synthase 2 & 4.78 & $5.41 \mathrm{E}-25$ \\
\hline PA5384 & lipolytic protein & 4.55 & $8.34 \mathrm{E}-30$ \\
\hline PA3589 & acetyl-CoA acetyltransferase & 4.52 & 4.40E-37 \\
\hline $\mathrm{fabH} 2$ & 3-oxoacyl-ACP synthase III & 4.27 & $9.59 \mathrm{E}-33$ \\
\hline PA3023 & lipid kinase & 4.26 & $4.74 \mathrm{E}-25$ \\
\hline atuF & geranyl-CoA carboxylase subunit alpha & 4.24 & $2.12 \mathrm{E}-28$ \\
\hline$m d c E$ & malonate decarboxylase subunit gamma & 4.21 & $2.10 \mathrm{E}-23$ \\
\hline PA1400 & pyruvate carboxylase & 4.09 & $1.29 \mathrm{E}-36$ \\
\hline$m m s B$ & 3-hydroxyisobutyrate dehydrogenase & 4.06 & $2.54 \mathrm{E}-25$ \\
\hline PA3312 & 3-hydroxyisobutyrate dehydrogenase & 4.06 & $6.21 \mathrm{E}-24$ \\
\hline PA2927 & hypothetical protein & 3.94 & $2.58 \mathrm{E}-33$ \\
\hline PA0214 & acyl transferase & 3.83 & $2.89 \mathrm{E}-25$ \\
\hline
\end{tabular}




\begin{tabular}{|c|c|c|c|}
\hline PA3590 & 3-hydroxyacyl-CoA dehydrogenase & 3.83 & $2.74 \mathrm{E}-31$ \\
\hline PA4980 & enoyl-CoA hydratase & 3.72 & $3.32 \mathrm{E}-24$ \\
\hline PA0190 & acid phosphatase & 3.58 & $2.31 \mathrm{E}-22$ \\
\hline PA3911 & hypothetical protein & 3.54 & $5.94 \mathrm{E}-2 \mathrm{C}$ \\
\hline PA3591 & enoyl-CoA hydratase & 3.52 & $3.26 \mathrm{E}-16$ \\
\hline azoR2 & FMN-dependent NADH-azoreductase & 3.50 & $5.95 \mathrm{E}-16$ \\
\hline PA4349 & hypothetical protein & 3.49 & $8.22 \mathrm{E}-22$ \\
\hline PA3593 & acyl-CoA dehydrogenase & 3.45 & $4.37 \mathrm{E}-28$ \\
\hline PA0743 & NAD-dependent L-serine dehydrogenase & 3.40 & $1.20 \mathrm{E}-26$ \\
\hline PA4008 & hydrolase & 3.37 & $3.97 \mathrm{E}-24$ \\
\hline PA4788 & hypothetical protein & 3.31 & $4.62 \mathrm{E}-23$ \\
\hline PA2841 & enoyl-CoA hydratase & 3.26 & $6.40 \mathrm{E}-21$ \\
\hline PA3426 & enoyl-CoA hydratase & 3.16 & $5.05 \mathrm{E}-19$ \\
\hline PA4339 & phospholipase & 3.14 & $2.76 \mathrm{E}-23$ \\
\hline PA1827 & short-chain dehydrogenase & 3.10 & $2.13 \mathrm{E}-13$ \\
\hline PA2940 & acyl-CoA thiolase & 3.10 & $2.28 \mathrm{E}-19$ \\
\hline PA3568 & propionyl-CoA synthetase & 2.95 & $2.65 \mathrm{E}-22$ \\
\hline $\operatorname{cdh} A$ & 3-hydroxybutyryl-CoA dehydrogenase & 2.89 & $9.22 \mathrm{E}-18$ \\
\hline PA5102 & hypothetical protein & 2.86 & $5.55 \mathrm{E}-18$ \\
\hline PA1629 & enoyl-CoA hydratase & 2.79 & $2.31 \mathrm{E}-12$ \\
\hline PA1018 & hypothetical protein & 2.77 & $4.07 \mathrm{E}-15$ \\
\hline PA0494 & $\begin{array}{l}\text { acetyl-CoA carboxylase biotin carboxylase } \\
\text { subunit }\end{array}$ & 2.60 & $1.08 \mathrm{E}-15$ \\
\hline$y g b P$ & $\begin{array}{l}\text { 2-C-methyl-D-erythritol 4-phosphate } \\
\text { cytidylyltransferase }\end{array}$ & 2.60 & $2.13 \mathrm{E}-14$ \\
\hline PA0744 & enoyl-CoA hydratase & 2.45 & $1.25 \mathrm{E}-12$ \\
\hline PA1869 & acyl carrier protein & 2.41 & $6.45 \mathrm{E}-05$ \\
\hline pcaF & beta-ketoadipyl CoA thiolase & 2.40 & $2.96 \mathrm{E}-10$ \\
\hline atuC & geranyl-CoA carboxylase subunit beta & 2.40 & $1.17 \mathrm{E}-10$ \\
\hline PA5089 & hypothetical protein & 2.27 & $5.22 \mathrm{E}-11$ \\
\hline PA2540 & hypothetical protein & 2.26 & $4.15 \mathrm{E}-10$ \\
\hline PA4011 & hypothetical protein & 2.25 & 1.26E-11 \\
\hline PA0308 & hypothetical protein & 2.22 & 1.79E-11 \\
\hline PA5188 & 3-hydroxyacyl-CoA dehydrogenase & 2.16 & $6.92 \mathrm{E}-12$ \\
\hline PA2002 & hypothetical protein & 2.16 & $2.06 \mathrm{E}-0 \mathrm{~S}$ \\
\hline$m d c A$ & malonate decarboxylase subunit alpha & 2.15 & $3.57 \mathrm{E}-0 \mathrm{~S}$ \\
\hline PA3925 & acyl-CoA thiolase & 2.15 & $2.35 \mathrm{E}-08$ \\
\hline PA0227 & CoA transferase subunit $B$ & 2.12 & $2.94 \mathrm{E}-06$ \\
\hline PA3994 & epoxide hydrolase & 2.10 & $1.18 \mathrm{E}-08$ \\
\hline PA2871 & hypothetical protein & 2.06 & $4.49 \mathrm{E}-08$ \\
\hline PA2554 & short-chain dehydrogenase & 2.06 & $4.94 \mathrm{E}-04$ \\
\hline PA1016 & thiolase & 2.04 & $2.70 \mathrm{E}-08$ \\
\hline
\end{tabular}




\begin{tabular}{|c|c|c|c|}
\hline \multicolumn{4}{|c|}{ Nucleotide transport and metabolism } \\
\hline PA2268 & hypothetical protein & 6.30 & 1.57E-38 \\
\hline pyrF & orotidine 5'-phosphate decarboxylase & 3.57 & $1.38 \mathrm{E}-22$ \\
\hline$p c a B$ & 3-carboxy-cis,cis-muconate cycloisomerase & 3.05 & $8.21 \mathrm{E}-19$ \\
\hline$x d h A$ & xanthine dehydrogenase & 2.75 & $2.28 \mathrm{E}-15$ \\
\hline PA0144 & hypothetical protein & 2.72 & $1.19 \mathrm{E}-16$ \\
\hline $\operatorname{cod} B$ & cytosine permease & 2.51 & $5.52 \mathrm{E}-16$ \\
\hline tmk & thymidylate kinase & 2.41 & $2.90 \mathrm{E}-10$ \\
\hline PA2625 & hypothetical protein & 2.38 & 7.77E-07 \\
\hline PA0166 & transporter & 2.15 & $1.08 \mathrm{E}-09$ \\
\hline PA3517 & adenylosuccinate lyase & 2.14 & 1.84E-10 \\
\hline PA1419 & transporter & 2.02 & $1.24 \mathrm{E}-07$ \\
\hline$x d h B$ & xanthine dehydrogenase & 2.01 & $9.83 \mathrm{E}-07$ \\
\hline \multicolumn{4}{|c|}{ Posttranslational modification, protein turnover, chaperones } \\
\hline$p q q F$ & coenzyme $P Q Q$ synthesis protein $F$ & 7.39 & $2.48 \mathrm{E}-57$ \\
\hline PA2437 & hypothetical protein & 7.22 & $2.50 \mathrm{E}-58$ \\
\hline PA2439 & hypothetical protein & 7.19 & 4.53E-62 \\
\hline PA2473 & glutathione S-transferase & 5.84 & $6.48 \mathrm{E}-35$ \\
\hline PA2478 & thiol:disulfide interchange protein DsbD & 5.33 & 3.34E-49 \\
\hline PA2438 & hypothetical protein & 5.29 & $1.48 \mathrm{E}-41$ \\
\hline PA4894 & hypothetical protein & 5.07 & $8.98 \mathrm{E}-40$ \\
\hline$n r d G$ & $\begin{array}{l}\text { class III (anaerobic) ribonucleoside- } \\
\text { triphosphate reductase activating protein NrdG }\end{array}$ & 4.86 & 4.90E-36 \\
\hline ureF & urease accessory protein UreF & 4.66 & $1.93 \mathrm{E}-23$ \\
\hline ureD & urease accessory protein & 4.60 & 8.03E-33 \\
\hline PA2371 & ClpA/B-type protease & 4.44 & 1.36E-24 \\
\hline PA0699 & PpiC-type peptidyl-prolyl cis-trans isomerase & 4.42 & 4.57E-34 \\
\hline PA3685 & hypothetical protein & 4.36 & $2.32 \mathrm{E}-28$ \\
\hline PA0451 & hypothetical protein & 4.28 & $8.75 \mathrm{E}-32$ \\
\hline PA0859 & hypothetical protein & 3.97 & $9.27 \mathrm{E}-19$ \\
\hline PA0058 & hypothetical protein & 3.82 & $1.05 \mathrm{E}-28$ \\
\hline PA5211 & hypothetical protein & 3.61 & $3.44 \mathrm{E}-24$ \\
\hline PA0277 & hypothetical protein & 3.57 & $8.28 \mathrm{E}-20$ \\
\hline PA2069 & carbamoyl transferase & 3.53 & $1.04 \mathrm{E}-25$ \\
\hline PA2725 & chaperone & 3.31 & 3.74E-24 \\
\hline PA4170 & hypothetical protein & 3.31 & $2.98 \mathrm{E}-15$ \\
\hline PA1242 & hypothetical protein & 3.19 & $5.64 \mathrm{E}-23$ \\
\hline PA1662 & ClpA/B-type protease & 3.17 & $3.63 \mathrm{E}-20$ \\
\hline PA0112 & hypothetical protein & 3.12 & $5.90 \mathrm{E}-15$ \\
\hline ureE & urease accessory protein UreE & 3.00 & $6.67 \mathrm{E}-14$ \\
\hline PA1522 & hypothetical protein & 2.94 & $9.26 \mathrm{E}-18$ \\
\hline PA2694 & thioredoxin & 2.93 & $2.12 \mathrm{E}-12$ \\
\hline
\end{tabular}




\begin{tabular}{|c|c|c|c|}
\hline ccmA & $\begin{array}{l}\text { cytochrome c biogenesis ATP-binding export } \\
\text { protein CcmA }\end{array}$ & 2.81 & $3.35 \mathrm{E}-17$ \\
\hline PA5290 & hypothetical protein & 2.76 & $1.28 \mathrm{E}-19$ \\
\hline $\operatorname{dipZ}$ & thiol:disulfide interchange protein & 2.76 & $7.21 \mathrm{E}-18$ \\
\hline PA0113 & protoheme IX farnesyltransferase & 2.73 & $2.94 \mathrm{E}-18$ \\
\hline PA3365 & chaperone & 2.60 & $1.32 \mathrm{E}-14$ \\
\hline$d s b B$ & disulfide bond formation protein & 2.48 & $6.54 \mathrm{E}-11$ \\
\hline lipH & lipase chaperone & 2.44 & 5.99E-11 \\
\hline PA0473 & glutathione S-transferase & 2.41 & $6.44 \mathrm{E}-12$ \\
\hline fdhE & formate dehydrogenase subunit epsilon & 2.40 & 4.63E-14 \\
\hline PA2726 & radical activating enzyme & 2.36 & $1.40 \mathrm{E}-10$ \\
\hline PA1890 & glutathione S-transferase & 2.28 & 9.27E-09 \\
\hline clpV1 & secretion protein ClpV1 & 2.27 & 4.24E-14 \\
\hline PA1068 & heat shock protein & 2.23 & $3.90 \mathrm{E}-13$ \\
\hline PA0467 & hypothetical protein & 2.17 & 1.89E-08 \\
\hline PA3871 & PpiC-type peptidyl-prolyl cis-trans isomerase & 2.04 & 9.36E-08 \\
\hline \multicolumn{4}{|c|}{ Replication, recombination and repair } \\
\hline PA2750 & hypothetical protein & 5.42 & 4.80E-33 \\
\hline$p s / N$ & hypothetical protein & 4.63 & 1.03E-35 \\
\hline ada & O6-methylguanine-DNA methyltransferase & 4.43 & $8.45 \mathrm{E}-26$ \\
\hline $\mathrm{recO}$ & DNA repair protein $\mathrm{RecO}$ & 4.05 & $1.04 \mathrm{E}-22$ \\
\hline PA1782 & serine/threonine-protein kinase & 3.92 & 9.25E-33 \\
\hline PA3564 & hypothetical protein & 3.89 & 2.19E-28 \\
\hline PA3596 & $\begin{array}{l}\text { methylated-DNA--protein-cysteine } \\
\text { methyltransferase }\end{array}$ & 3.61 & 6.37E-28 \\
\hline PA0670 & hypothetical protein & 3.53 & 4.30E-22 \\
\hline PA4392 & hypothetical protein & 3.44 & $5.13 \mathrm{E}-12$ \\
\hline PA0799 & helicase & 2.88 & $1.90 \mathrm{E}-20$ \\
\hline PA4172 & nuclease & 2.81 & $2.06 \mathrm{E}-16$ \\
\hline PA3961 & ATP-dependent helicase & 2.80 & $3.84 \mathrm{E}-18$ \\
\hline$r e c D$ & exodeoxyribonuclease $\mathrm{V}$ subunit alpha & 2.71 & $2.28 \mathrm{E}-20$ \\
\hline alkA & DNA-3-methyladenine glycosidase II & 2.47 & $9.57 \mathrm{E}-10$ \\
\hline sss & site-specific tyrosine recombinase XerC & 2.47 & $3.15 \mathrm{E}-14$ \\
\hline polB & DNA polymerase II & 2.41 & 7.87E-10 \\
\hline priA & primosome assembly protein PriA & 2.29 & 2.15E-14 \\
\hline$x \operatorname{se} A$ & exodeoxyribonuclease VII large subunit & 2.21 & $2.46 \mathrm{E}-10$ \\
\hline PA3470 & hypothetical protein & 2.16 & $5.10 \mathrm{E}-08$ \\
\hline recC & exodeoxyribonuclease $\mathrm{V}$ subunit gamma & 2.12 & 4.92E-11 \\
\hline$m t t C$ & secretion protein MttC & 2.11 & 4.72E-08 \\
\hline holB & DNA polymerase III subunit delta' & 2.01 & $1.10 \mathrm{E}-05$ \\
\hline \multicolumn{4}{|c|}{ RNA processing and modification } \\
\hline$r t c A$ & RNA 3'-terminal-phosphate cyclase & 3.54 & $6.71 \mathrm{E}-29$ \\
\hline
\end{tabular}




\begin{tabular}{|c|c|c|c|}
\hline \multicolumn{4}{|c|}{ Secondary metabolites biosynthesis, transport and catabolism } \\
\hline PA2034 & hypothetical protein & 6.47 & $2.16 \mathrm{E}-40$ \\
\hline$p v c B$ & paerucumarin biosynthesis protein $\mathrm{PvcB}$ & 5.99 & $1.46 \mathrm{E}-41$ \\
\hline PA1219 & hypothetical protein & 5.91 & $3.66 \mathrm{E}-44$ \\
\hline PA2411 & thioesterase & 5.42 & $2.68 \mathrm{E}-28$ \\
\hline$p c p S$ & 4'-phosphopantetheinyl transferase & 5.27 & $4.53 \mathrm{E}-42$ \\
\hline$p v c C$ & paerucumarin biosynthesis protein $\mathrm{PvcC}$ & 4.74 & $1.59 \mathrm{E}-35$ \\
\hline PA2475 & cytochrome P450 & 4.69 & 3.39E-29 \\
\hline$p v d L$ & peptide synthase & 4.69 & $4.89 \mathrm{E}-43$ \\
\hline PA1220 & hypothetical protein & 4.53 & $3.74 \mathrm{E}-38$ \\
\hline PA3329 & hypothetical protein & 4.47 & 7.97E-24 \\
\hline PA2858 & hypothetical protein & 4.34 & 1.73E-39 \\
\hline PA4089 & 3-ketoacyl-ACP reductase & 4.32 & $1.08 \mathrm{E}-22$ \\
\hline PA1215 & hypothetical protein & 4.32 & 3.37E-32 \\
\hline PA4148 & short-chain dehydrogenase & 4.21 & 3.17E-29 \\
\hline PA3327 & non-ribosomal peptide synthetase & 4.18 & $1.64 \mathrm{E}-40$ \\
\hline phzD1 & phenazine biosynthesis protein PhzD & 4.10 & 1.13E-25 \\
\hline PA1379 & short-chain dehydrogenase & 4.06 & $8.69 \mathrm{E}-25$ \\
\hline PA2857 & $A B C$ transporter ATP-binding protein & 3.88 & 9.36E-27 \\
\hline phzD2 & phenazine biosynthesis protein PhzD & 3.79 & 1.57E-21 \\
\hline PA2471 & hypothetical protein & 3.78 & $1.14 \mathrm{E}-18$ \\
\hline PA4786 & 3-ketoacyl-ACP reductase & 3.77 & 8.76E-28 \\
\hline PA3774 & acetylpolyamine aminohydrolase & 3.72 & $1.84 \mathrm{E}-28$ \\
\hline $\operatorname{gtd} A$ & gentisate 1,2-dioxygenase & 3.65 & $3.09 \mathrm{E}-23$ \\
\hline PA3679 & hypothetical protein & 3.59 & 8.87E-31 \\
\hline$p v d J$ & pyoverdine biosynthesis protein $\mathrm{PvdJ}$ & 3.30 & $1.07 \mathrm{E}-06$ \\
\hline PA2402 & peptide synthase & 3.26 & $5.01 \mathrm{E}-26$ \\
\hline PA3783 & hypothetical protein & 3.23 & $7.97 \mathrm{E}-19$ \\
\hline PA0543 & hypothetical protein & 3.14 & $9.53 \mathrm{E}-21$ \\
\hline PA3076 & hypothetical protein & 3.13 & $2.91 \mathrm{E}-22$ \\
\hline PA0098 & 3-oxoacyl-ACP synthase & 3.08 & $3.05 \mathrm{E}-20$ \\
\hline PA1221 & hypothetical protein & 3.06 & $3.75 \mathrm{E}-23$ \\
\hline PA3953 & hypothetical protein & 3.02 & 1.69E-17 \\
\hline$p c o A$ & copper resistance protein $\mathrm{A}$ & 3.00 & $2.09 \mathrm{E}-17$ \\
\hline fabF2 & 3-oxoacyl-ACP synthase & 2.99 & 4.13E-14 \\
\hline PA4078 & nonribosomal peptide synthetase & 2.87 & $2.18 \mathrm{E}-18$ \\
\hline PA3883 & short-chain dehydrogenase & 2.84 & $5.94 \mathrm{E}-17$ \\
\hline PA4093 & hypothetical protein & 2.76 & $3.92 \mathrm{E}-13$ \\
\hline PA0474 & esterase & 2.75 & $8.41 \mathrm{E}-12$ \\
\hline PA1860 & hypothetical protein & 2.69 & $3.50 \mathrm{E}-14$ \\
\hline catA & catechol 1,2-dioxygenase & 2.64 & $5.03 \mathrm{E}-16$ \\
\hline
\end{tabular}




\begin{tabular}{|c|c|c|c|}
\hline PA0117 & short-chain dehydrogenase & 2.60 & $6.09 \mathrm{E}-12$ \\
\hline$a t u B$ & citronellol catabolism dehydrogenase & 2.47 & $1.81 \mathrm{E}-10$ \\
\hline$p v d A$ & L-ornithine N5-oxygenase & 2.47 & $2.26 \mathrm{E}-03$ \\
\hline PA3212 & ABC transporter ATP-binding protein & 2.39 & $6.89 \mathrm{E}-10$ \\
\hline PA3331 & cytochrome P450 & 2.39 & $1.54 \mathrm{E}-10$ \\
\hline PA3846 & hypothetical protein & 2.36 & 1.33E-09 \\
\hline PA4830 & hypothetical protein & 2.31 & $3.18 \mathrm{E}-05$ \\
\hline PA1593 & hypothetical protein & 2.30 & $5.45 \mathrm{E}-07$ \\
\hline PA1166 & hypothetical protein & 2.29 & $3.57 \mathrm{E}-10$ \\
\hline$p c h C$ & pyochelin biosynthetic protein PchC & 2.27 & $1.08 \mathrm{E}-08$ \\
\hline PA4021 & transcriptional regulator & 2.26 & $6.49 \mathrm{E}-10$ \\
\hline PA0194 & hypothetical protein & 2.25 & $2.24 \mathrm{E}-09$ \\
\hline acoR & transcriptional regulator $A c o R$ & 2.25 & $1.35 \mathrm{E}-10$ \\
\hline PA1594 & hypothetical protein & 2.24 & 1.47E-06 \\
\hline PA4009 & hypothetical protein & 2.19 & $1.88 \mathrm{E}-09$ \\
\hline PA5222 & hypothetical protein & 2.11 & $2.75 \mathrm{E}-06$ \\
\hline PA2557 & AMP-binding protein & 2.05 & $8.91 \mathrm{E}-10$ \\
\hline PA0118 & hypothetical protein & 2.02 & 4.19E-05 \\
\hline PA2636 & hypothetical protein & 2.00 & $6.30 \mathrm{E}-06$ \\
\hline \multicolumn{4}{|c|}{ Signal transduction mechanisms } \\
\hline femR & sigma factor regulator FemR & 7.66 & $8.31 \mathrm{E}-47$ \\
\hline eras & sensor kinase EraS & 6.84 & $8.10 \mathrm{E}-47$ \\
\hline PA2094 & transmembrane sensor & 6.30 & $2.35 \mathrm{E}-38$ \\
\hline PA2833 & hypothetical protein & 6.22 & 1.49E-23 \\
\hline PA4895 & transmembrane sensor & 5.30 & $8.93 E-35$ \\
\hline eraR & response regulator EraR & 4.96 & $1.72 \mathrm{E}-30$ \\
\hline PA2881 & two-component response regulator & 4.93 & $1.35 \mathrm{E}-31$ \\
\hline PA1945 & transcriptional regulator & 4.92 & 3.03E-41 \\
\hline PA2480 & two-component sensor & 4.84 & $1.52 \mathrm{E}-45$ \\
\hline PA2133 & hypothetical protein & 4.66 & $5.84 \mathrm{E}-21$ \\
\hline PA1438 & two-component sensor & 4.20 & $1.24 \mathrm{E}-31$ \\
\hline PA0150 & transmembrane sensor & 4.17 & $1.72 \mathrm{E}-26$ \\
\hline stp1 & $\begin{array}{l}\text { serine/threonine phosphoprotein phosphatase } \\
\text { Stp1 }\end{array}$ & 4.13 & $1.23 \mathrm{E}-26$ \\
\hline PA2523 & two-component response regulator & 3.84 & 1.64E-20 \\
\hline PA2479 & two-component response regulator & 3.84 & $1.50 \mathrm{E}-19$ \\
\hline bfiS & protein BfiS & 3.64 & $1.94 \mathrm{E}-31$ \\
\hline stk1 & serine-threonine kinase Stk1 & 3.61 & 1.62E-21 \\
\hline ercs & sensor histidine kinase & 3.61 & $9.88 \mathrm{E}-27$ \\
\hline PA2072 & hypothetical protein & 3.54 & 3.83E-20 \\
\hline$P A 1646$ & chemotaxis transducer & 3.53 & $5.03 E-26$ \\
\hline PA3959 & hypothetical protein & 3.51 & $1.06 \mathrm{E}-25$ \\
\hline
\end{tabular}




\begin{tabular}{|c|c|c|c|}
\hline PA1665 & hypothetical protein & 3.39 & $3.56 \mathrm{E}-20$ \\
\hline PA1433 & hypothetical protein & 3.31 & $3.98 \mathrm{E}-24$ \\
\hline PA2788 & chemotaxis transducer & 3.29 & $8.30 \mathrm{E}-25$ \\
\hline PA4806 & transcriptional regulator & 3.26 & $2.08 \mathrm{E}-17$ \\
\hline ercS' & sensor histidine kinase & 3.25 & $3.27 \mathrm{E}-25$ \\
\hline PA4886 & two-component sensor & 3.25 & $2.86 \mathrm{E}-20$ \\
\hline pprA & two-component sensor PprA & 3.23 & 1.24E-23 \\
\hline PA0757 & two-component sensor & 3.23 & $3.28 \mathrm{E}-24$ \\
\hline PA1616 & hypothetical protein & 3.23 & $8.40 \mathrm{E}-14$ \\
\hline PA2524 & two-component sensor & 3.20 & 1.19E-17 \\
\hline cops & two-component sensor CopS & 3.11 & $4.37 \mathrm{E}-20$ \\
\hline PA2005 & transcriptional regulator & 3.00 & $4.00 \mathrm{E}-22$ \\
\hline PA4290 & chemotaxis transducer & 2.98 & $5.97 \mathrm{E}-22$ \\
\hline PA4982 & two-component sensor & 2.96 & 4.63E-17 \\
\hline$k d p D$ & two-component sensor KdpD & 2.89 & 3.16E-08 \\
\hline $\operatorname{tpbA}$ & protein tyrosine phosphatase $\mathrm{TpbA}$ & 2.84 & $2.72 \mathrm{E}-14$ \\
\hline PA1396 & two-component sensor & 2.83 & $2.27 \mathrm{E}-15$ \\
\hline PA3191 & two-component sensor & 2.78 & 1.99E-17 \\
\hline PA4781 & cyclic di-GMP phosphodiesterase & 2.73 & $5.26 \mathrm{E}-15$ \\
\hline ptrB & repressor PtrB & 2.73 & 7.96E-11 \\
\hline PA0172 & hypothetical protein & 2.67 & $2.31 \mathrm{E}-14$ \\
\hline$w s p C$ & biofilm formation methyltransferase WspC & 2.66 & 1.45E-17 \\
\hline hisJ & $\begin{array}{l}\text { histidine } A B C \text { transporter substrate-binding } \\
\text { protein HisJ }\end{array}$ & 2.65 & $3.14 \mathrm{E}-13$ \\
\hline PA0267 & hypothetical protein & 2.63 & 3.35E-17 \\
\hline pfes & two-component sensor histidine kinase PfeS & 2.60 & $2.18 \mathrm{E}-12$ \\
\hline PA1243 & sensor/response regulator hybrid protein & 2.59 & $1.14 \mathrm{E}-15$ \\
\hline PA1854 & hypothetical protein & 2.56 & $4.57 \mathrm{E}-13$ \\
\hline PA2882 & two-component sensor & 2.51 & $3.76 \mathrm{E}-14$ \\
\hline PA2561 & methyl-accepting chemotaxis protein $\mathrm{CtpH}$ & 2.49 & $6.07 \mathrm{E}-14$ \\
\hline PA4036 & two-component sensor & 2.47 & $1.12 \mathrm{E}-16$ \\
\hline PA4955 & hypothetical protein & 2.38 & $5.23 \mathrm{E}-14$ \\
\hline PA1260 & $\begin{array}{l}\text { amino acid ABC transporter substrate-binding } \\
\text { protein }\end{array}$ & 2.27 & $3.11 \mathrm{E}-07$ \\
\hline PA4112 & sensor/response regulator hybrid protein & 2.27 & $6.06 \mathrm{E}-13$ \\
\hline PA2867 & chemotaxis transducer & 2.26 & $2.33 E-13$ \\
\hline$p f e R$ & two-component response regulator $\mathrm{PfeR}$ & 2.25 & 1.30E-09 \\
\hline mucC & $\begin{array}{l}\text { positive regulator for alginate biosynthesis } \\
\text { MucC }\end{array}$ & 2.23 & $1.61 \mathrm{E}-07$ \\
\hline PA3077 & two-component response regulator & 2.21 & 2.63E-09 \\
\hline bfiR & protein BfiR & 2.21 & $2.89 \mathrm{E}-10$ \\
\hline PA3462 & sensor/response regulator hybrid protein & 2.19 & $2.48 \mathrm{E}-12$ \\
\hline
\end{tabular}




\begin{tabular}{|c|c|c|c|}
\hline$k d p E$ & two-component response regulator $\mathrm{KdpE}$ & 2.18 & $2.33 \mathrm{E}-08$ \\
\hline PA1851 & hypothetical protein & 2.16 & $2.72 \mathrm{E}-0 \mathrm{~S}$ \\
\hline PA2200 & hypothetical protein & 2.16 & $1.19 \mathrm{E}-08$ \\
\hline PA5442 & hypothetical protein & 2.14 & $1.31 \mathrm{E}-12$ \\
\hline PA1157 & two-component response regulator & 2.14 & $4.69 \mathrm{E}-06$ \\
\hline PA2654 & chemotaxis transducer & 2.10 & $7.08 \mathrm{E}-05$ \\
\hline pelD & pellicle/biofilm biosynthesis protein PelD & 2.10 & $1.35 \mathrm{E}-08$ \\
\hline PA3204 & two-component response regulator & 2.10 & $7.37 \mathrm{E}-06$ \\
\hline PA2652 & methyl-accepting chemotaxis protein & 2.10 & $2.34 \mathrm{E}-10$ \\
\hline PA4074 & transcriptional regulator & 2.05 & $7.83 \mathrm{E}-0 \mathrm{~g}$ \\
\hline PA3206 & two-component sensor & 2.04 & $1.43 \mathrm{E}-0 \mathrm{~S}$ \\
\hline chpC & chemotaxis protein & 2.03 & $4.53 \mathrm{E}-08$ \\
\hline \multicolumn{4}{|c|}{ Transcription } \\
\hline PA1884 & transcriptional regulator & 5.93 & $6.65 \mathrm{E}-35$ \\
\hline PA2383 & transcriptional regulator & 5.68 & $1.20 \mathrm{E}-39$ \\
\hline PA1351 & ECF subfamily sigma-70 factor & 5.47 & $2.39 \mathrm{E}-43$ \\
\hline PA1399 & transcriptional regulator & 5.24 & $9.36 \mathrm{E}-46$ \\
\hline PA2469 & transcriptional regulator & 5.19 & $1.34 \mathrm{E}-42$ \\
\hline PA2681 & transcriptional regulator & 5.06 & $5.54 \mathrm{E}-36$ \\
\hline PA2489 & transcriptional regulator & 4.95 & $3.11 \mathrm{E}-31$ \\
\hline PA0739 & transcriptional regulator & 4.87 & $1.48 \mathrm{E}-37$ \\
\hline PA2497 & transcriptional regulator & 4.53 & $1.13 \mathrm{E}-34$ \\
\hline PA1264 & transcriptional regulator & 4.49 & $8.55 \mathrm{E}-36$ \\
\hline PA2096 & transcriptional regulator & 4.43 & $8.02 \mathrm{E}-2 \varepsilon$ \\
\hline PA3381 & transcriptional regulator & 4.41 & $1.25 \mathrm{E}-33$ \\
\hline PA5431 & transcriptional regulator & 4.33 & $3.53 \mathrm{E}-33$ \\
\hline PA3420 & transcriptional regulator & 4.24 & $4.44 \mathrm{E}-4 \mathrm{C}$ \\
\hline PA1653 & transcriptional regulator & 4.23 & $1.84 \mathrm{E}-24$ \\
\hline PA2838 & transcriptional regulator & 4.23 & $2.05 \mathrm{E}-33$ \\
\hline PA2488 & transcriptional regulator & 4.19 & $1.92 \mathrm{E}-29$ \\
\hline PA2848 & transcriptional regulator & 4.18 & $5.80 \mathrm{E}-32$ \\
\hline PA1261 & transcriptional regulator & 4.14 & $5.18 \mathrm{E}-26$ \\
\hline PA1850 & transcriptional regulator & 4.13 & $6.48 \mathrm{E}-30$ \\
\hline PA1300 & ECF subfamily sigma-70 factor & 4.12 & $1.83 \mathrm{E}-24$ \\
\hline PA5116 & transcriptional regulator & 4.07 & $1.11 \mathrm{E}-24$ \\
\hline PA0279 & transcriptional regulator & 3.98 & $2.68 \mathrm{E}-31$ \\
\hline PA1050 & hypothetical protein & 3.98 & $1.39 \mathrm{E}-33$ \\
\hline PA2930 & transcriptional regulator & 3.97 & $2.24 \mathrm{E}-32$ \\
\hline cynR & DNA-binding transcriptional regulator CynR & 3.94 & $4.06 \mathrm{E}-24$ \\
\hline PA1223 & transcriptional regulator & 3.92 & $4.27 \mathrm{E}-2 \varepsilon$ \\
\hline PA4203 & transcriptional regulator & 3.91 & $1.68 \mathrm{E}-27$ \\
\hline
\end{tabular}




\begin{tabular}{|c|c|c|c|}
\hline PA3776 & transcriptional regulator & 3.91 & $2.22 \mathrm{E}-25$ \\
\hline PA1826 & transcriptional regulator & 3.90 & 1.97E-28 \\
\hline PA2121 & transcriptional regulator & 3.81 & 1.37E-19 \\
\hline PA3410 & ECF subfamily sigma-70 factor & 3.70 & $1.45 \mathrm{E}-22$ \\
\hline PA0149 & ECF subfamily sigma-70 factor & 3.69 & $1.80 \mathrm{E}-23$ \\
\hline PA3220 & transcriptional regulator & 3.67 & $7.05 \mathrm{E}-28$ \\
\hline PA1285 & transcriptional regulator & 3.66 & 1.93E-20 \\
\hline catR & transcriptional regulator CatR & 3.65 & $9.32 \mathrm{E}-25$ \\
\hline PA2665 & $\begin{array}{l}\text { anaerobic nitric oxide reductase transcriptional } \\
\text { regulator }\end{array}$ & 3.56 & $3.51 \mathrm{E}-30$ \\
\hline PA0512 & heme d1 biosynthesis protein $\mathrm{NirH}$ & 3.54 & 2.13E-21 \\
\hline PA1864 & transcriptional regulator & 3.52 & $5.43 \mathrm{E}-18$ \\
\hline PA2840 & ATP-dependent RNA helicase & 3.44 & $3.22 \mathrm{E}-26$ \\
\hline PA1467 & hypothetical protein & 3.37 & 7.49E-18 \\
\hline iciA & $\begin{array}{l}\text { chromosome replication initiation inhibitor } \\
\text { protein }\end{array}$ & 3.36 & 4.95E-23 \\
\hline PA1879 & hypothetical protein & 3.33 & $1.51 \mathrm{E}-11$ \\
\hline PA3565 & transcriptional regulator & 3.31 & $1.70 \mathrm{E}-24$ \\
\hline PA2267 & transcriptional regulator & 3.31 & 7.08E-19 \\
\hline PA2050 & RNA polymerase sigma factor & 3.25 & $5.09 \mathrm{E}-13$ \\
\hline PA0056 & transcriptional regulator & 3.22 & $3.41 \mathrm{E}-24$ \\
\hline PA2376 & transcriptional regulator & 3.18 & $2.58 \mathrm{E}-14$ \\
\hline chpD & transcriptional regulator & 3.16 & 1.47E-23 \\
\hline soxR & redox-sensitive transcriptional activator SoxR & 3.16 & 5.06E-16 \\
\hline PA1125 & NAD-dependent protein deacylase & 3.15 & 4.47E-21 \\
\hline PA2447 & transcriptional regulator & 3.15 & 1.94E-17 \\
\hline PA1182 & transcriptional regulator & 3.12 & 1.06E-17 \\
\hline PA3782 & transcriptional regulator & 3.11 & 2.14E-22 \\
\hline $\operatorname{trpl}$ & HTH-type transcriptional regulator Trpl & 3.08 & $3.54 \mathrm{E}-21$ \\
\hline PA4989 & transcriptional regulator & 3.08 & $1.49 \mathrm{E}-21$ \\
\hline PA2704 & transcriptional regulator & 3.08 & 4.00E-19 \\
\hline PA0791 & transcriptional regulator & 3.06 & 9.03E-19 \\
\hline PA0816 & transcriptional regulator & 3.05 & $9.88 \mathrm{E}-17$ \\
\hline PA1866 & hypothetical protein & 3.05 & 7.36E-19 \\
\hline PA3921 & transcriptional regulator & 3.04 & $2.20 \mathrm{E}-20$ \\
\hline PA1403 & transcriptional regulator & 2.99 & $9.51 \mathrm{E}-14$ \\
\hline PA0513 & heme $\mathrm{d} 1$ biosynthesis protein NirG & 2.99 & 1.79E-11 \\
\hline PA2879 & transcriptional regulator & 2.99 & $2.92 \mathrm{E}-13$ \\
\hline PA2093 & RNA polymerase sigma factor & 2.95 & 1.03E-11 \\
\hline PA0864 & transcriptional regulator & 2.94 & 2.03E-18 \\
\hline PA0701 & transcriptional regulator & 2.92 & $1.18 \mathrm{E}-19$ \\
\hline PA1226 & transcriptional regulator & 2.91 & 7.62E-17 \\
\hline
\end{tabular}




\begin{tabular}{|c|c|c|c|}
\hline PАЗ343 & transcriptional regulator & 2.90 & $5.46 \mathrm{E}-20$ \\
\hline PA0479 & transcriptional regulator & 2.89 & $3.08 \mathrm{E}-14$ \\
\hline PA1627 & transcriptional regulator & 2.89 & $1.93 \mathrm{E}-15$ \\
\hline PA0475 & transcriptional regulator & 2.88 & $1.78 \mathrm{E}-13$ \\
\hline PA2010 & transcriptional regulator & 2.85 & $1.51 \mathrm{E}-16$ \\
\hline PA4902 & transcriptional regulator & 2.84 & $6.88 \mathrm{E}-14$ \\
\hline PA0236 & transcriptional regulator & 2.83 & 3.65E-18 \\
\hline feml & ECF sigma factor Feml & 2.81 & $4.12 \mathrm{E}-11$ \\
\hline PA5342 & transcriptional regulator & 2.81 & $3.44 \mathrm{E}-17$ \\
\hline foxl & ECF sigma factor Foxl & 2.80 & 3.33E-13 \\
\hline PA5032 & transcriptional regulator & 2.80 & $5.25 \mathrm{E}-17$ \\
\hline PA1570 & transcriptional regulator & 2.77 & $3.32 \mathrm{E}-12$ \\
\hline PA1153 & hypothetical protein & 2.77 & $1.21 \mathrm{E}-10$ \\
\hline PA2484 & hypothetical protein & 2.77 & $1.97 \mathrm{E}-12$ \\
\hline PA3321 & transcriptional regulator & 2.76 & $2.39 \mathrm{E}-17$ \\
\hline PA4157 & transcriptional regulator & 2.73 & $1.21 \mathrm{E}-17$ \\
\hline PA2196 & transcriptional regulator & 2.70 & 4.06E-10 \\
\hline PA1067 & transcriptional regulator & 2.69 & $2.11 \mathrm{E}-13$ \\
\hline PA1229 & transcriptional regulator & 2.69 & $1.21 \mathrm{E}-13$ \\
\hline cifR & CifR protein & 2.67 & $1.16 \mathrm{E}-14$ \\
\hline PA2056 & transcriptional regulator & 2.67 & $9.23 \mathrm{E}-15$ \\
\hline PA1380 & transcriptional regulator & 2.67 & $4.51 \mathrm{E}-15$ \\
\hline PA1859 & transcriptional regulator & 2.66 & $5.68 \mathrm{E}-14$ \\
\hline PA3466 & ATP-dependent RNA helicase & 2.65 & $5.85 \mathrm{E}-11$ \\
\hline$r b s R$ & ribose operon repressor RbsR & 2.64 & $1.93 \mathrm{E}-15$ \\
\hline PA1413 & transcriptional regulator & 2.62 & $1.18 \mathrm{E}-13$ \\
\hline PA0121 & hypothetical protein & 2.62 & 1.42E-16 \\
\hline PA2115 & transcriptional regulator & 2.62 & $2.35 \mathrm{E}-14$ \\
\hline PA1142 & transcriptional regulator & 2.61 & $1.29 \mathrm{E}-08$ \\
\hline PA0477 & transcriptional regulator & 2.60 & $8.59 \mathrm{E}-16$ \\
\hline$m m s R$ & transcriptional regulator $\mathrm{MmsR}$ & 2.59 & $1.99 \mathrm{E}-13$ \\
\hline PA1263 & hypothetical protein & 2.59 & $5.27 \mathrm{E}-15$ \\
\hline PA3269 & transcriptional regulator & 2.57 & $4.84 \mathrm{E}-13$ \\
\hline PA2547 & transcriptional regulator & 2.57 & $4.42 \mathrm{E}-12$ \\
\hline PA1359 & transcriptional regulator & 2.55 & $7.46 \mathrm{E}-10$ \\
\hline PA0828 & transcriptional regulator & 2.54 & $2.81 \mathrm{E}-09$ \\
\hline PA2417 & transcriptional regulator & 2.54 & $1.78 \mathrm{E}-13$ \\
\hline PA5382 & transcriptional regulator & 2.53 & $9.45 \mathrm{E}-14$ \\
\hline PA5085 & transcriptional regulator & 2.50 & $8.06 \mathrm{E}-15$ \\
\hline PA1312 & transcriptional regulator & 2.50 & $2.51 \mathrm{E}-11$ \\
\hline PA3845 & transcriptional regulator & 2.46 & $7.26 \mathrm{E}-12$ \\
\hline
\end{tabular}




\begin{tabular}{|c|c|c|c|}
\hline PA1026 & hypothetical protein & 2.45 & $2.75 \mathrm{E}-10$ \\
\hline PA4174 & transcriptional regulator & 2.44 & 3.67E-12 \\
\hline PA1961 & transcriptional regulator & 2.41 & $3.50 \mathrm{E}-10$ \\
\hline PA2921 & transcriptional regulator & 2.41 & $1.52 \mathrm{E}-10$ \\
\hline PA2534 & transcriptional regulator & 2.40 & $6.87 \mathrm{E}-10$ \\
\hline PA3260 & transcriptional regulator & 2.38 & $1.12 \mathrm{E}-07$ \\
\hline PA0515 & heme d1 biosynthesis protein NirD & 2.37 & $5.23 \mathrm{E}-10$ \\
\hline PA2449 & transcriptional regulator & 2.37 & $1.54 \mathrm{E}-10$ \\
\hline PA1328 & transcriptional regulator & 2.36 & $3.57 \mathrm{E}-12$ \\
\hline PA2123 & transcriptional regulator & 2.34 & $6.10 \mathrm{E}-10$ \\
\hline PA4831 & transcriptional regulator & 2.34 & $6.60 \mathrm{E}-11$ \\
\hline$g / c C$ & DNA-binding transcriptional regulator GlcC & 2.33 & $8.02 \mathrm{E}-12$ \\
\hline PA2281 & transcriptional regulator & 2.32 & $2.81 \mathrm{E}-07$ \\
\hline PA4145 & transcriptional regulator & 2.28 & $4.50 \mathrm{E}-11$ \\
\hline aguR & transcriptional regulator AguR & 2.27 & $2.03 \mathrm{E}-08$ \\
\hline PA4987 & transcriptional regulator & 2.24 & $2.41 \mathrm{E}-09$ \\
\hline$p c a Q$ & transcriptional regulator $\mathrm{PcaQ}$ & 2.23 & $4.22 \mathrm{E}-11$ \\
\hline PA2766 & transcriptional regulator & 2.23 & $2.54 \mathrm{E}-08$ \\
\hline PA0253 & transcriptional regulator & 2.22 & $6.99 \mathrm{E}-10$ \\
\hline pruR & proline utilization regulator & 2.20 & $1.84 \mathrm{E}-08$ \\
\hline $\operatorname{arsR}$ & ArsR family transcriptional regulator & 2.19 & 2.64E-06 \\
\hline PA2076 & transcriptional regulator & 2.19 & $2.19 \mathrm{E}-06$ \\
\hline PA4341 & transcriptional regulator & 2.18 & $5.56 \mathrm{E}-10$ \\
\hline$a m p R$ & transcriptional regulator AmpR & 2.16 & $1.50 \mathrm{E}-10$ \\
\hline PA2270 & transcriptional regulator & 2.16 & $6.35 \mathrm{E}-07$ \\
\hline PA1141 & transcriptional regulator & 2.15 & $4.13 \mathrm{E}-10$ \\
\hline$p t x S$ & transcriptional regulator PtxS & 2.12 & 1.66E-06 \\
\hline PA5218 & transcriptional regulator & 2.11 & $3.34 \mathrm{E}-10$ \\
\hline PA0877 & transcriptional regulator & 2.08 & $1.05 \mathrm{E}-08$ \\
\hline PA1978 & glycerol metabolism activator & 2.06 & $7.44 \mathrm{E}-05$ \\
\hline nirL & heme d1 biosynthesis protein NirL & 2.06 & 4.79E-07 \\
\hline PA0181 & transcriptional regulator & 2.06 & 1.27E-08 \\
\hline PA2556 & transcriptional regulator & 2.06 & 5.17E-09 \\
\hline PA1138 & transcriptional regulator & 2.06 & $2.11 \mathrm{E}-09$ \\
\hline$p t x R$ & HTH-type transcriptional regulator PtxR & 2.04 & $6.35 \mathrm{E}-07$ \\
\hline PA0797 & transcriptional regulator & 2.02 & $3.90 \mathrm{E}-07$ \\
\hline PA1128 & transcriptional regulator & 2.02 & 1.64E-05 \\
\hline \multicolumn{4}{|c|}{ Translation, ribosomal structure and biogenesis } \\
\hline PA0814 & hypothetical protein & 6.99 & $6.33 E-47$ \\
\hline PA2499 & deaminase & 6.32 & $1.28 \mathrm{E}-40$ \\
\hline ans $A$ & L-asparaginase I & 5.26 & $1.51 \mathrm{E}-24$ \\
\hline
\end{tabular}




\begin{tabular}{|l|l|r|r|}
$P A 2179$ & hypothetical protein & 4.14 & $1.96 \mathrm{E}-23$ \\
\hline$P A 5470$ & peptide chain release factor-like protein & 3.43 & $3.97 \mathrm{E}-17$ \\
\hline IigT & 2'-5' RNA ligase & 3.24 & $1.85 \mathrm{E}-17$ \\
\hline aph & aminoglycoside 3-N-acetyltransferase & 3.11 & $2.66 \mathrm{E}-20$ \\
\hline$P A 4342$ & amidase & 3.06 & $2.31 \mathrm{E}-20$ \\
\hline$P A 4724$ & glutamyl-Q tRNA(Asp) synthetase & 3.01 & $2.35 \mathrm{E}-20$ \\
\hline$P A 3270$ & hypothetical protein & 2.94 & $2.84 \mathrm{E}-19$ \\
\hline$P A 4627$ & 16S rRNA methyltransferase & 2.89 & $2.28 \mathrm{E}-18$ \\
\hline tyrS & tyrosine--tRNA ligase & 2.80 & $3.37 \mathrm{E}-15$ \\
\hline$P A 0704$ & amidase & 2.57 & $8.25 \mathrm{E}-12$ \\
\hline fmt & methionyl-tRNA formyltransferase & 2.57 & $7.51 \mathrm{E}-15$ \\
\hline selB & selenocysteine-specific elongation factor & 2.48 & $1.45 \mathrm{E}-14$ \\
\hline$P A 5433$ & hypothetical protein & 2.45 & $1.71 \mathrm{E}-13$ \\
\hline & Ribosomal RNA small subunit & 2.42 & $1.12 \mathrm{E}-13$ \\
\hline$P A 0017$ & methyltransferase B & 2.34 & $9.18 \mathrm{E}-10$ \\
\hline$P A 0054$ & RNA 2'-phosphotransferase-like protein & 2.31 & $4.97 \mathrm{E}-10$ \\
\hline$P A 2043$ & hypothetical protein & 2.28 & $1.62 \mathrm{E}-12$ \\
\hline$P A 4617$ & hypothetical protein & 2.28 & $1.28 \mathrm{E}-13$ \\
\hline$P A 4163$ & amidase & 2.19 & $2.36 \mathrm{E}-09$ \\
\hline$P A 0868$ & peptidyl-tRNA hydrolase &
\end{tabular}


Table S3. List of genes downregulated in PANT by at least 2-fold with a false discovery rate (Padj-value) $<0.01$ during exposure to hexadecane-water interface for $24 \mathrm{~h}$ versus the control

\begin{tabular}{|c|c|c|c|}
\hline Gene & Description & $\begin{array}{l}\text { Fold } \\
\text { Change }\end{array}$ & Padj-value \\
\hline \multicolumn{4}{|c|}{ Amino acid transport and metabolism } \\
\hline $\operatorname{arcB}$ & ornithine carbamoyltransferase & -292.66 & 1.84E-62 \\
\hline$g \operatorname{lnK}$ & nitrogen regulatory protein $\mathrm{P}$-II 2 & -131.24 & 3.17E-76 \\
\hline $\operatorname{arcD}$ & arginine/ornithine antiporter & -124.31 & 7.41E-56 \\
\hline $\operatorname{arcA}$ & arginine deiminase & -111.40 & 1.48E-78 \\
\hline $\operatorname{arcC}$ & carbamate kinase & -68.39 & $2.00 \mathrm{E}-42$ \\
\hline serA & D-3-phosphoglycerate dehydrogenase & -43.83 & 1.03E-36 \\
\hline iscs & cysteine desulfurase & -34.16 & $1.35 \mathrm{E}-45$ \\
\hline phhA & phenylalanine 4-monooxygenase & -27.28 & $1.08 \mathrm{E}-137$ \\
\hline$g \ln A$ & glutamine synthetase & -25.23 & $3.89 \mathrm{E}-42$ \\
\hline$i / v H$ & acetolactate synthase small subunit & -23.26 & $8.43 \mathrm{E}-21$ \\
\hline cysE & O-acetylserine synthase & -22.67 & $1.31 \mathrm{E}-69$ \\
\hline serC & $\begin{array}{l}\text { 3-phosphoserine/phosphohydroxythreonine } \\
\text { aminotransferase }\end{array}$ & -19.60 & $1.24 \mathrm{E}-21$ \\
\hline braC & $\begin{array}{l}\text { branched-chain amino acid } \mathrm{ABC} \text { transporter } \\
\text { substrate-binding protein } \mathrm{BraC}\end{array}$ & -18.95 & 2.05E-73 \\
\hline hisE & phosphoribosyl-ATP pyrophosphatase & -18.49 & 5.69E-38 \\
\hline PA5547 & hypothetical protein & -17.30 & 1.07E-32 \\
\hline spuB & glutamine synthetase & -17.16 & $5.09 \mathrm{E}-50$ \\
\hline PA0604 & ABC transporter & -16.70 & $5.72 \mathrm{E}-25$ \\
\hline leuA & 2-isopropylmalate synthase & -15.27 & $1.02 \mathrm{E}-35$ \\
\hline spuD & $\begin{array}{l}\text { putrescine } A B C \text { transporter substrate-binding protein } \\
\text { SpuD }\end{array}$ & -15.26 & 9.77E-43 \\
\hline $\arg B$ & acetylglutamate kinase & -14.78 & 2.85E-84 \\
\hline pheA & $\begin{array}{l}\text { bifunctional chorismate mutase/prephenate } \\
\text { dehydratase }\end{array}$ & -14.31 & $3.56 \mathrm{E}-26$ \\
\hline hisG & ATP phosphoribosyltransferase & -13.94 & $4.93 \mathrm{E}-20$ \\
\hline ilvE & branched-chain amino acid aminotransferase & -12.04 & $1.15 \mathrm{E}-30$ \\
\hline hisA & $\begin{array}{l}\text { 1-(5-phosphoribosyl)-5-[(5- } \\
\text { phosphoribosylamino)methylideneamino] imidazole- } \\
\text { 4-carboxamide isomerase }\end{array}$ & -10.85 & 1.47E-26 \\
\hline $\operatorname{dad} A$ & D-amino acid dehydrogenase small subunit & -9.81 & $3.72 \mathrm{E}-84$ \\
\hline PA0605 & ABC transporter permease & -9.76 & $8.41 \mathrm{E}-12$ \\
\hline PA4913 & ABC transporter & -9.46 & $1.70 \mathrm{E}-15$ \\
\hline PA1750 & phospho-2-dehydro-3-deoxyheptonate aldolase & -9.34 & 4.07E-11 \\
\hline braF & ABC transporter ATP-binding protein & -9.22 & 2.62E-19 \\
\hline $\operatorname{trpG}$ & anthranilate synthase component II & -9.09 & 1.84E-20 \\
\hline $\operatorname{trpE}$ & anthranilate synthase component I & -8.99 & $4.35 \mathrm{E}-20$ \\
\hline
\end{tabular}




\begin{tabular}{|c|c|c|c|}
\hline PA1089 & hypothetical protein & -8.68 & 4.39E-11 \\
\hline speD & S-adenosylmethionine decarboxylase & -7.79 & $2.40 \mathrm{E}-10$ \\
\hline PA0006 & $\begin{array}{l}\text { D-glycero-beta-D-manno-heptose-1,7-bisphosphate } \\
\text { 7-phosphatase }\end{array}$ & -7.71 & 2.57E-11 \\
\hline PA5152 & $A B C$ transporter ATP-binding protein & -7.61 & $6.66 \mathrm{E}-14$ \\
\hline cysM & cysteine synthase B & -7.60 & $1.41 \mathrm{E}-16$ \\
\hline spuH & polyamine transporter Potl & -7.39 & $2.79 \mathrm{E}-12$ \\
\hline gcvH1 & glycine cleavage system protein $\mathrm{H}$ & -7.33 & 1.77E-21 \\
\hline metE & $\begin{array}{l}\text { 5-methyltetrahydropteroyltriglutamate--homocysteine } \\
\text { methyltransferase }\end{array}$ & -7.29 & $1.53 \mathrm{E}-57$ \\
\hline$P A 0606$ & $A B C$ transporter permease & -7.05 & $3.74 \mathrm{E}-16$ \\
\hline PA3602 & hypothetical protein & -7.01 & $1.22 \mathrm{E}-38$ \\
\hline $\arg G$ & argininosuccinate synthase & -6.91 & $2.19 \mathrm{E}-17$ \\
\hline spul & glutamine synthetase & -6.83 & $4.94 \mathrm{E}-51$ \\
\hline cysk & cysteine synthase $A$ & -6.83 & $4.48 \mathrm{E}-32$ \\
\hline aruE & succinylglutamate desuccinylase & -6.43 & $2.36 \mathrm{E}-53$ \\
\hline PA5378 & hypothetical protein & -6.29 & $4.08 \mathrm{E}-15$ \\
\hline aruB & $\mathrm{N}$-succinylarginine dihydrolase & -6.28 & $5.41 \mathrm{E}-44$ \\
\hline glyA3 & serine hydroxymethyltransferase & -6.28 & $7.71 \mathrm{E}-24$ \\
\hline PA5370 & major facilitator superfamily transporter & -6.24 & $2.71 \mathrm{E}-14$ \\
\hline spuE & $\begin{array}{l}\text { spermidine } A B C \text { transporter substrate-binding protein } \\
\text { SpuE }\end{array}$ & -6.13 & $6.48 \mathrm{E}-13$ \\
\hline PA0602 & $A B C$ transporter & -6.10 & 6.07E-11 \\
\hline PA4796 & hypothetical protein & -6.09 & 1.69E-57 \\
\hline putA & $\begin{array}{l}\text { bifunctional proline dehydrogenase/pyrroline-5- } \\
\text { carboxylate dehydrogenase }\end{array}$ & -5.82 & 3.47E-64 \\
\hline PA2776 & hypothetical protein & -5.80 & 1.77E-21 \\
\hline PA5376 & $A B C$ transporter ATP-binding protein & -5.78 & $4.06 \mathrm{E}-31$ \\
\hline gloA1 & lactoylglutathione lyase & -5.73 & $2.15 E-36$ \\
\hline aroQ1 & 3-dehydroquinate dehydratase & -5.64 & $1.49 \mathrm{E}-10$ \\
\hline PA3255 & hypothetical protein & -5.60 & $1.26 \mathrm{E}-16$ \\
\hline gloA3 & lactoylglutathione lyase & -5.59 & 9.97E-28 \\
\hline lysC & aspartokinase & -5.58 & $2.47 \mathrm{E}-22$ \\
\hline PA1810 & $\mathrm{ABC}$ transporter & -5.53 & $2.52 \mathrm{E}-13$ \\
\hline PA5283 & transcriptional regulator & -5.51 & 4.77E-20 \\
\hline asd & aspartate-semialdehyde dehydrogenase & -5.50 & 1.33E-22 \\
\hline $\operatorname{aroP} 1$ & aromatic amino acid transporter AroP & -5.45 & 3.90E-07 \\
\hline metH & B12-dependent methionine synthase & -5.43 & $3.50 \mathrm{E}-17$ \\
\hline PA4500 & $A B C$ transporter & -5.41 & $1.76 \mathrm{E}-10$ \\
\hline$P A 0323$ & $\mathrm{ABC}$ transporter & -5.33 & $3.51 \mathrm{E}-09$ \\
\hline PA0484 & hypothetical protein & -5.15 & 6.74E-08 \\
\hline PA2609 & hypothetical protein & -5.04 & $4.36 \mathrm{E}-25$ \\
\hline$g d h B$ & NAD-specific glutamate dehydrogenase & -5.01 & $2.25 \mathrm{E}-43$ \\
\hline
\end{tabular}




\begin{tabular}{|c|c|c|c|}
\hline hisC2 & histidinol-phosphate aminotransferase & -4.94 & 4.33E-26 \\
\hline braG & ABC transporter ATP-binding protein & -4.89 & $1.46 \mathrm{E}-21$ \\
\hline pepP & aminopeptidase & -4.88 & $2.22 \mathrm{E}-37$ \\
\hline PA4912 & branched-chain amino acid $\mathrm{ABC}$ transporter & -4.86 & $9.34 \mathrm{E}-11$ \\
\hline hisF1 & imidazole glycerol phosphate synthase subunit HisF & -4.82 & $9.81 \mathrm{E}-22$ \\
\hline PA4715 & aminotransferase & -4.81 & $8.61 \mathrm{E}-27$ \\
\hline $\operatorname{aspA}$ & aspartate ammonia-lyase & -4.80 & $1.02 \mathrm{E}-15$ \\
\hline PA0789 & amino acid permease & -4.77 & $1.40 \mathrm{E}-16$ \\
\hline dapD & $\begin{array}{l}\text { 2,3,4,5-tetrahydropyridine-2,6-dicarboxylate } \mathrm{N} \text { - } \\
\text { succinyltransferase }\end{array}$ & -4.76 & $6.18 \mathrm{E}-18$ \\
\hline ItaA & low specificity l-threonine aldolase & -4.74 & $7.86 \mathrm{E}-36$ \\
\hline potD & $\begin{array}{l}\text { polyamine } A B C \text { transporter substrate-binding protein } \\
\text { PotD }\end{array}$ & -4.73 & 1.35E-05 \\
\hline spuG & polyamine transporter $\mathrm{PotH}$ & -4.72 & $9.17 \mathrm{E}-09$ \\
\hline $\operatorname{aot} Q$ & arginine/ornithine $A B C$ transporter permease $A o t Q$ & -4.59 & $1.45 \mathrm{E}-05$ \\
\hline PA5249 & hypothetical protein & -4.50 & 3.97E-24 \\
\hline metF & 5,10-methylenetetrahydrofolate reductase & -4.40 & $1.29 \mathrm{E}-18$ \\
\hline speE & polyamine aminopropyltransferase & -4.29 & $1.32 \mathrm{E}-08$ \\
\hline $\operatorname{aroB}$ & 3-dehydroquinate synthase & -4.21 & $2.71 \mathrm{E}-32$ \\
\hline braE & $\begin{array}{l}\text { branched-chain amino acid ABC transporter } \\
\text { permease BraE }\end{array}$ & -4.20 & 2.43E-17 \\
\hline PA4757 & leucine export protein LeuE & -4.16 & $2.58 \mathrm{E}-16$ \\
\hline speC & ornithine decarboxylase & -4.02 & $7.88 \mathrm{E}-06$ \\
\hline PA1811 & solute-binding protein & -3.94 & $4.49 \mathrm{E}-10$ \\
\hline speA & arginine decarboxylase & -3.91 & 1.89E-27 \\
\hline hisC1 & histidinol-phosphate aminotransferase & -3.85 & 2.65E-09 \\
\hline PA5095 & $A B C$ transporter permease & -3.75 & $3.97 \mathrm{E}-15$ \\
\hline thrC & threonine synthase & -3.72 & 3.07E-15 \\
\hline PA2828 & aminotransferase & -3.63 & $2.69 \mathrm{E}-07$ \\
\hline PA5377 & $A B C$ transporter permease & -3.54 & $3.92 \mathrm{E}-16$ \\
\hline PA0266 & 5-aminovalerate aminotransferase DavT & -3.53 & 3.47E-22 \\
\hline kynA & tryptophan 2,3-dioxygenase & -3.49 & $7.34 \mathrm{E}-15$ \\
\hline PA2040 & glutamine synthetase & -3.45 & $3.34 \mathrm{E}-15$ \\
\hline$g d h A$ & glutamate dehydrogenase & -3.45 & $6.42 \mathrm{E}-19$ \\
\hline PA2831 & hypothetical protein & -3.43 & $5.64 \mathrm{E}-15$ \\
\hline PA4910 & $A B C$ transporter ATP-binding protein & -3.40 & $1.29 \mathrm{E}-08$ \\
\hline PA3890 & $A B C$ transporter permease & -3.39 & 4.26E-12 \\
\hline PA3389 & ring-cleaving dioxygenase & -3.38 & $1.51 \mathrm{E}-04$ \\
\hline $\operatorname{trpD}$ & anthranilate phosphoribosyltransferase & -3.38 & 7.10E-09 \\
\hline PA5317 & dipeptide $A B C$ transporter substrate-binding protein & -3.31 & $5.08 \mathrm{E}-14$ \\
\hline PA0603 & $A B C$ transporter ATP-binding protein & -3.30 & $1.30 \mathrm{E}-11$ \\
\hline hisl & phosphoribosyl-AMP cyclohydrolase & -3.27 & $3.64 \mathrm{E}-13$ \\
\hline
\end{tabular}




\begin{tabular}{|c|c|c|c|}
\hline PA3766 & aromatic amino acid transporter & $\mid-3.20$ & $3.43 \mathrm{E}-06$ \\
\hline PA1491 & transporter & -3.07 & $3.36 \mathrm{E}-05$ \\
\hline PA4909 & ABC transporter ATP-binding protein & -3.04 & $1.97 \mathrm{E}-12$ \\
\hline prlC & oligopeptidase A & -3.02 & $2.50 \mathrm{E}-19$ \\
\hline phhC & aromatic amino acid aminotransferase & -3.01 & $6.76 \mathrm{E}-15$ \\
\hline aruC & acetylornithine aminotransferase & -2.99 & $2.97 \mathrm{E}-16$ \\
\hline PA2041 & amino acid permease & -2.94 & $2.03 \mathrm{E}-04$ \\
\hline PA3798 & aminotransferase & -2.94 & $8.96 \mathrm{E}-12$ \\
\hline IysP & lysine-specific permease & -2.93 & $2.56 \mathrm{E}-09$ \\
\hline leuD & isopropylmalate isomerase small subunit & -2.90 & $3.87 \mathrm{E}-16$ \\
\hline PA2114 & major facilitator superfamily transporter & -2.88 & $6.65 \mathrm{E}-12$ \\
\hline hisM & histidine $\mathrm{ABC}$ transporter permease HisM & -2.84 & $1.51 \mathrm{E}-04$ \\
\hline PA2042 & serine/threonine transporter SstT & -2.82 & $1.48 \mathrm{E}-07$ \\
\hline PA2393 & dipeptidase & -2.81 & $1.38 \mathrm{E}-07$ \\
\hline braB & branched-chain amino acid transporter & -2.73 & 4.99E-09 \\
\hline PA2592 & spermidine/putrescine-binding protein & -2.73 & 5.94E-04 \\
\hline PA1009 & hypothetical protein & -2.72 & 1.64E-06 \\
\hline PA0325 & $A B C$ transporter permease & -2.70 & $3.45 \mathrm{E}-10$ \\
\hline PA1916 & amino acid permease & -2.68 & $1.79 \mathrm{E}-08$ \\
\hline thrH & phosphoserine phosphatase & -2.64 & 7.36E-03 \\
\hline PA4858 & hypothetical protein & -2.62 & $8.31 \mathrm{E}-06$ \\
\hline PA5326 & hypothetical protein & -2.56 & $4.16 \mathrm{E}-08$ \\
\hline PA4502 & $A B C$ transporter & -2.55 & $1.23 \mathrm{E}-10$ \\
\hline PA5137 & hypothetical protein & -2.54 & $3.40 \mathrm{E}-10$ \\
\hline$p v d N$ & pyoverdine biosynthesis protein PvdN & -2.48 & $1.57 \mathrm{E}-08$ \\
\hline phnW & 2-aminoethylphosphonate--pyruvate transaminase & -2.47 & $9.56 \mathrm{E}-10$ \\
\hline PA3253 & $A B C$ transporter permease & -2.46 & 9.79E-05 \\
\hline IdcA & $\begin{array}{l}\text { Iysine-specific pyridoxal 5'-phosphate-dependent } \\
\text { carboxylase LdcA }\end{array}$ & -2.45 & $3.21 \mathrm{E}-13$ \\
\hline PA3236 & glycine betaine-binding protein & -2.41 & $2.70 \mathrm{E}-07$ \\
\hline $\operatorname{trp} B$ & tryptophan synthase subunit beta & -2.39 & $2.42 \mathrm{E}-12$ \\
\hline PA3261 & hypothetical protein & -2.39 & 2.91E-07 \\
\hline aroK & shikimate kinase & -2.38 & $2.32 \mathrm{E}-10$ \\
\hline aotM & arginine/ornithine $\mathrm{ABC}$ transporter permease AotM & -2.37 & 1.06E-06 \\
\hline PA0313 & L-cysteine ABC transporter protein YecS & -2.34 & 1.23E-09 \\
\hline pepA & leucyl aminopeptidase & -2.34 & $5.65 \mathrm{E}-10$ \\
\hline gltB & glutamate synthase subunit alpha & -2.31 & $2.24 \mathrm{E}-13$ \\
\hline leuC & 3-isopropylmalate dehydratase large subunit & -2.30 & $5.02 \mathrm{E}-10$ \\
\hline hisB & imidazoleglycerol-phosphate dehydratase & -2.22 & 1.07E-08 \\
\hline PA5074 & $A B C$ transporter ATP-binding protein & -2.20 & 5.89E-04 \\
\hline PA5509 & hypothetical protein & -2.20 & $2.26 \mathrm{E}-08$ \\
\hline$g c v H 2$ & glycine cleavage system protein $\mathrm{H}$ & -2.20 & 8.61E-04 \\
\hline
\end{tabular}




\begin{tabular}{|c|c|c|c|}
\hline PA1256 & amino acid $A B C$ transporter ATP binding protein & -2.20 & 1.73E-05 \\
\hline spuF & polyamine transporter PotG & -2.19 & $4.72 \mathrm{E}-06$ \\
\hline PA2897 & transcriptional regulator & -2.18 & $7.11 \mathrm{E}-10$ \\
\hline pchB & isochorismate-pyruvate lyase & -2.15 & $1.92 \mathrm{E}-06$ \\
\hline PA3641 & amino acid permease & -2.14 & 1.32E-05 \\
\hline PA4548 & D-amino acid oxidase & -2.13 & $2.47 \mathrm{E}-06$ \\
\hline PA5396 & hypothetical protein & -2.08 & 9.36E-05 \\
\hline pchP & phosphorylcholine phosphatase & -2.06 & $5.01 \mathrm{E}-06$ \\
\hline PA4023 & transporter & -2.03 & $1.31 \mathrm{E}-08$ \\
\hline PA4960 & phosphoserine phosphatase & -2.03 & $4.78 \mathrm{E}-09$ \\
\hline $\operatorname{trpF}$ & N-(5'-phosphoribosyl)anthranilate isomerase & -2.02 & 3.57E-06 \\
\hline \multicolumn{4}{|c|}{ Carbohydrate transport and metabolism } \\
\hline ppsA & phosphoenolpyruvate synthase & -20.39 & $1.65 \mathrm{E}-28$ \\
\hline glmM & phosphoglucosamine mutase & -17.34 & $4.81 \mathrm{E}-16$ \\
\hline PA4425 & phosphoheptose isomerase & -14.77 & $8.79 \mathrm{E}-12$ \\
\hline eno & enolase & -12.87 & $5.12 \mathrm{E}-62$ \\
\hline PA5167 & C4-dicarboxylate-binding protein & -12.24 & $9.79 \mathrm{E}-18$ \\
\hline tpiA & triosephosphate isomerase & -11.86 & $4.35 \mathrm{E}-23$ \\
\hline rmd & oxidoreductase Rmd & -8.44 & $4.12 \mathrm{E}-12$ \\
\hline$f d a$ & fructose-1,6-bisphosphate aldolase & -7.61 & 7.00E-27 \\
\hline PA4466 & phosphoryl carrier protein & -7.40 & 4.99E-29 \\
\hline gapA & glyceraldehyde 3-phosphate dehydrogenase & -7.04 & $2.47 \mathrm{E}-32$ \\
\hline$f b p$ & fructose-1,6-bisphosphatase & -6.93 & $3.66 \mathrm{E}-16$ \\
\hline PA1517 & hypothetical protein & -6.78 & 7.97E-13 \\
\hline PA3295 & HIT family protein & -6.27 & $6.02 \mathrm{E}-09$ \\
\hline PA5168 & dicarboxylate transporter & -5.87 & $1.31 \mathrm{E}-10$ \\
\hline$r f a D$ & ADP-L-glycero-D-mannoheptose-6-epimerase & -5.78 & 3.37E-26 \\
\hline pykA & pyruvate kinase & -5.55 & $6.53 \mathrm{E}-46$ \\
\hline$r b s B$ & ribose $A B C$ transporter substrate-binding protein & -5.19 & $2.30 \mathrm{E}-40$ \\
\hline PA4616 & C4-dicarboxylate-binding protein & -4.91 & 2.13E-08 \\
\hline pgi & glucose-6-phosphate isomerase & -4.78 & 1.07E-25 \\
\hline$g / p R$ & glycerol-3-phosphate regulon repressor & -4.41 & $1.54 \mathrm{E}-20$ \\
\hline wzm & LPS efflux transporter membrane protein & -4.35 & $2.12 \mathrm{E}-09$ \\
\hline tal & transaldolase B & -4.31 & 4.47E-20 \\
\hline rpe & ribulose-phosphate 3-epimerase & -4.19 & 1.45E-17 \\
\hline PA1683 & methylthioribulose-1-phosphate dehydratase & -4.00 & $1.13 \mathrm{E}-10$ \\
\hline$g / m R$ & GImR transcriptional regulator & -3.73 & $4.38 \mathrm{E}-11$ \\
\hline PA3001 & glyceraldehyde-3-phosphate dehydrogenase & -3.29 & 3.67E-13 \\
\hline PA1490 & transcriptional regulator & -3.20 & 1.97E-09 \\
\hline PA2678 & $A B C$ transporter permease & -3.13 & $2.91 \mathrm{E}-05$ \\
\hline$i l v D$ & dihydroxy-acid dehydratase & -2.92 & $1.04 \mathrm{E}-17$ \\
\hline
\end{tabular}




\begin{tabular}{|c|c|c|c|}
\hline PA5160 & drug efflux transporter & -2.80 & 3.09E-09 \\
\hline PA3188 & sugar $A B C$ transporter permease & -2.70 & $9.79 \mathrm{E}-05$ \\
\hline$z w f$ & glucose-6-phosphate 1-dehydrogenase & -2.62 & $5.39 \mathrm{E}-11$ \\
\hline tktA & transketolase & -2.57 & $5.60 \mathrm{E}-12$ \\
\hline PA1293 & hypothetical protein & -2.54 & $4.51 \mathrm{E}-07$ \\
\hline PA3430 & aldolase & -2.51 & $6.65 \mathrm{E}-12$ \\
\hline$g / p F$ & glycerol uptake facilitator protein & -2.51 & $1.20 \mathrm{E}-07$ \\
\hline PA4834 & hypothetical protein & -2.49 & $2.64 \mathrm{E}-09$ \\
\hline PA1831 & hypothetical protein & -2.24 & $2.88 \mathrm{E}-10$ \\
\hline $\operatorname{prpB}$ & 2-methylisocitrate lyase & -2.09 & $2.60 \mathrm{E}-08$ \\
\hline PA0458 & major facilitator superfamily transporter & -2.06 & 1.03E-08 \\
\hline \multicolumn{4}{|c|}{ Cell cycle control, cell division, chromosome partitioning } \\
\hline ftsZ & cell division protein FtsZ & -139.60 & 1.37E-97 \\
\hline$f l e N$ & flagellar synthesis regulator FleN & -22.86 & $1.09 \mathrm{E}-65$ \\
\hline ftsE & cell division protein FtsE & -16.29 & $1.38 \mathrm{E}-31$ \\
\hline ftsL & cell division protein FtsL & -16.01 & $6.84 \mathrm{E}-24$ \\
\hline $\min D$ & cell division inhibitor MinD & -15.01 & $1.26 \mathrm{E}-18$ \\
\hline ftsA & cell division protein FtsA & -11.34 & 1.15E-75 \\
\hline $\min E$ & cell division topological specificity factor MinE & -7.58 & $9.48 \mathrm{E}-11$ \\
\hline PA1366 & hypothetical protein & -5.26 & 3.93E-10 \\
\hline PA1192 & tRNA 2-thiocytidine biosynthesis protein TtcA & -5.11 & $8.53 \mathrm{E}-10$ \\
\hline PA3634 & cell division protein FtsB & -3.92 & $8.28 \mathrm{E}-10$ \\
\hline$f t s W$ & cell division protein FtsW & -3.88 & $6.27 \mathrm{E}-15$ \\
\hline zipA & cell division protein ZipA & -3.54 & $1.70 \mathrm{E}-21$ \\
\hline PA3201 & intracellular septation protein $\mathrm{A}$ & -3.50 & 1.10E-12 \\
\hline soj & chromosome partitioning protein Soj & -3.46 & $1.78 \mathrm{E}-10$ \\
\hline ftsk & DNA translocase FtsK & -3.25 & $2.42 \mathrm{E}-11$ \\
\hline PA5028 & hypothetical protein & -2.73 & $1.69 \mathrm{E}-09$ \\
\hline rodA & rod shape-determining protein & -2.62 & $3.25 \mathrm{E}-10$ \\
\hline PA4686 & hypothetical protein & -2.39 & $5.80 \mathrm{E}-10$ \\
\hline PA2972 & hypothetical protein & -2.23 & $8.48 \mathrm{E}-06$ \\
\hline gidA & $\begin{array}{l}\text { tRNA uridine 5-carboxymethylaminomethyl } \\
\text { modification protein GidA }\end{array}$ & -2.14 & 2.90E-08 \\
\hline \multicolumn{4}{|c|}{ Cell motility } \\
\hline$f l i D$ & B-type flagellar hook-associated protein & -25.96 & 1.79E-29 \\
\hline cheZ & protein phosphatase CheZ & -24.80 & $5.34 \mathrm{E}-26$ \\
\hline$f l g B$ & flagellar basal-body rod protein FlgB & -21.37 & $6.37 \mathrm{E}-28$ \\
\hline$f l g G$ & flagellar basal body rod protein FlgG & -17.71 & $4.63 \mathrm{E}-45$ \\
\hline $\mathrm{flg} C$ & flagellar basal body rod protein FlgC & -15.03 & 8.95E-18 \\
\hline$f l g D$ & flagellar basal body rod modification protein & -13.61 & $5.98 \mathrm{E}-18$ \\
\hline$f l g L$ & flagellar hook-associated protein FlgL & -12.22 & $5.33 E-33$ \\
\hline pilB & type 4 fimbrial biogenesis protein PilB & -11.63 & $2.54 \mathrm{E}-22$ \\
\hline
\end{tabular}




\begin{tabular}{|c|c|c|c|}
\hline pilN & type 4 fimbrial biogenesis protein PilN & -11.37 & $1.20 \mathrm{E}-12$ \\
\hline PA1093 & hypothetical protein & -10.17 & $1.20 \mathrm{E}-10$ \\
\hline $\mathrm{flgF}$ & flagellar basal body rod protein FlgF & -10.07 & 8.24E-21 \\
\hline pilW & type 4 fimbrial biogenesis protein PilW & -9.97 & $1.35 \mathrm{E}-16$ \\
\hline$f i m U$ & type 4 fimbrial biogenesis protein FimU & -9.83 & $5.27 \mathrm{E}-12$ \\
\hline fliM & flagellar motor switch protein FliM & -8.88 & $1.70 \mathrm{E}-25$ \\
\hline$f l i Q$ & flagellar biosynthesis protein FliQ & -6.87 & $1.82 \mathrm{E}-15$ \\
\hline flic & B-type flagellin & -6.67 & $1.92 \mathrm{E}-14$ \\
\hline PA1464 & purine-binding chemotaxis protein & -6.58 & $1.27 \mathrm{E}-35$ \\
\hline pilV & type 4 fimbrial biogenesis protein PilV & -6.31 & $8.35 \mathrm{E}-07$ \\
\hline$f l g E$ & flagellar hook protein FlgE & -6.07 & $9.69 \mathrm{E}-22$ \\
\hline IppL & lipopeptide LppL & -5.89 & $1.38 \mathrm{E}-12$ \\
\hline pilT & twitching motility protein PilT & -5.79 & $3.04 \mathrm{E}-17$ \\
\hline pilX & type 4 fimbrial biogenesis protein PilX & -5.74 & $1.05 \mathrm{E}-17$ \\
\hline PA1442 & flagellar basal body protein FliL & -5.64 & $4.72 \mathrm{E}-20$ \\
\hline fIhA & flagellar biosynthesis protein FlhA & -5.63 & $1.29 \mathrm{E}-17$ \\
\hline$f l g K$ & flagellar hook-associated protein FlgK & -5.55 & $3.69 \mathrm{E}-45$ \\
\hline pilE & type 4 fimbrial biogenesis protein PilE & -4.87 & $8.02 \mathrm{E}-09$ \\
\hline fliG & flagellar motor switch protein FliG & -4.67 & $1.33 \mathrm{E}-14$ \\
\hline pill & twitching motility protein Pill & -4.47 & $4.71 \mathrm{E}-13$ \\
\hline PA5233 & flagellar basal body protein FliL & -4.43 & 2.95E-19 \\
\hline $\mathrm{flgH}$ & flagellar basal body L-ring protein & -4.29 & 1.47E-29 \\
\hline pilP & type 4 fimbrial biogenesis protein PilP & -4.14 & $2.23 \mathrm{E}-06$ \\
\hline PA4039 & hypothetical protein & -3.91 & $4.24 \mathrm{E}-10$ \\
\hline pilZ & type 4 fimbrial biogenesis protein PilZ & -3.80 & $1.58 \mathrm{E}-09$ \\
\hline flgl & flagellar basal body P-ring protein & -3.74 & $2.83 \mathrm{E}-20$ \\
\hline cupC3 & usher CupC3 & -3.10 & $6.83 \mathrm{E}-05$ \\
\hline fliR & flagellar biosynthesis protein FliR & -2.24 & $3.11 \mathrm{E}-06$ \\
\hline$m o t A$ & flagellar motor protein MotA & -2.14 & $1.69 \mathrm{E}-07$ \\
\hline \multicolumn{4}{|c|}{ Cell wall/membrane/envelope biogenesis } \\
\hline pilk & methyltransferase PilK & -2.10 & 1.24E-05 \\
\hline oprH & $\begin{array}{l}\text { PhoP/Q and low Mg2+ inducible outer membrane } \\
\text { protein } \mathrm{H} 1\end{array}$ & -2116.31 & $3.90 \mathrm{E}-115$ \\
\hline oprF & outer membrane porin $\mathrm{F}$ & -438.20 & 5.04E-197 \\
\hline oprL & peptidoglycan associated lipoprotein OprL & -158.49 & $5.05 \mathrm{E}-82$ \\
\hline$m s c L$ & large-conductance mechanosensitive channel & -50.41 & $2.84 \mathrm{E}-56$ \\
\hline IpxC & $\begin{array}{l}\text { UDP-3-O-[3-hydroxymyristoyl] N-acetylglucosamine } \\
\text { deacetylase }\end{array}$ & -48.55 & 3.34E-41 \\
\hline oprG & outer membrane protein OprG & -46.03 & $1.82 \mathrm{E}-80$ \\
\hline prc & tail-specific protease & -34.65 & $1.31 \mathrm{E}-40$ \\
\hline IpXA & $\begin{array}{l}\text { acyl-[acyl-carrier-protein]--UDP-N-acetylglucosamine } \\
\text { O-acyltransferase }\end{array}$ & -32.43 & $2.13 \mathrm{E}-44$ \\
\hline
\end{tabular}




\begin{tabular}{|c|c|c|c|}
\hline IspA & lipoprotein signal peptidase & -21.73 & 2.35E-41 \\
\hline $\mathrm{rm} / \mathrm{C}$ & dTDP-4-dehydrorhamnose 3,5-epimerase & -20.86 & $3.49 \mathrm{E}-34$ \\
\hline PA3647 & hypothetical protein & -19.25 & $7.50 \mathrm{E}-41$ \\
\hline tolA & translocation protein TolA & -18.22 & 1.19E-30 \\
\hline PA4420 & S-adenosyl-methyltransferase MraW & -16.88 & $1.20 \mathrm{E}-32$ \\
\hline lytB & 4-hydroxy-3-methylbut-2-enyl diphosphate reductase & -15.41 & $6.59 \mathrm{E}-18$ \\
\hline$m r a Y$ & phospho-N-acetylmuramoyl-pentapeptide-transferase & -13.31 & $8.26 \mathrm{E}-33$ \\
\hline $\operatorname{gid} B$ & 16S rRNA methyltransferase GidB & -13.07 & $5.91 \mathrm{E}-17$ \\
\hline$r m / A$ & glucose-1-phosphate thymidylyltransferase & -12.44 & $7.29 \mathrm{E}-21$ \\
\hline ftsQ & cell division protein $\mathrm{FtsQ}$ & -11.69 & 1.36E-78 \\
\hline$c m p X$ & hypothetical protein & -11.25 & $1.93 \mathrm{E}-25$ \\
\hline opr86 & outer membrane protein Opr86 & -10.95 & $2.95 \mathrm{E}-14$ \\
\hline PA5546 & hypothetical protein & -9.74 & 4.36E-37 \\
\hline wapR & alpha-1,3-rhamnosyltransferase WapR & -9.62 & $2.47 \mathrm{E}-17$ \\
\hline ftsl & penicillin-binding protein 3 & -9.59 & $4.16 \mathrm{E}-58$ \\
\hline PA2800 & hypothetical protein & -9.57 & 1.33E-19 \\
\hline wbpM & nucleotide sugar epimerase/dehydratase $\mathrm{WbpM}$ & -8.62 & $7.81 \mathrm{E}-13$ \\
\hline PA1198 & hypothetical protein & -8.48 & $1.40 \mathrm{E}-13$ \\
\hline PA0938 & hypothetical protein & -8.40 & $5.20 \mathrm{E}-14$ \\
\hline PA4457 & arabinose-5-phosphate isomerase KdsD & -8.11 & $6.25 \mathrm{E}-16$ \\
\hline gmd & GDP-mannose 4,6-dehydratase & -8.00 & $5.52 \mathrm{E}-15$ \\
\hline dacC & D-ala-D-ala-carboxypeptidase & -7.93 & $1.84 \mathrm{E}-59$ \\
\hline IepA & elongation factor 4 & -7.79 & $2.24 \mathrm{E}-16$ \\
\hline PA0664 & hypothetical protein & -7.15 & $1.30 \mathrm{E}-09$ \\
\hline wbpZ & glycosyltransferase WbpZ & -6.46 & 1.11E-09 \\
\hline PA0011 & lipid A biosynthesis lauroyl acyltransferase & -6.29 & 3.80E-09 \\
\hline$m i g A$ & alpha-1,6-rhamnosyltransferase MigA & -6.22 & $1.95 \mathrm{E}-15$ \\
\hline PA5551 & hypothetical protein & -6.18 & $1.61 \mathrm{E}-30$ \\
\hline IOIA & outer-membrane lipoprotein carrier protein & -6.06 & $7.98 \mathrm{E}-22$ \\
\hline PA0045 & hypothetical protein & -5.86 & $8.28 \mathrm{E}-11$ \\
\hline IptF & outer membrane porin $\mathrm{F}$ & -5.82 & $3.08 \mathrm{E}-39$ \\
\hline murA & UDP-N-acetylglucosamine 1-carboxyvinyltransferase & -5.34 & $8.08 \mathrm{E}-23$ \\
\hline murD & $\begin{array}{l}\text { UDP-N-acetylmuramoyl-L-alanyl-D-glutamate } \\
\text { synthetase }\end{array}$ & -5.30 & 4.12E-45 \\
\hline murB & UDP-N-acetylenolpyruvoylglucosamine reductase & -5.02 & $8.20 \mathrm{E}-15$ \\
\hline PA4394 & hypothetical protein & -4.97 & $2.37 \mathrm{E}-26$ \\
\hline waaL & O-antigen ligase WaaL & -4.90 & $1.56 \mathrm{E}-05$ \\
\hline PA0667 & hypothetical protein & -4.88 & 3.25E-07 \\
\hline$d d l B$ & D-alanine--D-alanine ligase & -4.77 & 1.06E-25 \\
\hline$r m / B$ & dTDP-D-glucose 4,6-dehydratase & -4.74 & $1.54 \mathrm{E}-14$ \\
\hline mltB1 & murein hydrolase $B$ & -4.72 & $1.34 \mathrm{E}-12$ \\
\hline$m l t D$ & membrane-bound lytic murein transglycosylase $D$ & -4.71 & $1.48 \mathrm{E}-11$ \\
\hline
\end{tabular}




\begin{tabular}{|c|c|c|c|}
\hline PA2988 & hypothetical protein & -4.37 & $9.54 \mathrm{E}-09$ \\
\hline murC & UDP-N-acetylmuramate--L-alanine ligase & -4.36 & $2.43 E-30$ \\
\hline $\operatorname{alg} D$ & GDP-mannose 6-dehydrogenase AlgD & -4.27 & $3.41 \mathrm{E}-06$ \\
\hline $\operatorname{mexA}$ & multidrug resistance protein MexA & -4.23 & 8.63E-24 \\
\hline PA1391 & glycosyl transferase family protein & -4.14 & $1.25 \mathrm{E}-08$ \\
\hline waaG & $\begin{array}{l}\text { UDP-glucose:(heptosyl) LPS alpha 1,3- } \\
\text { glucosyltransferase WaaG }\end{array}$ & -4.01 & $7.88 \mathrm{E}-17$ \\
\hline betT1 & choline transporter BetT & -3.81 & $8.95 \mathrm{E}-13$ \\
\hline PA5251 & hypothetical protein & -3.64 & 1.17E-06 \\
\hline PA5291 & choline transporter & -3.58 & $8.34 \mathrm{E}-19$ \\
\hline $\mathrm{plcH}$ & hemolytic phospholipase C & -3.52 & 9.86E-07 \\
\hline ostA & organic solvent tolerance protein OstA & -3.44 & 1.97E-09 \\
\hline PA1389 & glycosyl transferase family protein & -3.39 & 1.99E-05 \\
\hline PA1388 & hypothetical protein & -3.32 & 3.70E-05 \\
\hline$g I m U$ & $\begin{array}{l}\text { bifunctional glucosamine-1-phosphate } \\
\text { acetyltransferase/N-acetylglucosamine-1-phosphate } \\
\text { uridyltransferase }\end{array}$ & -3.27 & $1.95 \mathrm{E}-12$ \\
\hline$b / c$ & outer membrane lipoprotein Blc & -3.19 & $4.36 \mathrm{E}-11$ \\
\hline$p s / A$ & biofilm formation protein PsIA & -3.07 & $1.90 \mathrm{E}-15$ \\
\hline$d g k A$ & diacylglycerol kinase & -3.05 & 1.67E-06 \\
\hline PA1014 & glycosyl transferase family protein & -2.95 & 3.52E-05 \\
\hline alg8 & glycosyltransferase alg8 & -2.86 & 7.01E-05 \\
\hline PA5003 & hypothetical protein & -2.76 & $2.74 \mathrm{E}-14$ \\
\hline ponA & penicillin-binding protein $1 \mathrm{~A}$ & -2.75 & $9.09 \mathrm{E}-19$ \\
\hline PA2291 & glucose-sensitive porin & -2.74 & $5.31 \mathrm{E}-04$ \\
\hline PA3353 & hypothetical protein & -2.50 & 2.36E-06 \\
\hline PA3468 & hypothetical protein & -2.45 & $1.20 \mathrm{E}-07$ \\
\hline sltB1 & soluble lytic transglycosylase B & -2.43 & 1.86E-08 \\
\hline$k d s A$ & 2-dehydro-3-deoxyphosphooctonate aldolase & -2.40 & 3.32E-07 \\
\hline murF & $\begin{array}{l}\text { UDP-N-acetylmuramoyl-tripeptide--D-alanyl-D- } \\
\text { alanine ligase }\end{array}$ & -2.38 & $1.29 \mathrm{E}-15$ \\
\hline$m r c B$ & penicillin-binding protein 1B & -2.37 & 3.02E-07 \\
\hline lgt & prolipoprotein diacylglyceryl transferase & -2.36 & $5.62 \mathrm{E}-09$ \\
\hline PA1011 & hypothetical protein & -2.31 & $5.13 \mathrm{E}-07$ \\
\hline PA3623 & hypothetical protein & -2.29 & $6.31 \mathrm{E}-12$ \\
\hline PA3472 & hypothetical protein & -2.28 & $1.10 \mathrm{E}-06$ \\
\hline PA4735 & hypothetical protein & -2.22 & 1.10E-10 \\
\hline wzt & ABC transporter & -2.21 & $8.51 \mathrm{E}-10$ \\
\hline PA4374 & $\begin{array}{l}\text { resistance-nodulation-cell division (RND) efflux } \\
\text { membrane fusion protein }\end{array}$ & -2.17 & 3.73E-05 \\
\hline $\operatorname{dapA}$ & 4-hydroxy-tetrahydrodipicolinate synthase & -2.16 & $5.78 \mathrm{E}-05$ \\
\hline PA5232 & hypothetical protein & -2.07 & $5.98 \mathrm{E}-06$ \\
\hline wbpX & glycosyltransferase WbpX & -2.06 & $2.58 \mathrm{E}-07$ \\
\hline
\end{tabular}




\begin{tabular}{|c|c|c|c|}
\hline IpxD & UDP-3-O-acylglucosamine $\mathrm{N}$-acyltransferase & $\mid-2.00$ & 2.24E-06 \\
\hline \multicolumn{4}{|c|}{ Coenzyme transport and metabolism } \\
\hline ilvC & ketol-acid reductoisomerase & -76.59 & 3.21E-44 \\
\hline sahH & adenosylhomocysteinase & -59.77 & $2.25 \mathrm{E}-93$ \\
\hline spuC & aminotransferase & -48.12 & $1.26 \mathrm{E}-30$ \\
\hline bioB & biotin synthase & -24.96 & $2.03 \mathrm{E}-37$ \\
\hline PA4615 & oxidoreductase & -22.30 & $2.89 \mathrm{E}-33$ \\
\hline$i \mid V I$ & acetolactate synthase 3 catalytic subunit & -21.93 & $1.40 \mathrm{E}-26$ \\
\hline phhB & pterin-4-alpha-carbinolamine dehydratase & -17.97 & $2.56 \mathrm{E}-83$ \\
\hline folE2 & GTP cyclohydrolase I & -17.91 & $3.61 \mathrm{E}-54$ \\
\hline hemB & delta-aminolevulinic acid dehydratase & -15.18 & $1.91 \mathrm{E}-19$ \\
\hline lis & lipoyl synthase & -14.23 & $1.50 \mathrm{E}-49$ \\
\hline PA1772 & ribonuclease activity regulator protein RraA & -13.69 & $1.06 \mathrm{E}-50$ \\
\hline cysD & sulfate adenylyltransferase subunit 2 & -11.90 & $2.73 \mathrm{E}-15$ \\
\hline hemN & oxygen-independent coproporphyrinogen-III oxidase & -11.02 & $1.98 \mathrm{E}-22$ \\
\hline pncB1 & nicotinate phosphoribosyltransferase & -8.72 & $2.50 \mathrm{E}-19$ \\
\hline folP & dihydropteroate synthase & -8.10 & 9.79E-19 \\
\hline $\operatorname{lipB}$ & lipoate-protein ligase B & -7.47 & $7.61 \mathrm{E}-22$ \\
\hline folE1 & GTP cyclohydrolase I & -7.45 & $2.38 \mathrm{E}-13$ \\
\hline PA0862 & hypothetical protein & -7.36 & $1.07 \mathrm{E}-30$ \\
\hline metK & S-adenosylmethionine synthetase & -6.72 & $8.63 \mathrm{E}-22$ \\
\hline rimk & ribosomal protein S6 modification protein & -6.59 & $2.66 \mathrm{E}-20$ \\
\hline ribA & GTP cyclohydrolase II & -6.41 & $4.80 \mathrm{E}-20$ \\
\hline ribE & 6,7-dimethyl-8-ribityllumazine synthase & -6.28 & $9.39 \mathrm{E}-21$ \\
\hline$p d x Y$ & pyridoxamine kinase & -6.03 & $8.63 \mathrm{E}-11$ \\
\hline PA0655 & $\begin{array}{l}\text { 2-nonaprenyl-3-methyl-6-methoxy-1,4-benzoquinol } \\
\text { hydroxylase }\end{array}$ & -4.86 & 8.21E-24 \\
\hline pncB2 & nicotinate phosphoribosyltransferase & -4.68 & $4.58 \mathrm{E}-16$ \\
\hline PA0132 & beta alanine--pyruvate transaminase & -4.63 & $1.02 \mathrm{E}-12$ \\
\hline PA4805 & hypothetical protein & -4.54 & $2.43 \mathrm{E}-11$ \\
\hline bioA & $\begin{array}{l}\text { adenosylmethionine--8-amino-7-oxononanoate } \\
\text { aminotransferase BioA }\end{array}$ & -4.54 & 1.33E-21 \\
\hline thiG & thiazole synthase & -4.40 & $2.13 \mathrm{E}-18$ \\
\hline hemL & \begin{tabular}{|l|} 
glutamate-1-semialdehyde aminotransferase \\
\end{tabular} & -4.21 & $1.04 \mathrm{E}-24$ \\
\hline PA4675 & TonB-dependent receptor & -4.17 & $6.09 \mathrm{E}-23$ \\
\hline$n a d B$ & L-aspartate oxidase & -3.93 & $3.16 \mathrm{E}-30$ \\
\hline PA3518 & hypothetical protein & -3.83 & 3.34E-07 \\
\hline PA2993 & hypothetical protein & -3.59 & $6.13 \mathrm{E}-20$ \\
\hline PA5237 & 3-octaprenyl-4-hydroxybenzoate carboxy-lyase & -3.46 & $2.01 \mathrm{E}-17$ \\
\hline nadC & nicotinate-nucleotide pyrophosphorylase & -3.23 & $1.14 \mathrm{E}-14$ \\
\hline coaE & dephospho-CoA kinase & -3.18 & $7.68 \mathrm{E}-06$ \\
\hline $\operatorname{nad} A$ & quinolinate synthetase & -3.08 & $4.29 \mathrm{E}-20$ \\
\hline
\end{tabular}




\begin{tabular}{|c|c|c|c|}
\hline hemF & coproporphyrinogen III oxidase & -2.84 & $6.89 \mathrm{E}-13$ \\
\hline$i s p B$ & octaprenyl-diphosphate synthase & -2.74 & 1.07E-10 \\
\hline ubiE & $\begin{array}{l}\text { ubiquinone/menaquinone biosynthesis } \\
\text { methyltransferase }\end{array}$ & -2.40 & $6.49 \mathrm{E}-08$ \\
\hline hemE & uroporphyrinogen decarboxylase & -2.37 & $1.06 \mathrm{E}-04$ \\
\hline ribF & $\begin{array}{l}\text { bifunctional riboflavin kinase/FMN } \\
\text { adenylyltransferase }\end{array}$ & -2.36 & $8.59 E-06$ \\
\hline PA5257 & hypothetical protein & -2.34 & $5.35 \mathrm{E}-14$ \\
\hline nadE & NAD synthetase & -2.15 & $4.78 \mathrm{E}-04$ \\
\hline panD & aspartate alpha-decarboxylase & -2.08 & $1.13 \mathrm{E}-03$ \\
\hline PA0389 & hypothetical protein & -2.07 & $3.55 \mathrm{E}-04$ \\
\hline \multicolumn{4}{|c|}{ Defense mechanisms } \\
\hline ampC & beta-lactamase & -15.79 & $2.34 \mathrm{E}-53$ \\
\hline $\operatorname{mex} B$ & multidrug resistance protein MexB & -8.35 & $1.34 \mathrm{E}-19$ \\
\hline PA5230 & $A B C$ transporter permease & -7.33 & $2.86 \mathrm{E}-14$ \\
\hline$m s b A$ & transporter MsbA & -6.20 & $3.78 \mathrm{E}-19$ \\
\hline PA2812 & $A B C$ transporter ATP-binding protein & -4.53 & $2.43 \mathrm{E}-07$ \\
\hline PA0749 & hypothetical protein & -4.25 & $5.54 \mathrm{E}-06$ \\
\hline PA4375 & multidrug efflux protein & -4.15 & 4.83E-08 \\
\hline PA5514 & beta-lactamase & -4.12 & $2.31 \mathrm{E}-12$ \\
\hline$a m p D$ & $\mathrm{~N}$-acetyl-anhydromuranmyl-L-alanine amidase & -3.46 & $2.18 \mathrm{E}-12$ \\
\hline PA5542 & hypothetical protein & -3.13 & $2.60 \mathrm{E}-11$ \\
\hline PA4037 & $A B C$ transporter ATP-binding protein & -2.34 & 1.00E-06 \\
\hline PA2811 & $A B C$ transporter permease & -2.23 & 1.14E-04 \\
\hline PA2018 & multidrug efflux protein & -2.10 & 4.69E-08 \\
\hline $\operatorname{mexF}$ & $\begin{array}{l}\text { resistance-nodulation-cell division (RND) multidrug } \\
\text { efflux transporter MexF }\end{array}$ & -2.04 & $1.90 \mathrm{E}-08$ \\
\hline PA0158 & $\begin{array}{l}\text { resistance-nodulation-cell division (RND) efflux } \\
\text { transporter }\end{array}$ & -2.01 & $3.87 \mathrm{E}-10$ \\
\hline \multicolumn{4}{|c|}{ Energy production and conversion } \\
\hline sucC & succinyl-CoA ligase subunit beta & -208.78 & $9.80 \mathrm{E}-72$ \\
\hline sucD & succinyl-CoA ligase subunit alpha & -171.75 & $1.66 \mathrm{E}-119$ \\
\hline IpdG & $\begin{array}{l}\text { 2-oxoglutarate dehydrogenase complex dihydrolipoyl } \\
\text { dehydrogenase }\end{array}$ & -166.79 & 7.15E-79 \\
\hline atpD & ATP synthase subunit beta & -140.46 & $1.60 \mathrm{E}-96$ \\
\hline atpH & ATP synthase subunit delta & -125.68 & $1.64 \mathrm{E}-87$ \\
\hline atpG & ATP synthase subunit gamma & -118.29 & $4.28 \mathrm{E}-46$ \\
\hline atpF & ATP synthase subunit $B$ & -117.77 & $3.61 \mathrm{E}-48$ \\
\hline $\operatorname{atp} A$ & ATP synthase subunit alpha & -113.89 & $1.59 \mathrm{E}-51$ \\
\hline $\operatorname{sdh} A$ & succinate dehydrogenase flavoprotein subunit & -112.42 & $2.96 \mathrm{E}-81$ \\
\hline $\operatorname{sdh} B$ & succinate dehydrogenase iron-sulfur subunit & -84.70 & $3.10 \mathrm{E}-57$ \\
\hline nuol & NADH-quinone oxidoreductase subunit I & -68.71 & $1.35 \mathrm{E}-55$ \\
\hline icd & isocitrate dehydrogenase & -59.62 & $3.80 \mathrm{E}-63$ \\
\hline
\end{tabular}




\begin{tabular}{|c|c|c|c|}
\hline sucA & 2-oxoglutarate dehydrogenase subunit E1 & -52.61 & $3.66 \mathrm{E}-56$ \\
\hline etfB & electron transfer flavoprotein subunit beta & -49.88 & $3.51 \mathrm{E}-136$ \\
\hline glt $A$ & citrate synthase & -47.87 & $9.78 \mathrm{E}-45$ \\
\hline$s d h C$ & succinate dehydrogenase subunit $C$ & -45.04 & $3.77 \mathrm{E}-47$ \\
\hline$s d h D$ & succinate dehydrogenase subunit $D$ & -43.63 & $5.70 \mathrm{E}-38$ \\
\hline PA5046 & malic enzyme & -41.51 & $2.79 \mathrm{E}-91$ \\
\hline$i s c U$ & scaffold protein & -40.84 & $3.16 \mathrm{E}-36$ \\
\hline nuoE & $\mathrm{NADH}$-quinone oxidoreductase subunit $\mathrm{E}$ & -36.44 & $2.30 \mathrm{E}-53$ \\
\hline $\mathrm{ccoO} 2$ & cbb3-type cytochrome C oxidase subunit II & -34.29 & $2.28 \mathrm{E}-20$ \\
\hline PA4429 & cytochrome C1 & -30.10 & $1.63 \mathrm{E}-36$ \\
\hline nuoB & $\mathrm{NADH}$-quinone oxidoreductase subunit $\mathrm{B}$ & -21.84 & $3.75 \mathrm{E}-34$ \\
\hline PA4431 & iron-sulfur protein & -20.96 & $5.37 \mathrm{E}-22$ \\
\hline PA4430 & cytochrome b & -20.92 & $8.24 \mathrm{E}-26$ \\
\hline$f d x A$ & ferredoxin I & -20.02 & $8.61 \mathrm{E}-42$ \\
\hline azu & azurin & -18.38 & $1.41 \mathrm{E}-72$ \\
\hline nuoJ & $\mathrm{NADH}$-quinone oxidoreductase subunit $\mathrm{J}$ & -18.10 & $1.81 \mathrm{E}-24$ \\
\hline$i d h$ & isocitrate dehydrogenase & -17.99 & $8.83 \mathrm{E}-38$ \\
\hline ccoP2 & cytochrome C oxidase cbb3-type subunit CcoP & -17.19 & $5.34 \mathrm{E}-60$ \\
\hline PA5435 & pyruvate carboxylase subunit $B$ & -15.71 & 4.39E-39 \\
\hline nuok & NADH-quinone oxidoreductase subunit $\mathrm{K}$ & -15.52 & $9.64 \mathrm{E}-24$ \\
\hline atpC & ATP synthase subunit epsilon & -15.47 & 4.16E-22 \\
\hline atpB & ATP synthase subunit $A$ & -14.99 & $2.77 \mathrm{E}-15$ \\
\hline ccoO1 & cbb3-type cytochrome C oxidase subunit II & -13.41 & $2.96 \mathrm{E}-24$ \\
\hline ace E & pyruvate dehydrogenase subunit E1 & -13.39 & $1.66 \mathrm{E}-86$ \\
\hline ccoP1 & cytochrome $\mathrm{C}$ oxidase cbb3-type subunit CcoP & -13.35 & $4.79 \mathrm{E}-20$ \\
\hline PA1551 & ferredoxin & -12.78 & $5.00 \mathrm{E}-18$ \\
\hline$n q r D$ & $\begin{array}{l}\mathrm{Na}(+) \text {-translocating } \mathrm{NADH} \text {-quinone reductase } \\
\text { subunit D }\end{array}$ & -12.43 & $5.43 \mathrm{E}-11$ \\
\hline PA0918 & cytochrome b561 & -12.38 & $4.52 \mathrm{E}-18$ \\
\hline PA5312 & aldehyde dehydrogenase & -12.33 & $1.17 \mathrm{E}-56$ \\
\hline$n q r F$ & $\begin{array}{l}\mathrm{Na}(+) \text {-translocating } \mathrm{NADH} \text {-quinone reductase } \\
\text { subunit } \mathrm{F}\end{array}$ & -11.74 & $6.24 \mathrm{E}-83$ \\
\hline$a c n B$ & aconitate hydratase $\mathrm{B}$ & -11.63 & $9.46 \mathrm{E}-104$ \\
\hline etfA & electron transfer flavoprotein subunit alpha & -11.61 & $6.21 \mathrm{E}-90$ \\
\hline pckA & phosphoenolpyruvate carboxykinase & -11.57 & $1.60 \mathrm{E}-17$ \\
\hline PA0317 & hypothetical protein & -10.58 & $3.19 \mathrm{E}-24$ \\
\hline$n q r C$ & $\begin{array}{l}\mathrm{Na}(+) \text {-translocating } \mathrm{NADH} \text {-quinone reductase } \\
\text { subunit } \mathrm{C}\end{array}$ & -10.36 & $6.14 \mathrm{E}-48$ \\
\hline ppa & inorganic pyrophosphatase & -10.23 & $1.13 \mathrm{E}-15$ \\
\hline nuoD & NADH:-quinone oxidoreductase subunit C/D & -10.21 & $5.34 \mathrm{E}-35$ \\
\hline sth & soluble pyridine nucleotide transhydrogenase & -9.76 & $1.51 \mathrm{E}-12$ \\
\hline PA2953 & $\begin{array}{l}\text { electron transfer flavoprotein-ubiquinone } \\
\text { oxidoreductase }\end{array}$ & -9.09 & 8.27E-39 \\
\hline
\end{tabular}




\begin{tabular}{|c|c|c|c|}
\hline nqrE & $\begin{array}{l}\mathrm{Na}(+) \text {-translocating } \mathrm{NADH} \text {-quinone reductase } \\
\text { subunit } \mathrm{E}\end{array}$ & -8.74 & $1.63 \mathrm{E}-15$ \\
\hline nuoH & $\mathrm{NADH}$-quinone oxidoreductase subunit $\mathrm{H}$ & -8.46 & $3.52 \mathrm{E}-39$ \\
\hline ace $A$ & isocitrate lyase & -8.38 & $6.69 \mathrm{E}-19$ \\
\hline rubA2 & rubredoxin & -8.34 & $9.34 \mathrm{E}-14$ \\
\hline $\operatorname{sucB}$ & $\begin{array}{l}\text { 2-oxoglutarate dehydrogenase complex } \\
\text { dihydrolipoyllysine-residue succinyltransferase }\end{array}$ & -7.86 & $5.94 \mathrm{E}-52$ \\
\hline$n q r B$ & $\begin{array}{l}\mathrm{Na}(+) \text {-translocating } \mathrm{NADH} \text {-quinone reductase } \\
\text { subunit B }\end{array}$ & -7.75 & $3.67 \mathrm{E}-40$ \\
\hline betB & betaine aldehyde dehydrogenase & -7.25 & $5.29 \mathrm{E}-18$ \\
\hline $\operatorname{cox} B$ & cytochrome C oxidase subunit II & -6.84 & $9.06 \mathrm{E}-13$ \\
\hline nuoM & NADH-quinone oxidoreductase subunit M & -6.39 & $4.41 \mathrm{E}-41$ \\
\hline cyoA & cytochrome o ubiquinol oxidase subunit II & -6.21 & 4.43E-09 \\
\hline PA0541 & hypothetical protein & -5.92 & 2.83E-29 \\
\hline$f p r$ & ferredoxin-NADP reductase & -5.90 & $3.44 \mathrm{E}-17$ \\
\hline cyoC & cytochrome o ubiquinol oxidase subunit III & -5.78 & 6.69E-07 \\
\hline$f d n H$ & nitrate-inducible formate dehydrogenase subunit beta & -5.72 & $1.58 \mathrm{E}-43$ \\
\hline PA4571 & cytochrome C & -5.63 & $1.89 \mathrm{E}-40$ \\
\hline gltP & glutamate/aspartate:proton symporter & -5.18 & $6.64 \mathrm{E}-22$ \\
\hline adhC & alcohol dehydrogenase & -5.10 & $8.96 \mathrm{E}-39$ \\
\hline $\operatorname{cox} A$ & cytochrome $\mathrm{C}$ oxidase subunit I & -4.89 & $3.29 \mathrm{E}-10$ \\
\hline colll & cytochrome C oxidase subunit III & -4.85 & $9.82 \mathrm{E}-09$ \\
\hline nuоA & $\mathrm{NADH}$-quinone oxidoreductase subunit $\mathrm{A}$ & -4.80 & 3.91E-07 \\
\hline$g / c B$ & malate synthase $G$ & -4.79 & 1.17E-33 \\
\hline CyOB & cytochrome o ubiquinol oxidase subunit I & -4.77 & $1.18 \mathrm{E}-07$ \\
\hline PA4348 & hypothetical protein & -4.74 & $5.76 \mathrm{E}-16$ \\
\hline$f d x 2$ & $(2 \mathrm{Fe}-2 \mathrm{~S})$ ferredoxin & -4.70 & $1.71 \mathrm{E}-11$ \\
\hline PA5491 & cytochrome & -4.19 & $2.44 \mathrm{E}-14$ \\
\hline PA3471 & NAD-dependent malic enzyme & -3.91 & $1.91 \mathrm{E}-23$ \\
\hline PA5190 & nitroreductase & -3.91 & $1.58 \mathrm{E}-17$ \\
\hline$g / p K$ & glycerol kinase & -3.90 & $5.27 \mathrm{E}-20$ \\
\hline nuoN & $\mathrm{NADH}$-quinone oxidoreductase subunit $\mathrm{N}$ & -3.85 & 1.66E-26 \\
\hline PA5445 & coenzyme $\mathrm{A}$ transferase & -3.76 & $2.66 \mathrm{E}-26$ \\
\hline$g a b D$ & glutarate-semialdehyde dehydrogenase DavD & -3.73 & 1.10E-22 \\
\hline PA1751 & hypothetical protein & -3.72 & $4.04 \mathrm{E}-09$ \\
\hline gor & glutathione reductase & -3.57 & $3.67 \mathrm{E}-15$ \\
\hline PA3954 & hypothetical protein & -3.51 & $3.06 \mathrm{E}-13$ \\
\hline atpl & ATP synthase subunit I & -3.42 & 8.59E-05 \\
\hline $\operatorname{dct} A$ & C4-dicarboxylate transport protein & -3.38 & 2.73E-21 \\
\hline$b k d A 1$ & 2-oxoisovalerate dehydrogenase subunit alpha & -3.28 & $2.73 \mathrm{E}-25$ \\
\hline PA3795 & oxidoreductase & -3.28 & $1.72 \mathrm{E}-15$ \\
\hline nuoF & NADH dehydrogenase I subunit $F$ & -3.22 & $6.08 \mathrm{E}-22$ \\
\hline
\end{tabular}




\begin{tabular}{|c|c|c|c|}
\hline$b k d A 2$ & 2-oxoisovalerate dehydrogenase subunit beta & -3.12 & $6.09 \mathrm{E}-14$ \\
\hline prpC & methylcitrate synthase & -3.09 & $1.67 \mathrm{E}-15$ \\
\hline ace $F$ & dihydrolipoamide acetyltransferase & -3.05 & $3.98 \mathrm{E}-17$ \\
\hline PA2956 & hypothetical protein & -2.99 & $4.93 \mathrm{E}-14$ \\
\hline PA5325 & hypothetical protein & -2.96 & $9.13 \mathrm{E}-05$ \\
\hline PA4434 & oxidoreductase & -2.80 & $2.84 \mathrm{E}-09$ \\
\hline $\operatorname{cioB}$ & cyanide insensitive terminal oxidase & -2.75 & $1.37 \mathrm{E}-13$ \\
\hline PA4022 & aldehyde dehydrogenase & -2.73 & 3.01E-08 \\
\hline nqrA & $\begin{array}{l}\mathrm{Na}(+) \text {-translocating } \mathrm{NADH} \text {-quinone reductase } \\
\text { subunit } \mathrm{A}\end{array}$ & -2.66 & $1.30 \mathrm{E}-13$ \\
\hline $\operatorname{cc4} 4$ & cytochrome C4 & -2.65 & $1.18 \mathrm{E}-05$ \\
\hline nuoG & $\mathrm{NADH}$-quinone oxidoreductase subunit $\mathrm{G}$ & -2.63 & 2.57E-20 \\
\hline $\operatorname{acn} A$ & aconitate hydratase & -2.52 & 1.36E-09 \\
\hline$n d h$ & NADH dehydrogenase & -2.47 & $1.42 \mathrm{E}-10$ \\
\hline $\operatorname{cioA}$ & cyanide insensitive terminal oxidase & -2.45 & 7.05E-08 \\
\hline$f d n l$ & $\begin{array}{l}\text { nitrate-inducible formate dehydrogenase subunit } \\
\text { gamma }\end{array}$ & -2.41 & $7.47 \mathrm{E}-13$ \\
\hline PA4333 & fumarase & -2.39 & $3.16 \mathrm{E}-12$ \\
\hline PA0953 & thioredoxin & -2.35 & 5.01E-03 \\
\hline rubA1 & rubredoxin & -2.28 & $2.00 \mathrm{E}-04$ \\
\hline narH & respiratory nitrate reductase subunit beta & -2.27 & 4.03E-06 \\
\hline PA0366 & coniferyl aldehyde dehydrogenase & -2.21 & 4.71E-05 \\
\hline ackA & acetate kinase & -2.17 & $1.74 \mathrm{E}-06$ \\
\hline CycB & cytochrome C5 & -2.11 & $1.15 \mathrm{E}-08$ \\
\hline nuol & NADH-quinone oxidoreductase subunit $\mathrm{L}$ & -2.10 & 2.56E-08 \\
\hline \multicolumn{4}{|c|}{ Hypothetical, unclassified, unknown } \\
\hline PA4738 & hypothetical protein & -1033.66 & $4.90 \mathrm{E}-80$ \\
\hline PA5482 & hypothetical protein & -940.57 & $2.43 \mathrm{E}-65$ \\
\hline$p m p R$ & transcriptional regulator $\mathrm{PmpR}$ & -78.91 & $9.60 \mathrm{E}-37$ \\
\hline iscA & iron-binding protein IscA & -73.02 & 1.44E-54 \\
\hline pasP & hypothetical protein & -56.82 & $1.62 \mathrm{E}-121$ \\
\hline PA0974 & hypothetical protein & -38.84 & $4.04 \mathrm{E}-38$ \\
\hline PA4421 & cell division protein MraZ & -38.31 & $6.01 \mathrm{E}-28$ \\
\hline PA1847 & $\mathrm{Fe} / \mathrm{S}$ biogenesis protein $\mathrm{NfuA}$ & -30.94 & $5.20 \mathrm{E}-95$ \\
\hline PA2950 & reductase & -27.07 & $3.71 \mathrm{E}-26$ \\
\hline PA3819 & hypothetical protein & -20.62 & $5.06 \mathrm{E}-67$ \\
\hline PA0320 & hypothetical protein & -19.58 & $3.85 \mathrm{E}-25$ \\
\hline PA4460 & hypothetical protein & -19.35 & $1.84 \mathrm{E}-16$ \\
\hline PA3808 & hypothetical protein & -17.08 & $2.95 \mathrm{E}-25$ \\
\hline PA4104 & hypothetical protein & -15.81 & $1.28 \mathrm{E}-69$ \\
\hline PA0665 & iron-sulfur cluster insertion protein ErpA & -15.71 & $4.29 \mathrm{E}-26$ \\
\hline PA2659 & hypothetical protein & -15.70 & $4.48 \mathrm{E}-43$ \\
\hline
\end{tabular}




\begin{tabular}{|c|c|c|c|}
\hline PA1371 & hypothetical protein & $\mid-14.97$ & $3.24 \mathrm{E}-23$ \\
\hline PA0329 & hypothetical protein & -14.82 & $7.21 \mathrm{E}-19$ \\
\hline PA5446 & hypothetical protein & -13.56 & $2.81 \mathrm{E}-17$ \\
\hline PA5001 & hypothetical protein & -13.31 & $5.39 \mathrm{E}-32$ \\
\hline PA5286 & hypothetical protein & -12.20 & $4.58 \mathrm{E}-34$ \\
\hline PA5229 & hypothetical protein & -12.04 & $2.48 \mathrm{E}-29$ \\
\hline PA4611 & hypothetical protein & -11.48 & $4.34 \mathrm{E}-29$ \\
\hline PA5333 & hypothetical protein & -11.44 & $9.79 \mathrm{E}-19$ \\
\hline PA0586 & hypothetical protein & -11.41 & $1.91 \mathrm{E}-13$ \\
\hline PA5055 & hypothetical protein & -11.23 & 1.00E-51 \\
\hline PA5227 & hypothetical protein & -10.94 & 1.66E-57 \\
\hline PA4766 & hypothetical protein & -10.93 & $7.49 \mathrm{E}-15$ \\
\hline PA1769 & phosphoenolpyruvate synthase regulatory protein & -10.66 & $8.60 \mathrm{E}-20$ \\
\hline PA5178 & hypothetical protein & -10.18 & $1.55 \mathrm{E}-46$ \\
\hline PA4395 & nucleotide-binding protein & -9.89 & 1.27E-60 \\
\hline PA1533 & nucleoid-associated protein & -9.67 & $2.95 \mathrm{E}-30$ \\
\hline PA2630 & hypothetical protein & -9.03 & $8.58 \mathrm{E}-20$ \\
\hline PA4106 & hypothetical protein & -9.01 & $7.86 \mathrm{E}-30$ \\
\hline PA2621 & ATP-dependent Clp protease adapter protein Clp & -8.92 & $8.46 \mathrm{E}-15$ \\
\hline PA2705 & hypothetical protein & -8.90 & $5.52 \mathrm{E}-16$ \\
\hline PA4605 & hypothetical protein & -8.60 & 1.99E-09 \\
\hline PA2992 & hypothetical protein & -8.10 & 4.06E-14 \\
\hline nirs & nitrite reductase & -7.53 & 2.17E-16 \\
\hline PA0937 & hypothetical protein & -7.37 & $7.50 \mathrm{E}-10$ \\
\hline PA1034 & hypothetical protein & -7.36 & $3.29 \mathrm{E}-07$ \\
\hline PA3046 & hypothetical protein & -7.29 & $1.00 \mathrm{E}-08$ \\
\hline PA1035 & hypothetical protein & -7.10 & $4.29 \mathrm{E}-14$ \\
\hline PA1574 & hypothetical protein & -7.07 & $1.04 \mathrm{E}-17$ \\
\hline PA3756 & hypothetical protein & -6.38 & 1.09E-11 \\
\hline PA3979 & hypothetical protein & -6.25 & 1.14E-13 \\
\hline PA3040 & hypothetical protein & -6.21 & 1.33E-39 \\
\hline PA3826 & hypothetical protein & -5.89 & $6.69 \mathrm{E}-11$ \\
\hline PA4746 & hypothetical protein & -5.87 & $2.03 \mathrm{E}-06$ \\
\hline PA0563 & hypothetical protein & -5.77 & $2.95 \mathrm{E}-14$ \\
\hline PA4842 & hypothetical protein & -5.65 & $2.53 \mathrm{E}-29$ \\
\hline PA0084 & hypothetical protein & -5.61 & $9.51 \mathrm{E}-26$ \\
\hline PA3998 & hypothetical protein & -5.44 & $3.86 \mathrm{E}-13$ \\
\hline PA4459 & hypothetical protein & -5.37 & $2.79 \mathrm{E}-16$ \\
\hline PA4530 & zinc-binding protein & -5.22 & $7.45 \mathrm{E}-10$ \\
\hline PA1659 & hypothetical protein & -5.07 & $2.52 \mathrm{E}-06$ \\
\hline PA3696 & hypothetical protein & -5.03 & $2.50 \mathrm{E}-17$ \\
\hline
\end{tabular}




\begin{tabular}{|c|c|c|c|}
\hline PA4701 & hypothetical protein & $\mid-4.87$ & $8.70 \mathrm{E}-21$ \\
\hline PA0392 & hypothetical protein & -4.82 & $1.84 \mathrm{E}-13$ \\
\hline PA0013 & hypothetical protein & -4.81 & $3.06 \mathrm{E}-07$ \\
\hline PA0529 & hypothetical protein & -4.81 & 2.84E-18 \\
\hline PA0038 & hypothetical protein & -4.72 & $4.18 \mathrm{E}-20$ \\
\hline PA5423 & hypothetical protein & -4.71 & 1.47E-21 \\
\hline PA1842 & hypothetical protein & -4.68 & $2.06 \mathrm{E}-10$ \\
\hline PA0020 & hypothetical protein & -4.61 & \begin{tabular}{|l}
$4.16 \mathrm{E}-22$ \\
\end{tabular} \\
\hline PA4384 & hypothetical protein & -4.50 & $2.81 \mathrm{E}-18$ \\
\hline PA1516 & hypothetical protein & -4.46 & $4.44 \mathrm{E}-12$ \\
\hline PA3440 & hypothetical protein & -4.42 & $1.26 \mathrm{E}-12$ \\
\hline PA2706 & hypothetical protein & -4.25 & $3.55 \mathrm{E}-19$ \\
\hline PA3732 & hypothetical protein & -4.24 & 4.32E-09 \\
\hline PA3697 & hypothetical protein & -4.24 & $5.33 \mathrm{E}-15$ \\
\hline PA4532 & hypothetical protein & -4.22 & $6.33 \mathrm{E}-10$ \\
\hline PA1075 & hypothetical protein & -4.13 & $1.78 \mathrm{E}-07$ \\
\hline PA3012 & hypothetical protein & -4.12 & $2.90 \mathrm{E}-05$ \\
\hline PA0046 & hypothetical protein & -4.00 & $2.18 \mathrm{E}-11$ \\
\hline PA1684 & acireductone dioxygenase & -3.94 & $2.59 \mathrm{E}-07$ \\
\hline PA1667 & hypothetical protein & -3.92 & $5.96 \mathrm{E}-08$ \\
\hline PA4940 & hypothetical protein & -3.92 & $1.91 \mathrm{E}-07$ \\
\hline PA4441 & hypothetical protein & -3.85 & $4.18 \mathrm{E}-31$ \\
\hline PA1658 & hypothetical protein & -3.79 & $3.43 \mathrm{E}-07$ \\
\hline PA5424 & hypothetical protein & -3.67 & $8.20 \mathrm{E}-15$ \\
\hline PA3237 & hypothetical protein & -3.65 & 6.41E-07 \\
\hline PA4515 & hydroxylase & -3.64 & $3.72 \mathrm{E}-07$ \\
\hline PA3801 & hypothetical protein & -3.62 & $1.13 \mathrm{E}-22$ \\
\hline PA0661 & hypothetical protein & -3.62 & $2.43 \mathrm{E}-04$ \\
\hline PA0284 & hypothetical protein & -3.61 & 6.83E-07 \\
\hline PA0270 & hypothetical protein & -3.51 & $5.28 \mathrm{E}-12$ \\
\hline PA4564 & hypothetical protein & -3.51 & 1.73E-06 \\
\hline PA1657 & hypothetical protein & -3.46 & 2.37E-04 \\
\hline PA0948 & hypothetical protein & -3.42 & $6.48 \mathrm{E}-11$ \\
\hline PA0578 & hypothetical protein & -3.39 & $7.43 \mathrm{E}-11$ \\
\hline PA4005 & hypothetical protein & -3.37 & 1.32E-09 \\
\hline PA0587 & hypothetical protein & -3.23 & $2.68 \mathrm{E}-05$ \\
\hline PA3800 & outer membrane protein assembly factor BamB & -3.19 & $9.51 \mathrm{E}-20$ \\
\hline PA2754 & hypothetical protein & -3.19 & $1.31 \mathrm{E}-14$ \\
\hline PA0951 & hypothetical protein & -3.19 & 3.73E-06 \\
\hline PA0537 & hypothetical protein & -3.16 & $2.73 \mathrm{E}-14$ \\
\hline PA2980 & hypothetical protein & -3.12 & $1.94 \mathrm{E}-05$ \\
\hline
\end{tabular}




\begin{tabular}{|c|c|c|c|}
\hline PA5460 & hypothetical protein & $\mid-3.10$ & $3.66 \mathrm{E}-05$ \\
\hline PA2428 & hypothetical protein & -3.09 & $9.86 \mathrm{E}-10$ \\
\hline PA3566 & hypothetical protein & -3.07 & $2.85 \mathrm{E}-10$ \\
\hline PA4445 & hypothetical protein & -3.03 & $6.45 \mathrm{E}-08$ \\
\hline PA0856 & hypothetical protein & -3.03 & 3.94E-06 \\
\hline PA3539 & hypothetical protein & -3.02 & 1.60E-07 \\
\hline PA3413 & hypothetical protein & -2.99 & $1.78 \mathrm{E}-09$ \\
\hline PA0083 & hypothetical protein & -2.98 & $3.54 \mathrm{E}-10$ \\
\hline PA1841 & hypothetical protein & -2.97 & $1.23 \mathrm{E}-08$ \\
\hline PA1550 & hypothetical protein & -2.91 & 1.99E-11 \\
\hline PA5305 & hypothetical protein & -2.90 & $1.88 \mathrm{E}-08$ \\
\hline PA5444 & hypothetical protein & -2.88 & $2.37 \mathrm{E}-08$ \\
\hline$i c p$ & inhibitor of cysteine peptidase & -2.87 & $1.31 \mathrm{E}-10$ \\
\hline pcaC & 4-carboxymuconolactone decarboxylase & -2.85 & $9.26 \mathrm{E}-07$ \\
\hline PA3216 & hypothetical protein & -2.83 & 1.41E-06 \\
\hline PA1508 & hypothetical protein & -2.82 & 7.95E-03 \\
\hline PA1668 & hypothetical protein & -2.80 & $1.99 \mathrm{E}-06$ \\
\hline PA5244 & hypothetical protein & -2.76 & $1.25 \mathrm{E}-06$ \\
\hline PA4105 & hypothetical protein & -2.75 & 1.19E-18 \\
\hline PA0457.1 & hypothetical protein & -2.75 & $2.41 \mathrm{E}-08$ \\
\hline PA0540 & hypothetical protein & -2.67 & 5.82E-05 \\
\hline PA5279 & hypothetical protein & -2.66 & $2.63 \mathrm{E}-13$ \\
\hline PA0319 & hypothetical protein & -2.65 & $2.66 \mathrm{E}-08$ \\
\hline PA2017 & hypothetical protein & -2.65 & $7.98 \mathrm{E}-11$ \\
\hline PA1295 & hypothetical protein & -2.62 & $2.29 \mathrm{E}-05$ \\
\hline PA3674 & hypothetical protein & -2.60 & $3.76 \mathrm{E}-11$ \\
\hline PA0269 & hypothetical protein & -2.59 & $2.13 \mathrm{E}-08$ \\
\hline PA4004 & $\begin{array}{l}\text { 23S rRNA (pseudouridine(1915)-N(3))- } \\
\text { methyltransferase RlmH }\end{array}$ & -2.59 & 3.87E-08 \\
\hline PA3041 & hypothetical protein & -2.58 & $2.56 \mathrm{E}-10$ \\
\hline PA2184 & hypothetical protein & -2.56 & 2.71E-04 \\
\hline PA2954 & hypothetical protein & -2.54 & $9.55 \mathrm{E}-06$ \\
\hline PA4798 & hypothetical protein & -2.53 & $1.22 \mathrm{E}-13$ \\
\hline PA0398 & hypothetical protein & -2.48 & $1.48 \mathrm{E}-06$ \\
\hline PA3726 & hypothetical protein & -2.46 & 3.42E-05 \\
\hline PA1392 & hypothetical protein & -2.45 & 7.76E-03 \\
\hline PA4486 & hypothetical protein & -2.35 & 5.73E-08 \\
\hline PA4495 & hypothetical protein & -2.33 & $2.18 \mathrm{E}-08$ \\
\hline PA2864 & hypothetical protein & -2.28 & 6.71E-04 \\
\hline PA2722 & hypothetical protein & -2.27 & 7.34E-05 \\
\hline PA1031 & DNA recombination protein RmuC & -2.25 & 3.53E-08 \\
\hline PA0271 & hypothetical protein & -2.24 & 4.83E-05 \\
\hline
\end{tabular}




\begin{tabular}{|c|c|c|c|}
\hline PA4090 & hypothetical protein & -2.23 & $1.32 \mathrm{E}-03$ \\
\hline PA0131 & beta-alanine degradation protein $\mathrm{BauB}$ & -2.20 & $3.81 \mathrm{E}-06$ \\
\hline PA3951 & hypothetical protein & -2.19 & $1.90 \mathrm{E}-08$ \\
\hline PA4698 & hypothetical protein & -2.16 & 4.01E-05 \\
\hline PA2685 & hypothetical protein & -2.13 & 1.02E-05 \\
\hline PA0567 & hypothetical protein & -2.13 & $2.59 \mathrm{E}-03$ \\
\hline PA1661 & hypothetical protein & -2.12 & $2.55 \mathrm{E}-03$ \\
\hline PA1675 & hypothetical protein & -2.12 & $5.20 \mathrm{E}-06$ \\
\hline PA1792 & UDP-2,3-diacylglucosamine hydrolase & -2.07 & 7.93E-07 \\
\hline PA1042 & hypothetical protein & -2.06 & $1.03 \mathrm{E}-03$ \\
\hline PA0915 & hypothetical protein & -2.06 & $5.17 \mathrm{E}-04$ \\
\hline PA1299 & hypothetical protein & -2.06 & 3.09E-04 \\
\hline PA0565 & hypothetical protein & -2.05 & $2.90 \mathrm{E}-04$ \\
\hline PA0709 & hypothetical protein & -2.04 & $5.57 \mathrm{E}-03$ \\
\hline ssra & & -3369.42 & $3.52 \mathrm{E}-169$ \\
\hline oprl & outer membrane lipoprotein Oprl & -928.55 & $2.16 \mathrm{E}-119$ \\
\hline$r n p B$ & RNA component of RNaseP, RnpB & -812.66 & $1.20 \mathrm{E}-263$ \\
\hline $\operatorname{crcZ}$ & CrcZ & -796.86 & $1.20 \mathrm{E}-63$ \\
\hline PA4272.1 & P27 & -538.00 & $1.25 \mathrm{E}-142$ \\
\hline PA5481 & hypothetical protein & -222.66 & $4.52 \mathrm{E}-49$ \\
\hline PA3369 & hypothetical protein & -135.67 & $1.12 \mathrm{E}-35$ \\
\hline mvaT & transcriptional regulator MvaT & -125.92 & $1.26 \mathrm{E}-113$ \\
\hline PA4107 & hypothetical protein & -111.02 & $4.20 \mathrm{E}-213$ \\
\hline PA4270.1 & P26 & -102.71 & $4.49 \mathrm{E}-39$ \\
\hline PA4578 & hypothetical protein & -95.61 & $2.91 \mathrm{E}-118$ \\
\hline PA4793 & hypothetical protein & -84.66 & $2.08 \mathrm{E}-113$ \\
\hline PA4406.1 & & -71.11 & $6.00 \mathrm{E}-56$ \\
\hline PA4881 & hypothetical protein & -70.76 & $1.77 \mathrm{E}-28$ \\
\hline PA2883 & hypothetical protein & -70.12 & 2.58E-65 \\
\hline phrs & PhrS & -61.84 & $3.11 \mathrm{E}-43$ \\
\hline atpE & ATP synthase subunit $C$ & -49.19 & $6.40 \mathrm{E}-39$ \\
\hline PA1414 & hypothetical protein & -38.15 & $3.29 \mathrm{E}-110$ \\
\hline PA3370 & hypothetical protein & -34.56 & $5.77 \mathrm{E}-23$ \\
\hline PA0315 & hypothetical protein & -34.01 & $9.17 \mathrm{E}-48$ \\
\hline PA5494 & hypothetical protein & -31.44 & $6.68 \mathrm{E}-116$ \\
\hline PA0805 & hypothetical protein & -31.39 & $1.06 \mathrm{E}-50$ \\
\hline PA2667 & hypothetical protein & -28.89 & $1.38 \mathrm{E}-41$ \\
\hline PA1076 & hypothetical protein & -27.71 & $4.41 \mathrm{E}-66$ \\
\hline PA0943 & hypothetical protein & -25.83 & $2.71 \mathrm{E}-28$ \\
\hline PA0039 & hypothetical protein & -25.62 & $5.04 \mathrm{E}-38$ \\
\hline$P A 1761$ & hypothetical protein & -25.42 & \begin{tabular}{|l|}
$3.99 \mathrm{E}-25$ \\
\end{tabular} \\
\hline
\end{tabular}




\begin{tabular}{|c|c|c|c|}
\hline PA5061 & hypothetical protein & $\mid-25.27$ & 2.09E-70 \\
\hline PA1942 & hypothetical protein & -23.02 & $3.04 \mathrm{E}-13$ \\
\hline PA4623 & hypothetical protein & -20.51 & $4.39 \mathrm{E}-17$ \\
\hline PA4690.5 & 16S ribosomal RNA & -20.10 & 1.39E-31 \\
\hline PA5369.5 & 16S ribosomal RNA & -20.05 & $5.18 \mathrm{E}-32$ \\
\hline PA1747 & hypothetical protein & -19.90 & 1.73E-29 \\
\hline PA4280.5 & 16S ribosomal RNA & -19.80 & $1.02 \mathrm{E}-31$ \\
\hline PA0668.1 & $16 \mathrm{~S}$ ribosomal RNA & -19.62 & $4.19 \mathrm{E}-32$ \\
\hline PA4277.1 & tRNA-Thr & -19.14 & $2.42 \mathrm{E}-15$ \\
\hline PA2805 & hypothetical protein & -18.65 & $2.53 \mathrm{E}-38$ \\
\hline PA5108 & hypothetical protein & -18.09 & $1.95 \mathrm{E}-40$ \\
\hline PA1592 & hypothetical protein & -17.66 & $3.53 \mathrm{E}-35$ \\
\hline$k d p F$ & potassium-transporting ATPase subunit F & -17.40 & $4.68 \mathrm{E}-26$ \\
\hline pagL & lipid A 3-O-deacylase & -17.21 & $1.85 \mathrm{E}-70$ \\
\hline PA3691 & hypothetical protein & -17.20 & $5.72 \mathrm{E}-80$ \\
\hline PA2485 & hypothetical protein & -15.68 & $7.81 \mathrm{E}-13$ \\
\hline PA5461 & hypothetical protein & -15.57 & $9.06 \mathrm{E}-129$ \\
\hline PA3031 & hypothetical protein & -15.27 & $1.88 \mathrm{E}-27$ \\
\hline GenelD:880268 & unknown & -15.19 & $5.53 E-32$ \\
\hline PA4575 & hypothetical protein & -15.13 & $6.81 \mathrm{E}-37$ \\
\hline prtN & transcriptional regulator PrtN & -14.98 & $4.31 \mathrm{E}-17$ \\
\hline PA1579 & hypothetical protein & -13.80 & 6.33E-26 \\
\hline PA5316.1 & & -13.75 & $6.22 \mathrm{E}-54$ \\
\hline PA4607 & hypothetical protein & -13.39 & $2.83 \mathrm{E}-20$ \\
\hline PA0976.1 & tRNA-Lys & -13.23 & $4.77 \mathrm{E}-07$ \\
\hline PA2759 & hypothetical protein & -12.88 & 2.66E-09 \\
\hline PA1804.1 & tRNA-Asp & -12.80 & $5.65 \mathrm{E}-13$ \\
\hline PA4280.2 & 23S ribosomal RNA & -12.59 & $5.10 \mathrm{E}-17$ \\
\hline PA0951a & hypothetical protein & -12.56 & $8.39 \mathrm{E}-12$ \\
\hline$o p r D$ & porin $\mathrm{D}$ & -12.20 & 1.47E-12 \\
\hline PA2760 & hypothetical protein & -12.05 & $1.29 \mathrm{E}-17$ \\
\hline PA4690.2 & 23S ribosomal RNA & -12.00 & $1.66 \mathrm{E}-16$ \\
\hline PA5369.2 & 23S ribosomal RNA & -11.84 & $3.29 \mathrm{E}-16$ \\
\hline PA0668.4 & $23 \mathrm{~S}$ ribosomal RNA & -11.83 & $3.77 \mathrm{E}-16$ \\
\hline PA3574a & copper chaperone CopZ & -11.30 & $1.04 \mathrm{E}-21$ \\
\hline PA5269 & hypothetical protein & -11.29 & $2.55 \mathrm{E}-40$ \\
\hline PA5347 & hypothetical protein & -11.04 & $1.59 \mathrm{E}-20$ \\
\hline PA4277.3 & tRNA-Tyr & -10.98 & $4.78 \mathrm{E}-17$ \\
\hline PA0621 & hypothetical protein & -10.50 & 7.01E-28 \\
\hline PA1096 & hypothetical protein & -10.32 & $2.03 \mathrm{E}-11$ \\
\hline$n r d J b$ & hypothetical protein & -9.92 & $5.66 \mathrm{E}-11$ \\
\hline
\end{tabular}




\begin{tabular}{|c|c|c|c|}
\hline PA1746 & hypothetical protein & -9.88 & $1.86 \mathrm{E}-20$ \\
\hline PA1934 & hypothetical protein & -9.57 & $1.28 \mathrm{E}-17$ \\
\hline PA2560 & hypothetical protein & -9.51 & $2.07 \mathrm{E}-21$ \\
\hline crfX & hypothetical protein & -9.50 & 1.65E-12 \\
\hline PA5285 & hypothetical protein & -9.25 & $2.22 \mathrm{E}-22$ \\
\hline PA2790 & hypothetical protein & -9.22 & $6.66 \mathrm{E}-21$ \\
\hline PA0940 & hypothetical protein & -8.97 & $7.53 \mathrm{E}-09$ \\
\hline GenelD:878009 & unknown & -8.95 & $1.50 \mathrm{E}-35$ \\
\hline PA4276.1 & tRNA-Trp & -8.94 & $6.90 \mathrm{E}-08$ \\
\hline PA1343 & hypothetical protein & -8.70 & $4.80 \mathrm{E}-22$ \\
\hline PA2453 & hypothetical protein & -8.62 & $5.82 \mathrm{E}-42$ \\
\hline PA3010 & hypothetical protein & -8.39 & $5.14 \mathrm{E}-14$ \\
\hline PA0922 & hypothetical protein & -8.37 & $5.13 \mathrm{E}-10$ \\
\hline PA5526 & hypothetical protein & -8.28 & $4.29 \mathrm{E}-20$ \\
\hline PA4737 & hypothetical protein & -8.24 & $8.44 \mathrm{E}-14$ \\
\hline PA1030 & hypothetical protein & -8.22 & $3.10 \mathrm{E}-15$ \\
\hline PA0261 & hypothetical protein & -8.14 & $1.86 \mathrm{E}-16$ \\
\hline pilY2 & type 4 fimbrial biogenesis protein PilY2 & -8.12 & $7.73 \mathrm{E}-10$ \\
\hline PA3662 & hypothetical protein & -8.06 & $1.51 \mathrm{E}-26$ \\
\hline PA0032a & DOPA 4,5-dioxygenase & -8.03 & $9.71 \mathrm{E}-28$ \\
\hline PA0251 & hypothetical protein & -8.02 & $2.28 \mathrm{E}-09$ \\
\hline PA1190 & hypothetical protein & -7.90 & 4.87E-17 \\
\hline PA1013.1 & tRNA-Ser & -7.85 & $7.77 \mathrm{E}-17$ \\
\hline PA3698 & hypothetical protein & -7.73 & $1.72 \mathrm{E}-11$ \\
\hline PA1206 & hypothetical protein & -7.65 & $1.38 \mathrm{E}-17$ \\
\hline PA0769 & hypothetical protein & -7.60 & 4.36E-25 \\
\hline PA4933 & hypothetical protein & -7.52 & $4.81 \mathrm{E}-52$ \\
\hline PA0012 & hypothetical protein & -7.45 & $1.22 \mathrm{E}-07$ \\
\hline PA4736 & hypothetical protein & -7.40 & 1.03E-20 \\
\hline PA5306 & hypothetical protein & -7.36 & 1.67E-21 \\
\hline PA4972 & hypothetical protein & -7.32 & $1.76 \mathrm{E}-13$ \\
\hline PA0900 & hypothetical protein & -7.23 & $6.93 \mathrm{E}-38$ \\
\hline PA2166 & hypothetical protein & -6.92 & $9.33 \mathrm{E}-07$ \\
\hline PA1767 & hypothetical protein & -6.84 & $2.45 \mathrm{E}-09$ \\
\hline PA3371 & hypothetical protein & -6.51 & 5.70E-09 \\
\hline PA0836.1 & $\mathrm{P} 5$ & -6.50 & $1.35 \mathrm{E}-12$ \\
\hline PA4377 & hypothetical protein & -6.48 & $6.39 \mathrm{E}-13$ \\
\hline PA0573 & hypothetical protein & -6.31 & $5.08 \mathrm{E}-05$ \\
\hline PA1755 & hypothetical protein & -6.28 & $7.08 \mathrm{E}-10$ \\
\hline PA0905.1 & tRNA-Ser & -6.27 & 7.06E-08 \\
\hline PA2756 & hypothetical protein & -6.24 & 3.57E-09 \\
\hline
\end{tabular}




\begin{tabular}{|c|c|c|c|}
\hline amiL & AmiL & -6.12 & $1.20 \mathrm{E}-06$ \\
\hline PA3908 & hypothetical protein & -6.10 & $4.16 \mathrm{E}-11$ \\
\hline PA2793 & hypothetical protein & -6.10 & $1.20 \mathrm{E}-07$ \\
\hline PA2755a & hypothetical protein & -6.05 & $1.32 \mathrm{E}-10$ \\
\hline PA4531 & hypothetical protein & -6.04 & $1.85 \mathrm{E}-09$ \\
\hline PA3611 & hypothetical protein & -5.98 & $3.32 \mathrm{E}-11$ \\
\hline PA0258 & hypothetical protein & -5.86 & $4.50 \mathrm{E}-11$ \\
\hline PA5527 & hypothetical protein & -5.85 & 1.70E-10 \\
\hline PA4437 & hypothetical protein & -5.75 & $5.48 \mathrm{E}-08$ \\
\hline PA4533 & hypothetical protein & -5.73 & $9.03 \mathrm{E}-16$ \\
\hline PA0736a & hypothetical protein & -5.65 & $3.99 \mathrm{E}-21$ \\
\hline PA0260 & hypothetical protein & -5.63 & $5.24 \mathrm{E}-18$ \\
\hline PA5566 & hypothetical protein & -5.61 & 1.74E-06 \\
\hline PA1112a & hypothetical protein & -5.45 & $1.42 \mathrm{E}-08$ \\
\hline PA0955 & hypothetical protein & -5.43 & $1.27 \mathrm{E}-13$ \\
\hline PA3229 & hypothetical protein & -5.38 & $2.84 \mathrm{E}-09$ \\
\hline PA4754 & hypothetical protein & -5.37 & $7.29 \mathrm{E}-16$ \\
\hline PA2568 & hypothetical protein & -5.37 & 4.49E-06 \\
\hline PA3902 & hypothetical protein & -5.34 & $2.12 \mathrm{E}-09$ \\
\hline PA2901 & hypothetical protein & -5.30 & $2.76 \mathrm{E}-15$ \\
\hline PA4685 & hypothetical protein & -5.27 & $1.74 \mathrm{E}-11$ \\
\hline PA0388 & hypothetical protein & -5.27 & $1.65 \mathrm{E}-25$ \\
\hline PA4103 & hypothetical protein & -5.26 & $9.63 \mathrm{E}-39$ \\
\hline$a m r Z$ & alginate and motility regulator $Z$ & -5.25 & $8.57 \mathrm{E}-14$ \\
\hline PA1324 & hypothetical protein & -5.23 & $3.22 \mathrm{E}-26$ \\
\hline PA3033 & hypothetical protein & -5.19 & $5.83 \mathrm{E}-12$ \\
\hline PA1797a & hypothetical protein & -5.13 & 5.47E-09 \\
\hline PA5397 & hypothetical protein & -5.12 & $2.88 \mathrm{E}-08$ \\
\hline PA2433 & hypothetical protein & -5.10 & $1.04 \mathrm{E}-20$ \\
\hline GenelD:878959 & unknown & -5.03 & 1.75E-25 \\
\hline PA4697 & hypothetical protein & -4.96 & $3.29 \mathrm{E}-06$ \\
\hline PA3278 & hypothetical protein & -4.93 & $1.08 \mathrm{E}-17$ \\
\hline PA5062 & hypothetical protein & -4.91 & $3.34 \mathrm{E}-13$ \\
\hline PA3224 & hypothetical protein & -4.87 & $5.47 \mathrm{E}-13$ \\
\hline PA5405 & hypothetical protein & -4.85 & $1.15 \mathrm{E}-08$ \\
\hline PA1112.1 & & -4.84 & $7.71 \mathrm{E}-04$ \\
\hline PA0256 & hypothetical protein & -4.84 & $5.39 \mathrm{E}-12$ \\
\hline PA4537 & hypothetical protein & -4.80 & $2.00 \mathrm{E}-06$ \\
\hline PA2791 & hypothetical protein & -4.78 & 1.72E-06 \\
\hline PA0952 & hypothetical protein & -4.73 & $1.52 \mathrm{E}-05$ \\
\hline PA1244 & hypothetical protein & -4.69 & $1.21 \mathrm{E}-07$ \\
\hline
\end{tabular}




\begin{tabular}{|c|c|c|c|}
\hline PA3793 & hypothetical protein & $\mid-4.67$ & $3.41 \mathrm{E}-12$ \\
\hline PA0910 & hypothetical protein & -4.66 & $1.03 \mathrm{E}-11$ \\
\hline PA2736.1 & tRNA-Pro & -4.65 & $1.89 \mathrm{E}-03$ \\
\hline PA4608 & hypothetical protein & -4.60 & 5.37E-21 \\
\hline PA3794 & hypothetical protein & -4.57 & $1.55 \mathrm{E}-06$ \\
\hline PA2581 & hypothetical protein & -4.56 & $5.32 \mathrm{E}-06$ \\
\hline PA3824.1 & tRNA-Leu & -4.54 & $1.30 \mathrm{E}-04$ \\
\hline PA0624 & hypothetical protein & -4.49 & $5.90 \mathrm{E}-15$ \\
\hline PA4639 & hypothetical protein & -4.46 & $2.82 \mathrm{E}-14$ \\
\hline PA0100 & hypothetical protein & -4.39 & $2.71 \mathrm{E}-08$ \\
\hline PA0554 & hypothetical protein & -4.37 & $1.55 \mathrm{E}-19$ \\
\hline PA5271 & hypothetical protein & -4.31 & $1.93 \mathrm{E}-20$ \\
\hline PA2570.1 & tRNA-Leu & -4.31 & 1.63E-04 \\
\hline PA2486 & hypothetical protein & -4.29 & $6.62 \mathrm{E}-06$ \\
\hline PA4278 & hypothetical protein & -4.26 & $4.12 \mathrm{E}-07$ \\
\hline PA0911 & hypothetical protein & -4.25 & $2.90 \mathrm{E}-04$ \\
\hline PA0429 & hypothetical protein & -4.24 & $1.34 \mathrm{E}-18$ \\
\hline PA3740 & hypothetical protein & -4.22 & 1.97E-11 \\
\hline PA4874 & hypothetical protein & -4.21 & $7.64 \mathrm{E}-21$ \\
\hline PA2792 & hypothetical protein & -4.20 & $1.48 \mathrm{E}-05$ \\
\hline prfB & peptide chain release factor 1 & -4.19 & $6.80 \mathrm{E}-18$ \\
\hline PA2799 & hypothetical protein & -4.19 & $1.84 \mathrm{E}-11$ \\
\hline PA4690 & hypothetical protein & -4.18 & $6.35 \mathrm{E}-05$ \\
\hline PA0921 & hypothetical protein & -4.05 & $1.11 \mathrm{E}-06$ \\
\hline PA4683 & hypothetical protein & -4.00 & $2.23 \mathrm{E}-05$ \\
\hline PA4141 & hypothetical protein & -4.00 & 2.03E-09 \\
\hline PA4690a & paraquat-inducible protein $\mathrm{A}$ & -3.93 & 5.31E-04 \\
\hline PA1492 & hypothetical protein & -3.92 & $5.21 \mathrm{E}-07$ \\
\hline PA0713 & hypothetical protein & -3.88 & $2.11 \mathrm{E}-05$ \\
\hline PA5191 & hypothetical protein & -3.87 & $9.69 \mathrm{E}-05$ \\
\hline PA4277.2 & tRNA-Gly & -3.83 & $1.52 \mathrm{E}-04$ \\
\hline PA4390 & hypothetical protein & -3.81 & $4.40 \mathrm{E}-05$ \\
\hline PA2364 & hypothetical protein & \begin{tabular}{|l|}
-3.77 \\
\end{tabular} & $1.53 \mathrm{E}-10$ \\
\hline PA0989 & hypothetical protein & -3.76 & $1.43 \mathrm{E}-08$ \\
\hline PA4313a & hypothetical protein & -3.70 & 2.93E-14 \\
\hline PA4690.4 & tRNA-Ile & -3.70 & $2.41 \mathrm{E}-04$ \\
\hline PA0905.2 & tRNA-Arg & -3.70 & 1.02E-04 \\
\hline PA1369 & hypothetical protein & -3.68 & $3.16 \mathrm{E}-04$ \\
\hline PA5404 & hypothetical protein & -3.67 & 2.05E-09 \\
\hline PA4802.1 & tRNA-Sec & -3.66 & $7.45 \mathrm{E}-08$ \\
\hline PA0887.1 & P7 & -3.64 & $2.45 \mathrm{E}-04$ \\
\hline
\end{tabular}




\begin{tabular}{|c|c|c|c|}
\hline PA3057 & hypothetical protein & $\mid-3.63$ & 2.10E-05 \\
\hline PA1509 & hypothetical protein & -3.62 & $3.90 \mathrm{E}-06$ \\
\hline PA0926 & hypothetical protein & -3.62 & $3.48 \mathrm{E}-10$ \\
\hline PA4937.1 & tRNA-Leu & -3.60 & 3.82E-04 \\
\hline PA2565 & hypothetical protein & -3.58 & $2.69 \mathrm{E}-03$ \\
\hline PA0007 & hypothetical protein & -3.57 & $3.47 \mathrm{E}-17$ \\
\hline PA4682 & hypothetical protein & -3.56 & $1.73 \mathrm{E}-05$ \\
\hline PA2820 & hypothetical protein & -3.56 & $4.23 \mathrm{E}-18$ \\
\hline PA2763 & hypothetical protein & -3.53 & 2.94E-04 \\
\hline PA0532 & hypothetical protein & -3.50 & 1.10E-06 \\
\hline PA0060 & hypothetical protein & -3.49 & $3.65 \mathrm{E}-08$ \\
\hline PA2205 & hypothetical protein & -3.44 & 1.87E-08 \\
\hline PA0553 & hypothetical protein & -3.44 & $1.21 \mathrm{E}-15$ \\
\hline PA4469 & hypothetical protein & -3.43 & $1.23 \mathrm{E}-03$ \\
\hline PA2569 & hypothetical protein & -3.38 & 3.06E-04 \\
\hline PA2264 & hypothetical protein & -3.34 & $2.22 \mathrm{E}-16$ \\
\hline PA2753 & hypothetical protein & -3.33 & $2.19 \mathrm{E}-13$ \\
\hline PA5402 & hypothetical protein & -3.32 & $2.72 \mathrm{E}-06$ \\
\hline PA2381 & hypothetical protein & -3.30 & $4.21 \mathrm{E}-11$ \\
\hline PA3572 & hypothetical protein & -3.29 & $2.35 \mathrm{E}-09$ \\
\hline PA4581.1 & tRNA-Arg & -3.27 & $8.16 \mathrm{E}-08$ \\
\hline PA5369.4 & tRNA-Ile & -3.24 & 1.74E-03 \\
\hline PA1308 & hypothetical protein & -3.19 & $6.48 \mathrm{E}-12$ \\
\hline GenelD:879706 & unknown & -3.18 & $9.85 \mathrm{E}-14$ \\
\hline PA2559a & hypothetical protein & -3.18 & $6.49 \mathrm{E}-05$ \\
\hline PA1383 & hypothetical protein & -3.15 & 4.86E-05 \\
\hline PA3367 & hypothetical protein & -3.13 & $5.25 \mathrm{E}-07$ \\
\hline PA3015 & hypothetical protein & -3.11 & $1.64 \mathrm{E}-10$ \\
\hline PA0135 & hypothetical protein & -3.11 & $3.30 \mathrm{E}-03$ \\
\hline PA2670 & hypothetical protein & -3.06 & 8.18E-05 \\
\hline PA4535 & hypothetical protein & -3.05 & $3.41 \mathrm{E}-15$ \\
\hline PA0442 & hypothetical protein & -3.05 & $6.32 \mathrm{E}-03$ \\
\hline PA3139.1 & tRNA-Asn & -3.03 & $4.36 \mathrm{E}-03$ \\
\hline PA5226 & hypothetical protein & -3.02 & $2.82 \mathrm{E}-10$ \\
\hline PA3362 & transporter protein AmiS & -3.01 & 5.89E-04 \\
\hline ssrs & 6S RNA & -2.98 & $1.11 \mathrm{E}-15$ \\
\hline lecB & fucose-binding lectin PA-IIL & -2.97 & $3.52 \mathrm{E}-04$ \\
\hline PA0668.2 & tRNA-Ile & -2.95 & $3.08 \mathrm{E}-03$ \\
\hline plcB & phospholipase C & -2.95 & $7.32 \mathrm{E}-11$ \\
\hline PA3966 & hypothetical protein & -2.92 & $3.99 \mathrm{E}-03$ \\
\hline PA0874 & hypothetical protein & -2.91 & 3.83E-03 \\
\hline
\end{tabular}




\begin{tabular}{|c|c|c|c|}
\hline PA1038 & hypothetical protein & $\mid-2.91$ & 2.74E-08 \\
\hline PA0894 & hypothetical protein & -2.88 & $8.85 \mathrm{E}-08$ \\
\hline PA4669.1 & tRNA-GIn & -2.85 & $2.35 \mathrm{E}-03$ \\
\hline PA2761 & hypothetical protein & -2.85 & 5.84E-03 \\
\hline PA0050 & hypothetical protein & -2.84 & $2.28 \mathrm{E}-06$ \\
\hline PA4280.4 & tRNA-Ile & -2.82 & $8.20 \mathrm{E}-03$ \\
\hline PA4108a & hypothetical protein & -2.82 & 7.90E-07 \\
\hline ffs & $4.5 \mathrm{~S}$ ribosomal RNA & -2.81 & $7.23 \mathrm{E}-03$ \\
\hline PA3519 & hypothetical protein & -2.81 & $8.39 \mathrm{E}-05$ \\
\hline PA4327 & hypothetical protein & -2.78 & $2.37 \mathrm{E}-11$ \\
\hline PA1387 & hypothetical protein & -2.77 & 6.30E-05 \\
\hline alkB2 & alkane-1 monooxygenase & -2.76 & $1.08 \mathrm{E}-07$ \\
\hline PA3018 & hypothetical protein & -2.71 & 1.85E-09 \\
\hline PA0306a & transcriptional regulator & -2.71 & $1.55 \mathrm{E}-07$ \\
\hline PA5414 & hypothetical protein & -2.71 & $1.98 \mathrm{E}-11$ \\
\hline PA0714 & hypothetical protein & -2.70 & $6.95 \mathrm{E}-03$ \\
\hline PA3451 & hypothetical protein & -2.67 & $5.70 \mathrm{E}-03$ \\
\hline PA3009 & hypothetical protein & -2.67 & $1.23 \mathrm{E}-04$ \\
\hline PA3716 & hypothetical protein & -2.66 & $1.78 \mathrm{E}-12$ \\
\hline PA4961 & hypothetical protein & -2.65 & $8.44 \mathrm{E}-15$ \\
\hline PA2763a & hypothetical protein & -2.65 & 6.35E-04 \\
\hline PA0160 & hypothetical protein & -2.64 & 3.77E-03 \\
\hline PA2429 & hypothetical protein & -2.64 & $8.74 \mathrm{E}-06$ \\
\hline PA1370 & hypothetical protein & -2.60 & $2.63 \mathrm{E}-03$ \\
\hline PA1305 & hypothetical protein & -2.59 & $5.58 \mathrm{E}-10$ \\
\hline GenelD:882377 & unknown & -2.58 & $4.95 \mathrm{E}-03$ \\
\hline PA5340 & hypothetical protein & -2.57 & $3.95 \mathrm{E}-14$ \\
\hline PA2775 & hypothetical protein & -2.56 & $1.80 \mathrm{E}-03$ \\
\hline PA2501 & hypothetical protein & -2.53 & 3.86E-07 \\
\hline PA0343 & hypothetical protein & -2.52 & $1.72 \mathrm{E}-11$ \\
\hline PA1106 & hypothetical protein & -2.49 & 5.05E-06 \\
\hline PA1728 & hypothetical protein & -2.49 & 1.17E-03 \\
\hline PA0234 & hypothetical protein & -2.47 & 9.49E-05 \\
\hline PA4782 & hypothetical protein & -2.47 & $2.24 \mathrm{E}-09$ \\
\hline PA4523 & hypothetical protein & -2.47 & 3.03E-11 \\
\hline$o p d C$ & histidine porin OpdC & -2.46 & $1.62 \mathrm{E}-11$ \\
\hline PA2669 & hypothetical protein & -2.44 & 9.40E-03 \\
\hline PA2779 & hypothetical protein & -2.43 & $8.25 \mathrm{E}-05$ \\
\hline PA1641 & hypothetical protein & -2.43 & $2.46 \mathrm{E}-05$ \\
\hline PA4317 & hypothetical protein & -2.42 & 1.03E-04 \\
\hline PA3733a & hypothetical protein & -2.41 & 8.18E-04 \\
\hline
\end{tabular}




\begin{tabular}{|c|c|c|c|}
\hline PA5252a & hypothetical protein & $\mid-2.40$ & 1.91E-06 \\
\hline PA0505 & hypothetical protein & -2.40 & 1.19E-04 \\
\hline PA0365 & hypothetical protein & -2.40 & $2.75 \mathrm{E}-03$ \\
\hline PA0122 & hypothetical protein & -2.38 & 3.67E-09 \\
\hline PA2559 & hypothetical protein & -2.37 & 2.66E-08 \\
\hline GeneID:881406 & unknown & -2.37 & $7.24 \mathrm{E}-08$ \\
\hline PA1643a & aldehyde-activating protein & -2.32 & 2.72E-05 \\
\hline PA4681 & hypothetical protein & -2.31 & 2.89E-05 \\
\hline PA1606 & hypothetical protein & -2.31 & $9.41 \mathrm{E}-04$ \\
\hline PA0776 & hypothetical protein & -2.29 & $1.58 \mathrm{E}-03$ \\
\hline PA0845 & neutral ceramidase & -2.29 & 3.13E-06 \\
\hline PA1530 & hypothetical protein & -2.28 & $7.85 \mathrm{E}-05$ \\
\hline PA5533 & hypothetical protein & -2.28 & $5.68 \mathrm{E}-05$ \\
\hline opdP & glycine-glutamate dipeptide porin OpdP & -2.27 & $9.81 \mathrm{E}-09$ \\
\hline PA4603 & hypothetical protein & -2.27 & $3.59 \mathrm{E}-07$ \\
\hline PA3440a & type III effector protein & -2.26 & 3.05E-05 \\
\hline PA4596 & transcriptional regulator & -2.23 & $1.75 \mathrm{E}-03$ \\
\hline PA1837a & hypothetical protein & -2.22 & 1.00E-03 \\
\hline PA1852 & hypothetical protein & -2.21 & 7.34E-06 \\
\hline PA3661 & hypothetical protein & -2.21 & 6.17E-03 \\
\hline algP & alginate regulatory protein $\mathrm{AlgP}$ & -2.19 & $5.58 \mathrm{E}-07$ \\
\hline PA1763 & hypothetical protein & -2.16 & $1.51 \mathrm{E}-03$ \\
\hline PA0109 & hypothetical protein & -2.13 & $8.35 \mathrm{E}-04$ \\
\hline GenelD:883111 & unknown & -2.12 & $1.28 \mathrm{E}-07$ \\
\hline PA1833a & alpha/beta hydrolase & -2.11 & $8.16 \mathrm{E}-04$ \\
\hline PA4703 & hypothetical protein & -2.11 & $3.11 \mathrm{E}-03$ \\
\hline PA3496 & hypothetical protein & -2.11 & $8.71 \mathrm{E}-07$ \\
\hline opdH & cis-aconitate porin OpdH & -2.08 & $8.65 \mathrm{E}-05$ \\
\hline PA3488 & hypothetical protein & -2.08 & $2.80 \mathrm{E}-03$ \\
\hline PA0099 & hypothetical protein & -2.06 & $2.16 \mathrm{E}-03$ \\
\hline PA0042 & hypothetical protein & -2.06 & $1.23 \mathrm{E}-03$ \\
\hline PA5520 & hypothetical protein & -2.06 & $9.84 \mathrm{E}-04$ \\
\hline PA1167 & hypothetical protein & -2.05 & 4.79E-06 \\
\hline$y f i R$ & hypothetical protein & -2.03 & $8.58 \mathrm{E}-06$ \\
\hline PA2754a & hypothetical protein & -2.01 & 5.84E-03 \\
\hline \multicolumn{4}{|c|}{ General function prediction only } \\
\hline PA4739 & hypothetical protein & -1052.39 & $1.58 \mathrm{E}-73$ \\
\hline$h f q$ & RNA-binding protein $\mathrm{Hfq}$ & -88.62 & $4.01 \mathrm{E}-68$ \\
\hline PA2971 & hypothetical protein & -46.39 & $8.50 \mathrm{E}-32$ \\
\hline$f a b G$ & 3-oxoacyl-[acyl-carrier-protein] reductase FabG & -44.73 & $4.17 \mathrm{E}-70$ \\
\hline PA4465 & hypothetical protein & -33.70 & $4.15 \mathrm{E}-36$ \\
\hline
\end{tabular}




\begin{tabular}{|c|c|c|c|}
\hline hpd & 4-hydroxyphenylpyruvate dioxygenase & -28.49 & 4.40E-97 \\
\hline PA1749 & hypothetical protein & -19.28 & $1.93 \mathrm{E}-23$ \\
\hline PA1372 & hypothetical protein & -16.52 & $5.48 \mathrm{E}-29$ \\
\hline PA4461 & $A B C$ transporter ATP-binding protein & -16.21 & $4.23 \mathrm{E}-20$ \\
\hline PA2604 & hypothetical protein & -15.09 & $6.26 \mathrm{E}-38$ \\
\hline PA3806 & $\begin{array}{l}\text { 23S rRNA (adenine(2503)-C(2))-methyltransferase } \\
\text { RImN }\end{array}$ & -15.08 & 5.73E-18 \\
\hline PA3978 & hypothetical protein & -14.54 & $7.30 \mathrm{E}-28$ \\
\hline PA0729 & hypothetical protein & -14.53 & 3.24E-22 \\
\hline PA4426 & hypothetical protein & -14.22 & $9.39 \mathrm{E}-18$ \\
\hline PA2119 & alcohol dehydrogenase & -12.70 & 4.94E-35 \\
\hline PA3615 & hypothetical protein & -12.05 & $9.84 \mathrm{E}-38$ \\
\hline PA1440 & hypothetical protein & -12.02 & $2.62 \mathrm{E}-22$ \\
\hline putP & sodium/proline symporter PutP & -11.82 & $4.18 \mathrm{E}-57$ \\
\hline PA4794 & hypothetical protein & -11.44 & $9.28 \mathrm{E}-97$ \\
\hline PA3799 & GTPase Der & -11.13 & $2.10 \mathrm{E}-16$ \\
\hline PA4115 & hypothetical protein & -10.66 & $1.98 \mathrm{E}-68$ \\
\hline mliC & Iysozyme inhibitor & -10.57 & $3.14 \mathrm{E}-18$ \\
\hline $\operatorname{ssp} B$ & ClpXP protease specificity-enhancing factor & -10.46 & $2.05 \mathrm{E}-09$ \\
\hline PA3753 & hypothetical protein & -10.45 & $5.09 \mathrm{E}-50$ \\
\hline PA0968 & hypothetical protein & -9.87 & 3.37E-13 \\
\hline PA5492 & ribosome biogenesis GTP-binding protein YsxC & -9.48 & $4.35 \mathrm{E}-20$ \\
\hline PA4674 & hypothetical protein & -9.08 & $2.18 \mathrm{E}-15$ \\
\hline PA5545 & hypothetical protein & -8.87 & $7.03 \mathrm{E}-13$ \\
\hline PA5488 & hypothetical protein & -8.52 & $1.19 \mathrm{E}-40$ \\
\hline PA0066 & hypothetical protein & -8.44 & 1.67E-36 \\
\hline obg & GTPase ObgE & -8.08 & $1.34 \mathrm{E}-46$ \\
\hline PA1788 & hypothetical protein & -7.72 & 1.47E-10 \\
\hline PA2707 & hypothetical protein & -7.50 & $5.49 \mathrm{E}-51$ \\
\hline$f d n G$ & formate dehydrogenase-O major subunit & -7.15 & $9.38 \mathrm{E}-69$ \\
\hline PA0619 & bacteriophage protein & -7.05 & $2.88 \mathrm{E}-19$ \\
\hline PA0622 & bacteriophage protein & -6.95 & $1.72 \mathrm{E}-27$ \\
\hline pfpl & protease Pfpl & -6.80 & $2.11 \mathrm{E}-23$ \\
\hline PA0623 & bacteriophage protein & -6.41 & $7.96 \mathrm{E}-13$ \\
\hline PA4833 & hypothetical protein & -6.40 & $5.01 \mathrm{E}-31$ \\
\hline PA1807 & ABC transporter ATP-binding protein & -6.32 & $1.93 \mathrm{E}-16$ \\
\hline PA0618 & bacteriophage protein & -6.22 & $2.19 \mathrm{E}-17$ \\
\hline PA1307 & hypothetical protein & -6.21 & $7.46 \mathrm{E}-39$ \\
\hline PA0959 & hypothetical protein & -6.04 & $6.56 \mathrm{E}-10$ \\
\hline PA1012 & hypothetical protein & -5.97 & $1.99 \mathrm{E}-16$ \\
\hline PA2575 & hypothetical protein & -5.90 & $4.29 \mathrm{E}-41$ \\
\hline PA0617 & bacteriophage protein & -5.76 & 1.64E-08 \\
\hline
\end{tabular}




\begin{tabular}{|c|c|c|c|}
\hline PA3836 & hypothetical protein & -5.73 & $6.82 \mathrm{E}-32$ \\
\hline PA1808 & $A B C$ transporter permease & -5.61 & 1.97E-09 \\
\hline amiE & acylamide amidohydrolase & -5.53 & $3.97 \mathrm{E}-18$ \\
\hline PA5177 & hydrolase & -5.46 & $3.45 \mathrm{E}-22$ \\
\hline PA3827 & hypothetical protein & -5.46 & $2.06 \mathrm{E}-23$ \\
\hline PA0068 & hypothetical protein & -5.37 & $7.99 \mathrm{E}-14$ \\
\hline PA1762 & hypothetical protein & -5.35 & $7.70 \mathrm{E}-06$ \\
\hline PA4595 & $A B C$ transporter ATP-binding protein & -5.31 & $4.55 \mathrm{E}-46$ \\
\hline PA2631 & acetyltransferase & -5.15 & $5.63 \mathrm{E}-26$ \\
\hline PA0976 & 7-cyano-7-deazaguanine synthase & -5.12 & 1.35E-07 \\
\hline PA0608 & phosphoglycolate phosphatase & -5.11 & $1.53 \mathrm{E}-21$ \\
\hline PA3849 & nucleoid-associated protein NdpA & -4.96 & $2.60 \mathrm{E}-21$ \\
\hline PA2566 & hypothetical protein & -4.93 & 2.93E-08 \\
\hline PA3828 & hypothetical protein & -4.89 & $2.06 \mathrm{E}-09$ \\
\hline PA1007 & hypothetical protein & -4.89 & $2.11 \mathrm{E}-06$ \\
\hline PA0124 & hypothetical protein & -4.88 & $1.05 \mathrm{E}-08$ \\
\hline PA0065 & 5'-nucleotidase & -4.86 & $1.35 \mathrm{E}-24$ \\
\hline PA4943 & GTP-binding protein & -4.86 & 6.74E-33 \\
\hline PA0620 & bacteriophage protein & -4.75 & $5.71 \mathrm{E}-08$ \\
\hline PA4534 & hypothetical protein & -4.75 & $3.38 \mathrm{E}-14$ \\
\hline pstC & phosphate $A B C$ transporter permease & -4.69 & $5.75 \mathrm{E}-22$ \\
\hline PA5567 & tRNA modification GTPase TrmE & -4.57 & $4.49 \mathrm{E}-33$ \\
\hline surE & 5'-nucleotidase SurE & -4.56 & $4.72 \mathrm{E}-15$ \\
\hline cat & chloramphenicol acetyltransferase & -4.46 & 1.12E-05 \\
\hline PA3752 & hypothetical protein & -4.46 & $2.19 \mathrm{E}-09$ \\
\hline PA2536 & phosphatidate cytidylyltransferase & -4.39 & $9.58 \mathrm{E}-08$ \\
\hline PA0935 & nucleoside triphosphate pyrophosphohydrolase & -4.38 & $4.46 \mathrm{E}-07$ \\
\hline PA1643 & tRNA 2-selenouridine synthase & -4.30 & 8.17E-22 \\
\hline PA0115 & hypothetical protein & -4.29 & 1.52E-17 \\
\hline PA0628 & hypothetical protein & -4.27 & $3.74 \mathrm{E}-08$ \\
\hline cbrA & two-component sensor CbrA & -4.23 & 1.15E-24 \\
\hline PA2884 & hypothetical protein & -4.17 & $9.73 \mathrm{E}-08$ \\
\hline PA4657 & hypothetical protein & -4.13 & $2.93 \mathrm{E}-20$ \\
\hline PA3982 & metalloprotease & -4.12 & $6.10 \mathrm{E}-13$ \\
\hline PA0988 & hypothetical protein & -4.12 & $1.51 \mathrm{E}-06$ \\
\hline PA1829 & hypothetical protein & -4.10 & $5.87 \mathrm{E}-26$ \\
\hline PA0596 & hypothetical protein & -4.08 & $1.53 \mathrm{E}-20$ \\
\hline phzA1 & phenazine biosynthesis protein & -4.07 & $1.21 \mathrm{E}-03$ \\
\hline PA4562 & hypothetical protein & -4.07 & $2.42 \mathrm{E}-08$ \\
\hline $\operatorname{sen} C$ & cytochrome c oxidase assembly protein SenC & -4.04 & $6.59 \mathrm{E}-10$ \\
\hline PA1518 & 5-hydroxyisourate hydrolase & -4.04 & $5.79 \mathrm{E}-06$ \\
\hline
\end{tabular}




\begin{tabular}{|c|c|c|c|}
\hline PA5362 & hypothetical protein & -4.04 & $1.81 \mathrm{E}-14$ \\
\hline PA5088 & hypothetical protein & -3.98 & $4.20 \mathrm{E}-06$ \\
\hline PA5521 & short-chain dehydrogenase & -3.89 & $3.72 \mathrm{E}-11$ \\
\hline adhA & alcohol dehydrogenase & -3.89 & $3.68 \mathrm{E}-10$ \\
\hline PA4882 & hypothetical protein & -3.89 & $2.19 \mathrm{E}-14$ \\
\hline PA3310 & hypothetical protein & -3.88 & $9.30 \mathrm{E}-08$ \\
\hline PA2974 & hydrolase & -3.84 & $1.88 \mathrm{E}-09$ \\
\hline$g b c A$ & protein GbcA & -3.79 & $6.61 \mathrm{E}-13$ \\
\hline qor & oxygen-dependent quinone oxidoreductase & -3.72 & $2.43 \mathrm{E}-23$ \\
\hline eco & ecotin & -3.68 & $6.60 \mathrm{E}-06$ \\
\hline PA0483 & acetyltransferase & -3.58 & $1.91 \mathrm{E}-10$ \\
\hline PA2762 & hypothetical protein & -3.53 & 4.75E-04 \\
\hline spuA & glutamine amidotransferase & -3.53 & $2.28 \mathrm{E}-11$ \\
\hline PA0627 & hypothetical protein & -3.48 & 4.83E-03 \\
\hline PA0360 & hypothetical protein & -3.46 & $5.07 \mathrm{E}-21$ \\
\hline comL & competence protein ComL & -3.37 & $1.50 \mathrm{E}-12$ \\
\hline PA1964 & ABC-F family ATPase & -3.34 & $1.06 \mathrm{E}-11$ \\
\hline PA1415 & hypothetical protein & -3.31 & $2.10 \mathrm{E}-23$ \\
\hline PA1135 & molecular chaperone Hsp31/glyoxalase & -3.29 & $9.37 \mathrm{E}-08$ \\
\hline $\operatorname{aspP}$ & adenosine diphosphate sugar pyrophosphatase & -3.22 & $4.38 \mathrm{E}-20$ \\
\hline PA2963 & hypothetical protein & -3.17 & $9.79 \mathrm{E}-07$ \\
\hline PA5540 & hypothetical protein & -3.16 & $2.85 \mathrm{E}-06$ \\
\hline wrbA & $\mathrm{NAD}(\mathrm{P}) \mathrm{H}$ dehydrogenase & -3.12 & 1.45E-07 \\
\hline PA2564 & trans-aconitate 2-methyltransferase & -3.08 & $1.38 \mathrm{E}-11$ \\
\hline PA4038 & hypothetical protein & -2.96 & 3.84E-09 \\
\hline PA4667 & hypothetical protein & -2.88 & 1.12E-13 \\
\hline PA4714 & hypothetical protein & -2.87 & $1.59 \mathrm{E}-06$ \\
\hline PA0371 & hypothetical protein & -2.72 & $4.78 \mathrm{E}-14$ \\
\hline PA1605 & hypothetical protein & -2.71 & $5.66 \mathrm{E}-05$ \\
\hline pta & phosphate acetyltransferase & -2.67 & $2.01 \mathrm{E}-09$ \\
\hline PA3747 & hypothetical protein & -2.67 & 1.29E-04 \\
\hline PA4604 & hypothetical protein & -2.67 & $6.76 \mathrm{E}-11$ \\
\hline PA2580 & hypothetical protein & -2.67 & 4.23E-03 \\
\hline PA0485 & hypothetical protein & -2.62 & $1.13 \mathrm{E}-07$ \\
\hline PA1390 & glycosyl transferase family protein & -2.43 & 3.36E-03 \\
\hline PA5314 & hypothetical protein & -2.40 & 9.82E-05 \\
\hline PA1428 & hypothetical protein & -2.39 & $2.42 \mathrm{E}-06$ \\
\hline era & GTPase Era & -2.34 & $1.99 \mathrm{E}-06$ \\
\hline PA5080 & prolyl aminopeptidase & -2.34 & 2.92E-08 \\
\hline PA4968 & hypothetical protein & -2.34 & 2.86E-06 \\
\hline$m q o B$ & malate:quinone oxidoreductase & -2.33 & $2.92 \mathrm{E}-09$ \\
\hline
\end{tabular}




\begin{tabular}{|c|c|c|c|}
\hline PA1575 & hypothetical protein & -2.32 & 3.02E-06 \\
\hline PA3234 & acetate permease & -2.27 & $3.46 \mathrm{E}-08$ \\
\hline PA3616 & recombination regulator $\operatorname{Rec} X$ & -2.25 & $1.12 \mathrm{E}-03$ \\
\hline PA3663 & hypothetical protein & -2.25 & $2.90 \mathrm{E}-05$ \\
\hline PA4689 & hypothetical protein & -2.24 & $1.73 \mathrm{E}-13$ \\
\hline PA1542 & hypothetical protein & -2.23 & $6.08 \mathrm{E}-03$ \\
\hline PA3079 & hypothetical protein & -2.20 & 5.41E-05 \\
\hline PA4692 & sulfite oxidase subunit YedY & -2.17 & 7.21E-05 \\
\hline PA4438 & hypothetical protein & -2.17 & $3.01 \mathrm{E}-05$ \\
\hline PA4539 & hypothetical protein & -2.12 & 1.47E-08 \\
\hline PA4517 & hypothetical protein & -2.12 & $4.26 \mathrm{E}-08$ \\
\hline PA4584 & hypothetical protein & -2.06 & 1.05E-03 \\
\hline PA4379 & hypothetical protein & -2.05 & $8.08 \mathrm{E}-04$ \\
\hline PA5544 & hypothetical protein & -2.02 & $1.01 \mathrm{E}-08$ \\
\hline PA2770 & isomerase & -2.01 & $5.60 \mathrm{E}-06$ \\
\hline \multicolumn{4}{|c|}{ Inorganic ion transport and metabolism } \\
\hline $\operatorname{sod} B$ & superoxide dismutase & -135.79 & 7.83E-157 \\
\hline PA1673 & bacteriohemerythrin & -62.16 & $9.62 \mathrm{E}-76$ \\
\hline PA0962 & DNA-binding stress protein & -60.33 & $2.83 \mathrm{E}-52$ \\
\hline fur & ferric uptake regulation protein & -26.89 & $2.00 \mathrm{E}-79$ \\
\hline ppk & polyphosphate kinase & -24.79 & $2.11 \mathrm{E}-26$ \\
\hline bfrB & bacterioferritin & -24.38 & $4.10 \mathrm{E}-48$ \\
\hline katA & catalase & -18.91 & $4.62 \mathrm{E}-24$ \\
\hline PA5208 & hypothetical protein & -16.74 & $1.77 \mathrm{E}-25$ \\
\hline$p s t B$ & phosphate $A B C$ transporter ATP-binding protein & -15.38 & $4.97 \mathrm{E}-22$ \\
\hline PA3983 & hypothetical protein & -14.73 & 1.03E-33 \\
\hline PA5505 & TonB-dependent receptor & -13.22 & $3.31 \mathrm{E}-105$ \\
\hline bfrA & bacterioferritin & -12.09 & $1.95 \mathrm{E}-10$ \\
\hline PA5078 & glucan biosynthesis protein $\mathrm{G}$ & -11.15 & $3.14 \mathrm{E}-28$ \\
\hline phou & phosphate uptake regulatory protein $\mathrm{PhoU}$ & -10.98 & $1.34 \mathrm{E}-18$ \\
\hline kdpA & potassium-transporting ATPase subunit A & -10.16 & $3.01 \mathrm{E}-14$ \\
\hline PA5250 & hypothetical protein & -9.77 & $6.24 \mathrm{E}-17$ \\
\hline PA5130 & hypothetical protein & -8.98 & $1.07 \mathrm{E}-11$ \\
\hline PA0950 & arsenate reductase & -8.40 & $2.35 \mathrm{E}-29$ \\
\hline PA1538 & flavin-containing monooxygenase & -8.22 & $6.91 \mathrm{E}-40$ \\
\hline cysP & sulfate $A B C$ transporter substrate-binding protein & -8.21 & $1.79 \mathrm{E}-15$ \\
\hline pstS & phosphate $A B C$ transporter substrate-binding protein & -7.96 & $7.42 \mathrm{E}-14$ \\
\hline PA4292 & phosphate transporter & -7.09 & 3.64E-18 \\
\hline cysW & sulfate transporter CysW & -6.94 & $6.60 \mathrm{E}-32$ \\
\hline PA4880 & bacterioferritin & -6.85 & $9.03 \mathrm{E}-12$ \\
\hline mgtE & Mg transporter MgtE & -6.26 & $1.13 \mathrm{E}-13$ \\
\hline
\end{tabular}




\begin{tabular}{|c|c|c|c|}
\hline PA1058 & monovalent cation $/ \mathrm{H}+$ antiporter subunit $\mathrm{F}$ & -6.14 & 3.65E-11 \\
\hline $\operatorname{ccpR}$ & cytochrome C551 peroxidase & -6.05 & $2.31 \mathrm{E}-17$ \\
\hline $\operatorname{trk} A$ & $\begin{array}{l}\text { potassium transporter inner membrane associated } \\
\text { protein }\end{array}$ & -5.52 & 3.87E-20 \\
\hline PA0102 & carbonic anhydrase & -5.01 & $4.31 \mathrm{E}-27$ \\
\hline PA5529 & sodium/proton antiporter & -4.72 & $2.86 \mathrm{E}-17$ \\
\hline PA2608 & hypothetical protein & -4.64 & $1.01 \mathrm{E}-10$ \\
\hline PA5530 & MFS dicarboxylate transporter & -4.53 & $3.55 \mathrm{E}-06$ \\
\hline sodM & superoxide dismutase & -3.91 & $1.59 \mathrm{E}-05$ \\
\hline PA1057 & monovalent cation/ $\mathrm{H}+$ antiporter subunit $\mathrm{E}$ & -3.80 & 7.17E-13 \\
\hline PA4514 & iron transport outer membrane receptor & -3.74 & $8.70 \mathrm{E}-06$ \\
\hline corA & magnesium/cobalt transporter & -3.71 & $1.50 \mathrm{E}-06$ \\
\hline PA2563 & sulfate transporter & -3.59 & 7.39E-13 \\
\hline PA0397 & cation efflux system protein & -3.53 & $5.88 \mathrm{E}-16$ \\
\hline PA4156 & TonB-dependent receptor & -3.47 & $2.49 \mathrm{E}-12$ \\
\hline PA1059 & monovalent cation $/ \mathrm{H}+$ antiporter subunit $\mathrm{G}$ & -3.37 & 9.94E-08 \\
\hline snr1 & cytochrome C Snr1 & -3.30 & $6.49 \mathrm{E}-05$ \\
\hline$k d p B$ & potassium-transporting ATPase subunit B & -3.28 & 1.09E-04 \\
\hline PA5217 & iron $\mathrm{ABC}$ transporter substrate-binding protein & -3.09 & $5.23 E-13$ \\
\hline PA2607 & hypothetical protein & -3.02 & $1.40 \mathrm{E}-08$ \\
\hline katB & catalase & -2.99 & $2.77 \mathrm{E}-13$ \\
\hline PA3250 & hypothetical protein & -2.91 & 1.70E-09 \\
\hline thil & thiamine biosynthesis protein Thil & -2.75 & $5.03 \mathrm{E}-10$ \\
\hline PA3265 & transporter & -2.73 & 3.44E-04 \\
\hline kefB & $\begin{array}{l}\text { glutathione-regulated potassium-efflux system } \\
\text { protein KefB }\end{array}$ & -2.70 & $2.98 \mathrm{E}-09$ \\
\hline cmaX & transporter & -2.70 & $1.54 \mathrm{E}-05$ \\
\hline$p p x$ & exopolyphosphatase & -2.65 & $2.59 \mathrm{E}-12$ \\
\hline$s b p$ & sulfate-binding protein & -2.56 & $5.59 \mathrm{E}-12$ \\
\hline $\operatorname{cys} N$ & $\begin{array}{l}\text { bifunctional sulfate adenylyltransferase subunit } \\
\text { 1/adenylylsulfate kinase }\end{array}$ & -2.55 & $1.31 \mathrm{E}-16$ \\
\hline PA3931 & hypothetical protein & -2.54 & 3.44E-04 \\
\hline PA4676 & carbonic anhydrase & -2.52 & 2.06E-04 \\
\hline oprP & phosphate-specific outer membrane porin OprP & -2.51 & 5.97E-08 \\
\hline antA & anthranilate dioxygenase large subunit & -2.50 & $6.48 \mathrm{E}-04$ \\
\hline fptA & $\mathrm{Fe}(\mathrm{III})$-pyochelin outer membrane receptor & -2.45 & $3.20 \mathrm{E}-11$ \\
\hline hitA & ferric iron-binding periplasmic protein HitA & -2.45 & $2.60 \mathrm{E}-14$ \\
\hline PA0689 & hypothetical protein & -2.42 & $7.95 \mathrm{E}-05$ \\
\hline PA3268 & TonB-dependent receptor & -2.35 & $2.28 \mathrm{E}-11$ \\
\hline nark1 & nitrite extrusion protein 1 & -2.33 & $2.04 \mathrm{E}-08$ \\
\hline PA1292 & 3-mercaptopyruvate sulfurtransferase & -2.23 & $4.04 \mathrm{E}-08$ \\
\hline norB & nitric oxide reductase subunit $B$ & -2.21 & 1.67E-04 \\
\hline
\end{tabular}




\begin{tabular}{|c|c|c|c|}
\hline PA0688 & alkaline phosphatase L & $\mid-2.18$ & |4.45E-05 \\
\hline np20 & transcriptional regulator & -2.16 & 2.17E-07 \\
\hline PA0128 & hypothetical protein & -2.07 & 3.72E-03 \\
\hline PA1541 & drug efflux transporter & -2.04 & 1.50E-03 \\
\hline cysl & sulfite reductase & -2.04 & 1.70E-07 \\
\hline PA5504 & D-methionine $A B C$ transporter & -2.03 & 1.95E-07 \\
\hline \multicolumn{4}{|c|}{ Intracellular trafficking, secretion, and vesicular transport } \\
\hline $\sec Y$ & preprotein translocase subunit $\mathrm{SecY}$ & -125.42 & 6.09E-58 \\
\hline $\sec B$ & preprotein translocase subunit SecB & -36.73 & $1.89 \mathrm{E}-85$ \\
\hline PA3822 & preprotein translocase subunit YajC & -34.83 & $3.10 \mathrm{E}-33$ \\
\hline tolR & translocation protein ToIR & -22.79 & 7.01E-21 \\
\hline $\sec A$ & preprotein translocase subunit SecA & -21.45 & $2.79 \mathrm{E}-40$ \\
\hline tolB & translocation protein TolB & -19.88 & $3.51 \mathrm{E}-24$ \\
\hline to/Q & translocation protein TolQ & -19.86 & 2.82E-15 \\
\hline $\sec G$ & preprotein translocase subunit SecG & -17.16 & $3.39 \mathrm{E}-23$ \\
\hline pilM & type 4 fimbrial biogenesis protein PilM & -16.46 & 5.99E-19 \\
\hline $\operatorname{tat} A$ & twin-arginine translocation protein TatA & -16.13 & $1.30 \mathrm{E}-74$ \\
\hline PA5568 & inner membrane protein translocase subunit YidC & -15.24 & $1.71 \mathrm{E}-31$ \\
\hline $\sec E$ & preprotein translocase subunit SecE & -12.52 & 5.57E-24 \\
\hline pilF & type 4 fimbrial biogenesis protein PilF & -12.18 & $3.25 \mathrm{E}-17$ \\
\hline $\sec F$ & preprotein translocase subunit SecF & -12.03 & $2.60 \mathrm{E}-47$ \\
\hline $\operatorname{lepB}$ & signal peptidase I & -9.03 & $2.51 \mathrm{E}-15$ \\
\hline pilY1 & type 4 fimbrial biogenesis protein PilY1 & -8.62 & $3.44 \mathrm{E}-38$ \\
\hline pilQ & $\begin{array}{l}\text { type } 4 \text { fimbrial biogenesis outer membrane protein } \\
\text { PilQ }\end{array}$ & -8.46 & $5.30 \mathrm{E}-15$ \\
\hline pill & twitching motility protein PilU & -8.01 & $9.52 \mathrm{E}-17$ \\
\hline pilO & type 4 fimbrial biogenesis protein PilO & -7.92 & 1.18E-10 \\
\hline PA2973 & peptidase & -6.50 & $1.87 \mathrm{E}-12$ \\
\hline pilD & type 4 prepilin peptidase PilD & -6.03 & 5.74E-19 \\
\hline PA1478 & heme exporter protein $\mathrm{CcmD}$ & -5.74 & $1.74 \mathrm{E}-04$ \\
\hline PA4624 & hypothetical protein & -4.89 & 2.73E-08 \\
\hline PA2983 & translocation protein TolQ & -4.12 & 4.13E-09 \\
\hline$p s c U$ & translocation protein in type III secretion & -4.04 & $3.85 \mathrm{E}-10$ \\
\hline$f / p$ & type IVb pilin Flp & -3.99 & 1.74E-03 \\
\hline flie & flagellar hook-basal body complex protein FliE & -3.85 & 1.84E-09 \\
\hline cupB1 & fimbrial subunit CupB1 & -3.83 & 1.74E-04 \\
\hline cupC1 & fimbrial subunit CupC1 & -3.75 & 6.67E-06 \\
\hline PA5284 & hypothetical protein & -3.69 & $2.06 \mathrm{E}-10$ \\
\hline PA2633 & hypothetical protein & -3.52 & 2.63E-14 \\
\hline $\sec D$ & preprotein translocase subunit SecD & -3.43 & $9.65 \mathrm{E}-13$ \\
\hline$x с p T$ & type II secretion system protein G & -3.02 & $2.73 \mathrm{E}-08$ \\
\hline PA5205 & multiple drug resistance protein MarC & -2.99 & 5.63E-07 \\
\hline
\end{tabular}




\begin{tabular}{|c|c|c|c|}
\hline PA4541 & hypothetical protein & -2.91 & $2.31 \mathrm{E}-16$ \\
\hline fimT & type 4 fimbrial biogenesis protein FimT & -2.88 & $1.20 \mathrm{E}-05$ \\
\hline PA1382 & type II secretion system protein & -2.76 & $1.43 \mathrm{E}-04$ \\
\hline PA2672 & type II secretion system protein & -2.68 & 1.61E-05 \\
\hline PA0095 & hypothetical protein & -2.38 & 1.19E-10 \\
\hline oprM & outer membrane protein OprM & -2.34 & $1.64 \mathrm{E}-13$ \\
\hline PA1832 & protease & -2.09 & $6.01 \mathrm{E}-06$ \\
\hline PA3619 & hypothetical protein & -2.07 & $6.24 \mathrm{E}-06$ \\
\hline PA2676 & type II secretion system protein & -2.04 & 1.84E-03 \\
\hline \multicolumn{4}{|c|}{ Lipid transport and metabolism } \\
\hline acpP & acyl carrier protein & -120.66 & $2.51 \mathrm{E}-94$ \\
\hline PA1830 & hypothetical protein & -33.63 & $2.09 \mathrm{E}-34$ \\
\hline fabA & 3-hydroxydecanoyl-ACP dehydratase & -31.28 & $4.86 \mathrm{E}-23$ \\
\hline gcdH & glutaryl-CoA dehydrogenase & -25.56 & 1.30E-96 \\
\hline foaB & 3-ketoacyl-CoA thiolase & -21.65 & $2.67 \mathrm{E}-29$ \\
\hline$f a b Z$ & $\begin{array}{l}\text { 3-hydroxyacyl-[acyl-carrier-protein] dehydratase } \\
\text { FabZ }\end{array}$ & -17.76 & $3.84 \mathrm{E}-24$ \\
\hline PA1288 & hypothetical protein & -17.64 & $2.88 \mathrm{E}-74$ \\
\hline$P A 0461$ & acyltransferase & -16.92 & $2.52 \mathrm{E}-23$ \\
\hline$d h c A$ & dehydrocarnitine CoA transferase subunit $\mathrm{A}$ & -14.38 & $2.29 \mathrm{E}-40$ \\
\hline$g c p E$ & $\begin{array}{l}\text { 4-hydroxy-3-methylbut-2-en-1-yl diphosphate } \\
\text { synthase (flavodoxin) }\end{array}$ & -13.79 & $9.19 \mathrm{E}-40$ \\
\hline $\operatorname{lin} A$ & isovaleryl-CoA dehydrogenase & -13.34 & $1.71 \mathrm{E}-64$ \\
\hline pssA & phosphatidylserine synthase & -11.26 & $4.39 \mathrm{E}-31$ \\
\hline $\operatorname{acc} A$ & $\begin{array}{l}\text { acetyl-CoA carboxylase carboxyltransferase subunit } \\
\text { alpha }\end{array}$ & -11.03 & $2.08 \mathrm{E}-23$ \\
\hline PA5436 & acetyl-CoA carboxylase subunit alpha & -10.80 & 3.70E-48 \\
\hline speA & 3-ketoacyl-ACP reductase & -10.00 & $8.33 \mathrm{E}-20$ \\
\hline accC & acetyl-CoA carboxylase biotin carboxylase subunit & -9.73 & $9.80 \mathrm{E}-29$ \\
\hline fabl & NADH-dependent enoyl-ACP reductase & -8.78 & $1.61 \mathrm{E}-53$ \\
\hline PA4767 & hypothetical protein & -7.57 & $1.08 \mathrm{E}-33$ \\
\hline PA0506 & acyl-CoA dehydrogenase & -7.39 & $1.90 \mathrm{E}-29$ \\
\hline$a c c D$ & $\begin{array}{l}\text { acetyl-CoA carboxylase carboxyltransferase subunit } \\
\text { beta }\end{array}$ & -7.11 & $1.79 \mathrm{E}-14$ \\
\hline$d h c B$ & dehydrocarnitine CoA transferase subunit $B$ & -7.08 & $8.89 E-46$ \\
\hline PA1748 & enoyl-CoA hydratase & -6.71 & 3.39E-09 \\
\hline faoA & fatty acid oxidation complex subunit alpha & -6.49 & $2.50 \mathrm{E}-49$ \\
\hline $\operatorname{des} A$ & delta-9 fatty acid desaturase DesA & -6.41 & $1.31 \mathrm{E}-39$ \\
\hline pcs & phosphatidylcholine synthase & -5.30 & $1.59 \mathrm{E}-25$ \\
\hline PA4435 & acyl-CoA dehydrogenase & -4.77 & $1.11 \mathrm{E}-18$ \\
\hline PA3302 & hypothetical protein & -4.43 & $4.18 \mathrm{E}-20$ \\
\hline PA1821 & enoyl-CoA hydratase & -4.34 & $4.70 \mathrm{E}-14$ \\
\hline PA5519 & acyl-CoA thioesterase & -4.32 & $2.83 \mathrm{E}-17$ \\
\hline
\end{tabular}




\begin{tabular}{|c|c|c|c|}
\hline PA0449 & acyl-CoA thioesterase & $\mid-4.12$ & $5.26 \mathrm{E}-35$ \\
\hline rhIA & rhamnosyltransferase subunit $A$ & -3.82 & $2.61 \mathrm{E}-06$ \\
\hline PA4589 & hypothetical protein & -3.73 & $8.66 \mathrm{E}-12$ \\
\hline PA3741 & acyl-CoA thioesterase & -3.69 & $4.11 \mathrm{E}-05$ \\
\hline IptA & Iysophosphatidic acid acyltransferase & -3.57 & $2.42 \mathrm{E}-14$ \\
\hline $\operatorname{tes} B$ & acyl-CoA thioesterase II & -3.50 & $1.75 \mathrm{E}-10$ \\
\hline PA0358 & hypothetical protein & -3.36 & 7.87E-09 \\
\hline PA4015 & hypothetical protein & -3.17 & $2.85 \mathrm{E}-06$ \\
\hline$p q s C$ & hypothetical protein & -3.11 & $4.34 \mathrm{E}-06$ \\
\hline PA2550 & acyl-CoA dehydrogenase & -3.02 & $3.62 \mathrm{E}-10$ \\
\hline azoR3 & FMN-dependent NADH-azoreductase & -2.84 & $4.52 \mathrm{E}-08$ \\
\hline PA4636 & hypothetical protein & -2.78 & $6.90 \mathrm{E}-07$ \\
\hline PA5371 & acyl-CoA thioesterase & -2.72 & $2.64 \mathrm{E}-10$ \\
\hline alkB1 & alkane-1 monooxygenase & -2.65 & $4.92 \mathrm{E}-03$ \\
\hline PA3727 & hypothetical protein & -2.60 & $9.46 \mathrm{E}-10$ \\
\hline$d x s$ & 1-deoxy-D-xylulose-5-phosphate synthase & -2.59 & $2.74 \mathrm{E}-12$ \\
\hline uppS & ditrans, polycis-undecaprenyl-diphosphate synthase & -2.57 & $2.95 \mathrm{E}-14$ \\
\hline PA1737 & 3-hydroxyacyl-CoA dehydrogenase & -2.51 & $8.52 \mathrm{E}-08$ \\
\hline PA3972 & acyl-CoA dehydrogenase & -2.32 & 4.43E-05 \\
\hline PA1022 & acyl-CoA dehydrogenase & -2.24 & 3.09E-06 \\
\hline$p / s X$ & phosphate acyltransferase & -2.21 & 1.45E-04 \\
\hline liuB & methylcrotonyl-CoA carboxylase subunit beta & -2.11 & $2.05 \mathrm{E}-04$ \\
\hline pldA & phospholipase D & -2.08 & $2.46 \mathrm{E}-10$ \\
\hline pgpA & phosphatidylglycerophosphatase A & -2.01 & $2.79 \mathrm{E}-05$ \\
\hline \multicolumn{4}{|c|}{ Nucleotide transport and metabolism } \\
\hline purC & $\begin{array}{l}\text { phosphoribosylaminoimidazole-succinocarboxamide } \\
\text { synthase }\end{array}$ & -39.92 & 7.27E-49 \\
\hline$n d k$ & nucleoside diphosphate kinase & -39.33 & $5.01 \mathrm{E}-26$ \\
\hline prs & ribose-phosphate pyrophosphokinase & -19.72 & $3.02 \mathrm{E}-25$ \\
\hline purN & phosphoribosylglycinamide formyltransferase & -15.07 & 1.07E-19 \\
\hline carB & carbamoyl phosphate synthase large subunit & -14.69 & 1.76E-50 \\
\hline pyrG & CTP synthetase & -11.29 & 7.67E-21 \\
\hline purU1 & formyltetrahydrofolate deformylase & -8.74 & $5.20 \mathrm{E}-50$ \\
\hline$n r d J a$ & ribonucleoside-diphosphate reductase & -6.90 & $2.96 \mathrm{E}-18$ \\
\hline cmk & cytidylate kinase & -6.26 & $2.26 \mathrm{E}-14$ \\
\hline purU2 & formyltetrahydrofolate deformylase & -6.18 & $7.14 \mathrm{E}-14$ \\
\hline PA1514 & ureidoglycolate hydrolase & -6.17 & $5.54 \mathrm{E}-10$ \\
\hline$n r d B$ & ribonucleotide-diphosphate reductase subunit beta & -6.06 & 1.35E-25 \\
\hline thyA & thymidylate synthase & -5.91 & $2.02 \mathrm{E}-25$ \\
\hline upp & uracil phosphoribosyltransferase & -5.81 & 5.45E-08 \\
\hline$a d k$ & adenylate kinase & -5.75 & $9.89 \mathrm{E}-16$ \\
\hline gmk & guanylate kinase & -5.73 & 4.27E-21 \\
\hline
\end{tabular}




\begin{tabular}{|c|c|c|c|}
\hline uraA & uracil permease & -5.71 & 1.43E-24 \\
\hline purM & phosphoribosylformylglycinamidine cyclo-ligase & -5.63 & 2.66E-09 \\
\hline carA & carbamoyl phosphate synthase small subunit & -4.86 & $2.18 \mathrm{E}-11$ \\
\hline pyrB & aspartate carbamoyltransferase & -4.43 & $9.57 \mathrm{E}-18$ \\
\hline PA4645 & hypoxanthine-guanine phosphoribosyltransferase & -4.40 & $2.28 \mathrm{E}-09$ \\
\hline purA & adenylosuccinate synthetase & -4.13 & $1.04 \mathrm{E}-25$ \\
\hline$n r d A$ & ribonucleotide-diphosphate reductase subunit alpha & -3.93 & $4.38 \mathrm{E}-11$ \\
\hline purB & adenylosuccinate lyase & -3.65 & $1.35 \mathrm{E}-06$ \\
\hline PA5081 & hypothetical protein & -3.37 & $2.97 \mathrm{E}-10$ \\
\hline PA3480 & deoxycytidine triphosphate deaminase & -3.25 & 2.27E-06 \\
\hline PA3767 & hypothetical protein & -3.22 & $1.28 \mathrm{E}-05$ \\
\hline PA0990 & hypothetical protein & -3.12 & $1.08 \mathrm{E}-05$ \\
\hline guaA & GMP synthase & -3.06 & $3.00 \mathrm{E}-09$ \\
\hline purH & $\begin{array}{l}\text { bifunctional } \\
\text { phosphoribosylaminoimidazolecarboxamide } \\
\text { formyltransferase/IMP cyclohydrolase }\end{array}$ & -2.85 & 8.00E-10 \\
\hline pyrH & uridylate kinase & -2.55 & $2.62 \mathrm{E}-13$ \\
\hline cyaA & adenylate cyclase & -2.47 & $1.65 \mathrm{E}-12$ \\
\hline purF & amidophosphoribosyltransferase & -2.47 & $5.09 \mathrm{E}-07$ \\
\hline PA0148 & adenosine deaminase & -2.38 & $7.18 \mathrm{E}-09$ \\
\hline PA3043 & deoxyguanosinetriphosphate triphosphohydrolase & -2.14 & 7.84E-06 \\
\hline PA0656 & HIT family protein & -2.04 & 7.97E-04 \\
\hline apt & adenine phosphoribosyltransferase & -2.02 & 1.72E-05 \\
\hline \multicolumn{4}{|c|}{ Posttranslational modification, protein turnover, chaperones } \\
\hline groEL & molecular chaperone GroEL & -438.43 & $3.76 \mathrm{E}-180$ \\
\hline ahpC & alkyl hydroperoxide reductase & -163.61 & $5.55 \mathrm{E}-89$ \\
\hline Ion & Lon protease & -156.49 & $1.05 \mathrm{E}-202$ \\
\hline groES & co-chaperonin GroES & -116.82 & $2.18 \mathrm{E}-203$ \\
\hline PA3529 & peroxidase & -70.98 & $8.10 \mathrm{E}-39$ \\
\hline ppiB & peptidyl-prolyl cis-trans isomerase $\mathrm{B}$ & -64.71 & $8.96 \mathrm{E}-41$ \\
\hline$h f I C$ & protease subunit $\mathrm{HfIC}$ & -53.28 & $2.44 \mathrm{E}-52$ \\
\hline$c / p X$ & ATP-dependent protease ATP-binding subunit ClpX & -51.17 & 1.95E-37 \\
\hline tig & trigger factor & -50.62 & $5.13 \mathrm{E}-42$ \\
\hline PA2827 & methionine sulfoxide reductase $B$ & -48.26 & 5.36E-59 \\
\hline dnak & molecular chaperone DnaK & -42.84 & $6.22 \mathrm{E}-39$ \\
\hline$d s b A$ & thiol:disulfide interchange protein DsbA & -41.35 & $7.00 \mathrm{E}-65$ \\
\hline hfIK & protease subunit HfIK & -37.36 & $6.53 \mathrm{E}-89$ \\
\hline $\operatorname{trx} A$ & thioredoxin & -35.11 & $2.38 \mathrm{E}-47$ \\
\hline$c / p P$ & ATP-dependent Clp protease proteolytic subunit & -33.35 & $1.60 \mathrm{E}-48$ \\
\hline PA3262 & FkbP-type peptidyl-prolyl cis-trans isomerase & -32.03 & $1.99 \mathrm{E}-33$ \\
\hline PA0838 & glutathione peroxidase & -31.32 & $2.71 \mathrm{E}-90$ \\
\hline $\operatorname{ccoQ1}$ & cytochrome C oxidase cbb3-type subunit CcoQ & -27.80 & $1.26 \mathrm{E}-28$ \\
\hline
\end{tabular}




\begin{tabular}{|c|c|c|c|}
\hline clpA & ATP-binding protease component ClpA & -23.03 & $4.41 \mathrm{E}-47$ \\
\hline $\operatorname{ccoQ2}$ & cytochrome C oxidase cbb3-type subunit CcoQ & -21.23 & $1.82 \mathrm{E}-21$ \\
\hline $\mathrm{ftsH}$ & cell division protein $\mathrm{FtsH}$ & -20.51 & 3.32E-140 \\
\hline PA1095 & B-type flagellar protein FliS & -19.58 & $1.62 \mathrm{E}-23$ \\
\hline$m u c D$ & serine protease MucD & -17.26 & $9.14 \mathrm{E}-25$ \\
\hline ppiD & peptidyl-prolyl cis-trans isomerase $\mathrm{D}$ & -17.11 & $4.74 \mathrm{E}-25$ \\
\hline$b c p$ & bacterioferritin comigratory protein & -15.73 & 1.91E-27 \\
\hline PA4558 & FkbP-type peptidyl-prolyl cis-trans isomerase & -15.04 & $9.03 \mathrm{E}-18$ \\
\hline slyD & peptidyl-prolyl cis-trans isomerase SlyD & -14.60 & $1.14 \mathrm{E}-16$ \\
\hline $\operatorname{ccoN} 2$ & cbb3-type cytochrome C oxidase subunit I & -13.82 & $2.22 \mathrm{E}-22$ \\
\hline $\operatorname{ssp} A$ & stringent starvation protein $\mathrm{A}$ & -13.77 & $5.80 \mathrm{E}-19$ \\
\hline $\operatorname{clp} B$ & chaperone protein ClpB & -13.28 & $1.15 \mathrm{E}-36$ \\
\hline PA2826 & glutathione peroxidase & -10.62 & $1.73 \mathrm{E}-13$ \\
\hline ppiA & peptidyl-prolyl cis-trans isomerase A & -9.60 & $5.22 \mathrm{E}-13$ \\
\hline$g r x$ & glutaredoxin & -9.21 & $5.51 \mathrm{E}-24$ \\
\hline $\operatorname{trxB1}$ & thioredoxin reductase & -9.21 & $2.64 \mathrm{E}-26$ \\
\hline PA3533 & hypothetical protein & -8.42 & $2.89 \mathrm{E}-54$ \\
\hline$d s b c$ & thiol:disulfide interchange protein DsbC & -8.14 & $1.09 \mathrm{E}-10$ \\
\hline $\operatorname{grp} E$ & heat shock protein GrpE & -7.91 & 4.81E-20 \\
\hline PA0941 & hypothetical protein & -7.78 & 1.55E-08 \\
\hline$s m p B$ & SsrA-binding protein & -7.72 & $1.53 \mathrm{E}-20$ \\
\hline pcm & protein-L-isoaspartate O-methyltransferase & -7.46 & $1.12 \mathrm{E}-28$ \\
\hline surA & chaperone SurA & -7.32 & $4.48 \mathrm{E}-52$ \\
\hline PA3326 & ATP-dependent Clp protease proteolytic subunit & -6.97 & $7.11 \mathrm{E}-11$ \\
\hline$h s c B$ & co-chaperone HscB & -6.96 & $2.63 \mathrm{E}-25$ \\
\hline IpxO2 & lipopolysaccharide biosynthetic protein LpxO & -6.81 & $3.77 \mathrm{E}-10$ \\
\hline$h t p G$ & chaperone protein $\mathrm{HtpG}$ & -6.74 & 4.93E-18 \\
\hline $\operatorname{ccoN} 1$ & cbb3-type cytochrome C oxidase subunit I & -6.70 & 3.81E-12 \\
\hline$d s b H$ & disulfide bond formation protein & -6.46 & $5.01 \mathrm{E}-13$ \\
\hline PA0779 & ATP-dependent protease & -6.40 & $1.11 \mathrm{E}-25$ \\
\hline PA3350 & flagellar basal body P-ring biosynthesis protein FlgA & -6.10 & $5.17 \mathrm{E}-13$ \\
\hline PA5254 & FkbP-type peptidyl-prolyl cis-trans isomerase & -5.92 & 1.96E-09 \\
\hline PA2618 & arginyl-tRNA--protein transferase & -5.78 & $8.00 \mathrm{E}-10$ \\
\hline PA4576 & ATP-dependent protease & -5.77 & $5.68 \mathrm{E}-55$ \\
\hline PA1006 & hypothetical protein & -5.70 & $2.18 \mathrm{E}-08$ \\
\hline PA0462 & hypothetical protein & -5.67 & $4.52 \mathrm{E}-17$ \\
\hline PA0975 & radical activating enzyme & -5.41 & $1.26 \mathrm{E}-06$ \\
\hline PA2821 & glutathione S-transferase & -5.32 & $9.50 \mathrm{E}-24$ \\
\hline PA2610 & hypothetical protein & -4.96 & $4.78 \mathrm{E}-10$ \\
\hline PA5005 & carbamoyl transferase & -4.91 & $3.91 \mathrm{E}-22$ \\
\hline PA1623 & hypothetical protein & -4.68 & $1.01 \mathrm{E}-29$ \\
\hline
\end{tabular}




\begin{tabular}{|c|c|c|c|}
\hline PA3450 & antioxidant protein & $\mid-4.60$ & 4.87E-08 \\
\hline PA1768 & hypothetical protein & -4.47 & $1.18 \mathrm{E}-05$ \\
\hline PA1564 & sulfurtransferase TusA & -4.46 & 1.97E-05 \\
\hline IpxO1 & lipopolysaccharide biosynthetic protein LpxO & -4.32 & $1.02 \mathrm{E}-08$ \\
\hline$t p x$ & 2-Cys peroxiredoxin & -4.02 & $2.50 \mathrm{E}-16$ \\
\hline PA5148 & hypothetical protein & -3.74 & $4.26 \mathrm{E}-21$ \\
\hline PA3338 & hypothetical protein & -3.72 & $2.13 \mathrm{E}-08$ \\
\hline fppA & Flp prepilin peptidase FppA & -3.69 & 5.14E-07 \\
\hline aat & leucyl/phenylalanyl-tRNA--protein transferase & -3.64 & $1.59 \mathrm{E}-14$ \\
\hline $\mathrm{ccmC}$ & heme exporter protein $\mathrm{CcmC}$ & -3.47 & $4.46 \mathrm{E}-16$ \\
\hline PA0653 & hypothetical protein & -3.44 & 3.98E-04 \\
\hline PA2813 & glutathione S-transferase & -3.36 & $1.12 \mathrm{E}-14$ \\
\hline PA0107 & cytochrome $\mathrm{C}$ oxidase assembly protein & -3.24 & 8.49E-08 \\
\hline hslU & ATP-dependent protease ATP-binding subunit HsIU & -3.19 & $7.22 \mathrm{E}-15$ \\
\hline$h s c A$ & chaperone protein $\mathrm{HscA}$ & -3.14 & $9.08 \mathrm{E}-16$ \\
\hline PA1191 & hypothetical protein & -3.14 & $6.15 \mathrm{E}-08$ \\
\hline$g \ln D$ & $\begin{array}{l}\text { bifunctional uridylyltransferase/uridylyl-removing } \\
\text { protein }\end{array}$ & -3.14 & $1.41 \mathrm{E}-10$ \\
\hline PA5196 & hypothetical protein & -3.07 & 3.33E-13 \\
\hline PA0848 & alkyl hydroperoxide reductase & -2.99 & 8.11E-09 \\
\hline ppiC2 & peptidyl-prolyl cis-trans isomerase C2 & -2.88 & 9.77E-07 \\
\hline PA1033 & glutathione S-transferase & -2.79 & $7.24 \mathrm{E}-10$ \\
\hline PA1655 & glutathione S-transferase & -2.74 & 6.81E-08 \\
\hline ohr & organic hydroperoxide resistance protein & -2.71 & $1.82 \mathrm{E}-07$ \\
\hline PA1287 & glutathione peroxidase & -2.67 & $8.20 \mathrm{E}-08$ \\
\hline PA1203 & hypothetical protein & -2.42 & 1.27E-07 \\
\hline PA0457 & hypothetical protein & -2.32 & 1.18E-07 \\
\hline PA4133 & cbb3-type cytochrome $\mathrm{C}$ oxidase subunit I & -2.32 & 2.02E-06 \\
\hline $\mathrm{ccmH}$ & cytochrome c-type biogenesis protein $\mathrm{CcmH}$ & -2.28 & $5.78 \mathrm{E}-05$ \\
\hline cyst & sulfate transporter CysT & -2.28 & $3.41 \mathrm{E}-04$ \\
\hline$i b p A$ & heat-shock protein IbpA & -2.26 & $1.48 \mathrm{E}-06$ \\
\hline$h s / V$ & ATP-dependent protease peptidase subunit & -2.23 & 1.87E-04 \\
\hline ppiC1 & peptidyl-prolyl cis-trans isomerase $\mathrm{C} 1$ & -2.10 & $2.00 \mathrm{E}-04$ \\
\hline$f k I B$ & peptidyl-prolyl cis-trans isomerase FkIB & -2.05 & $1.21 \mathrm{E}-05$ \\
\hline$f \operatorname{lgJ}$ & peptidoglycan hydrolase FlgJ & -2.02 & $2.10 \mathrm{E}-06$ \\
\hline \multicolumn{4}{|c|}{ Replication, recombination and repair } \\
\hline hupB & DNA-binding protein $\mathrm{HU}$ & -639.88 & 7.77E-118 \\
\hline $\operatorname{himA}$ & integration host factor subunit alpha & -166.99 & $2.33 \mathrm{E}-150$ \\
\hline recF & DNA replication and repair protein RecF & -55.84 & $2.39 \mathrm{E}-65$ \\
\hline PA5348 & DNA-binding protein & -46.32 & 4.82E-68 \\
\hline $\operatorname{himD}$ & integration host factor subunit beta & -34.29 & $2.41 \mathrm{E}-24$ \\
\hline$d n a N$ & DNA polymerase III subunit beta & -25.82 & $1.28 \mathrm{E}-25$ \\
\hline
\end{tabular}




\begin{tabular}{|c|c|c|c|}
\hline ygdP & RNA pyrophosphohydrolase & -20.84 & 3.02E-29 \\
\hline topA & DNA topoisomerase I & -19.19 & $1.07 \mathrm{E}-19$ \\
\hline gyrB & DNA gyrase subunit $B$ & -18.23 & 1.08E-137 \\
\hline crc & catabolite repression control protein & -17.38 & $8.21 \mathrm{E}-21$ \\
\hline PA4424 & hypothetical protein & -17.18 & $1.13 \mathrm{E}-18$ \\
\hline PA3940 & DNA binding protein & -15.72 & $6.14 \mathrm{E}-38$ \\
\hline ung & uracil-DNA glycosylase & -14.42 & $2.49 \mathrm{E}-19$ \\
\hline recA & recombinase $\mathrm{A}$ & -11.07 & 2.33E-92 \\
\hline parE & DNA topoisomerase IV subunit B & -10.18 & $1.01 \mathrm{E}-34$ \\
\hline dnaB & replicative DNA helicase & -9.55 & 7.76E-20 \\
\hline$r n h B$ & ribonuclease HII & -9.26 & $1.30 \mathrm{E}-39$ \\
\hline ruvA & Holliday junction ATP-dependent DNA helicase RuvA & -9.12 & $7.21 \mathrm{E}-13$ \\
\hline gyrA & DNA gyrase subunit $A$ & -8.91 & 1.19E-40 \\
\hline dnaE & DNA polymerase III subunit alpha & -7.66 & $3.99 \mathrm{E}-30$ \\
\hline $\operatorname{tag}$ & DNA-3-methyladenine glycosidase I & -7.54 & 5.81E-08 \\
\hline ogt & methylated-DNA--protein-cysteine methyltransferase & -6.41 & $3.41 \mathrm{E}-10$ \\
\hline ruvC & crossover junction endodeoxyribonuclease RuvC & -6.24 & $1.61 \mathrm{E}-10$ \\
\hline nth & endonuclease III & -6.02 & $1.41 \mathrm{E}-16$ \\
\hline$s b c B$ & exonuclease I & -6.01 & $3.85 \mathrm{E}-15$ \\
\hline rep & ATP-dependent DNA helicase Rep & -5.83 & $2.23 \mathrm{E}-08$ \\
\hline uvrB & excinuclease $A B C$ subunit $B$ & -4.80 & $1.96 \mathrm{E}-16$ \\
\hline PA0947 & DNA replication initiation factor & -4.51 & $1.52 \mathrm{E}-13$ \\
\hline ruvB & Holliday junction ATP-dependent DNA helicase RuvB & -4.40 & $6.08 \mathrm{E}-16$ \\
\hline PA0257 & hypothetical protein & -4.24 & 7.47E-06 \\
\hline$x \operatorname{xth} A$ & exonuclease III & -3.96 & $1.46 \mathrm{E}-12$ \\
\hline PA2613 & recombination factor protein RarA & -3.88 & $2.34 \mathrm{E}-16$ \\
\hline rnhA & ribonuclease $\mathrm{HI}$ & -3.85 & $2.67 \mathrm{E}-12$ \\
\hline$r n t$ & ribonuclease $\mathrm{T}$ & -3.84 & $4.65 \mathrm{E}-12$ \\
\hline PA2221 & hypothetical protein & -3.78 & $4.82 \mathrm{E}-05$ \\
\hline PA0987 & hypothetical protein & -3.78 & $1.05 \mathrm{E}-05$ \\
\hline polA & DNA polymerase I & -3.45 & $1.74 \mathrm{E}-15$ \\
\hline PA3140 & hypothetical protein & -3.39 & $2.78 \mathrm{E}-04$ \\
\hline PA0979 & hypothetical protein & -3.38 & $5.89 \mathrm{E}-05$ \\
\hline PA4998 & hypothetical protein & -3.07 & $9.56 \mathrm{E}-10$ \\
\hline PA1938 & hypothetical protein & -2.85 & 8.84E-05 \\
\hline PA0978 & hypothetical protein & -2.85 & $1.29 \mathrm{E}-04$ \\
\hline$d n a A$ & chromosome replication initiator DnaA & -2.74 & $4.54 \mathrm{E}-18$ \\
\hline PA0728 & bacteriophage integrase & -2.72 & $3.16 \mathrm{E}-03$ \\
\hline PA1368 & hypothetical protein & -2.66 & 2.39E-03 \\
\hline PA1937 & hypothetical protein & -2.44 & $2.14 \mathrm{E}-03$ \\
\hline PA3263 & recombination associated protein $\mathrm{RdgC}$ & -2.33 & $1.70 \mathrm{E}-06$ \\
\hline
\end{tabular}




\begin{tabular}{|c|c|c|c|}
\hline $\mathrm{recN}$ & DNA repair protein $\mathrm{RecN}$ & $\mid-2.27$ & 3.53E-09 \\
\hline uvrC & excinuclease $A B C$ subunit $C$ & -2.19 & $5.15 \mathrm{E}-07$ \\
\hline uvrD & DNA-dependent helicase II & -2.14 & $1.24 \mathrm{E}-07$ \\
\hline dnaG & DNA primase & -2.08 & 3.75E-09 \\
\hline parC & DNA topoisomerase IV subunit A & -2.06 & $6.29 \mathrm{E}-06$ \\
\hline \multicolumn{4}{|c|}{ Secondary metabolites biosynthesis, transport and catabolism } \\
\hline PA1202 & hydrolase & -66.48 & $1.75 \mathrm{E}-152$ \\
\hline PA4454 & hypothetical protein & -19.11 & $2.50 \mathrm{E}-24$ \\
\hline$f a b B$ & 3-oxoacyl-ACP synthase & -9.52 & $5.23 \mathrm{E}-33$ \\
\hline PA0957 & hypothetical protein & -8.45 & 3.35E-13 \\
\hline antB & anthranilate dioxygenase small subunit & -5.55 & $2.66 \mathrm{E}-10$ \\
\hline pcaG & protocatechuate 3,4-dioxygenase subunit alpha & -5.31 & $5.65 \mathrm{E}-24$ \\
\hline PA5245 & glutamine amidotransferase & -5.08 & $7.28 \mathrm{E}-19$ \\
\hline PA5150 & short-chain dehydrogenase & -5.02 & $8.44 \mathrm{E}-22$ \\
\hline fadD1 & Iong-chain-fatty-acid--CoA ligase & -4.96 & $2.99 \mathrm{E}-25$ \\
\hline fadD2 & long-chain-fatty-acid--CoA ligase & -4.03 & 1.36E-06 \\
\hline PA3924 & Iong-chain-fatty-acid--CoA ligase & -3.52 & $9.55 \mathrm{E}-15$ \\
\hline PA5174 & beta-ketoacyl synthase & -3.41 & $9.04 \mathrm{E}-12$ \\
\hline catC & muconolactone delta-isomerase & -3.40 & $3.75 \mathrm{E}-07$ \\
\hline PA4456 & ABC transporter ATP-binding protein & -3.34 & $1.76 \mathrm{E}-13$ \\
\hline$h m g A$ & homogentisate 1,2-dioxygenase & -3.29 & $2.10 \mathrm{E}-28$ \\
\hline PA1537 & Baeyer-Villiger monooxygenase & -3.15 & $3.03 \mathrm{E}-17$ \\
\hline PA1835 & hypothetical protein & -3.07 & $1.58 \mathrm{E}-09$ \\
\hline fabF1 & 3-oxoacyl-ACP synthase & -3.04 & $2.35 \mathrm{E}-13$ \\
\hline PA3213 & hypothetical protein & -3.02 & $2.61 \mathrm{E}-08$ \\
\hline PA4453 & hypothetical protein & -3.02 & 1.97E-08 \\
\hline PA1828 & short-chain dehydrogenase & -2.97 & $1.62 \mathrm{E}-13$ \\
\hline PA1088 & hypothetical protein & -2.80 & $2.38 \mathrm{E}-15$ \\
\hline PA3334 & acyl carrier protein & -2.72 & $2.59 \mathrm{E}-04$ \\
\hline lasl & acyl-homoserine-lactone synthase & -2.60 & $3.25 \mathrm{E}-03$ \\
\hline PA5507 & hypothetical protein & -2.47 & $1.22 \mathrm{E}-05$ \\
\hline PA0318 & hypothetical protein & -2.47 & $6.35 \mathrm{E}-13$ \\
\hline PA5026 & hypothetical protein & -2.42 & $2.06 \mathrm{E}-06$ \\
\hline PA2419 & hydrolase & -2.22 & $4.18 \mathrm{E}-04$ \\
\hline \multicolumn{4}{|c|}{ Signal transduction mechanisms } \\
\hline PA3919 & hypothetical protein & -89.60 & $2.82 \mathrm{E}-80$ \\
\hline cheY & chemotaxis protein $\mathrm{CheY}$ & -45.35 & $6.63 \mathrm{E}-66$ \\
\hline PA0588 & hypothetical protein & -39.44 & $8.28 \mathrm{E}-33$ \\
\hline PA3309 & hypothetical protein & -38.66 & $9.11 \mathrm{E}-90$ \\
\hline$p t s N$ & nitrogen regulatory IIA protein & -37.31 & $4.79 \mathrm{E}-86$ \\
\hline pilG & pilus biosynthesis/twitching motility protein PilG & -33.89 & $1.62 \mathrm{E}-30$ \\
\hline
\end{tabular}




\begin{tabular}{|c|c|c|c|}
\hline$r s m A$ & carbon storage regulator & -31.74 & $2.82 \mathrm{E}-36$ \\
\hline PA3205 & hypothetical protein & -28.71 & $5.99 \mathrm{E}-27$ \\
\hline PA2137 & hypothetical protein & -23.32 & $1.83 \mathrm{E}-21$ \\
\hline PA5153 & amino acid $A B C$ transporter substrate-binding protein & -23.19 & $1.99 \mathrm{E}-47$ \\
\hline PA1789 & hypothetical protein & -21.36 & $5.53 \mathrm{E}-29$ \\
\hline pprB & two-component response regulator PprB & -17.92 & $8.71 \mathrm{E}-57$ \\
\hline PA0431 & hypothetical protein & -16.48 & $2.17 \mathrm{E}-56$ \\
\hline bfmR & protein BfmR & -14.04 & $3.08 \mathrm{E}-101$ \\
\hline PA3349 & chemotaxis protein & -12.75 & $2.83 \mathrm{E}-25$ \\
\hline mucA & sigma factor AlgU negative regulator MucA & -12.02 & $3.97 \mathrm{E}-38$ \\
\hline IexA & LexA repressor & -10.66 & 1.02E-20 \\
\hline spot & $\begin{array}{l}\text { guanosine-3',5'-bis(diphosphate) 3'- } \\
\text { pyrophosphohydrolase }\end{array}$ & -10.47 & $8.30 \mathrm{E}-40$ \\
\hline PA0601 & two-component response regulator & -10.44 & $6.27 \mathrm{E}-17$ \\
\hline aotJ & $\begin{array}{l}\text { arginine/ornithine } A B C \text { transporter substrate-binding } \\
\text { protein AotJ }\end{array}$ & -10.37 & 1.25E-28 \\
\hline hom & homoserine dehydrogenase & -10.20 & 1.46E-19 \\
\hline PA2798 & two-component response regulator & -10.11 & $8.18 \mathrm{E}-14$ \\
\hline PA5138 & hypothetical protein & -9.55 & 8.97E-15 \\
\hline relA & GTP pyrophosphokinase & -9.40 & $7.93 \mathrm{E}-40$ \\
\hline pilJ & twitching motility protein PilJ & -9.06 & $5.32 \mathrm{E}-80$ \\
\hline PA2797 & hypothetical protein & -8.52 & $1.63 \mathrm{E}-13$ \\
\hline algR & alginate biosynthesis regulatory protein AlgR & -7.68 & $1.10 \mathrm{E}-20$ \\
\hline$d k s A$ & suppressor protein DksA & -7.61 & $6.66 \mathrm{E}-15$ \\
\hline gacA & response regulator GacA & -7.25 & $1.85 \mathrm{E}-08$ \\
\hline PA4381 & two-component response regulator & -6.85 & $2.65 \mathrm{E}-14$ \\
\hline PA0250 & hypothetical protein & -6.77 & $3.40 \mathrm{E}-21$ \\
\hline anr & transcriptional regulator Anr & -6.35 & 1.19E-15 \\
\hline PA3017 & hypothetical protein & -6.06 & 1.10E-32 \\
\hline PA4032 & two-component response regulator & -5.98 & 8.49E-09 \\
\hline PA0314 & L-cysteine $A B C$ transporter protein FliY & -5.70 & $1.31 \mathrm{E}-23$ \\
\hline$n t r B$ & two-component sensor $\mathrm{NtrB}$ & -5.48 & $2.83 \mathrm{E}-15$ \\
\hline PA3981 & hypothetical protein & -5.42 & 7.37E-45 \\
\hline PA3825 & hypothetical protein & -5.23 & $3.20 \mathrm{E}-10$ \\
\hline$v f r$ & cAMP-regulatory protein & -5.05 & $2.67 \mathrm{E}-07$ \\
\hline$p t s P$ & $\begin{array}{l}\text { phosphoenolpyruvate-protein phosphotransferase } \\
\text { PtsP }\end{array}$ & -5.02 & $3.64 \mathrm{E}-37$ \\
\hline PA2572 & two-component response regulator & -4.64 & $2.70 \mathrm{E}-08$ \\
\hline PA0861 & hypothetical protein & -4.61 & $2.15 \mathrm{E}-24$ \\
\hline PA5139 & hypothetical protein & -4.59 & $1.23 \mathrm{E}-09$ \\
\hline rocS1 & two-component sensor & -4.58 & $4.97 \mathrm{E}-12$ \\
\hline PA5082 & ABC transporter & -4.48 & $1.79 \mathrm{E}-12$ \\
\hline
\end{tabular}




\begin{tabular}{|c|c|c|c|}
\hline PA4915 & chemotaxis transducer & -4.47 & $4.69 \mathrm{E}-19$ \\
\hline rocR & DNA-binding response regulator RocR & -4.38 & $1.24 \mathrm{E}-07$ \\
\hline PA2583 & sensor/response regulator hybrid protein & -4.37 & $3.80 \mathrm{E}-08$ \\
\hline rhll & acyl-homoserine-lactone synthase & -4.34 & 1.10E-12 \\
\hline PA5270 & hypothetical protein & -4.32 & $7.24 \mathrm{E}-14$ \\
\hline inaA & hypothetical protein & -4.10 & $6.39 \mathrm{E}-13$ \\
\hline $\operatorname{cbp} A$ & cAMP-binding protein $\mathrm{A}$ & -4.07 & $3.87 \mathrm{E}-06$ \\
\hline PA4352 & hypothetical protein & -4.02 & $1.11 \mathrm{E}-10$ \\
\hline PA0179 & two-component response regulator & -3.97 & 7.94E-09 \\
\hline PA5346 & hypothetical protein & -3.91 & $8.93 \mathrm{E}-30$ \\
\hline pheC & cyclohexadienyl dehydratase & -3.89 & $5.44 \mathrm{E}-19$ \\
\hline typA & regulatory protein TypA & -3.86 & $1.64 \mathrm{E}-11$ \\
\hline narL & transcriptional regulator NarL & -3.83 & 8.92E-22 \\
\hline wspA & chemotaxis transducer & -3.81 & 1.19E-22 \\
\hline PA2822 & hypothetical protein & -3.70 & $2.85 \mathrm{E}-06$ \\
\hline parR & two-component response regulator $\mathrm{Par} R$ & -3.70 & $9.55 \mathrm{E}-05$ \\
\hline$f l e Q$ & transcriptional regulator $\mathrm{FleQ}$ & -3.69 & $1.47 \mathrm{E}-18$ \\
\hline amiR & aliphatic amidase regulator & -3.61 & $1.73 \mathrm{E}-11$ \\
\hline PA5076 & $A B C$ transporter & -3.48 & $2.81 \mathrm{E}-08$ \\
\hline PA1342 & ABC transporter & -3.44 & $9.74 \mathrm{E}-15$ \\
\hline PA2567 & hypothetical protein & -3.33 & $2.91 \mathrm{E}-14$ \\
\hline PA3865 & amino acid binding protein & -3.33 & $1.66 \mathrm{E}-16$ \\
\hline PA4606 & hypothetical protein & -3.32 & $1.80 \mathrm{E}-21$ \\
\hline $\operatorname{alg} Z$ & alginate biosynthesis protein AlgZ/FimS & -3.23 & $5.42 \mathrm{E}-17$ \\
\hline PA3345 & hypothetical protein & -3.20 & 5.39E-06 \\
\hline PA5536 & hypothetical protein & -3.19 & 1.32E-07 \\
\hline PA5017 & hypothetical protein & -3.17 & 1.12E-21 \\
\hline$d n r$ & transcriptional regulator Dnr & -3.11 & $2.53 \mathrm{E}-11$ \\
\hline PA2204 & ABC transporter & -3.06 & 4.77E-08 \\
\hline PA0033 & hypothetical protein & -3.01 & $2.29 \mathrm{E}-08$ \\
\hline PA0575 & hypothetical protein & -2.82 & $5.88 \mathrm{E}-20$ \\
\hline$p h o Q$ & two-component sensor PhoQ & -2.80 & $6.37 \mathrm{E}-09$ \\
\hline PA2571 & two-component sensor & -2.72 & $6.67 \mathrm{E}-04$ \\
\hline PA1753 & hypothetical protein & -2.50 & $1.15 \mathrm{E}-06$ \\
\hline pils & two-component sensor PilS & -2.33 & $9.18 \mathrm{E}-10$ \\
\hline ptpA & phosphotyrosine protein phosphatase & -2.31 & $2.74 \mathrm{E}-05$ \\
\hline PA0758 & hypothetical protein & -2.29 & 8.47E-04 \\
\hline PA4870 & hypothetical protein & -2.26 & 1.33E-05 \\
\hline fles & two-component sensor & -2.24 & $6.37 \mathrm{E}-04$ \\
\hline $\mathrm{apaH}$ & bis(5'-nucleosyl)-tetraphosphatase & -2.23 & $4.70 \mathrm{E}-10$ \\
\hline PA3714 & two-component response regulator & -2.20 & $3.61 \mathrm{E}-04$ \\
\hline
\end{tabular}




\begin{tabular}{|c|c|c|c|}
\hline PA0356 & hypothetical protein & -2.17 & $2.23 \mathrm{E}-05$ \\
\hline PA4195 & $A B C$ transporter & -2.16 & 4.95E-04 \\
\hline PA5027 & hypothetical protein & -2.02 & 4.04E-07 \\
\hline \multicolumn{4}{|c|}{ Transcription } \\
\hline rроA & DNA-directed RNA polymerase subunit alpha & -407.18 & $3.61 \mathrm{E}-92$ \\
\hline rpoC & DNA-directed RNA polymerase subunit beta' & -159.76 & $8.01 \mathrm{E}-128$ \\
\hline capB & major cold shock protein CspA & -151.50 & $4.20 \mathrm{E}-51$ \\
\hline$r p o B$ & DNA-directed RNA polymerase subunit beta & -113.68 & $9.32 \mathrm{E}-72$ \\
\hline $\operatorname{sig} X$ & RNA polymerase sigma factor SigX & -96.94 & $1.94 \mathrm{E}-65$ \\
\hline PA0456 & cold-shock protein & -80.42 & 1.43E-42 \\
\hline liuR & liu genes regulator & -79.64 & $5.62 \mathrm{E}-83$ \\
\hline phoP & two-component response regulator PhoP & -48.38 & 3.65E-51 \\
\hline nusA & transcription elongation factor NusA & -44.20 & $1.43 \mathrm{E}-42$ \\
\hline greA & transcription elongation factor GreA & -42.43 & $7.56 \mathrm{E}-83$ \\
\hline PA5301 & transcriptional regulator & -40.70 & $7.48 \mathrm{E}-58$ \\
\hline $\operatorname{alg} Q$ & anti-RNA polymerase sigma 70 factor & -34.24 & $5.05 \mathrm{E}-29$ \\
\hline algu & RNA polymerase sigma factor AlgU & -33.67 & $4.25 \mathrm{E}-127$ \\
\hline nusG & transcription antitermination protein NusG & -31.65 & $3.40 \mathrm{E}-29$ \\
\hline rpoN & RNA polymerase factor sigma- 54 & -29.36 & $7.36 \mathrm{E}-44$ \\
\hline $\operatorname{csp} D$ & cold-shock protein CspD & -27.82 & 1.12E-51 \\
\hline PA2737 & hypothetical protein & -25.74 & $3.34 \mathrm{E}-23$ \\
\hline rpos & RNA polymerase sigma factor RpoS & -21.72 & $7.10 \mathrm{E}-31$ \\
\hline cysB & transcriptional regulator $\mathrm{CysB}$ & -18.32 & $5.13 \mathrm{E}-25$ \\
\hline rho & transcription termination factor Rho & -17.45 & $8.04 \mathrm{E}-20$ \\
\hline flgM & protein FlgM & -17.30 & $9.29 \mathrm{E}-60$ \\
\hline lasR & transcriptional regulator LasR & -16.11 & $8.60 \mathrm{E}-29$ \\
\hline rpoz & DNA-directed RNA polymerase subunit omega & -15.84 & $4.69 \mathrm{E}-36$ \\
\hline$r p o D$ & RNA polymerase sigma factor RpoD & -14.57 & $7.42 \mathrm{E}-67$ \\
\hline psrA & transcriptional regulator PsrA & -13.63 & $6.33 \mathrm{E}-34$ \\
\hline$i s c R$ & HTH-type transcriptional regulator & -10.77 & 1.75E-22 \\
\hline fliA & flagellar biosynthesis sigma factor FliA & -9.90 & $4.94 \mathrm{E}-35$ \\
\hline ospR & transcriptional regulator & -9.67 & 7.04E-22 \\
\hline PA1526 & transcriptional regulator & -9.29 & $3.81 \mathrm{E}-14$ \\
\hline pilH & twitching motility protein PilH & -9.23 & $2.06 \mathrm{E}-49$ \\
\hline PA0942 & transcriptional regulator & -8.28 & $7.52 \mathrm{E}-16$ \\
\hline $\operatorname{mexR}$ & multidrug resistance operon repressor MexR & -8.05 & $1.10 \mathrm{E}-13$ \\
\hline $\mathrm{rpoH}$ & RNA polymerase sigma factor $\mathrm{RpoH}$ & -7.69 & $8.31 \mathrm{E}-37$ \\
\hline prtR & HTH-type transcriptional regulator PrtR & -7.41 & $1.88 \mathrm{E}-17$ \\
\hline PA2577 & transcriptional regulator & -7.35 & $1.52 \mathrm{E}-15$ \\
\hline rocA1 & two-component response regulator RocA1 & -7.27 & $1.06 \mathrm{E}-10$ \\
\hline PA3895 & transcriptional regulator & -7.23 & $3.70 \mathrm{E}-22$ \\
\hline
\end{tabular}




\begin{tabular}{|c|c|c|c|}
\hline PA3034 & transcriptional regulator & $\mid-6.99$ & 1.96E-14 \\
\hline PA0225 & transcriptional regulator & -6.51 & $2.99 \mathrm{E}-12$ \\
\hline bexR & bistable expression regulator BexR & -6.30 & $4.67 \mathrm{E}-35$ \\
\hline PA1607 & hypothetical protein & -5.67 & $4.75 \mathrm{E}-25$ \\
\hline PA0939 & hypothetical protein & -5.42 & $2.20 \mathrm{E}-03$ \\
\hline PA2957 & transcriptional regulator & -5.24 & 1.04E-06 \\
\hline PA4279 & pantothenate kinase & -5.14 & $2.95 \mathrm{E}-06$ \\
\hline PA5324 & transcriptional regulator & -5.12 & $2.23 \mathrm{E}-31$ \\
\hline atuR & atu genes repressor & -5.02 & $4.36 \mathrm{E}-19$ \\
\hline PA2020 & transcriptional regulator & -4.54 & 4.84E-12 \\
\hline$r n r$ & exoribonuclease $\mathrm{R}$ & -4.51 & $1.99 \mathrm{E}-33$ \\
\hline PA0218 & transcriptional regulator & -4.50 & $1.99 \mathrm{E}-23$ \\
\hline PA1759 & transcriptional regulator & -4.49 & 1.49E-34 \\
\hline nald & transcriptional regulator & -4.47 & $7.35 \mathrm{E}-19$ \\
\hline PA0116 & hypothetical protein & -4.45 & $8.60 \mathrm{E}-16$ \\
\hline$r h / R$ & transcriptional regulator RhIR & -4.40 & $1.03 \mathrm{E}-08$ \\
\hline PA0217 & transcriptional regulator & -4.32 & $2.57 \mathrm{E}-23$ \\
\hline birA & biotin--protein ligase & -4.30 & $5.40 \mathrm{E}-07$ \\
\hline $\operatorname{Irp}$ & leucine-responsive regulatory protein & -4.17 & $3.20 \mathrm{E}-08$ \\
\hline PA3965 & transcriptional regulator & -4.15 & $8.91 \mathrm{E}-08$ \\
\hline PA0125 & hypothetical protein & -4.03 & $3.29 \mathrm{E}-05$ \\
\hline PA5438 & transcriptional regulator & -3.98 & $2.75 \mathrm{E}-23$ \\
\hline PA5475 & hypothetical protein & -3.98 & 1.29E-11 \\
\hline $\operatorname{roxR}$ & DNA-binding response regulator RoxR & -3.95 & 2.82E-09 \\
\hline PA4354 & hypothetical protein & -3.67 & $2.50 \mathrm{E}-05$ \\
\hline PA4499 & transcriptional regulator & -3.64 & 4.22E-07 \\
\hline PA0528 & transcriptional regulator & -3.59 & $4.85 \mathrm{E}-18$ \\
\hline spoOJ & chromosome partitioning protein & -3.54 & $8.57 \mathrm{E}-15$ \\
\hline oxyR & transcriptional regulator & -3.45 & $4.20 \mathrm{E}-16$ \\
\hline PA4451 & hypothetical protein & -3.41 & 2.03E-05 \\
\hline nalc & transcriptional regulator & -3.32 & $1.58 \mathrm{E}-10$ \\
\hline PA2551 & transcriptional regulator & -3.28 & $4.59 \mathrm{E}-14$ \\
\hline$g f n R$ & $\begin{array}{l}\text { glutathione-dependent formaldehyde neutralization } \\
\text { regulator GfnR }\end{array}$ & -3.08 & $4.02 \mathrm{E}-12$ \\
\hline PA5403 & transcriptional regulator & -2.99 & 1.90E-03 \\
\hline PA4080 & response regulator & -2.95 & 3.46E-04 \\
\hline nusB & transcription antitermination protein NusB & -2.85 & $5.33 \mathrm{E}-12$ \\
\hline$r h l$ & ATP-dependent RNA helicase RhIB & -2.85 & $4.99 \mathrm{E}-12$ \\
\hline PA0436 & transcriptional regulator & -2.84 & 2.13E-11 \\
\hline PA3458 & transcriptional regulator & -2.84 & $1.40 \mathrm{E}-08$ \\
\hline PA4769 & transcriptional regulator & -2.62 & $8.68 \mathrm{E}-12$ \\
\hline PA1283 & transcriptional regulator & -2.62 & 4.69E-07 \\
\hline
\end{tabular}




\begin{tabular}{|c|c|c|c|}
\hline PA4784 & transcriptional regulator & $\mid-2.58$ & $1.96 \mathrm{E}-03$ \\
\hline PA3711 & transcriptional regulator & -2.53 & $1.22 \mathrm{E}-09$ \\
\hline PA0034 & two-component response regulator & -2.48 & 6.53E-06 \\
\hline$p v d S$ & extracytoplasmic-function sigma-70 factor & -2.46 & $3.68 \mathrm{E}-03$ \\
\hline PA4878 & transcriptional regulator & -2.30 & 1.37E-05 \\
\hline PA3285 & ECF subfamily sigma-70 factor & -2.26 & $5.86 \mathrm{E}-07$ \\
\hline hutC & histidine utilization repressor HutC & -2.26 & 6.87E-09 \\
\hline PA0428 & ATP-dependent RNA helicase & -2.25 & $6.90 \mathrm{E}-05$ \\
\hline PA3133 & transcriptional regulator & -2.21 & $4.50 \mathrm{E}-05$ \\
\hline PA2758 & transcriptional regulator & -2.21 & 3.44E-04 \\
\hline exsA & exoenzyme $S$ transcriptional regulator ExsA & -2.16 & $9.79 \mathrm{E}-03$ \\
\hline PA4659 & transcriptional regulator & -2.11 & $1.62 \mathrm{E}-08$ \\
\hline PA5437 & transcriptional regulator & -2.07 & $1.94 \mathrm{E}-08$ \\
\hline PA4436 & transcriptional regulator & -2.06 & $7.29 \mathrm{E}-07$ \\
\hline$m v f R$ & transcriptional regulator MvfR & -2.04 & 5.09E-06 \\
\hline \multicolumn{4}{|c|}{ Translation, ribosomal structure and biogenesis } \\
\hline$r p / X$ & 50 S ribosomal protein L24 & -1261.65 & $5.41 \mathrm{E}-187$ \\
\hline rpmJ & 50 S ribosomal protein L36 & -1133.64 & $9.42 \mathrm{E}-184$ \\
\hline rplJ & $50 S$ ribosomal protein $\mathrm{L} 10$ & -1102.73 & $1.69 \mathrm{E}-138$ \\
\hline $\mathrm{rpml}$ & 50 S ribosomal protein L35 & -1072.76 & $0.00 \mathrm{E}+00$ \\
\hline PA4463 & hypothetical protein & -1018.58 & 1.47E-142 \\
\hline$r p / W$ & 50 S ribosomal protein L23 & -941.66 & $8.20 \mathrm{E}-169$ \\
\hline$r p / N$ & 50S ribosomal protein L14 & -901.44 & $2.32 \mathrm{E}-103$ \\
\hline rp/L & $50 S$ ribosomal protein L7/L12 & -886.00 & $4.70 \mathrm{E}-131$ \\
\hline$r p / K$ & 50 S ribosomal protein L11 & -862.84 & $7.06 \mathrm{E}-225$ \\
\hline rplE & 50 S ribosomal protein L5 & -831.10 & $1.18 \mathrm{E}-90$ \\
\hline$r p s D$ & 30S ribosomal protein $\mathrm{S} 4$ & -807.43 & $2.46 \mathrm{E}-91$ \\
\hline infC & translation initiation factor IF-3 & -747.63 & $4.01 \mathrm{E}-182$ \\
\hline rpsS & 30 S ribosomal protein S19 & -678.36 & $2.51 \mathrm{E}-130$ \\
\hline$r p s N$ & 30 s ribosomal protein S14 & -574.56 & 2.21E-105 \\
\hline$r p m D$ & 50 S ribosomal protein L30 & -509.49 & 3.16E-99 \\
\hline rpsM & 30 S ribosomal protein $\mathrm{S} 13$ & -435.43 & $9.87 \mathrm{E}-131$ \\
\hline$r p / V$ & 50 S ribosomal protein L22 & -423.66 & $5.76 \mathrm{E}-111$ \\
\hline rpsE & 30 S ribosomal protein S5 & -422.98 & $5.92 \mathrm{E}-78$ \\
\hline$r p / T$ & 50 S ribosomal protein L20 & -422.84 & $4.06 \mathrm{E}-263$ \\
\hline$r p s Q$ & 30 S ribosomal protein S17 & -419.05 & $1.14 \mathrm{E}-130$ \\
\hline rpsC & 30 S ribosomal protein S3 & -414.82 & $6.79 E-82$ \\
\hline $\mathrm{rpmC}$ & 50 S ribosomal protein L29 & -413.38 & 3.67E-103 \\
\hline rpsO & 30 S ribosomal protein S15 & -412.00 & $5.71 \mathrm{E}-106$ \\
\hline rpsK & 30 s ribosomal protein $\mathrm{S} 11$ & -351.41 & $4.19 \mathrm{E}-131$ \\
\hline$r p / P$ & $50 S$ ribosomal protein L16 & -346.84 & $6.79 \mathrm{E}-82$ \\
\hline
\end{tabular}




\begin{tabular}{|c|c|c|c|}
\hline$r p / O$ & $50 S$ ribosomal protein $L 15$ & -341.16 & $1.18 \mathrm{E}-73$ \\
\hline fusA1 & elongation factor $\mathrm{G}$ & -313.39 & 4.85E-91 \\
\hline$r p / R$ & $50 S$ ribosomal protein $\mathrm{L} 18$ & -296.05 & $1.81 \mathrm{E}-124$ \\
\hline$r p / Q$ & 50 S ribosomal protein $\mathrm{L} 17$ & -278.38 & $5.25 \mathrm{E}-95$ \\
\hline$r p / C$ & 50 S ribosomal protein L3 & -258.49 & $1.21 \mathrm{E}-64$ \\
\hline$r p s L$ & $30 \mathrm{~S}$ ribosomal protein $\mathrm{S} 12$ & -248.50 & $2.84 \mathrm{E}-57$ \\
\hline rpsH & $30 S$ ribosomal protein $\mathrm{S} 8$ & -247.14 & $8.39 \mathrm{E}-89$ \\
\hline$r p / U$ & $50 S$ ribosomal protein $\mathrm{L} 21$ & -241.89 & 1.07E-107 \\
\hline tufA & elongation factor Tu & -230.11 & $8.29 \mathrm{E}-105$ \\
\hline$r p / A$ & 50 S ribosomal protein $\mathrm{L} 1$ & -212.25 & 3.47E-64 \\
\hline$r p / B$ & 50 S ribosomal protein L2 & -209.82 & 3.47E-61 \\
\hline rplF & $50 S$ ribosomal protein $\mathrm{L} 6$ & -201.02 & $3.38 \mathrm{E}-86$ \\
\hline tufB & elongation factor $\mathrm{Tu}$ & -188.31 & 1.44E-111 \\
\hline$r p s G$ & 30 S ribosomal protein $\mathrm{S} 7$ & -187.23 & $1.73 \mathrm{E}-86$ \\
\hline$r p / D$ & $50 S$ ribosomal protein $\mathrm{L} 4$ & -186.49 & $5.99 \mathrm{E}-60$ \\
\hline$r p / S$ & 50S ribosomal protein L19 & -171.19 & 7.45E-95 \\
\hline rpsA & $30 \mathrm{~S}$ ribosomal protein $\mathrm{S} 1$ & -169.33 & $3.81 \mathrm{E}-79$ \\
\hline$r p s B$ & 30 S ribosomal protein S2 & -157.89 & $2.28 \mathrm{E}-54$ \\
\hline PA4671 & $50 \mathrm{~S}$ ribosomal protein L25/general stress protein Ctc & -145.76 & 8.71E-89 \\
\hline$r p s R$ & $30 \mathrm{~S}$ ribosomal protein $\mathrm{S} 18$ & -132.20 & $6.04 \mathrm{E}-53$ \\
\hline$r p / M$ & $50 S$ ribosomal protein $\mathrm{L} 13$ & -128.33 & 1.12E-52 \\
\hline rpsJ & $30 \mathrm{~S}$ ribosomal protein $\mathrm{S} 10$ & -113.82 & $1.97 \mathrm{E}-43$ \\
\hline rpmB & $50 S$ ribosomal protein L28 & -111.78 & $2.81 \mathrm{E}-85$ \\
\hline$r p m H$ & 50S ribosomal protein L34 & -106.63 & $8.98 \mathrm{E}-60$ \\
\hline rpmA & 50S ribosomal protein L27 & -100.10 & $3.38 \mathrm{E}-81$ \\
\hline$r p s F$ & 30 S ribosomal protein $\mathrm{S} 6$ & -84.97 & $2.84 \mathrm{E}-159$ \\
\hline pnp & polynucleotide phosphorylase & -71.94 & $1.22 \mathrm{E}-57$ \\
\hline tsf & elongation factor Ts & -70.24 & $2.51 \mathrm{E}-68$ \\
\hline$r p m F$ & 50 S ribosomal protein L32 & -66.76 & 1.94E-39 \\
\hline efp & elongation factor $\mathrm{P}$ & -53.36 & $1.64 \mathrm{E}-82$ \\
\hline trmD & tRNA (guanine-N(1)-)-methyltransferase & -50.26 & $8.08 \mathrm{E}-38$ \\
\hline rnpA & ribonuclease $\mathrm{P}$ & -49.54 & $3.22 \mathrm{E}-38$ \\
\hline $\operatorname{rim} M$ & ribosome maturation factor RimM & -48.53 & $1.90 \mathrm{E}-48$ \\
\hline rpll & $50 \mathrm{~S}$ ribosomal protein $\mathrm{L9}$ & -44.48 & $3.79 \mathrm{E}-152$ \\
\hline rpsl & 30 S ribosomal protein $\mathrm{S} 9$ & -43.86 & $1.38 \mathrm{E}-44$ \\
\hline frr & ribosome recycling factor & -33.44 & $7.46 \mathrm{E}-36$ \\
\hline$r p m G$ & 50 S ribosomal protein L33 & -29.35 & 4.94E-34 \\
\hline asps & aspartate--tRNA ligase & -28.42 & $2.09 \mathrm{E}-23$ \\
\hline rpst & 30 S ribosomal protein $\mathrm{S} 20$ & -27.82 & 1.12E-37 \\
\hline$r p s U$ & 30 S ribosomal protein $\mathrm{S} 21$ & -23.93 & 1.64E-44 \\
\hline iles & isoleucine--tRNA ligase & -19.12 & $7.55 \mathrm{E}-44$ \\
\hline
\end{tabular}




\begin{tabular}{|c|c|c|c|}
\hline gatC & aspartyl/glutamyl-tRNA amidotransferase subunit C & -18.58 & $6.10 \mathrm{E}-36$ \\
\hline hiss & histidine--tRNA ligase & -16.72 & $1.30 \mathrm{E}-94$ \\
\hline PA4852 & hypothetical protein & -16.45 & $5.00 \mathrm{E}-30$ \\
\hline $\operatorname{infB}$ & translation initiation factor IF-2 & -16.15 & 8.69E-151 \\
\hline thrS & threonine--tRNA ligase & -14.11 & $1.31 \mathrm{E}-23$ \\
\hline PA4753 & hypothetical protein & -14.06 & $4.08 \mathrm{E}-41$ \\
\hline PA4673 & GTP-dependent nucleic acid-binding protein EngD & -13.45 & $5.31 \mathrm{E}-19$ \\
\hline $\operatorname{infA}$ & translation initiation factor IF-1 & -13.15 & $1.29 \mathrm{E}-17$ \\
\hline def & peptide deformylase & -12.70 & $1.06 \mathrm{E}-30$ \\
\hline$g \ln S$ & glutamine--tRNA ligase & -12.06 & $6.02 \mathrm{E}-19$ \\
\hline PA3614 & hypothetical protein & -10.81 & $4.56 \mathrm{E}-38$ \\
\hline PA4672 & peptidyl-tRNA hydrolase & -10.50 & $1.76 \mathrm{E}-26$ \\
\hline PA5339 & hypothetical protein & -9.99 & $7.19 \mathrm{E}-60$ \\
\hline tyrZ & tyrosine--tRNA ligase & -9.99 & $4.60 \mathrm{E}-12$ \\
\hline$r m f$ & ribosome modulation factor & -9.53 & $1.42 \mathrm{E}-16$ \\
\hline omIA & outer membrane lipoprotein OmIA & -9.46 & $1.23 \mathrm{E}-12$ \\
\hline gatB & aspartyl/glutamyl-tRNA amidotransferase subunit B & -8.58 & $5.13 E-34$ \\
\hline tgt & queuine tRNA-ribosyltransferase & -8.27 & $1.06 \mathrm{E}-18$ \\
\hline$r b f A$ & ribosome-binding factor $A$ & -8.07 & $3.97 \mathrm{E}-39$ \\
\hline PA5303 & hypothetical protein & -7.74 & $1.92 \mathrm{E}-40$ \\
\hline$g \mid t X$ & glutamate--tRNA ligase & -7.61 & $8.00 \mathrm{E}-39$ \\
\hline lysS & lysine--tRNA ligase & -7.41 & $3.11 \mathrm{E}-21$ \\
\hline prfC & peptide chain release factor 3 & -7.22 & $3.03 E-14$ \\
\hline truB & tRNA pseudouridine synthase $B$ & -7.09 & $4.64 \mathrm{E}-29$ \\
\hline$g l y Q$ & glycine--tRNA ligase subunit alpha & -6.51 & $9.29 \mathrm{E}-09$ \\
\hline pros & proline--tRNA ligase & -6.08 & $3.20 \mathrm{E}-20$ \\
\hline vals & valine--tRNA ligase & -6.05 & $3.47 \mathrm{E}-29$ \\
\hline sers & serine--tRNA ligase & -5.87 & $2.95 \mathrm{E}-17$ \\
\hline rpsP $P$ & 30 S ribosomal protein $\mathrm{S} 16$ & -5.64 & $1.00 \mathrm{E}-46$ \\
\hline truA & tRNA pseudouridine synthase $A$ & -5.34 & 1.11E-19 \\
\hline cafA & cytoplasmic axial filament protein & -5.34 & $9.22 \mathrm{E}-11$ \\
\hline PA1766 & hypothetical protein & -5.30 & $7.73 \mathrm{E}-15$ \\
\hline PA0916 & ribosomal protein S12 methylthiotransferase RimO & -4.95 & $1.01 \mathrm{E}-06$ \\
\hline $\operatorname{args}$ & arginine--tRNA ligase & -4.80 & $2.28 \mathrm{E}-18$ \\
\hline map & methionine aminopeptidase & -4.60 & $1.75 \mathrm{E}-24$ \\
\hline ftsJ & cell division protein FtsJ & -4.38 & $7.64 \mathrm{E}-18$ \\
\hline phes & phenylalanine--tRNA ligase subunit alpha & -3.95 & $4.51 \mathrm{E}-12$ \\
\hline rpmE & 50 S ribosomal protein L31 & -3.86 & $1.78 \mathrm{E}-14$ \\
\hline PA1678 & $\begin{array}{l}\text { 50S ribosomal protein L3 glutamine } \\
\text { methyltransferase }\end{array}$ & -3.69 & $3.22 \mathrm{E}-09$ \\
\hline PA3601 & 50 S ribosomal protein $\mathrm{L} 31$ type $\mathrm{B}$ & -3.26 & $3.60 \mathrm{E}-06$ \\
\hline osmE & OsmE family transcriptional regulator & -3.23 & $1.31 \mathrm{E}-17$ \\
\hline
\end{tabular}




\begin{tabular}{|l|l|l|l|}
\hline$P A 3980$ & (dimethylallyl)adenosine tRNA methylthiotransferase & -3.16 & $2.04 \mathrm{E}-17$ \\
\hline leuS & leucine--tRNA ligase & -3.11 & $2.59 \mathrm{E}-09$ \\
\hline rluD & pseudouridine synthase & -3.01 & $8.66 \mathrm{E}-11$ \\
\hline$P A 3945$ & hypothetical protein & -2.99 & $3.66 \mathrm{E}-10$ \\
\hline$k s g A$ & ribosomal RNA small subunit methyltransferase A & -2.97 & $1.79 \mathrm{E}-14$ \\
\hline$m e t G$ & methionine--tRNA ligase & -2.85 & $2.50 \mathrm{E}-07$ \\
\hline$t r m U$ & tRNA-specific 2-thiouridylase MnmA & -2.69 & $8.74 \mathrm{E}-11$ \\
\hline$P A 5127$ & rRNA methylase & -2.62 & $7.73 \mathrm{E}-08$ \\
\hline$P A 1944$ & hypothetical protein & -2.61 & $1.03 \mathrm{E}-03$ \\
\hline$t r m A$ & tRNA (uracil-5-)-methyltransferase & -2.46 & $9.02 \mathrm{E}-13$ \\
\hline$r p h$ & ribonuclease PH & -2.43 & $1.64 \mathrm{E}-12$ \\
\hline$P A 1472$ & hypothetical protein & -2.42 & $7.69 \mathrm{E}-05$ \\
\hline$r n e$ & ribonuclease E & -2.28 & $3.22 \mathrm{E}-05$ \\
\hline$P A 2795$ & tRNA-dihydrouridine synthase A & -2.26 & $2.91 \mathrm{E}-08$ \\
\hline$P A 3199$ & hypothetical protein & -2.26 & $1.15 \mathrm{E}-08$ \\
\hline alaS & alanine--tRNA ligase & -2.14 & $6.63 \mathrm{E}-05$ \\
\hline
\end{tabular}

Table S4. List of genes upregulated in PASL by at least 2-fold with a false discovery rate (Padjvalue) $<0.01$ during exposure to hexadecane-water interface for $24 \mathrm{~h}$ versus the control.

\begin{tabular}{|c|c|c|c|}
\hline Gene & Description & $\begin{array}{l}\text { Fold } \\
\text { Change }\end{array}$ & Padj-value \\
\hline \multicolumn{4}{|c|}{ Cell cycle control, cell division, chromosome partitioning } \\
\hline ftsL & cell division protein FtsL & 2.36 & $1.62 \mathrm{E}-31$ \\
\hline \multicolumn{4}{|c|}{ Energy production and conversion } \\
\hline atpl & ATP synthase subunit I & 2.22 & 1.08E-14 \\
\hline PA4430 & cytochrome b & 2.05 & $3.17 \mathrm{E}-48$ \\
\hline \multicolumn{4}{|c|}{ Hypothetical, unclassified, unknown } \\
\hline PA2621 & ATP-dependent Clp protease adapter protein Clp & 2.64 & $7.91 \mathrm{E}-21$ \\
\hline PA4690.1 & $5 \mathrm{~S}$ ribosomal RNA & 2.24 & $2.05 \mathrm{E}-09$ \\
\hline PA4280.1 & 5 S ribosomal RNA & 2.15 & 1.74E-08 \\
\hline PA4421 & cell division protein MraZ & 2.04 & $2.81 \mathrm{E}-24$ \\
\hline \multicolumn{4}{|c|}{ General function prediction only } \\
\hline PA2971 & hypothetical protein & 2.01 & 1.24E-26 \\
\hline \multicolumn{4}{|c|}{ Intracellular trafficking, secretion, and vesicular transport } \\
\hline tolR & translocation protein TolR & 2.00 & $1.48 \mathrm{E}-13$ \\
\hline \multicolumn{4}{|c|}{ Posttranslational modification, protein turnover, chaperones } \\
\hline clpP & ATP-dependent CIp protease proteolytic subunit & 2.19 & $8.98 \mathrm{E}-50$ \\
\hline PA0941 & hypothetical protein & 2.10 & $9.18 \mathrm{E}-14$ \\
\hline \multicolumn{4}{|c|}{ Signal transduction mechanisms } \\
\hline mucA & sigma factor AlgU negative regulator MucA & 2.33 & 1.89E-72 \\
\hline \multicolumn{4}{|c|}{ Transcription } \\
\hline
\end{tabular}




\begin{tabular}{|l|l|r|r|} 
algU & RNA polymerase sigma factor AlgU & 2.85 & $4.39 \mathrm{E}-80$ \\
\hline PA2737 & hypothetical protein & 2.18 & $4.42 \mathrm{E}-33$ \\
\hline nusG & transcription antitermination protein NusG & 2.05 & $1.29 \mathrm{E}-20$ \\
\hline \multicolumn{2}{|c|}{ Translation, ribosomal structure and biogenesis } \\
\hline rpsL & 30S ribosomal protein S12 & 2.09 & $1.27 \mathrm{E}-16$ \\
\hline$r p m F$ & 50S ribosomal protein L32 & 2.04 & $8.27 \mathrm{E}-11$ \\
\hline$r p I D$ & 50 S ribosomal protein L4 & 2.01 & $6.32 \mathrm{E}-33$ \\
\hline
\end{tabular}

Reference:

[1] M.J. Franklin, D.E. Nivens, J.T. Weadge, P.L. Howell, Biosynthesis of the Pseudomonas aeruginosa extracellular polysaccharides, alginate, Pel, and Psl, Frontiers in microbiology 2 (2011) 167. 